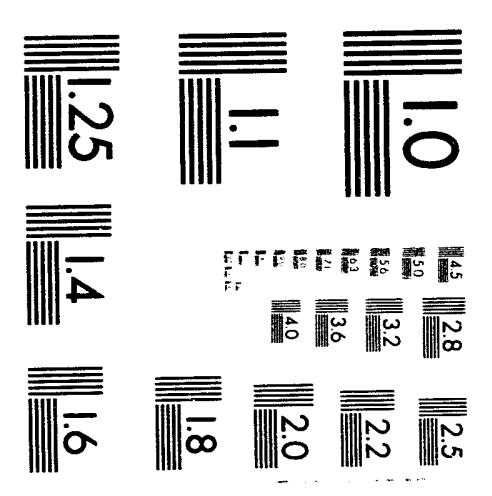



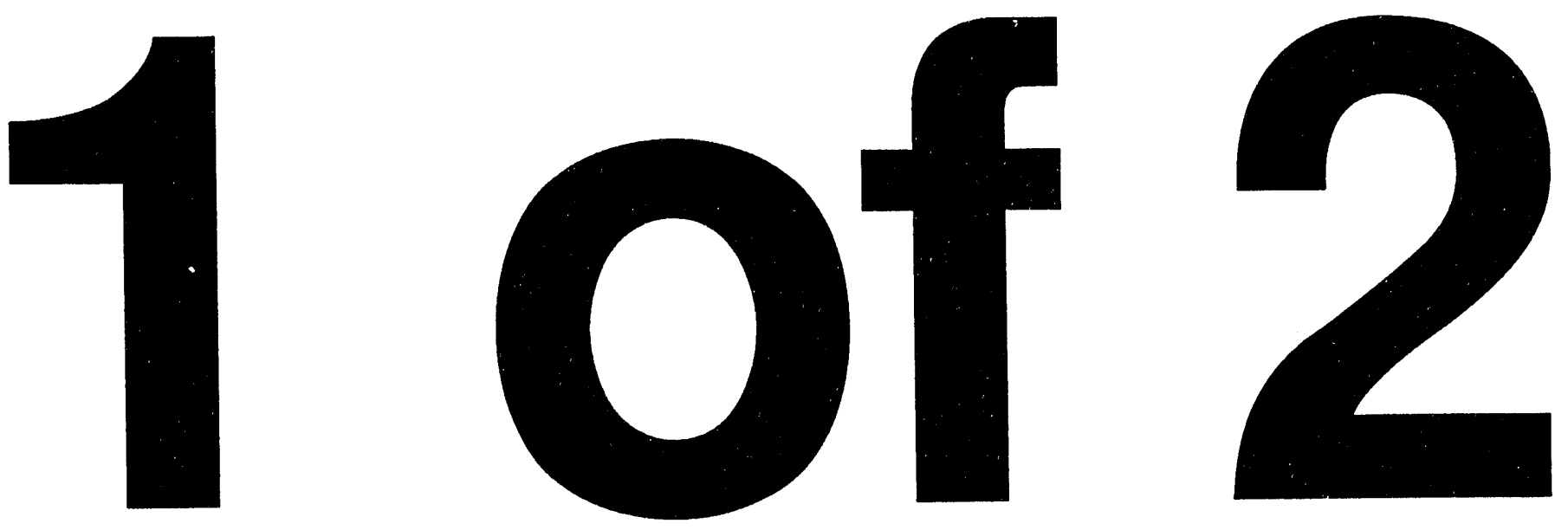
SAND93-3899

Unlimited Release

Distribution

Printed February 1994

Category UC-212

\title{
Utility Battery Storage Systems Program Report for FY93
}

Paul C. Butler, Manager

Storage Batteries Department

Sandia National Laboratories

Albuquerque, New Mexico 87185

\begin{abstract}
Sandia National Laboratories, New Mexico, conducts the Utility Battery Storage Systems Program, which is sponsored by the U. S. Department of Energy's Office of Energy Management. In this capacity, Sandia is responsible for the engineering analyses, contract development, and testing of rechargeable batteries and systems for utility-energy-storage applications. This report details the technical achievements realized during fiscal year 1993.
\end{abstract}




\section{Contributors}

\section{Sandia National Laboratories:}

A. Akhil, Battery Systems Analysis and Industry Outreach

J. Braithwaite, Subsystems Engineering, Sodium/Sulfur

N. Clark, Subsystems Engineering, Zinc/Bromine

G. Corey, System Integration and System Field Evaluation, Pacific Gas \& Electric Co.

J. Freese, Subsystems Engineering, Evaluation

S. Klassen, Applied Research, Zinc/Bromine

R. Jungst, Subsystems Engineering, Lead-Acid, and System Field Evaluation, Special Evaluation

L. Lachenmeyer, Planning and Reporting

\section{Contractors/Subcontractors:}

H. Meyer, Omnion Power Corporation

J. Szymborski, GNB Industrial Battery Co.

B. Norris, Pacific Gas \& Electric Co.

M. Anderson, University of Missouri - Rolla

P. Eidler, Johnson Controls Battery Group, Inc.

A. Koenig, Silent Power, Inc.

J. Rasmussen, Silent Power, Inc. 


\section{Contents}

Acronyms and Abbreviations

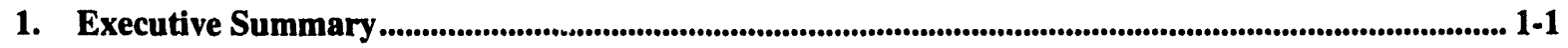

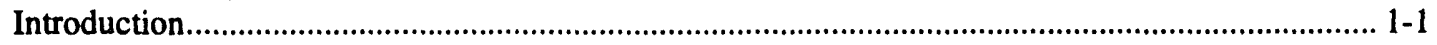

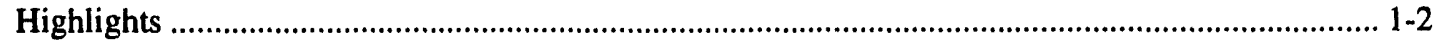

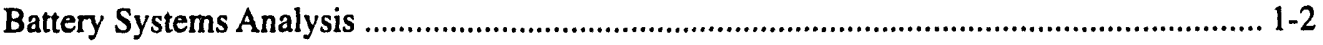

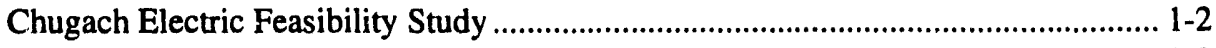

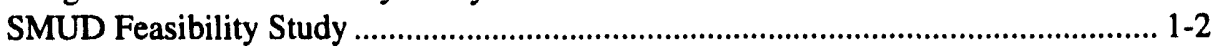

USBD at PG\&E............................................................................................ 1-2

National Benefits Study .............................................................................. 1-2

Other Activities ....................................................................................................... 1-3

Subsystems Engineering - Lead-Acid .............................................................................. 1-3

Technology Development - GNB ............................................................................ 1-3

Technology Evaluation - SNL ....................................................................... $1-4$

Applied Research - SNL ....................................................................................... 1-4

Subsystems Engineering - Zinc/Bromine ......................................................................... 1-4

Technology Development - JCBGI ........................................................................ 1-4

Technology Evaluation - SNL .......................................................................... 1-5

Applied Research - SNL and JCBGI .................................................................... 1-5

Subsystems Engineering - Sodium/Sulfur ....................................................................... 1-5

Technology Development - SPI ........................................................................ 1-5

Technology Evaluation - SNL .............................................................................. 1-6

Subsystems Engineering - Electrical................................................................................... 1-6

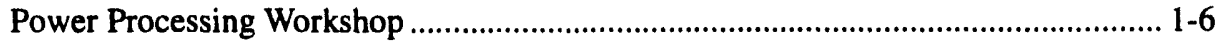

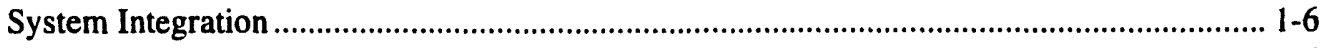

AC Battery Development - Omnion ........................................................................ 1-6

System Field Evaluation .................................................................................................. 1-7

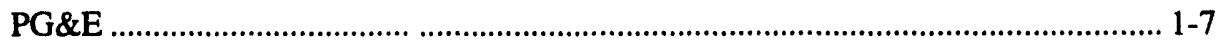

Special Evaluation at SNL - PREPA/C\&D Lead-Acid Battery .................................. 1-7

Industry Outreach .................................................................................................................... 1-7

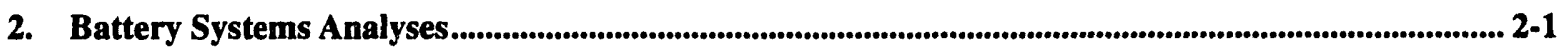

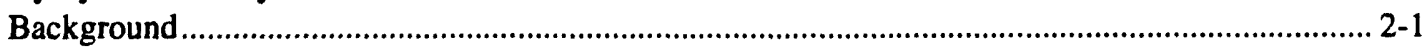

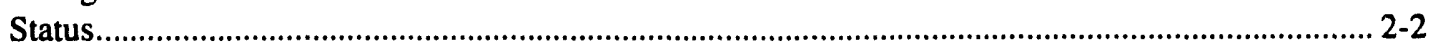

Chugach Electric Association ................................................................................................ 2-2

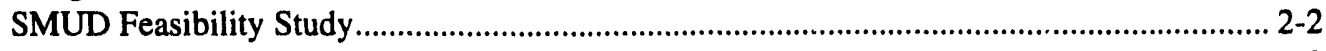

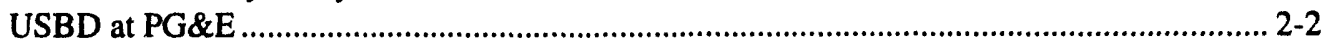

National Benefits Study .......................................................................................... 2-3

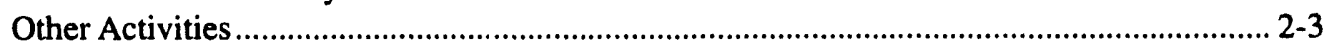

Utility Energy Storage Program ................................................................................ 2-3

Battery/SMES Qualitative Assessment Study .......................................................... 2-5

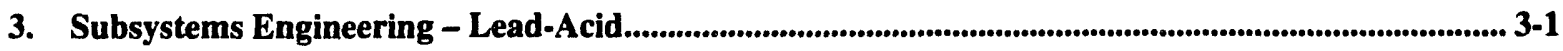

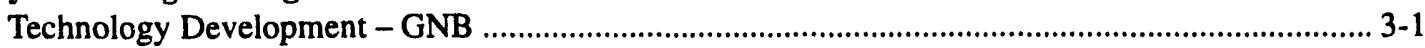

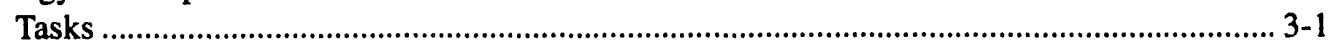

Task 1/Phase 1. VRLA Battery Improvements ............................................................ 3-2

Task 1/Phase 2. VRLA Battery Advancements ..................................................... 3-10

Task 2. Baseline Design and Economics Study .................................................... 3-16

Technology Evaluation - SNL......................................................................................... 3-24

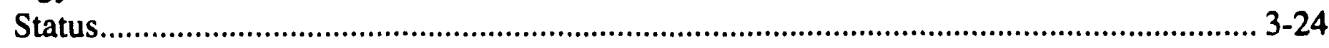

Applied Research - SNL ................................................................................................ 3-25 
4. Subsystems Engineering - Zinc/Bromine ........................................................................................................... 4-1

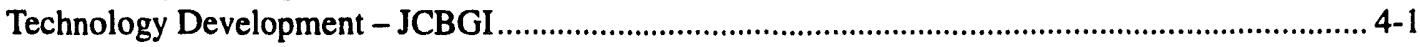

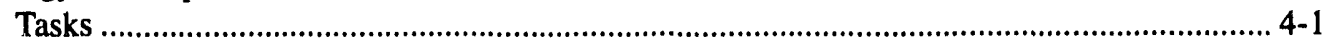

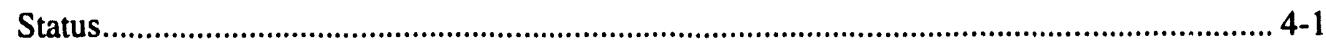

Battery Testing ……..................................................................................................... 4-

Other Test Results ................................................................................................... 4-10

Core Technology Advances ...................................................................................... 4-14

New Battery Design ................................................................................................... 4-17

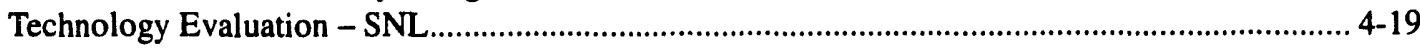

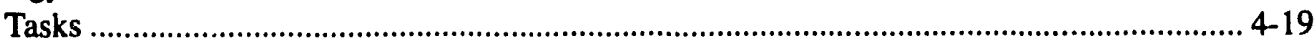

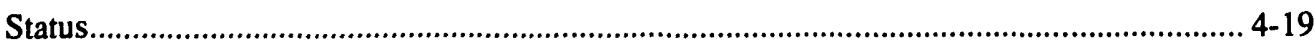

Applied Research - Complexing Agents for the Zinc/Bromine Battery Electrolyte......................... 4-20

Background .................................................................................................................. 4-20

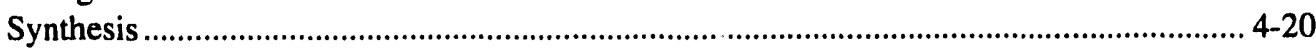

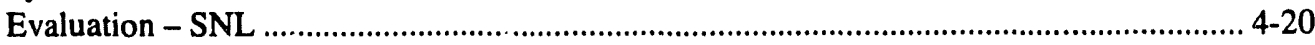

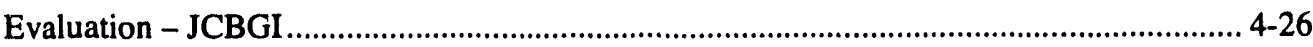

Complexing Ability of Experimental Quats ............................................................. 4-26

Performance in a Battery ................................................................................. 4-29

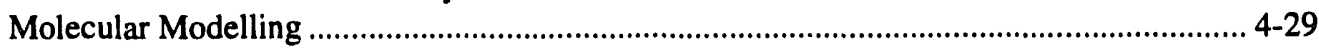

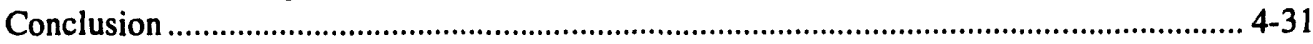

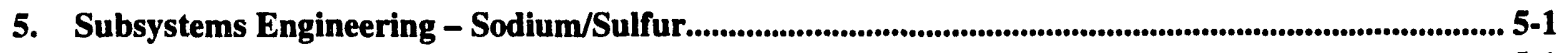

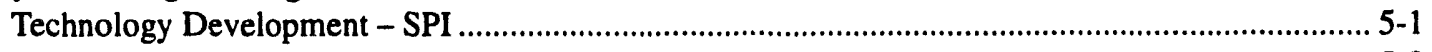

Tasks ………

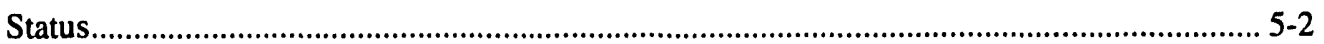

Task 1. UES Applications Assessment .................................................................. 5-2

Task 2. UES Cell \& Battery Component Development ................................................ 5-5

Task 3. Design \& Fabrication of UES Module ........................................................ 5-19

Task 4. Full-Scale Battery Plant Design............................................................. 5-20

Technology Evaluation - SNL .................................................................................................. 5-24

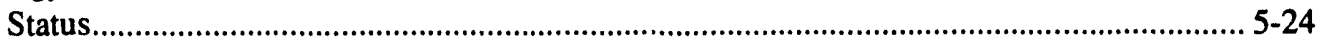

Task 1. 40-Cell XPB Module ………................................................................ 5-24

Task 2. XPB Single Cells ................................................................................ 5-24

Task 3. Four-Cell Strings..................................................................................... 5-25

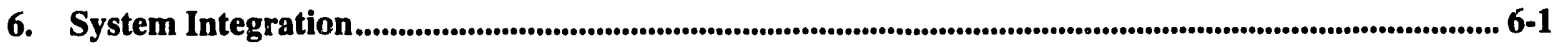

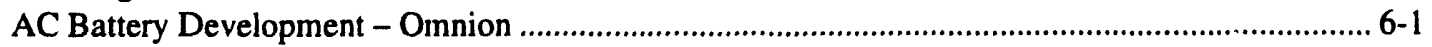

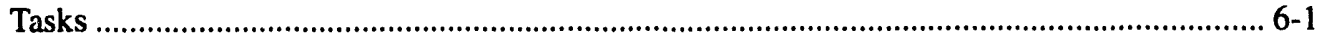

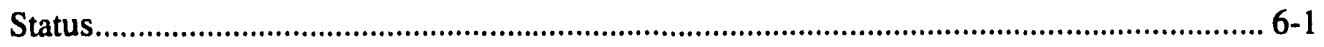

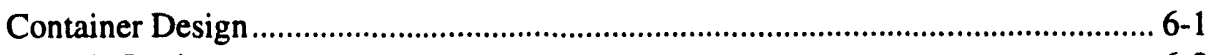

Module Design .......................................................................................................... 6-2

PCS Design ...................................................................................................... 6-2

EPRI Intensive Monitoring Instrumentation System ............................................... 6-4

Factory Acceptance and Characterization Testing ................................................ 6-4

Miscellaneous Items ................................................................................................... 6-5

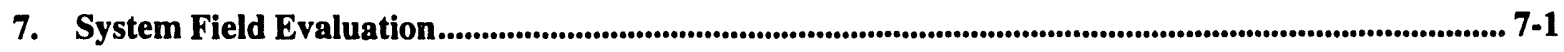

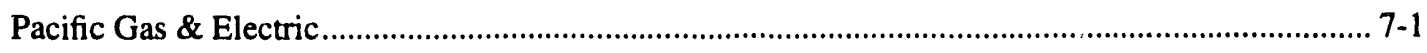

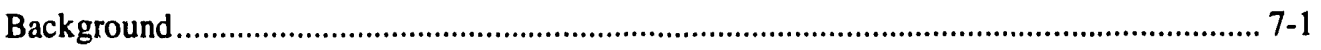

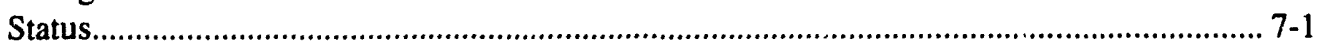

Site Preparation …………......................................................................................... 7-1

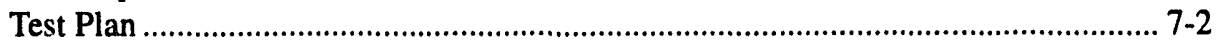

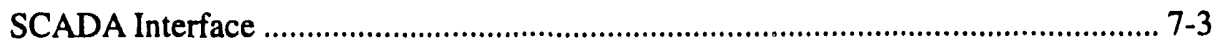

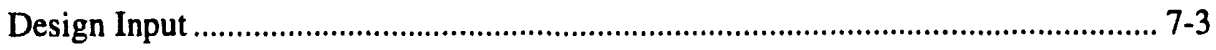




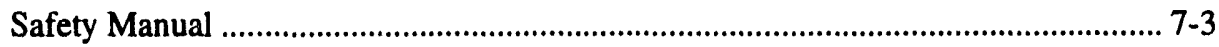

Special Evaluation at SNL - PREPA/C\&D Lead-Acid Battery ............................................................. 7-3

Set-Up of Test Parameters ......................................................................................................... 7-4

Collection of Thermal Data .............................................................................................. 7-6

Evaluation of Battery Operating Characteristics .................................................................... 7-9

Analysis of Thermal Data ....................................................................................................... 7-9

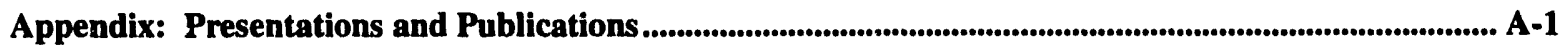

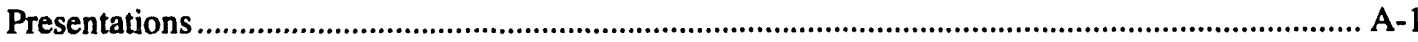

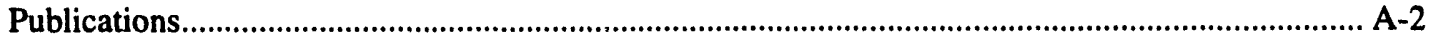

\section{Figures}

3-1 Flow Chart of Product Designations Anticipated During the VRLA Development Process................... 3-2

3-2 Vent/Reseal Operation of Six Randomly Selected ABSOLYTE Pressure Relief Vents During the First $50 \mathrm{hr}$ of an Accelerated Life Test ............................................................................................. 3-4

3-3 Vent/Reseal Operation of Six Randomly Selected ABSOLYTE Pressure Relief Vents During the Last $50 \mathrm{hr}$ of a 500-hr Accelerated Life Test......................................................................................... 3-4

3-4 Overcharge Test of an ABSOLYTE Battery Module in a Steel Tray ........................................................ 3-7

3-5 Temperature Measurements at Various Locations in an ABSOLYTE Battery Module Being Overcharged at $2.65 \mathrm{vpc}$ in a Steel Tray ....................................................................................... 3-7

3-6 Recharge Profile of an ABSOLYTE Battery using a Fixed Time Charge Termination Technique........... 3-8

3-7 Current Sharing between ABSOLYTE Battery Modules Connected in Parallel when Recharged Using the Three-Step CI/CV/CI Technique Developed for Utility Applications....................................... 3-9

3-8 Temperature Comparison for ABSOLYTE Cells Being Charged at $2.45 \mathrm{vpc}$ in Polypropylene or

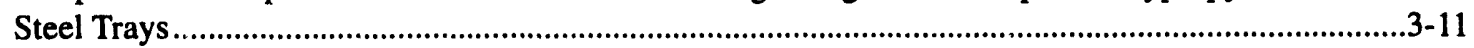

3-9 Sketch of Proposed 2-V Battery Module for Portable Utility Applications.......................................... 3-14

3-10 Conceptual Sketch of a Negative Grid Constructed from Copper-Cored, Lead-Coated Wires Molded into a Plastic Frame and Having a Cast-On Lead Lug and Top Frame as the Current Collector.

3-11 Cabinet Designed to Contain 40 GNB VRLA MSB-2460 Battery Modules......................................... 3-17

3-12 Floor Plan Proposed by UMR for a 0.5-MW, 2-hr (1.0-MWh) PG\&E BES System Facility ............... 3-18

3-13 Side View of the UMR Floor Plan for the PG\&E BES System Facility Showing that Four of the Five Rows of Battery Cabinets Are Placed Back-to-Back and Stacked Two High in the Center of

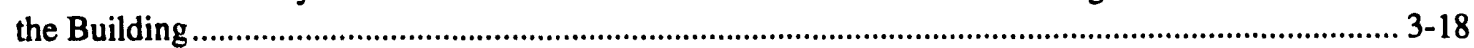

3-14 Cabinet Designed for the LSB-1340 Battery Selected for the PREPA Spinning Reserve and Area Regulation BES System Application.

3-15 Floor Plan Proposed by UMR for the PREPA BES System Facility ..................................................... 3-19

3-16 Side View of the UMR Floor Plan for the PREPA BES System....................................................... 3-20

3-17 Surnmary of Site Data for the Cases Included in the PG\&E Battery Dispatch Modeling Study........... 3-24

4-1 V1-67 Baseline Cycle Efficiencies (1-kWh, 8-Cell Battery Stack) ........................................................... 4-3

4-2 V1-71 Baseline Cycle Efficiencies (1-kWh, 8-Cell Battery Stack) ........................................................ 4-4

4-3 V1-72 Baseline Cycle Efficiencies (1-kWh, 8-Cell Battery Stack) ............................................................ 4-5

4-4 V1-73 Baseline Cycle Efficiencies (1-kWh, 8-Cell Battery Stack) ........................................................... 4-5

4-5 V1-74 Baseline Cycle Efficiencies (1-kWh, 8-Cell Battery Stack) .......................................................... 4-6

4-6 V1-75 Baseline Cycle Efficiencies (1-kWh, 8-Cell Battery Stack) .......................................................... 4-7

4-7 V1-76 Baseline Cycle Efficiencies (1-kWh, 8-Cell Battery Stack) ............................................................. 4-7

4-8 V1-77 Baseline Cycle Efficiencies (1-kWh, 8-Cell Battery Stack) ............................................................. 4-8

4-9 V1-78 Baseline Cycle Efficiencies (1-kWh, 8-Cell Battery Stack) ........................................................ 4-9

4-10 V1-79 Baseline Cycle Efficiencies (1-kWh, 8-Cell Battery Stack) ........................................................... 4-9 
4-11 V25-01-08 Baseline Cycle Efficiencies (2-kWh, 8-Cell Battery Stack)

4-12 Overvoltage Losses for V1-74 Measured by the Current Interrupt Method (1-kWh, 8-Cell

Battery Stack).

4-13 IR Losses for V1-74 Measured by the Current Interrupt Method (1-kWh, 8-Cell Battery Stack) ........ 4-12

4-14 Overvoltage Losses for V1-74 Measured by the AC Resistance Method (1-kWh, 8-Cell

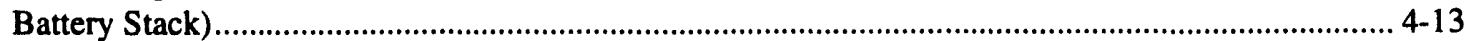

4-15 Polarization vs Surface Area for Cycled Battery Electrodes ............................................................ 4-16

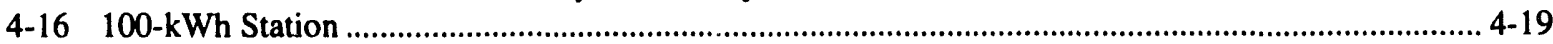

4-17 Bar Graphs of Aqueous Phase Bromine Concentration Data for Candidate Bromine Complexing Agents

4-18 One View of the Space-Filling Model of the Complex Between Bromine and N-Methyl-

$\mathrm{N}$-ethylpyrrolidinium Bromide .......................................................................................................... 4-32

5-1 300-kW NAS-P ac Transportable System ............................................................................................. 5-3

5-2 Role of Advanced Batteries in Utility Energy Storage .................................................................... 5-3

5-3 Battery Energy Storage Relative Capital Costs .................................................................................. 5-4

5-4 NAS-P $P_{\text {ac }}$ Battery System Demand Charge Savings ........................................................................ 5-4

5-5 c/S Cell Top Section Showing Baseline TCB Seal Design ................................................................... 5-6

5-6 Cross Section of Seal Variant Using Kovar Backing Ring .................................................................. 5-7

5-7 Cross Section of Brazed Seal Assembly ........................................................................................... 5-9

5-8 Alternate Sodium Filling Design ............................................................................................... 5-10

5-9 30-Cell TES Experiment Plan View................................................................................................. 5-10

5-10 30-Cell TES Experiment 240-W Discharge/150-W Charge (Ceramic Cement)......................................5-11

5-11 30-Cell TES Experiment 300-W Discharge/150-W Charge (Cemented) ............................................... 5-12

5-12 30-Cell TES Experiment 400-W Discharge/150-W Charge (Cemented) ............................................. 5-12

5-13 30-Cell TES Experiment 300-W Discharge .................................................................................... 5-13

5-14 DOD Plots of Cycles 7, 38, and 75 for Cell 017 …..................................................................... 5-16

5-15 Cell Resistance at the Beginning of Discharge and Charge for a Molybdenum UES Cell.................... 5-17

5-16 Effect of Changing Discharge and Charge Conditions on Cell Capacity and Unrecoverable Capacity ........................................................................................................................................ 5-17

5-17 Depth of Discharge and f1 for Ni/Cr UES Cell Showing Effects of a Deep Discharge ...................... 5-18

5-18 Resistance of UES Cell \#40 (Nichrome Coated from Wire Stock) ..................................................... 5-18

5-19 Resistance of UES Cell \#62 (Nichrome Coated from Metal Powder) .................................................. 5-19

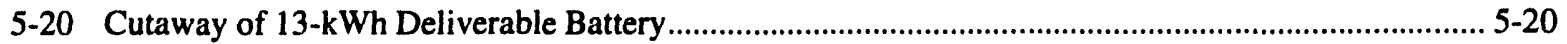

5-21 NAS-P $\mathrm{P}_{\mathrm{ac}}$ Battery Electrical Compartment ............................................................................... 5-22

5-22 System Block Diagram ................................................................................................................ 5-22

5-23 Battery Interface and BMS Diagram............................................................................................ 5-23

5-2.4 Total Ah Discharged per SFR Cycle for XPB Cells \#527 and \#528 ..................................................... 5-25

5-25 Baseline Capacity of Cell \#528 at $330^{\circ} \mathrm{C}(\mathrm{C} / 3$ discharge, $\mathrm{C} / 5$ charge $)$............................................... 5-26

6-1 AC Battery Container when Closed ................................................................................................. 6-2

6-2 Opened AC Battery Container Showing Orientation of Modules......................................................... 6-3

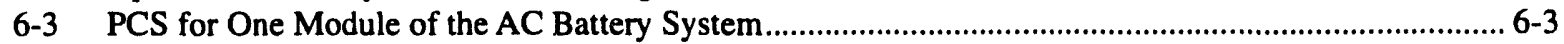

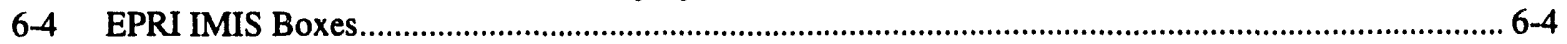

7-1 Schematic of PG\&E's Smart Substation with AC Battery Installed ....................................................... 7-2

7-2 Schematic of SCADA System and AC Battery Container ..................................................................... 7-4

7-3 Twelve-Cell Series String of Lead-Acid Batteries Mounted for Testing .............................................. 7-5

7-4 Diagram of the UES Cycle............................................................................................................. 7-6

7-5 Basic 160-min Subcycle That Serves as a Building Block for Frequency Regulation Testing ............... 7-7

7-6 Representative Cell and Chamber Temperatures for UES Cycles Starting from Different

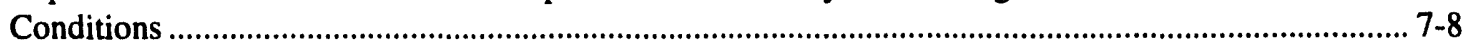

7-7 Battery Resistances Calculated from Voltage and Current Data Measured During Frequency Regulation Starting at $90^{\circ} \mathrm{F}$

7-8 Typical Fit of Model to Spinning Reserve Test Data Using Only One Degree of Freedom (905 UES Cycle, 7/14/93) .................................................................................................................. 7-13

7-9 Calculated Temperature Rise During $110 \mathrm{hr}$ of Frequency Regulation ................................................ 7-15 


\title{
Tables
}

\begin{abstract}
$\begin{array}{rlll}\text { Page } & \end{array}$
\end{abstract}
2-1 Estimate of Benefits by Application.

$2-4$

3-1 Published Cost Data for Six Existing/Proposed BES System Installations ........................................... 3-22

3-2 BES System Costs Estimated Using Existing Facility Costs ................................................................. 3-22

4-1 Improvements in Battery Performance ……..................................................................................... 4-2

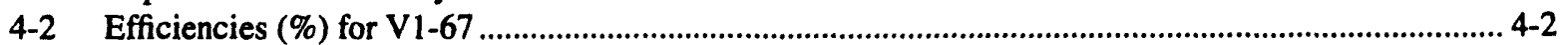

4-3 Baseline Cycle Efficiencies Before and After Electrode Reconditioning ...............................................4-11

4-4 Efficiencies (\%) for Single-Cell Nonflow Battery During Stand Loss Cycling....................................... 4-14

4-5 Interface Carbon Test Samples......................................................................................................... 4-15

4-6 Terminal Electrode Samples ................................................................................................................ 4-15

4-7 Polarization and Surface Area for Cycled and Uncycled Bromine Electrodes ....................................... 4-16

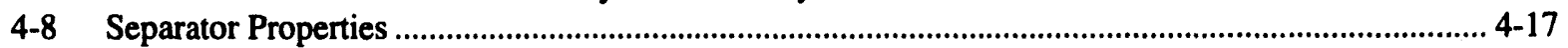

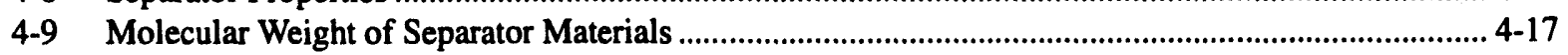

4-10 Status of the Quat Synthetic Work ……......................................................................................... 4-21

4-11 Electrolyte Formulations for the Simulated States of Charge Used in Testing Quats .......................... 4-22

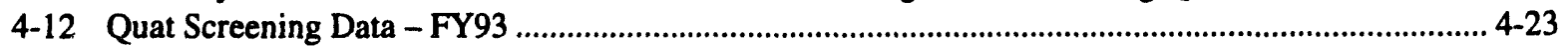

4-13 Electrolyte Resistivity (Ohm-Cm) ................................................................................................. 4-29

4-14 State of Aqueous Phases and Quat-Bromine Complexes at Low Temperatures.................................... 4-30

4-15 Aqueous Phase Bromine Concentration (M) for Electrolyte with 33\% Quat $C$ and 67\%

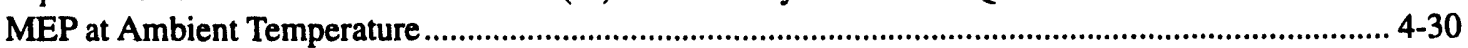

4-16 Aqueous Bromine Concentration and Evaporation Rates for Experimental Quarternary Complexing Agents

4-17 Single-Cell Battery Efficiencies for Experimental Quaternary Complexing Agents (\%) ....................... 4-31

5-1 Freeze/Thaw Results on Sodium Seals ............................................................................................. 5-8

5-2 UES Central Sulfur Cell Testing Summary ............................................................................... 5-14

5-3 Projected BOL Electrical Performance for the UES Central Sulfur Cell .............................................. 5-15

5-4 NAS-P $\mathrm{ac}_{\mathrm{ac}}$ Battery Energy Storage System Specifications................................................................... 5-21

7-1 Estimated and Scaled Power Levels for the UES Cycle .............................................................................. 7-6

7-2 Sulfuric Acid Density in PREPA Battery Cells at Full Charge .................................................................. 7-11

7-3 Capacity Test Data on the PREPA Battery …………......................................................................... 7-12

7-4 Average Parameters Obtained from Fits of the Model to Experimental Data ......................................... 7-12

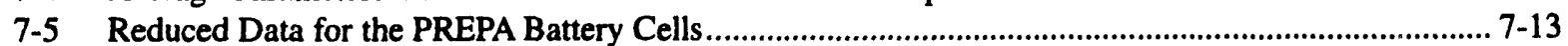

7-6 Cell Electrical Resistance Parameters from Fits of Spinning Reserve Test Data ................................... 7-14 


\section{Acronyms and Abbreviations}

\begin{tabular}{ll} 
AML\&P & Anchorage Municipal Light \& Power \\
B/C & benefit to cost \\
BES & battery energy storage \\
BEST & Battery Energy Storage Test (Facility) \\
BMS & battery management system \\
BOL & beginning of life \\
BOP & balance of plant \\
C\&D & C\&D Charter Power Systems, Inc. \\
CAES & compressed air energy storage \\
CDAS & control and data acquisition system \\
CE & coulombic efficiency \\
CEA & Chugach Electric Association \\
CI & constant current \\
c/S & central sulfur \\
CT & current transducer \\
CV & constant voltage \\
CY & calendar year \\
DOD & depth-of-discharge \\
DOE & Department of Energy \\
ECC & electro chemical compatibility \\
EE & energy efficiency \\
EIA & Energy Information Administration \\
EOC & end of charge \\
EOD & end of discharge \\
EOL & end of life \\
EPDM & ethylene-propylene-diene monomer \\
EPRI & Electric Power Research Institute \\
FERC & Federal Energy Regulatory Commission \\
FM & frequency modulated \\
F/T & freeze/thaw \\
FY & fiscal year \\
GNB & GNB Industrial Battery Company \\
GVEA & Golden Valley Electric Association \\
HVAC & heating, ventilation, and air conditioning \\
ILZRO & International Lead Zinc Research Organization, Inc. \\
IMIS & Intensive Monitoring Instrumentation System \\
IR & internal resistance \\
\hline
\end{tabular}




\begin{tabular}{|c|c|}
\hline JCBGI & Johnson Controls Battery Group, Inc. \\
\hline MEM & $\mathrm{N}$-Methyl-N-ethylmorpholinium bromide \\
\hline MEP & N-Methyl-N-ethylpyrrolidinium bromide \\
\hline MGTF & Modular Generation Test Facility \\
\hline Mw & molecular weight \\
\hline NERC & North American Electric Reliability Council \\
\hline NIMO & Niagra Mohawk Power Corp. \\
\hline NRECA & National Rural Electric Cooperative Association \\
\hline OEM & Office of Energy Managemeit (DOE) \\
\hline PAM & positive active material \\
\hline PC & personal computer \\
\hline PCS & power conversion system \\
\hline PG\&E & Pacific Gas \& Electric \\
\hline PLC & programmable logic controller \\
\hline PNL & Pacific Northwest Laboratory \\
\hline PREPA & Puerto Rico Electric Power Authority \\
\hline PT & power transducer \\
\hline PTFE & polytetrafluoroethylene \\
\hline PV & photovoltaic \\
\hline PVDF & polyvinylidene difluoride \\
\hline R\&D & research and development \\
\hline RFI & radio frequency interference \\
\hline RFP & request for proposal \\
\hline SCADA & supervisory control and data acquisition \\
\hline SMUD & Sacramento Municipal Utility District \\
\hline SFR & Simplified Frequency Regulation \\
\hline SMES & superconductive magnetic energy storage \\
\hline SNL & Sandia National Laboratories \\
\hline SOC & state-of-charge \\
\hline SOW & statement of work \\
\hline SPI & Silent Power, Incorporated \\
\hline SPL & Silent Power, Limited \\
\hline TBS & Transportable Battery System \\
\hline TCB & thermal compression bond \\
\hline TES & thermal energy storage \\
\hline UBG & Utility Battery Group \\
\hline UBS & Utility Battery Storage Systems \\
\hline UES & utility energy storage \\
\hline UMR & University of Missouri - Rolla \\
\hline UNM & University of New Mexico \\
\hline
\end{tabular}


USBD Utility-Scale Battery Demonstration

vpc volts per cell

VE voltaic efficiency

VRLA valve-regulated lead-acid 


\section{Executive Summary}

\section{Introduction}

This report documents the fiscal year (FY) 1993 activities of the Utility Battery Storage Systems (UBS) Program of the U.S. Department of Energy (DOE), Office of Energy Management (OEM). The UBS Program is conducted by Sandia National Laboratories (SNL). See SAND92-2272, Utility Battery Storage Systems Program Report for FY92, for a description of the previous year's activities.

UBS is responsible for the engineering development of battery systems for use in utility energy storage (UES) and other stationary applications. Development is accomplished through cost-shared contracts with industrial partners. In addition to program management and technical direction of the contracts, SNL conducts analyses of the benefits of battery storage in utility systems and performs appropriate applied research activities. The performance and life of prototype batteries or components produced by development contractors are also characterized.

UBS is organized into five elements:

- Battery Systerns inalysis

- Subsystems Engineering

- Lead-Acid

- Technology Development at GNB Industrial Battery (GNB)

- Evaluation at SNL

- Applied Research at SNL

- Zinc/Bromine

- Technology Development at Johnson Controls Battery Group, Inc. (JCBGI)

- Evaluation at SNL

- Applied Research at SNL and JCBGI

- Sodium/Sulfur

- Technology Development at Silent Power, Inc. (SPI)

- Evaluation at SNL

- Electrical

- System Integration

- AC Battery Development - Omnion Power Engineering Corp.

- System Field Evaluation

- Pacific Gas and Electric (PG\&E)

- Special Evaluation

\section{- Industry Outreach}

Progress made on each of the program elements during the past year is described in this report. A chapter is devoted to each element, except for Subsystems Engineering. Because the majority of the current UBS activity is performed within this element, progress is presented in several chapters by technology.

In the Battery Systems Analysis program element, the UBS Program continues to study battery system benefits and to quantify the value of these benefits to utilities. Already, twelve benefits of battery storage for utility use have been identified. Assessments of battery storage thus far have primarily involved specific utilities, and the results have been correspondingly dedicated to the individual utility. The program is now ready to characterize benefit values that apply to utilities nationwide. Some of these benefits have been tested and proven by battery systems in actual utility operation. Several other benefits will need to be verified by the utilities in tests in upcoming years.

Subsystems Engineering improves the subsystems that make up battery energy storage (BES) systems. The battery subsystem needs lower costs, higher performance, and improved integration with other system components. Consequently, the UBS Program is developing an improved battery technology, the maintenancefree valve-regulated lead-acid (VRLA) battery. When the existing cost-shared contract is completed, the technology will be ready for integration into utility systems. The use of improved near-term battery technology, such as VRLA, offers the potential to increase the quantity and types of utility applications that can be served by battery storage compared with conventional lead-acid batteries.

Under the UBS Program, the advanced battery technologies zinc/bromine and sodium/sulfur are also being progressed specifically for these applications under cost-shared contracts. The primary advantages of each are the possibility for lower life-cycle costs and lower footprint requirements. Although a number of candidate advanced battery technologies are being developed with private and public funding, zinc/bromine and sodium/sulfur are felt to have the best chance to provide the desired benefits and be commercially available around the year 2000 . The technologies have different sets of obstacles to overcome because two radically different types of batteries are represented. In this 
program, development is focusing solely on the needs for UES applications, which possess different requirements than those for other energy storage applications, such as electric vehicles. While both mandate safety first, the UES application must emphasize cost over weight-based or volume-based performance requirements. Nevertheless, during the course of this program, external development of any emerging battery technology (e.g., lithium/polymer electrolyte, nickel/metalhydride) will be monitored to determine whether a utility-specific activity is warranted.

For the electrical subsystem, UBS will develop standardized, modular designs that will lead to lower manufacturing costs. The focus is to improve the electrical components (power conversion, control, and switch gear) by pursuing design standardization leading to lower manufacturing costs and incorporating advances in power electronics to improve performance.

In the Systems Integration element, the UBS Program develops complete units that include energy storage devices, electrical power conditioning equipment, and other required ancillaries. A "modular" system design approach is being promoted in all UBS subsystem engineering and system integration activities. This approach is viewed as the most effective way to reduce production costs as well as one-of-a-kind engineering and design costs associated with most of the present systems.

In the System Field Evaluation element, field qualification of hardware that incorporates the prototype designs and associated manufacturing methods is completed. This activity refresents the final step of this phase of engineering development. For the technology being developed under UBS, the qualification process involves the detailed characterization of performance, maintenance requirements, and reliability of integrated systems at relevant utility sites.

The UBS Program uses a variety of mechanisms to disseminate the latest battery information to utilities through its Industry Outreach program element. The program assists the Utility Battery Group (UBG) in its efforts to encourage utilities to examine the potential of battery systems. The UBG is a utility interest group composed of representatives from several utilities; manufacturers of batteries, converters, and systems; and consultants. The program also interacts with the Electric Power Research Institute's (EPRI) efforts to inform its utility members about battery systems, to develop battery storage evaluation software, and to quantify the benefits of battery storage. DOE and SNL regularly publish articles and attend engineering and utility meetings to inform the public about BES.
The highlights of the achievements for each of these projects during FY93 are given in the remainder of this chapter.

\section{Highlights}

\section{Battery Systems Analysis}

\section{Chugach Electric Feasibility Study}

Two neighboring utilities in Alaska, Golden Valley Electric Association (GVEA) and Anchorage Municipal Light \& Power (AML\&P), have expressed an interest in joining Chugach Electric Association (CEA) in a utility battery system feasibility study. The statement of work (SOW) for the feasibility study has been drafted by SNL. In addition to SNL support, CEA has obtained funding from EPRI and National Rural Electrical Cooperative Association (NRECA) for the planned effort.

\section{SMUD Feasibility Study}

Sacramento Municipal Utility District (SMUD) has recently purchased $40 \mathrm{MW}$ of wind turbines that are scheduled for phased installation beginning in the near future, and another $300 \mathrm{MW}$ of renewable generation is being planned. A BES benefits study with this generation mix is planned that will generate site-specific requirements and battery specifications for two candidate sites.

\section{USBD at PG\&E}

Extensive input was provided to PG\&E in the planning and release of their request for proposal (RFP) for a Utility-Scale Battery Demonstration (USBD) project. The USBD is a transportable battery in the 2-MW/4MWh size range that is specifically designed to meet the substation application requirements. PG\&E is requesting proposals for the project on a turnkey basis from a single supplier.

The RFP was released by PG\&E in September. SNL will participate in the proposal review and evaluation process; the vendor selection announcements are planned for early 1994. SNL is planning on cost-sharing the deveiopment of the USBD with PG\&E.

\section{National Benefits Study}

A limited-scope study was performed to estimate the national benefits of BES to utilities. The study focused on six battery applications in the utility network 
and estimated the benefits and related system costs through the year 2010. Results of the analysis indicate the potential for $\sim 11 \mathrm{GW}$ of battery storage being used by utilities over this time frame. The present value of the utility benefits equals $\$ 17.2$ billion (1993 $\$$ ).

\section{Other Activities}

\section{Utility Energy Storage Plan}

The UBS program developed the preliminary concept for a Utility Energy Storage Plan to serve as an umbrella to coordinate all present and future utility energy storage programs supported by OEM. The plan defined the overall benefits of storage to the national utility network and establishes the goals for energy storage penetration. Based on this information, a technology development timeline was developed to assist OEM in planning the development of individual storage technologies to meet utility needs in a timely manner.

Further development and implementation of the Utility Energy Storage Plan will be carried out by SNL, CA.

\section{Battery/SMES Qualitative Assessment Study}

Battery energy storage and SMES systems have similar operating characteristics, and consequently, may be used for the same utility applications. A qualitative comparison of the merits of battery energy storage and SMES technology for utility applications was performed to understand the potential role of each technology in the utility network and technology development areas needed for wide scale utilization of each technology.

The full study will be released as an independent report early in FY94.

\section{Subsystems Engineering - Lead-Acid}

\section{Technology Development - GNB}

VRLA battery technology development has made good progress during this year. Cycle testing of standard and modified ABSOLYTE pressure relief vents in an accelerated test at room temperature has been completed. The results have provided more confidence in the operation of the standard vents and have also shown that the alternatives need more work before they can replace the present vent configuration. Charging studies have recently shown that the pressure window for operation of VRLA batteries in utility applications should be increased, and various vent concepts that could be used to achieve this are being discussed. The low positive plate growth with grids made from GNB's patented MFX alloy has been verified by analysis of field return batteries. Other concepts for mitigating the effects of positive plate growth, such as shortened plates and insulating boots, have also been proposed, and a series of test cells has been built for accelerated life tests during the coming year. Testing has been completed that demonstrates the thermal stability of the ABSOLYTE II battery configuration, even under severely abusive charging conditions. A three-step, constant current (CI)/ constant voltage $(\mathrm{CV}) /$ constant current $(\mathrm{CI})$ recharge profile has been developed that minimizes charging time while limiting temperature rise in the battery. Several charge termination algorithms are being evaluated for their effectiveness with the parallel string configurations expected to be present in utility installations. Prototype nonmetallic battery trays that will help to prevent ground faults in the unlikely event of an electrolyte leak have been studied for their effect on battery thermal management. While a plastic battery tray did not dissipate heat as well as a steel tray under overcharge conditions, thermal management capabilities of the two designs were similar under float charge conditions. Refinements to the plastic tray design are being considered. Positive electrode active material structures that will improve cycle life under deep discharge conditions are being developed by modifying paste formulation, mixing, and curing processes. Preliminary results with a pulse formation process on plates pasted with a leady oxide precursor have been quite encouraging, and cells have been assembled for cycle life and accelerated float life tests.

Phase 2 battery advancement tasks have also progressed. A highlight this year was the commercial introduction of the ABSOLYTE IIP, which provides about a $17 \%$ improvement in capacity at all discharge rates over the ABSOLYTE II. Accelerated float life tests on the ABSOLYTE IIP have completed the equivalent of $11 \mathrm{yr}$ of float charge operation with the capacity still above the rated value. Prototypes of the advanced LSB design, which is optimized for high-power applications, have shown a $66 \%$ capacity improvement over the ABSOLYTE IIP at the 15-min discharge rate. An analysis of leakage problems with these prototype cells has shown that excessive temperatures were being developed at the lead/plastic interface during welding. Design changes have been made and verified to reduce thermal damage during welding, and tooling and parts modifications are under way so that more cells can be produced. GNB has also completed detailed designs of the container for a 2-V modular battery that would minimize space and weight while preserving flexibility for installation in various utility applications. An analysis 
of the design is under way to evaluate its dimensional stability at the expected internal pressures. Lead-coated copper is being studied as a possible negative grid material that can be used to reduce the internal resistance and weight of the advanced VRLA battery. A proposed design that uses co-extruded copper-cored wire has been selected for further study. The plastic mold needed to form the grid frame has been ordered so that prototype grids can be fabricated during the next fiscal year. Work has also continued on searching for a positive grid alloy that will improve VRLA performance. Nine alloy compositions have been selected for detailed study and have been built into $15412-\mathrm{V}$ batteries. These batteries have been filled and formed, and have gone through baseline characterizations. Cycle testing will begin during the next year. Sources for materials that can be used as additives to stabilize the positive plate structure are also being identified and samples ordered for further study. Processing trials on a nonglass separator material have been encouraging, and plans have been made to test the material for stability in small test cells and in 100-Ah ABSOLYTE cells during the next quarter.

The baseline system design and economics study has also made significant progress during the year. The University of I fissouri - Rolla (UMR) has prepared specifications fo: two utility applications of interest to PG\&E and the Puerto Rico Electric Power Authority (PREPA) who are the host utilities teamed with GNB on this program. In their final report, UMR also presented system layout designs, heating and cooling requirements, and cost estimates for the distributed storage application and for a spinning-reserve/area-regulation facility. The layout of the PREPA BES facility shows the smaller volume that would be required by the advanced LSB batteries compared to conventional flooded cells. Costs were estimated from normalized costs calculated from published data on existing battery systems. For both cases, the battery itself was estimated to be less than $40 \%$ of the overall facility cost. PG\&E has also completed an economic analysis of the viability of battery storage to defer traditional transmission and distribution system upgrades using four case study sites on their system. Even for a 5-yr battery life, the allowable battery system cost was $\$ 554 / \mathrm{kW}(\$ 277 / \mathrm{kWh})$.

\section{Technology Evaluation - SNL}

Seven capacity tests have been run on a baseline ABSOLYTE II (6-V VRLA) module furnished by GNB. The capacity of this battery, at the $\mathrm{C} / 8$ rate to an end of discharge voltage of $5.25 \mathrm{~V}$, exceeded the 1040-Ah rated value. As the battery was cycled, a gradual increase in capacity was observed. Additional test equipment is on order to support testing of the next program deliverable, three ABSOLYTE IIP modules. Both the test equipment and the modules are expected to be received at SNL during the first quarter of FY94.

\section{Applied Research - SNL}

SNL has coated the surface of rubber plugs used as the seal in battery pressure relief vents to determine whether this would enhance vent reliability. These sarnples were built into vents by GNB and cycled for $500 \mathrm{hrr}$ by being attached to an overcharged battery. The performance of some of the vents containing coated plugs was more uniform than that for the standard devices, but the opening pressure declined below the desired operating range. Recent charging analvsis data have indicated that the operating pressure in the battery should actually be increased slightly for utility applications, so a redesign of the vent is now being discussed. Additional evaluations of the coated plugs will be supported by SNL if it is determined that this part will still have a role in the redesigned vent assembly.

\section{Subsystems Engineering - Zinc/ Bromine}

\section{Technology Development - JCBGI}

Design, fabrication, and testing of parts for the 100 $\mathrm{kWh}$ deliverable are continuing. A $2500-\mathrm{cm}^{2}$ cell stack design has been completed, and initial parts have been manufactured. Welded stacks have been able to withstand up to 25 psi ( $-3 \times$ the nominal pressure) without failure. The design of a system controller is complete, and a prototype is being tested. The $100-\mathrm{kWh}$ deliverable station has been designed. A haz-mat building was chosen for containment, and the layout of other components in this structure is complete.

Testing of prototype batteries has shown that $\mathrm{Zn} / \mathrm{Br}$ can exceed requirements in not only standard tests but also in special regimes. Recent eight-cell batteries have seen an average increase in life expectancy from 298 to 378 cycles with an average increase of $3.2 \%$ in energy efficiency over the lifetime of the battery. The increases are due to lower resistance electrodes with improved carbon activation layers. Special tests with battery V1-71 have been conducted to simulate utility type cycle regimes. In four trials, this battery completed 52 , 56, 69, and 78 continuous 1-hr charge/1-hr discharge cycles before the 1.0 volts per cell (vpc) low voltage cutoff was reached. This is a significant improvement over lead-acid data. A stand test procedure was done using a 50-cell stack. As anticipated, the average bromine transport decreased during a stand, since the con- 
centration of bromine in the catholyte also decreases. The transport current was higher when the cell stack was mounted horizontally. Other tests to measure the heat generation and gassing are also being investigated.

An electrode reconditioning process has demonstrated significant improvements in efficiencies for three poorly performing batteries. The process appears to be much more effective if it is performed before the battery energy efficiency is allowed to get too low.

Component development has resulted in improvements. Screen coatings at the metal-screen/carbon-plastic interface have been found to lower the resistance of terminal electrodes. Experimental separator materials have been developed with $25 \%$ lower resistivity and $2.5 \%$ lower bromine transport rate than the standard zinc bromine battery separator. Energy efficiencies are projected to increase by 3 to $4 \%$ with this new separator formulation.

\section{Technology Evaluation - SNL}

Due to delay in the delivery of the eight-cell battery, there was no zinc/bromine battery testing at SNL during FY93.

\section{Applied Research - SNL and JCBGI}

A project to reformulate the electrolyte was requested by JCBGI and is being carried out in collaboration with JCBGI personnel. The objective is to develop bromine complexing agents which will allow further improvements in safety in the event of exposure to electrolyte and also in operating efficiency. Fourteen different candidate complexing agents were synthesized at the University of New Mexico (UNM) during FY93. Bromine complexation data were collected at SNL at different simulated states of charge and temperatures. Based on this data, some complexing agents remain candidates for further work, but many can be ruled out. Performance data were collected at JCBGI for three of the candidates. Mini-Cell tests have shown favorable results, including decreased bromine concentration with one experimental quaternary complexing agent.

\section{Subsystems Engineering - Sodium/ Sulfur}

\section{Technology Development - SPI}

FY93 activity focused on the design and initial fabrication of a prototype UES battery. The performance of this 13-kWh unit will be evaluated starting in early 1994 at SNL. The preliminary design was completed in February, after which three critical design reviews were held with SPI (Salt Lake City), Silent Power, Limited (SPL) (Runcorn) and SNL, respectively. This sub-scale battery contains all of the features proposed for the batteries contained in modular $600-\mathrm{kWh}$ NAS-P $\mathrm{ac}_{\mathrm{ac}}$ system. The most important component introduced in this design is a novel passive thermal management system that uses a latent-heat storage material to reduce cell temperature rise. Also, a iow-cost, reusable thermal enclosure is employed. Cells are tightly packed to maximize thermal conductance and the use of the available sensible heat capacitance. The battery is rated to deliver $6 \mathrm{~kW}$ for $2 \mathrm{hr}$ of continuous operation in a typical customer peaking application. It could also be used in loadfollowing or frequency control modes.

As of the end of FY93, ail the needed cells for the deliverable battery had been manufactured and other battery components ordered. SPI is preparing to assemble and test the first of eight banks at its Salt Lake City facility during early FY94. Final assembly of the pretested banks will be performed during December. This battery represents the principal deliverable from this contract, and its fabrication is on schedule, permitting at least one year of testing to be completed prior to completion of the contract.

The development of the 50-Wh central sulfur (c/S) cell specifically designed for UES applications has constituted the bulk of the remaining effort. The justification to shift to a $\mathrm{c} / \mathrm{S}$ cell configuration was based on a demonstrated 9-yr life for an earlier design of c/S cells by SPL. While the early UES cell results were encouraging, problems have arisen, especially with the largediameter sodium seal. This seal was recognized from the beginning as one of the more speculative aspects of the design, yet necessitated by the $\mathrm{c} / \mathrm{S}$ configuration. Nearly $100 \mathrm{c} / \mathrm{S}$ cells have been built to date, with the longest lived group having exceeded 1 yr and 750 cycles on test.

A controlled set of UES cell builds and subsequent testing has led to the preliminary conclusion that the thermal compression bond (TCB) that constitutes the sodium seal is susceptible to degradation in sodium. This problem is principally because of high mechanical stress applied to the seal as a result of the thermal expansion mismatch in the seal materials and its large diameter. Several design changes have been instituted to overcome this deficiency, including the use of a thicker aluminum gasket, the incorporation of alternate seal materials offering a closer expansion match, and the use of brazing in place of a TCB. 


\section{Technology Evaluation - SNL}

The second of two 8-V, 40-cell XPB sodium/sulfur modules was placed on test during FY92. Its capacity at $100 \%$ depth of discharge (DOD) was 305 Ah (rated = $300 \mathrm{Ah}$ ). The module was placed on a simplified frequency regulation test profile. Thermal problems prevented a full life-cycle characterization from being completed as was done with the first 40-cell module. Because the decision was made to use SPL's "PB" cell in the principal battery deliverable for this contract, testing was terminated and the module was returned to SPL.

To characterize the capabilities of the sodium/sulfur technology relative to fiequency regulation at different operating temperatures, two 30-Ah XPB cells were placed on a life-cycle test using a simplified test profile. An additional $75 \mathrm{Ah}$ per cycle was cycled through the cell that was operating $20^{\circ} \mathrm{C}$ higher than the other cell $\left(350^{\circ} \mathrm{C}\right)$. However, the number of $\mathrm{Ah}$ removed declined with each cycle. On cycle 104, this cell failed and was removed from test. The cell operating at $330^{\circ} \mathrm{C}$ had a much steadier capacity history, and was eventually removed from test at cycle 150 . Because the frequency regulation cycle keeps the cells at relatively high depths of discharge, corrosion of the container and the effects of the corrosion products on the operation of the sulfur electrode probably caused the difference in service life.

Two four-cell PB strings were placed on test near the end of the fiscal year to allow the effects of high recharge rates at high state of charge to be characterized. By the end of the reporting period, all break-in cycles had been performed. The actual test plan will be completed next year.

\section{Subsystems Engineering - Electrical}

\section{Power Processing Workshop}

During the past several years, costs associated with the design and manufacturing of power conditioning systems (PCS) have become a serious issue with the utilities. It appears that the manufacturers of PCS equipment do not have a standard product that can serve multiple applications. Consequently, a custom-designed PCS is produced for each new power conversion application.

To gain a bettering understanding of the scope of this high-interest problem, a team consisting of engineers from SNL's storage energy and renewable energy centers was assembled. The team was tasked with identifying and organizing a representative group from throughout the country consisting of a cross-section of experts from the storage energy and renewable energy hardware manufacturers and technologists, PCS manufacturers, and members from the utility industry. The purpose of the workshop is to develop a better understanding of (1) the costs associated with PCS design and manufacturing, (2) the needs and expectations of the users of PCSs, and (3) the problems associated with trying to serve multiple power conversion requirements with a common PCS design.

Final plans for the Power Processing Workshop were formulated during the latter half of FY93. The invitation list was carefully developed to insure a good representation from the utilities, technolngy groups (batteries, photovoltaic, wind, and Superconducting Magnetic Energy Source (SMES), and PCS manufacturers while limiting the group to a manageable size. Approximately 66 individual were selected to receive invitations to the workshop.

To increase the probability of getting a good turnout, plans were developed to hold the workshop in San Ramon, CA, immediately following the Utility Battery Group meeting scheduled for the week of November 8, 1993. The workshop was scheduled for November 11-12, 1993. Approximately 50 attendees are anticipated.

Following the workshop, findings will be published and disseminated to attendees and others who have requested information on the results of the workshop.

\section{System Integration}

\section{AC Battery Development - Omnion}

Electrical and structural safety analysis activities conducted by SNL were completed. No significant problems were encountered for the electrical safety analysis, and several enhancements were identified for future application. The structural safety study indicated that the container corner beams could possibly fail during crane lifting operations in the event that accelerations exceeded $1 \mathrm{~g}$, that is, if the container were exposed to jerk during lifting and placement operations. An easily implemented structural reinforcement modification was designed and installed. The modification increased the structural integrity by a factor of four.

Final design modifications based on factory testing of the fully assembled AC Battery were completed. Factory acceptance and characterization testing were completed during the period. A baseline/benchmark test was identified to track the AC Battery performance specifications throughout the life of the unit. On Sep- 
tember 13, 1993, the AC Battery system was operated at its rated capacity of $250 \mathrm{~kW}$ of power.

Shipping of the AC Battery for field testing at PG\&E, San Ramon, CA, was scheduled for late October 1993.

\section{System Field Evaluation}

\section{PG\&E}

The AC Battery Test Site in San Ramon, CA, was completed with foundation, fencing, conduit and cabling, grounding, fire equipment, shower/eyewash station, and landscaping.

The PG\&E Test Plan was completed with detailed objectives and procedures for various performance and longevity tests. The Test Plan is currently being published as a PG\&E report.

Control and data acquisition software has been written that conforms to the standard PG\&E Supervisory Control and Data Acquisition (SCADA) protocol. Custom software has been developed for battery system control and has been successfully demonstrated at the manufacturer's headquarters to control the AC Battery container and collect data through the EPRI intensive monitoring instrumentation system.

PG\&E attended design and safety reviews to ensure that the system conforms to PG\&E's interface practices, meets strict safety requirements, and meets the requirements for the intended distributed peaking application.

An "Operational Safety Procedure" manual has been written an 1 approved by the AC Battery Operations Manager and the Health and Safety Coordinator.

\section{Special Evaluation at SNL - PREPAC\&D Lead- Acid Battery}

During this year, equipment and operating cycles have been set up to perform thermal tests on a representative fraction of the PREPA/C\&D Charter Power Systems, Inc. (C\&D) battery. A fully functional test capability and an analytical model for the data are now in place. During the last quarter, thermal data have been collected at an intermediate starting temperature for the battery $\left(90^{\circ} \mathrm{F}\right)$ to go along with earlier experiments at ambient and $100^{\circ} \mathrm{F}$. These results were consistent with the previous tests. Maintenance of the battery and capacity testing have also been carried out now that approximately 2.5 mo of operating time have been accumulated. The battery has continued to operate well. A very slight decrease in capacity during this round of testing may indicate that an equalization of the cells should be carried out.

The thermal model for the battery has been improved to include a variable heat sink temperature to account for fluctuating ambient temperatures at the test facility. This model has now been used to analyze experimental results measured in tests conducted at all three initial temperatures. Both frequency regulation and spinning reserve discharge modes of battery operation were included. Results from the frequency regulation tests were fairly consistent, indicatirg that thermal equilibrium should be reached after approximately $10 \mathrm{hr}$ and that the average thermal power from the cells will be $20 \mathrm{~W}$ at a capacity turnover rate of 2.55 . Analysis of the spinning reserve part of the data was less satisfactory because of the relatively short time involved and a greater amount of noise in the results. An average cell resistance of $250 \times 10^{-6} \mathrm{ohms}$ was obtained from fitting the model to these data.

Initial predictions of thermal behavior in the PREPA BES system have been made using parameters obtained from the data-fits. Adjustments were made to account for differences between the SNL test chamber and the BES facility in the areas of radiative heat transfer and volumetric air flow rate. The model predicts that battery temperature in the BES system will rise approximately $6^{\circ} \mathrm{C}$ above ambient during frequency regulation and that an additional $4^{\circ} \mathrm{C}$ rise is possible during a spinning reserve discharge. These estimates are being refined as replicate thermal data are collected.

\section{Industry Outreach}

FY93 was a busy year for expanding contacts with utilities and exploring new opportunities for the application of BES systems. At the beginning of the FY, the Program Review Meeting in November 1992 in Valley Forge provided the opportunity to meet several utilities interested in finding out more about the UBS Program and the plans for future system studies.

The Fourth and Fifth Utility Battery Group meetings were held during the year and continued to draw strong support from its membership. The fourth meeting was held in conjunction with the UBS Program Review Meeting in November. One of the highlights of this meeting was an announcement by DOE and EPRI of a collaborative development of the Transportable Battery System (TBS) or the "Battery on Wheels." Both DOE and EPRI would jointly pursue the concept development, design, and fabrication of separate prototype 
systems that would be demonstrated at various utility sites. The UBG was also given a tour of the C\&D facility.

The fifth meeting of the UBG was held in May 1993 in Indianapolis and was hosted by Delco-Remy. The presentations included updates on various battery projects, including PRĩPA. The Steering Committee of the UBG, which is composed of representatives from the eight founding members, decided to admit SNL and EPRI as nonvoting members to the Steering Committee. Representatives of SNL and EPRI then joined the Steering Committee in its deliberations. With the continued growth of this interest group, there are several critical issues regarding its future activities and organization structure to assure its continued effectiveness.

Niagara Mohawk Power Corp. (NIMO), serving central and northern New York region, is interested in applying AC Battery modules in conjunction with gridconnected photovoltaic arrays. They have purchased one AC Battery module that will be operated in this mode. SNL has an understanding with NIMO to share the operating results information generated by this module to add to the overall AC Battery operational experience base. Delmarva Power \& Light Company, serving Delaware, has expressed an interest in developing a hybrid-PV AC Battery module that is capable of combining photovoltaic input directly with the battery string on the DC bus of the AC Battery PCS. SNL will place a contract with AC Battery during FY94 for the development of a hybrid-PV AC Battery system.

Several national laboratories are collaborating with the 1996 Olympics organizing committee to explore opportunities for the application and demonstration of alternative power generation technologies. BES systems have been selected as one of the candidate technologies. The potential applications of BES include providing power quality/backup support to communication and television broadcasting trailers that provide coverage of the games, as well as storage for remote event locations where the local power company does not have existing distribution lines. The UBS program is pursuing this opportunity, and it is expected that activity in this area will increase during the next year.

The UBS was represented at the Fourth International Conference on Batteries for Energy Storage in Berlin. Papers were presented on the progress in the UBS Program in benefits assessment and technology development activities. SNL also chaired a session. The conference was attended by approximately 60 people from Europe, Asia, and the U.S., representing utilities, battery manufacturers, power electronics manufacturers, and government research organizations. The major issues discussed at the meeting concerned the cost effectiveness of battery systems in utility applications, improving the understanding of the benefits of battery storage by utilities, and uncertainty about the advantages of advanced batteries for these applications. Three sites around Berlin were visited that related to electric energy generation, transmission, and storage.

In conjunction with the international conference, SNL also attended a meeting of several European utilities that was convened by ILZRO to review the success of the UBG in the U.S., and to focus European utilities on the progress being made in the U.S. towards distributed applications of battery energy storage in the utility network. The organizing committee of the international conference announced a decision to hold the next conference in Puerto Rico in 1995. PREPA will host this conference and plans to showcase its 20-MW BES facility for the event.

Silent Power, Ltd., Runcorn, UK, was visited to discuss and review sodium/sulfur battery development. SPL's U.S. subsidiary is under contract to SNL to develop this battery technology. Utility battery applications, battery development, and battery testing were discussed. SPL has made significant progress in the area of electric-vehicle battery engineering. The SPL facilities in Runcorn were toured briefly. 


\section{Battery Systems Analysis}

The Battery Systems Analysis activities are intended to identify high-value benefits of battery energy storage in a wide variety of utility applications. These activities will enable utilities to quantify the usefulness of battery storage and to make decisions regarding suitability to their applications. Widespread acceptance of this technology by the utility industry will eventually make it possible for utility planners to include battery storage in their planning scenarios routinely. Such acceptance is necessary for the eventual commercialization of this technology.

There are three subelements in the Battery Systems Analysis program element:

\section{Applications Analysis/System Studies \\ Feasibility Studies \\ Opportunities Analysis}

A "system study" is an initial screening study performed in cooperation with a host utility to identify and evaluate the potential benefits of battery energy storage to that utility. This screening-level study establishes a coarse estimate of battery benefits-to-cost ratio based on a limited examination of utility-specific operation and financial data. The exact size of the battery energy storage facility, its location in the utility network, and operational details of the battery energy storage system are not defined at this time.

The follow-on "feasibility study" goes beyond the initial system study and firmly establishes the quantitative value of battery energy storage to a higher level of confidence by examining detailed forecasts of utility operating costs and other operational parameters for the entire life of the battery energy storage project. A sitespecific conceptual design of the batiery energy storage system is included in the feasibility study to determine the cost of the battery system needed to generate these benefits.

A feasibility study is recommended if the results of the previous system study indicate a potential for a sufficiently high benefit/cost ratio. There are no widely accepted norms for the benefit/cost ratio that trigger a commitment to a feasibility study, but generally, a ratio of 1.5 may be acceptable justification to proceed to the feasibility study phase. The results of the feasibility study lay the foundation for any future battery energy storage project and become an essential part of its project planning.
The principal desired outcomes of the entire Battery Systems Analysis element are produced within the Opportunities Analysis subelement. As such, the results of the other two activities are directly utilized. First, the economic benefits at the national level are characterized; these must include the identification of market size, timing, and specific applications. Systrm-level requirements for each application are defined, but working definitions of these requirements are critically needed to allow effective system design and engineering to proceed. The desired information incudes systemlevel specifications related to power, energy, cost, and duty cycle along with any special needs such as power quality and/or general siting constraints (e.g., environmental, physical). Detailed design-specific information, such as the performance requirements for the various individual components of the system, their configuration, or operating conditions, is not included. Finally, a study will be performed to match specific battery technologies with specific applications.

\section{Background}

Four utility-specific systems studies were completed in FY92. The findings of these studies showed potentially strong benefits of battery energy storage in each utility's network, and recommendations were made to each host utility for follow-on feasibility studies.

These four systems studies were a first-of-a-kind effort, where there was direct interaction with the planning and operations personnel of the host utility to identify applications of battery storage in the utility's network. Because of the landmark nature of these studies, there is a need to document the tasks, methodology, lessons learned, and the broader implications of the study results. Insights gained from this evaluation of the methodology, findings, and lessons learned will guide future activity in this area and identify the nature of barriers that could prevent the widespread commercial application of this technology.

Additionally, the results of the systems studies completed in FY92 and other system or feasibility studies conducted in FY93 will be used to estimate the benefits of battery energy storage to utilities on a national scale. The applications identified by these studies and the related benefits are sound indicators of benefits that can 
be captured by other utilities with similar operating conditions.

One approach being evaluated at this time for estimating national benefits is to review the operating and planning information that is routinely reported by utilities to various government regulating agencies, such as the Energy Information Administration (EIA), Federal Energy Regulatory Commission (FERC), and North American Electric Reliability Council (NERC). These data bases are indicators of planned generation and transmission expansions, operating reserve margins, production cost, and types of fuels used and other performance trends in the utility industry. Detailed examination of this information will allow performance trends in the utility industry to be established and the results of the previous systems and feasibility studies to be extrapolated to a national perspective on the benefits of battery energy storage to utilities. Other studies, such as those performed by the inuividual utilities or EPRI, will also be reviewed and used as appropriate. This activity will lead to a comprehensive estimate of battery energy storage benefits stated in terms of operating and capital cost savings to utilities and their customers on a national scale.

\section{Status}

\section{Chugach Electric Association}

One of the four utilities that participated in the System Studies conducted during FY91-92 was CEA, which serves the areas around Anchorage, AK, and some rural areas in that region. The findings of the system studies were encouraging, and CEA has decided to undertake a follow-on feasibility study to refine further the benefits estimates and to prepare the specifications for the acquisition of a battery system. Two neighboring utilities, AML\&P and GVEA participated informally with CEA during the initial system study. At this point, both wish to partner with CEA during the feasibility study phase, with CEA taking the lead role. GVEA serves the Fairbanks area and AML\&P serves the city of Anchorage. Both utilities buy power from CEA. GVEA plans to investigate displacing planned upgrades to the transmission line that connects Anchorage to Fairbanks with the BES system. The scope of the feasibility study has been expanded to accommodate the needs of these neighboring utilities. If the feasibility study results indicate strong benefits of battery storage at these utilities, then the basic battery system design concept developed for CEA will be modified to meet the require- ments of the other utilities. A SOW has been drafted by SNL for the feasibility study.

In addition to DOE/SNL funding support, CEA has also found support for the feasibility study from EPRI and the research and development (R\&D) arm of the NRECA. At present, it is in the process of setting up a tailored collaboration agreement with EPRI for the performance of the study. CEA expects to issue a RFP by mid-1994, following resolution of contractual relationships and discrete separation of the study tasks. The SOW for the study will lead to the development of two conceptual designs to meet the needs of CEA, GVEA, and AML\&P.

\section{SMUD Feasibility Study}

SMUD, which serves the Sacramento, CA, area, has been very active in supporting demonstrations of alternate technologies, such as photovoltaics and wind. SMUD has recently purchased $40 \mathrm{MW}$ of wind turbines that are scheduled for a phased installation beginning in the near future. Another $300 \mathrm{MW}$ of renewable generation is being planned over the next 5 to $10 \mathrm{yr}$. A BES benefits study with this generation mix will be a valuable addition to the set of prior system studies that did not incorporate any renewables.

A new partnership is being formed with SMUD to perform a feasibility study. The SMUD feasibility study includes refinements over SOWs written for previous studies. The SMUD SOW specifically includes a final task that generates site-specific requirements and battery specifications for two candidate sites. It is the strong desire of both SMUD and SNL that this study should lead to a BES system demonstrated at a SMUD site.

\section{USBD at PG\&E}

The Utility-Scale Battery Demonstration (USBD) is a 2-MW/4-MWh transportable, modular battery system development undertaken by PG\&E and co-funded by SNL. It is designed to solve local peaking problems and offer distribution planners an alternative to premature upgrade of existing substation capacity. The transportability feature of the battery system allows it to be moved from one substation site to another as needed by each substations load requirements.

PG\&E planners have indicated that footprint and power quality are major concerns for the design of such a transportable battery system, and reactive power (VAR) control capability is desirable but not required. Planners believe that this system will enable them to 
manage load growth cost-effectively at several substation sites within their planning area over the life of the system. USBD is intended to meet the needs of utility planners by demonstrating that battery system technology has reached a state of maturity where performance requirements can be met at costs that are competitive with traditional transmission and distribution planning options.

PG\&E will cost-share the design, fabrication, and testing of the USBD with SNL on a greater than 50/50 basis. It is expected that the preject will last through 1995 if it is started by early 1994. SNL will be involved with PG\&E in all phases of the design and fabrication, including proposal and design review and providing review of field installation and testing. A full-scale prototype will be delivered to PG\&E for field testing at one or two sites.

Extensive input was provided to PG\&E in the planning and release of its RFP. The RFP was released in September, and the proposals that were received are being evaluated. SNL participated in the proposal review and evaluation process. PG\&E is planning to announce vendor selection and contract award decision in early 1994.

\section{National Benefits Study}

Following the completion of the four System Studies performed in FY91-92, it was planned to extrapolate their results to estimate the benefits of battery storage to utilities on a national scale. This estimate would capture the benefits associated with the wider range of battery applications identified by the system studies and other analysis within the past few years.

A two-phase work plan was drafted and presented for DOE/OEM review in late April 1993. Phase I of this plan included a regional approach for quantifying the national benefits. Phase II included a survey to identify the market for battery systems in the utility industry in specific time frames. The complete study, including the two phases, was to last approximately $15 \mathrm{mo}$. However, because of time and funding constraints in FY93, this proposed study was deferred to FY94. Instead, a limited-scope analysis to estimate the national benefits was recommended and performed during May, and a draft of its findings was prepared in late June for internal review.

This limited-scope analysis focused on six applications and estimated the benefits and the related cost for installing the battery systems to capture those benefits. The analysis relied on planning data reported by utilities to the DOE/Energy Information Administration (ELA) and the trends observed in the SNL system studies. The six applications analyzed were:

- Spinning Reserve

- Capacity Deferral

- Generation Dispatch

- Transmission Line Deferral

- Distribution Substation

- Demand-side Management

Distribution substation benefits were not estimated during this exercise because load growth data that affect substation planning by utilities are not reported by utilities to the EIA or other government agencies. These data will be obtained from other sources, and a future revision will add in the additional benefits of this application.

Results of the analysis indicate the potential for $\sim 11$ GW of battery storage by the year 2010. The present value of all the utility benefits equals $\$ 17$ billion (1993 $\$$ ). The corresponding estimate of the capital cost of the battery systems needed to capture this benefit is $\$ 9.1$ billion, which yields a benefit/cost ratio of 1.9 . This battery systems capital cost is based on an estimate of $\$ 800 / \mathrm{kW}$ for the entire study period, and no cost reductions were assumed in the out years resulting from higher production volumes and/or introduction of improved performance, lower cost advanced battery systems in the late 1990 s and early 2000 s.

These results are summarized in Talle 2-1. The estimate of battery systems installed is comprised of battery systems installed to capture generation-side benefits as well as battery systems installed on the customer-side-of-the-meter as a demand-side management tool. The results of this limited-scope analysis will be documented in detail in a final report.

\section{Other Activities}

\section{Utility Energy Storage Program}

At present, the OEM funds the UBS at SNL and a Thermal Energy Storage program at Pacific Northwest Laboratory (PNL). These are the only storage technology development programs funded primarily for electric utility applications. With the growing interest by utilities in storage technologies and significant advances in emerging technologies such as SMES and flywheels, it is likely that OEM will undertake development activities in these storage technologies also. In response to an 


\section{Table 2-1. Estimate of Benefits by Application Through 2010, in billions, 1993 \$}

(Captured by installing $11.33 \mathrm{GW}$ of batteries at a cost of $\$ 9.06$ billion)

\begin{tabular}{|cc|}
\hline \multicolumn{1}{c}{ Battery Energy Storage Application } & Benefit \\
\hline Generation & $\$ 10.3$ \\
Spinning Reserve & $\$ 3.3$ \\
Capacity Deferral & $\$ 5.7$ \\
Generation Dispatch & $\$ 1.3$ \\
Transmission and Distribution & $\$ 3.9$ \\
Transmission Line Deferral & $\$ 3.9$ \\
Distribution Substation* & $\mathrm{TBD}$ \\
Customer-Side & $\$ 3.0$ \\
Demand-Side Management & $\$ 3.0$ \\
\hline Total Battery Energy Storage Benefits & $\$ 17.2$ \\
\hline Cost for Installing 11.33 GW of Battery Storage & $\$ 9.1$ \\
Benefit/Cost Ratio & 1.9 \\
\hline
\end{tabular}

- Distribution substation benefits could not be estimated because of a lack of source data at the time of the analysis. Benefits related to this application will be estimated in the follow-on study.

OEM request, the UBS program supported the development of the conceptual framework of the a Utility Energy Storage Program. The program was conceived as an umbrella to coordinate the development of present and future utility energy storage programs supported by OEM. The program would be managed by SNL to assist the DOE in implementing a consistent plan for developing a portfolio of storage technologies to meet a wide range of utility storage needs over a 20-yr planning horizon. The program aims at capturing near-term utility applications with systems that are ready for field demonstration today, as well as sustaining the development of other storage technologies that are capable of large-scale utility applications at specific times in this 20-yr planning horizon.

A key task in the initial stages of the UES Program plan will estimate the benefits and role of all storage technologies in the national utility network. The scope of this task goes beyond the National Benefits Study conducted in the UBS program because it includes all storage technologies such as SMES and thermal storage and emerging technologies such as flywheels, in addition to batteries. The results of this task, combined with the commercial readiness of existing and emerging storage technologies will assist the DOE in planning the development path of individual storage technologies to meet utility needs in a timely manner.

According to EIA statistics, energy storage constitutes a mere $3 \%$ of the national generation capability. This limited penetration can be solely attributed to the fact that pumped hydro is the only energy storage technology that is regarded as "commercially ready" by the utility industry. Yet, pumped hydro has had limited utilization by the utility industry due to the severe environmental impact associated with its use. The majority of the pumped hydro facilities in existence today were built and commissioned in the 1950 to 1970 period, when it was relatively easy to permit and license these projects. Today, there are a heightened environmental awareness and increased public oversight of land and water resources that make it impossible to further utilize this storage option. In the absence of energy storage 
technologies that are feasible, utilities have virtually eliminated the use of storage options in their resource planning, even though they recognize that energy storage offers a higher degree of flexibility and several operating advantages to the utility network.

On a conceptual level, the potential role for storage on the national utility network could be very large, because the availability of storage in the utility network allows the decoupling between the generation and consumption of electricity. In this context, storage transforms electricity into a commodity that can be generated and stored independent of the time and location of its use. This conceptual utilization of energy storage could have strategic importance in the future, especially if utilities are deregulated and a truly competitive electric energy supply infrastructure evolves.

These were the primary concepts that formed the framework of the UES Program plan that evolved during the latter part of the third quarter and most of the fourth quarter of FY93. A preliminary plan was formally presented to OEM in August. Further refinements and more management structure detail were presented in a series of reviews that lasted through September. At that time, further development and implementation of the UES plan were transferred to SNL, CA.

\section{Battery/SMES Qualitative Assessment Study}

Battery energy storage and SMES systems have similar operating characteristics, and consequently, may be used for the same utility applications. A qualitative comparison of the merits of battery energy storage and
SMES technology for utility applications was performed to understand the potential role of each technology in the utility network and technology development areas needed for wide scale utilization of each technology.

The results of the assessment indicate that BES is well suited for applications that require fast response as well as storage capacities up to three hours. In the nearterm, the primary technology development needs are for standardized, integrated system designs that can be purchased by utilities on a turn-key basis. Further support for field demonstrations at utility sites to validate performance is highly desirable. In the longer term, sustained development of advanced battery technologies, such as sodium/sulfur and zinc/bromine, is needed to ensure that improved-performance battery systems will be available to meet anticipated utility needs.

SMES offers rapid charge/discharge capability, but is limited by storage capacity. Considerable development effort will be required to increase SMES capacity beyond its present capability of a few seconds to approximately three hours in order to meet certain utility application requirements. Widespread application of both technologies requires development of off-the-shelf PCS hardware and vendor capability. The one-of-a-kind PCS hardware that was built for earlier battery projects will be incapable of meeting the energy storage market needs as it grows.

The full study will be released as an independent report early in FY94. 


\section{Subsystems Engineering - Lead-Acid}

The lead-acid battery has been in existence for over a hundred years and has found use in a wide variety of energy and power storage applications, including vehicle engine starting, telecommunications standby power, forklift truck propulsion power, computer hackup power systems, and naval submarine propulsion power. The widespread use of the lead-acid couple is the result of its good electrical performance capabilities under a wide variety of operational scenarios, the ready availability and relatively low cost of its materials and components, and the generally "user-friendly" characteristics of this battery system from its manufacture through its operating lifetime and to its disposal and reclamation for reuse in other lead-acid batteries.

As the demands for electric power increase in our society, battery systems are being examined for energy storage to provide utility applications and power management capabilities. The battery could provide additional electrical energy to meet demand during daily and seasonal peak load periods; and batteries could also be used by the utilities to resolve issues such as capacity constraints, air quality management, power quality deterioration, localized power brown-outs and expensive online, fuel-powered peaking capacity. Several BES-type load-levelir:- prujects around the world have demonstrated the feasibility and benefits to utilities of installing and operating battery-based energy storage systems. However, questions regarding the maintenance, reliability, and lifetimes of these battery-based energy storage systems remain, and hence retard the widespread acceptance of BES systems.

The lead-acid battery subsystems engineering project has as its objective the development of advanced VRLA batteries. The goal is to have advanced VRLA designs that meet utility application requirements available for implementation in the mid- to late-1990s. This would precede the commercial introduction of advanced battery systems, which is not expected before the year 2000 . The central portion of this effort is a $3-\mathrm{yr}, \$ 2.83 \mathrm{M}$ cost-shared development contract with GNB Industrial Battery Company. The objective of this development contract is to achieve performance improvements in VRLA batteries through better designs and processes so as to enhance their potential for widespread use in electric utility applications. A second objective is to quantify, together with utility companies, the benefits of these improvements in specific utility applications for which battery system requirements are defined.
Included are activities such as improvement of VRLA battery performance, development of specifications and designs for VRLA batteries, and quantification of the costs and benefits of the conceptual designs. SNL supports the GNB contract work by evaluating the performance of battery modules furnished at several stages during the contract and is also carrying out material development and characterization studies on selected battery components.

\section{Technology Development - GNB}

\section{Tasks}

The GNB effort under this contract comprises three tasks. Task 1 is a two-phase activity intended to improve the performance of VRLA batteries through changes in battery design, materials, and manufacturing processes. The objectives of Task 2 are to develop specifications and baseline zonceptual battery system designs for two specific types of applications and to perform economic analyses of battery system costs for these same two cases. Task 3 seeks to quantify the cost/ benefits of the improvements identified in Task 1 and to incorporate the improved VRLA battery system into the economic model developed during Task 2.

Tasks 2 and 3 are being led by the University of Missouri - Rolla (UMR) and require extensive participation by the host utilities. PG\&E, and PREPA. Tasks 1 and 2 are currently under way, while Task 3 , which requires information developed from the first two tasks, has not yet started.

The first phase of Task 1 seeks to improve current VRLA battery designs to match or exceed the performance of flooded lead-acid batteries at a cost equal to or lower than that of these competing designs. All this must be accomplished without sacrificing the inherent advantages of the VRLA technology. The technical approach for this first phase is focusing on performance issues such as vent valve reliability, thermal management, charging profiles, positive plate behavior, and ground fault prevention, which have been perceived by the utility industry as barriers to the widespread implementation of VRLA battery systems. The studies and improvements conducted in this phase will generate cell-level data proving and improving the performance 
of GNB's ABSOLYTE technology in utility applications. An additional objective is to improve the consistency of cell performance through manufacturing process control.

In Phase 2 of Task 1, GNB is completing the development of an advanced VRLA battery design optimized for high-power applications. The specific development efforts are investigating evolutionary and revolutionary changes in grid and active materials make-up and in electrolyte immobilization technique to improve the efficiency of energy delivery and the life of the VRLA battery. Manufacturing processes that improve consistency and control costs will be evaluated and appropriately implemented.

These various improvements in the VRLA technology will be incorporated in stages, and in some cases, the changes incorporated will be to produce designs that address the needs of specific utility applications. Figure 3-1 shows a flow chart of the product designations that are anticipated at this point in the develo ?ment process. ABSOLYTE II is an existing product marketed for telecommunications and other standby power applications. Some of the improvements identified in Task 1, Phase 1, have been incorporated into the ABSOLYTE IIP, which is an intermediate product. Production of the ABSOLYTE IIP began during the first quarter of 1993.
The MSB product contains many of the enhancements developed during Task 1, Phase 1, and is designated "improved." The MSB is optimized for a set of life, performance, and installation flexibility requirements as recommended by PG\&E, a host utility in this project. Prototypes of this particular MSB design will become available in mid-1994. The LSB product will incorporate technology developed during Phase 2 of Task 1 and is therefore called "advanced." The LSB design will be optimized for the power needed in spinning reserve and frequency regulation applications as anticipated by PREPA. The advanced design LSB VRLAs will also become available for site demonstration in mid-1994.

The technical progress made against each of the specific task items over the past year is summarized in this report. The reader is referred to the previous reports in this project for detailed background information and prior technical progress.

\section{Task 1/Phase 1. VRLA Battery Improvements}

\section{Vent Valve Reliability}

VRLA batteries operate on the "oxygen cycle" wherein oxygen gas generated during charge at the posi-

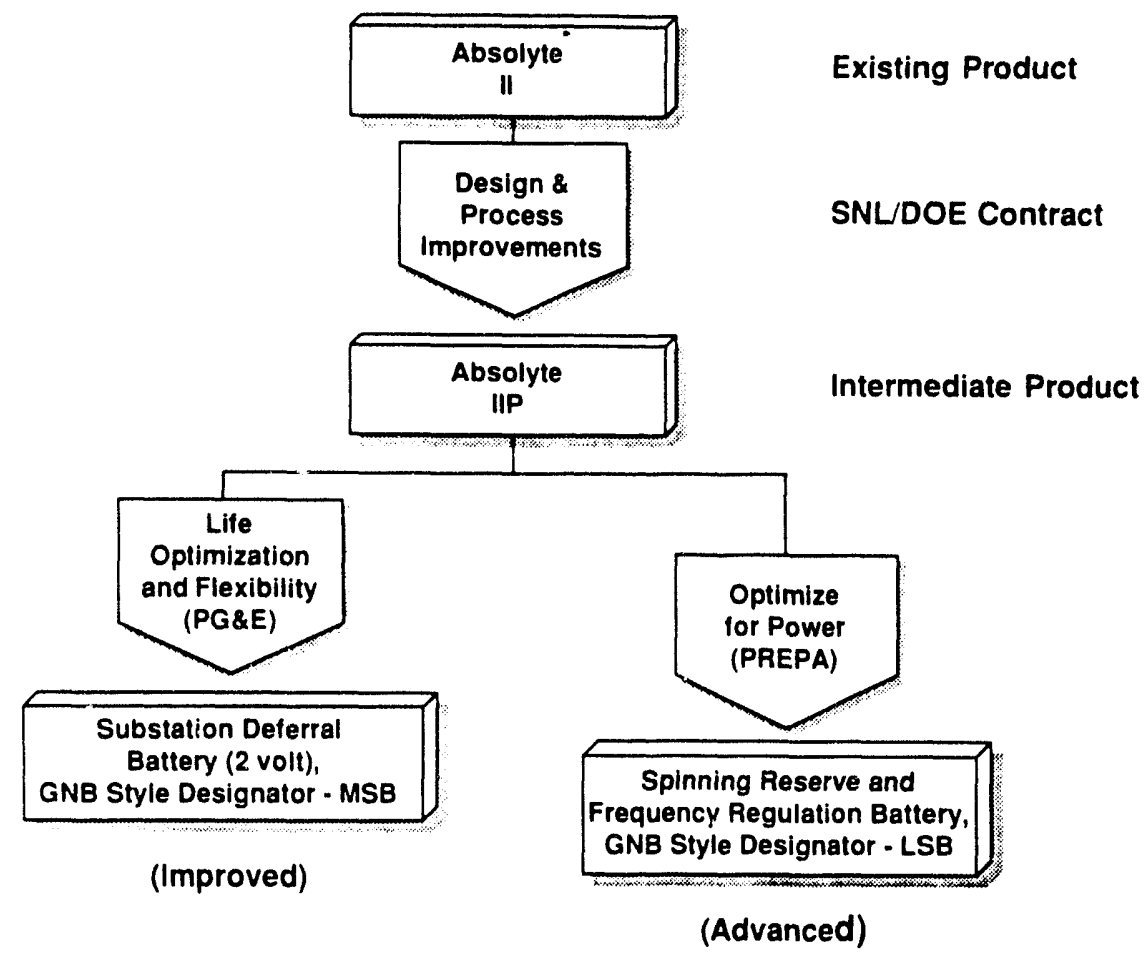

Figure 3-1. Flow Chart of Product Designations Anticipated During the VRLA Development Process 
tive plate is recombined on the negative plate. As such, some positive internal pressure must be anticipated during the operation of a VRLA battery. The containers for VRLA batteries are typically made of an acid-resistant plastic and are not capable of withstanding extremely high internal operating pressures. This is particularly true in large-capacity VRLA batteries where the large, thin-walled plastic jars are incapable of withstanding more than a relatively small internal pressure without deforming. For this reason, these large VRLA batteries are often assembled into stronger metal structures to prevent them from deforming even at the relatively low internal pressures at which they operate.

The pressure relief vent incorporated into the design of all VRLA batteries is provided as a safety device to allow excess gasses built up during periods of high rate charging or overcharging to be vented to the ambient atmosphere. Because the VRLA battery does operate with some positive internal pressure, the vent must stay closed during normal operation. If the vent opens at too low a pressure, unnecessary quantities of oxygen and/or hydrogen gas will be allowed to vent from the cell, causing loss of water from the electrolyte and potentially resulting in cell "dry-out" and eventual failure. If the vent opens at too high a pressure, the plastic cell case can deform, causing stresses at the seals and joints that can deteriorate and potentially develop into leaks. A further requirement for the vent valve assembly is to prevent the ingress of oxygen from the surrounding environment to the cell, which will accelerate the rate of self-discharge of the VRLA battery by reacting with the charged negative plate.

The vent valve system incorporated into each GNB ABSOLYTE cell has been designed with the requirements enumerated above in mind, and operates well, as evidenced by over $10 \mathrm{yr}$ of operational history. This vent valve operates within a 3-10 psi opening pressure range. It was shown earlier in this project that valve operational characteristics were a function of the dimensional tolerances of the vent valve assembly components, the ultrasonic weld zone thickness variations, and material properties of the rubber vent cylinder. Efforts this year focused on demonstrating vent operating capabilities using an accelerated test method, and the evaluation of alternative rubber cylinder materials in the ABSOLYTE vent design to reduce the pressure difference between vent and reseal operation further.

Consistency of vent operation over the battery lifetime was demonstrated by testing sample vent valves in ABSOLYTE cells that were being severely overcharged by a constant current method. Under these abusive conditions, the ABSOLYTE cell was forced to generate both oxygen and hydrogen gas during the overcharge, causing the pressure inside the cell to build up to the point where the vent was required to operate. The continuous constant current overcharge assured repetitive operation of the pressure relief vent. Pressure transducers were mounted on the test cells and internal cell pressure was continuously recorded. Vent and reseal operation was clearly identified by the changes in internal pressure observed and recorded. The cells were overcharged and the vent valves forced to operate repetitively over a $500-\mathrm{hr}$ period. It was felt that the number of vent and reseal operations experienced by the pressure relief valves during this 500 -hr overcharge period far exceeded the number of vent and reseal operations expected under normal operation during the cell's lifetime.

Six standard ABSOLYTE pressure relief vent valves were randomly selected from production and placed on the accelerated pressure vent test at room temperature. The vent and reseal characteristics of these pressure relief vents for the first $50 \mathrm{hr}$ of test and the last $50 \mathrm{hr}$ of the 500-hr-long test are shown in Figures 3-2 and 3-3. These data show the ABSOLYTE vents operating consistently over the test period, venting at about 5-7 psi and resealing at about 4-6 psi. In general, the range between vent and reseal pressure for an individual pressure relief vent valve was less than 2 psi over the entire 500-hr-long test. An important fact to note is that at no time during the test did any of the pressure relief vent valves allow the internal pressure of the cell to drop to zero, which could allow oxygen gas to enter the cell and increase the self-discharge rate.

In addition, several variations to the vent's rubber cylinder construction were tested to determine whether enhancements to consistency of performance could be achieved or whether the cost of the vent assembly could be reduced. The variations included changes to the rubber's durometer, treatment of the sealing surface of the rubber cylinder to enhance vent and reseal characteristics, and changing the production method to one based on cutting an extruded rod of the rubber material to form the vent cylinder.

The results of these tests showed that the standard ABSOLYTE vent design exhibited the most consistent vent/reseal cycling behavior. The vent valves assembled using certain of the surface-treated cylinders also showed consistent behavior, but generally operated below the desired vent/reseal operating pressure range. Valves prepared using the extruded and cut rubber cylinders were not able to operate consistently in the specified 3-10 psi range because of distortion of the sealing surface that occurred during the cutting operation. Pres- 


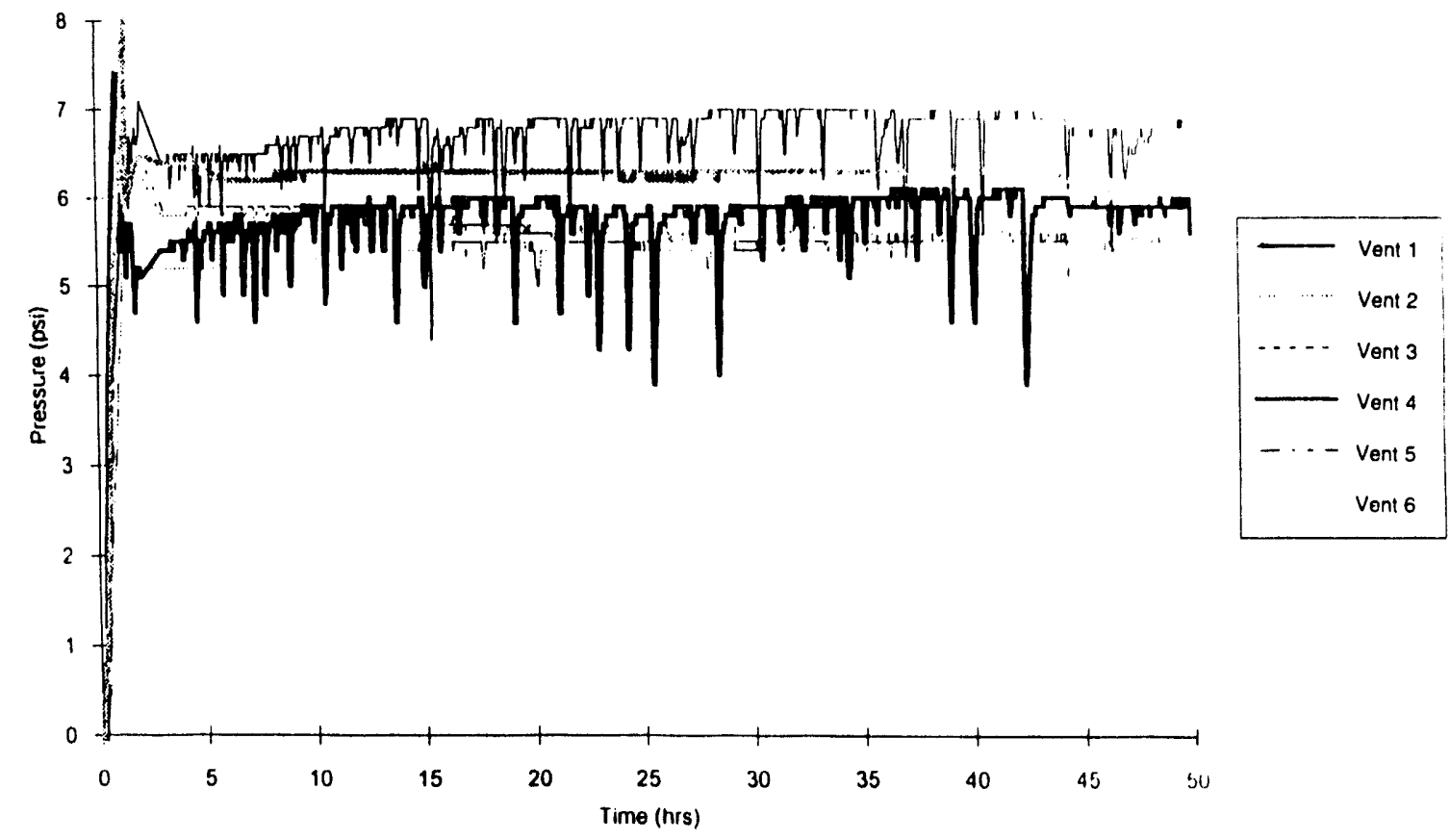

Figure 3-2. Vent/Reseal Operation of Six Randomly Selected ABSOLYTE Pressure Relief Vents During the First $50 \mathrm{hr}$ of an Accelerated Life Test

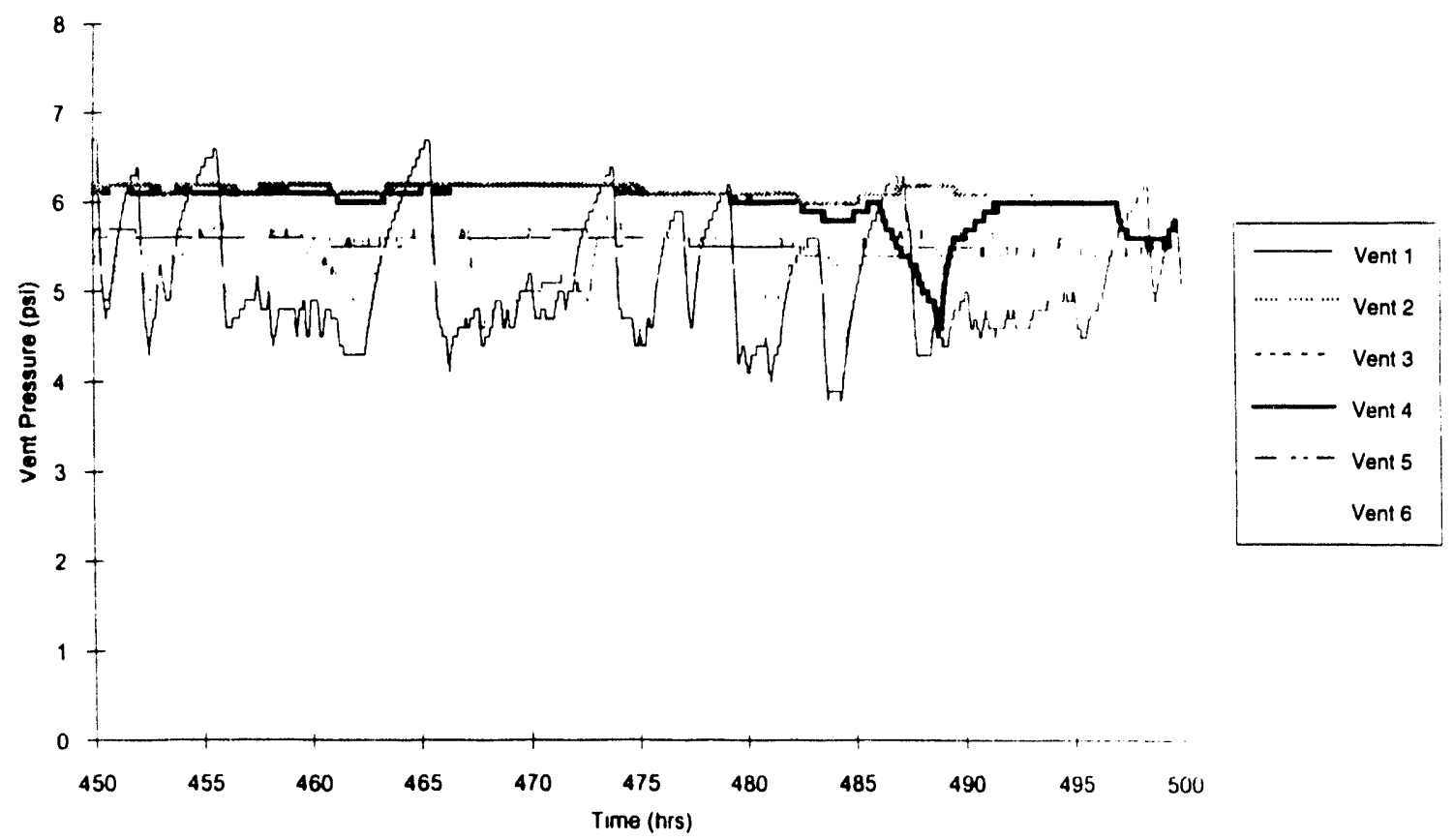

Figure 3-3. Vent/Reseal Operation of Six Randomly Selected ABSOLYTE Pressure Relief Vents During the Last $50 \mathrm{hr}$ of a 500-hr Accelerated Life Test 
sure relief vent valves assembled with higher durometer rubber cylinders, regardless of the material composition, could not be brought into the specified operating range even by manipulating the ultrasonic weld assembly settings.

Results of charging studies reported later in this report suggest that a higher venting pressure is needed for the recharge conditions envisioned in utility applications. The limited off-peak recharge periods restrict total recharge times to less than $8-10 \mathrm{hr}$, forcing recharge conditions that result in higher internal operating pressures. These conditions in turn require that the vent operating range be increased slightly from about 37 psi to at least 5-10 psi to minimize the number of vent operations under utility application recharging. Future work under this task will examine how this pressure increase can be achieved using the ABSOLYTE vent design. In addition, a different vent concept, an umbrella valve design, will be compared to the rubber cylinder vent for advanced battery designs with limited head and top cover space. Selected vent designs will be tested under a proposed life accelerating test wherein the pressure relief vent systems will be repetitively required to vent and reseal at elevated temperatures.

\section{Positive Plate Growth}

The normal wearout mechanism anticipated in any lead-acid battery is the anodic corrosion of the positive grid structure. The product of this anodic corrosion reaction of the lead grid with sulfuric acid is lead dioxide. The density of lead dioxide is roughly $80 \%$ of that of the lead metal from which the lead dioxide is formed during the corrosion process. As a result of this density change, the grid structure deforms and commonly undergoes what is referred to in the battery industry as "plate growth." The plate will attempt to grow in the direction of least mechanical resistance; in the battery, this is typically along the grid frame opposite the side where the plate lug is connected to the terminal strap. The extent of growth is dependent on both the type of corrosion the grid alloy experiences (i.e., surface corrosion versus intergranular corrosion) and the actual length of the grid. As the battery size (both physical size and electrical capacity) increases, plate growth can become a significant potential failure mode.

Grid growth can result in the loss of electrical contact between the positive active material and the grid structure itself, and/or in cell shorting of the positive plate to the underside of the negative plate strap. In addition to grid alloy composition and physical shape of the grid, operating temperature and charging conditions can influence the rate at which the positive plate will grow.
GNB's ABSOLYTE cells use the patented MFX alloy in the positive grid. This alloy has excellent corrosion resistance characteristics, and GNB's R\&D efforts have determined that the annualized corrosion rate for the MFX alloy when maintained at $25^{\circ} \mathrm{C}$ and at a float voltage of $2.25 \mathrm{vpc}$ is $1.8 \mathrm{mils} / \mathrm{yr}$. That is, under these charging conditions, the positive grid will corrode 0.00184 in. of its cross-sectional radius each year. Further, the mechanism of corrosion for the MFX alloy is a surface reaction that evenly corrodes the leac grid structure. This type of corrosion results in the least amount of grid growth. In comparison, intergranular penetration corrosion results in the greatest amount of corrosionderived grid growth.

GNB has examined and analyzed positive grids removed from ABSOLYTE cells that were recovered from field-aged batteries. The positive grid from an 8yr-old ABSOLYTE battery in a telecommunications installation was recently examined. The positive corrosion layer thickness was measured at 0.005 in., corresponding to an average annual corrosion rate of 0.625 mils/yr, approximately one-third of the corrosion rate allowed in the design. The measured horizontal growth of this positive grid was $0.26 \% / y r$, and the vertical growth was $0.14 \% / y r$. Over a projected $20-y r$ lifetime, the extrapolated growth of this grid would be approximately $2.8 \%$. The design allowance for vertical growth in the ABSOLYTE design is $6 \%$.

Although the MFX alloy affords a good deal of resistance to plate growth, GNB has proposed incorporating other concepts into the cell design to provide additional protection against the deleterious effects of positive plate growth. These are (1) designing the positive grid so that dimensionally it is shorter than the negative plate, and (2) fitting the positive plate into an insulating boot designed to collapse as the positive grid grows and hence accommodate its growth. The shortened positive plate concept has been incorporated into GNB's ABSOLYTE IIP design, and test cells are awaiting temperature accelerated life testing. Because of the accelerated nature of these tests, results will become available during the next year.

\section{Thermal Management and Charging Analysis}

Elevated temperature has a deleterious effect on the life of any lead-acid battery. In flooded electrolyte types, the reduction in life is from the acceleration of positive grid corrosion. In VRLA batteries, in addition to the acceleration of the grid corrosion process, it is suspected that elevated operating temperatures may also induce failures from accelerated loss of water by gassing and diffusion through the container material and the pressure relief vent valve. 
Heat generation mechanisms are associated with the operation of any battery including the resistive heating effects caused during discharge, the heat released from the chemical and electrochemical reactions on charge, coupled with the resistive heating effects during charge, and miscellaneous heating effects from polarization and the grid corrosion reaction. VRLA batteries have one additional significant heat generating sourcethe oxygen recombination reaction occurring at the negative plate during overcharge.

Normally, heat is dissipated in a lead-acid cell by conduction through the cell materials, particularly the lead in the grids, straps and terminal posts; convection from the surface of the battery and its components to the surrounding air; a small amount by radiation only if the temperature differential is large; and evaporative cooling caused by the gasses being vented from the battery. Being an electrolyte-starved system, VRLA batteries have a lower heat capacity than do flooded electrolyte equivalents, have no internal convection, and have an additional mechanism for heat generation. These conditions raise suspicion of thermal instability and the prospect for thermal runaway.

GNB's ABSOLYTE II cells are assembled in modular steel trays, and the trays are designed to allow them to be stacked one atop the other in a horizontal orientation. The surrounding steel trays improve the ability of the design to dissipate heat away from the cells, and the stacking arrangement provides inherent air circulation channels, both between layers in the stack and between stacks in large battery installations. These features aid the thermal stability of the battery under normal operating conditions.

To demonstrate the thermal stability characteristics of the ABSOLYTE II battery configuration, a 6-cell modular battery assembly was instrumented with thermocouples and subjected to overcharge at increasingly higher voltages. The thermocouples were placed so as to measure the temperature of the interior-most cell as well as the cells at the ends of the modular tray. The battery was overcharged for $50 \mathrm{hr}$ each at voltages starting from $2.45 \mathrm{vpc}$ to $2.65 \mathrm{vpc}$ in 50 millivolt/cell increments. These charge voltages were selected because they significantly exceed the recommended float charge voltage ( $2.25 \mathrm{vpc})$ and are higher than the recommended boost charge voltage $(2.35 \mathrm{vpc})$ for the ABSO!.YTE products. They therefore simulate the charging voltages possible if about $10 \%$ of the cells in a large battery system were to fail in a short circuit condition. This scenario is highly unlikely, but the test demonstrates the thermal stability of the design even under severely abusive conditions.
The charging current required to maintain the battery at each of the charging voltage setpoints is shown in Figure 3-4 and indicates that the battery attained thermal and charging equilibrium at all voltages up to $2.65 \mathrm{vpc}$. Individual thermocouple recordings shown in Figure 35 during the overcharge test at $2.65 \mathrm{vpc}$ indicate that despite the observed elevated temperatures, approaching $125^{\circ} \mathrm{F}$ at the center of the battery pack, the system reached a thermal equilibrium that prevented the onset of a thermal runaway condition. The elevated temperatures observed would affect the overall life of the battery pack; however, the probability of a thermal runaway occurrence was mitigated by the battery packaging and installation schemes.

Utility energy storage applications require that the batteries be recharged during off-peak hours, and usually limit available recharge times to less than $8 \mathrm{hr}$. Additional charging constraints could be imposed to limit the temperature rise in the cells to control grid corrosion and water loss and to extend battery life, and in the extreme case to prevent thermal runaway. The ideal recharge profile would minimize recharge time and temperature rise during charging while maintaining battery capacity. An additional objective for this project is to identify recharge parameters and optimum charge termination algorithms that can be programmed into the utility power control systems.

GNB is optimizing the parameters for a three-step constant current $\mathrm{CI} / \mathrm{CV} / \mathrm{CI}$ recharge profile that achieves the objectives for battery recharging in utility applications. Testing has shown that the optimum in-rush current for the ABSOLYTE VRLA design is approximately $25 \mathrm{~A}$ per $100 \mathrm{Ah}$ of rated battery capacity. At this charging rate, battery charge acceptance is maximized in the shortest time while limiting the amount of temperature rise in the battery. The constant voltage step limits the battery's charging voltage to $2.32-2.35 \mathrm{vpc}$ and forces the charge current to taper before the battery's gassing point is reached. The final constant current portion prevents the battery from continuing towards a float charge condition and allows the input of $100-105 \%$ of the capacity discharged in the $8-10 \mathrm{hr}$ available for recharge. A finishing current of $2 \mathrm{~A}$ per $100 \mathrm{Ah}$ of rated battery capacity has been identified as acceptable while minimizing gas venting and temperature buildup.

Several charge termination algorithms have been tried, including both first and second derivatives of voltage vs time $(d v / d t)$ and fixed time interval. Both $d v / d t$ approaches provided reasonable charge termination indication to prevent excessive gassing and temperature increase in single battery string configurations. The sensitivity of this approach decreased, however, when a 


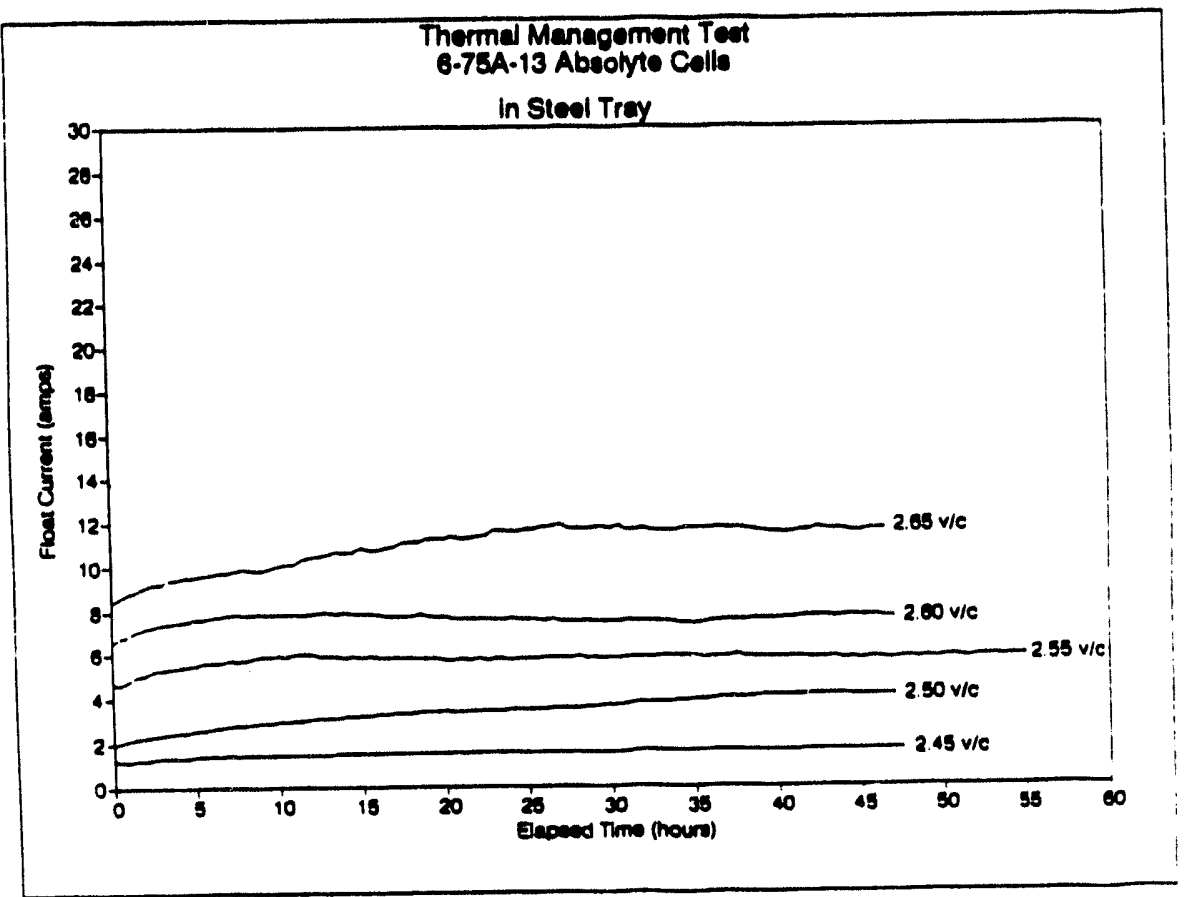

Figure 3-4. Overcharge Test of an ABSOLYTE Battery Module in a Steel Tray

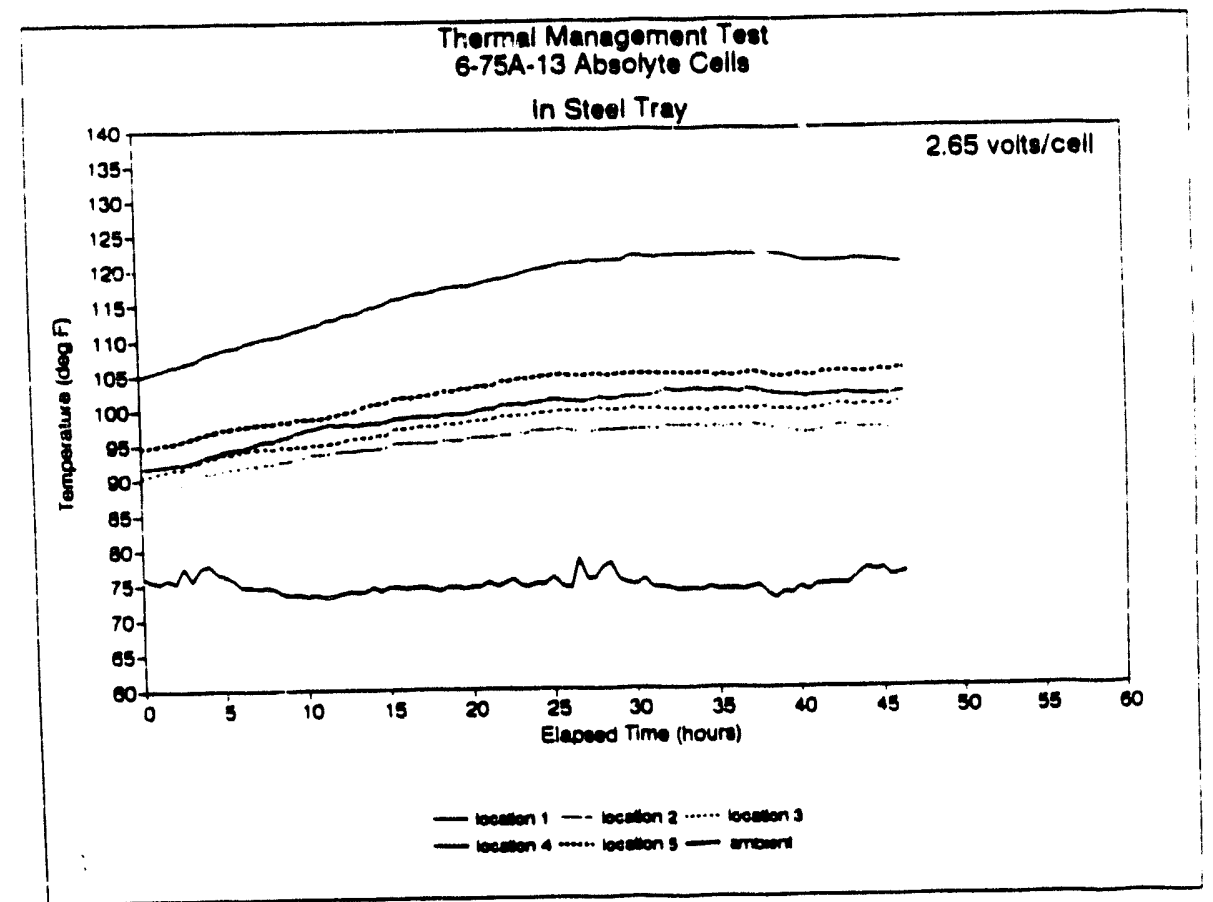

Figure 3-5. Temperature Measurements at Various Locations in an ABSOLYTE Battery Module Being Overcharged at $2.65 \mathrm{vpc}$ in a Steel Tray 
paralleled string configuration such as would be likely to occur in large utility installations was tested. A timed finish charge termination is being studied and may be very effective when followed by a constant voltage float charge until the battery is required to be dispatched into service. Using the fixed time finish charge termination as shown in Figure 3-6, it was possible to return about $106 \%$ of the capacity removed in an $80 \%$ depth discharge in less than $7 \mathrm{hr}$ with acceptable internal pressure and temperature rise. Additional testing to further refine this charge termination technique is planned.

Utilities are concerned that battery installations requiring charging of several parallel battery strings could result in serious string imbalance leading to battery performance deterioration and shortened battery lifetime. Previous testing conducted by GNB indicated that battery installations with parallel strings of ABSOLYTE cells could be operated with consistent charge current sharing even under very deep discharge conditions. A similar test conducted using the three-step CI-CV-Cl charge profile with the dv/dt charge termination criterion shows parallel battery modules accepting charge current equally (Figure 3-7). It is important to note that the percent recharge for the two strings is virtually identical throughout the constant current finishing charge step. Furthermore, GNB does not expect any charge imbalance when the timed finish charge termination technique is used to control recharge of the ABSOLYTE battery modules.

Recharge testing of the improved ABSOLYTE IIP design using the charge profiles developed and following discharges simulating actual utility discharge profiles are planned for the next contract period.

\section{Ground Fault Elimination}

By its nature, a utility-based BES system will be large in capacity and will operate at relatively high DC voltages. As such, ground faults could pose a serious safety risk to operators and utility personnel. Furthermore, they can lead to premature failure of a portion of the battery because all of the battery charging voltage could be borne by the cells between the ground fault point and the facility ground.

ABSOLYTE battery modules at present have cells contained in steel modules that have a baked-on, powdered polyester paint. To aid with thermal management and to achieve the desired compression on the cell plate stack, the jars of the cells are placed in intimate contact with the walls of these steel modules. Electrolyte leaking from a cell could contact the steel module creating a ground fault path.

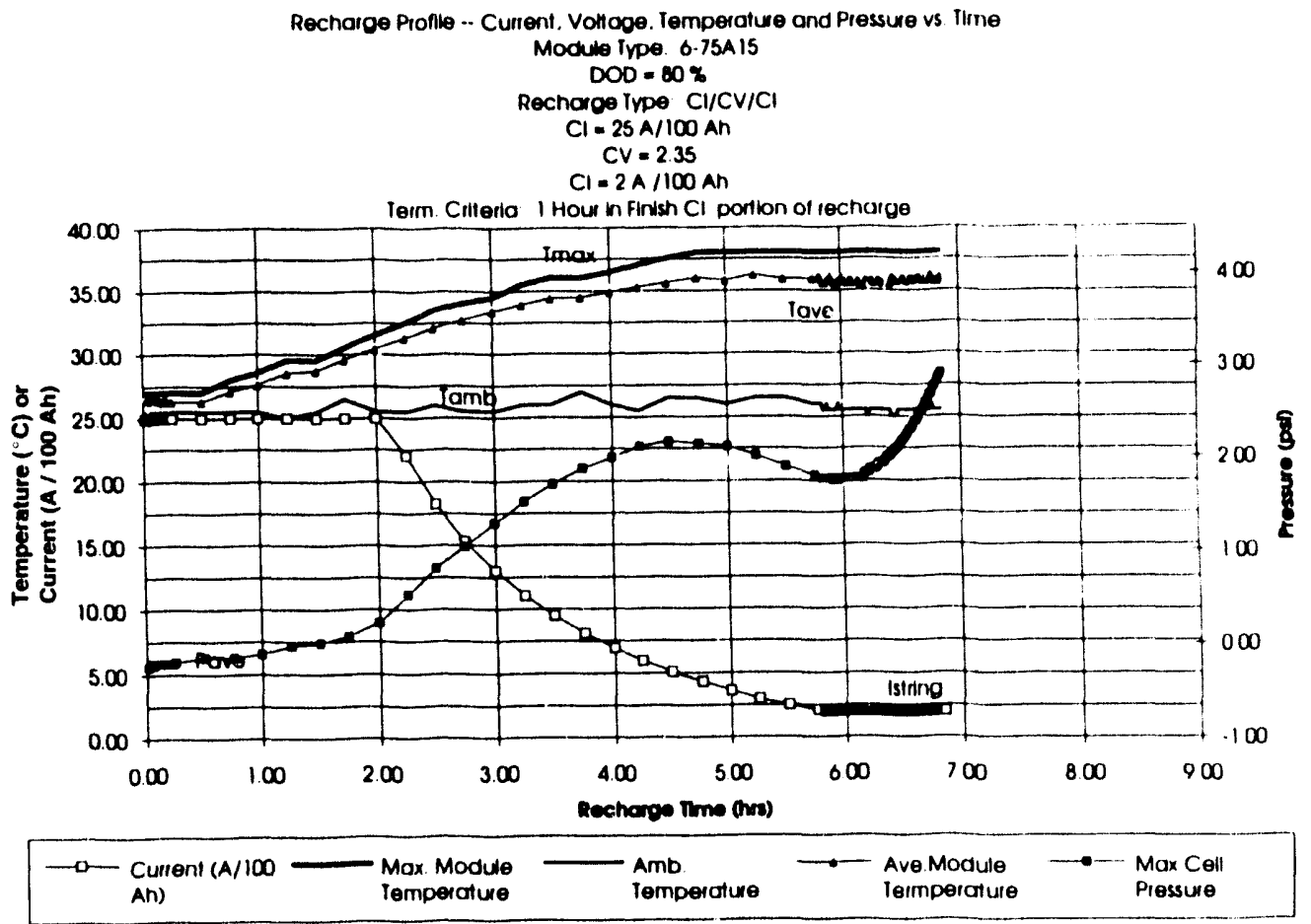

Figure 3-6. Recharge Prolile of an ABSOLYTE Battery Using a Fixed Time Charge Termination Technique 

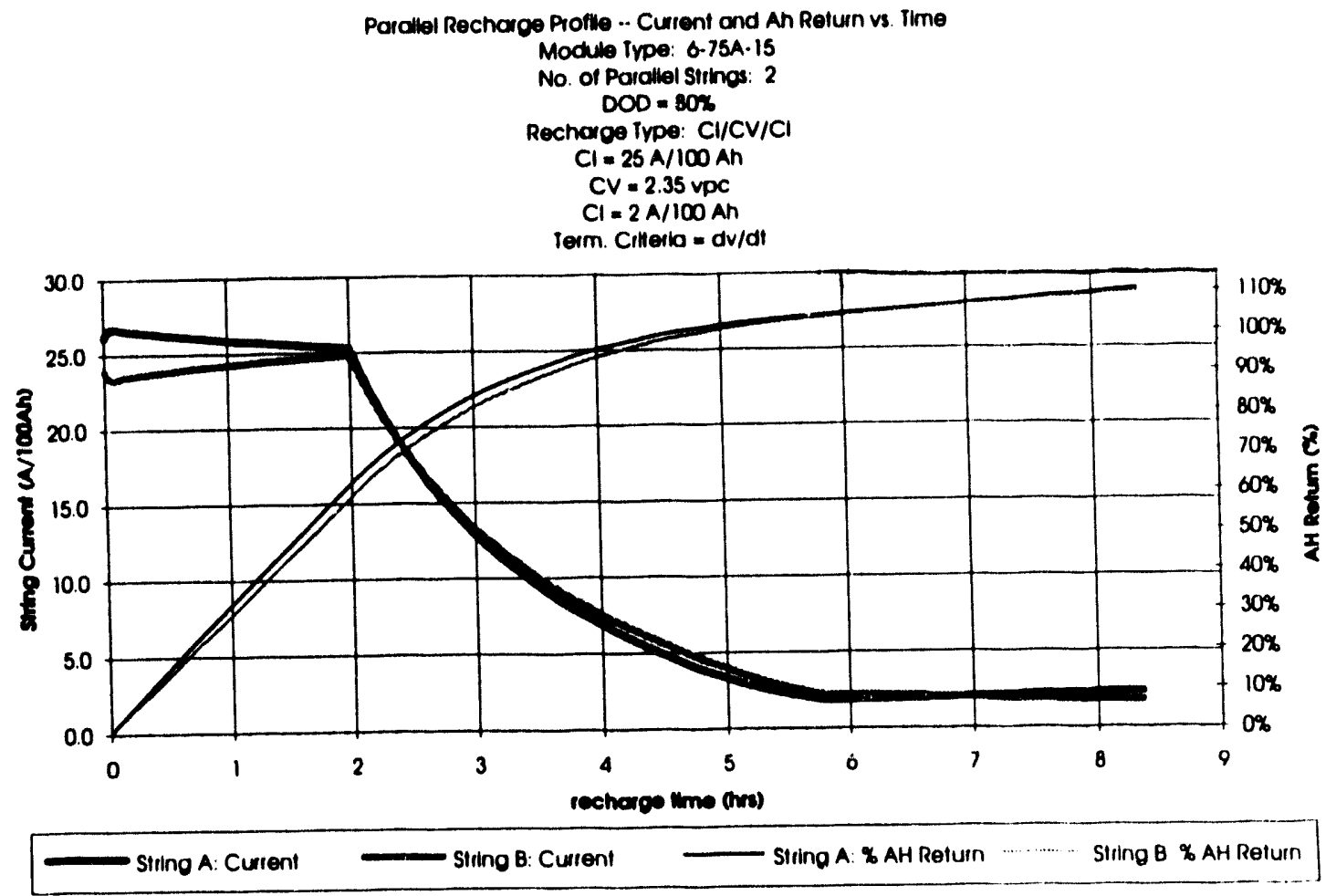

Figure 3-7. Current Sharing Between ABSOLYTE Battery Modules Connected in Parallel when Recharged Using the Three-Step CI/CV/CI Technique Developed for Utility Applications

GNB's approach to this issue was to eliminate the potential for electrolyte leakage from the cell and, secondly, to evaluate battery module constructions that would not allow a ground fault to arise even if an electrolyte leak should occur. Several design and manufacturing process improvements discussed in the last annual report, including an improved electrolyte filling process, an improved jar-to-cover heat sealing process and an improved leak detection test method were developed and implemented with the introduction of the ABSOLYTE IIP. The evaluation of alternative battery tray constructions continued into this reporting period.

Aluminum trays with a special electrostatic dip coating and a nonmetallic glass reinforced polypropylene battery tray were evaluated. After fabrication of the aluminum trays, it was determined that cells could not be uniformly fitted into the individual cell compartments. This was found to be because of dimensional discrepancies caused by warpage of the aluminum panels during welding. Because it would be cost prohibitive to compensate for the uncontrolled warpage of the aluminum panels during welding of the battery trays, the aluminum design approach was deemed not to be viable to provide components with the dimensional tolerances required for proper operation of VRLA cells.
The greatest concern with a nonmetallic battery tray for VRLA batteries was the thermal management characteristics. Tests conducted with ABSOLYTE cells installed in a prototype glass-filled polypropylene battery tray while monitoring temperature at several locations in the battery assembly showed comparable thermal management capabilities for both the steel battery tray and the plastic counterpart under normal float charge conditions (2.25-2.30 vpc charge). Above 2.50 vpc, the steel battery tray dissipated the heat being generated by the cells much more effectively, while the plastic battery tray caused the temperature of the cells to increase to unacceptable levels. At charge voltages between 2.3 and $2.5 \mathrm{vpc}$, higher cell temperatures and more erratic temperature behavior were observed for the plastic tray as shown in the comparison plots of Figure 3-8.

Refinements to the plastic tray design are being considered. These include:

- Providing ribs on the sides, endwalls and bottom to increase stiffness and to promote air flow around the cells. 
- Incorporating stepped C-channels that force tray stack alignment and provide stability against lateral seismic forces.

- Molding in slots in the $\mathrm{C}$-channels to eliminate the need for lifting hooks during installation.

- Installing shims between the cells and the tray walls to offset the draft angle required in the mold for the tray and to provide uniform compression on the cells.

\section{Positive Active Material}

The positive electrode active material has a significant effect in determining the life of a lead-acid battery. The positive plate in a lead-acid battery is considered to be the "workhorse" plate because the positive active material undergoes much greater crystal structure and morphology changes than the negative active materials during discharge/charge cycling. The objective of this project task is to determine paste formulation/mixing and plate curing process parameters to achieve material structures that exhibit optimized performance and life.

A plate curing process has been developed that converts the pasted oxide mixture to a tetrabasic lead sulfate crystal form. Conversion levels of $80-100 \%$ have been achieved. Furthermore, the process is able to consistently achieve crystal sizes of about 50 microns, which are needed to obtain efficient electrochemical conversion during the formation step. Free lead contents of about 5\% have been achieved using a leady oxide precursor oxide containing $25 \%$ or more free particulate lead. It was determined that the amount of free lead conversion is related to the acid absorption characteristics of the leady oxide. This paste mix/plate curing process will be the basis for follow-on formation trials and extended cycle life testing.

Attempts at a conventional constant current formation of the leady oxide based positive plate cells within the same time constraints as the present formation process have not been successful. Formation times are increased by $12-24 \mathrm{hr}$, which is opposed to the objective of this overall project to reduce the cost of VRLA cells in order to expand their use in utility applications. However, a pulse formation experiment was attempted using cells from an earlier pasting trial and provided some promise for an efficient approach to forming the leady oxide/tetrabasic cured positive plates.

Preliminary results as compared to the experimental targets are shown in the following table:
Pulse Formation Experiment Results

\begin{tabular}{lcc} 
& Targot & Actual \\
\cline { 2 - 3 } Lead Dioxide Conversion & $>90 \%$ & $89 \%$ \\
Initial Capacity & $>92 \%$ & $95 \%$ \\
Acid Specific Gravity & 1.305 & 1.298 \\
Void Saturation & $97 \%$ & $91 \%$ \\
Formation Timu (Days) & 7 & 6.2
\end{tabular}

These results are encouraging and deserve further attention. The electrolyte concentration and void saturation results can be modified to more accurately approach the target values by adjustments during electrolyte filling.

Cells built with plates processed using the leady oxide and the tetrabasic cure have been assembled and have completed their initial conditioning cycles. Cycle life tests as well as an accelerated float life test will begin shortly and compare the leady oxide cells to the standard ABSOLYTE design. We expect that the leady oxide cells will enhance the deep discharge cycle life without degrading the float life characteristics.

\section{Task 1/ Phase 2. VRLA Battery Advancements}

\section{Cell Design}

This subtask consists of two parts: an intermediate cell design that is evolutionary in nature and seeks to increase the 8-hr capacity of the existing ABSOLYTE cells, and an advanced design that is revolutionary and seeks to maximize the short duration power capability of VRLA cells for utility power regulation applications.

\section{Intermediate Design (ABSOLYTE IIP)}

The intermediate design developed under this subtask was introduced as a commercially available product, the ABSOLYTE IIP, early in 1993. This introduction followed a series of test builds and prototype sample testing to verify expected performance under a variety of discharge rates. The ABSOLYTE IIP design provides about a $17 \%$ improvement in performance at all discharge rates and has been proposed as the battery for several BES systems being considered by utilities in Alaska and Hawaii.

Accelerated float life tests of the ABSOLYTE IIP design are under way. The tests at $60^{\circ} \mathrm{C}$ have completed the equivalent of $11 \mathrm{yr}$ of float charge operation at $25^{\circ} \mathrm{C}$, 
SREגI päS

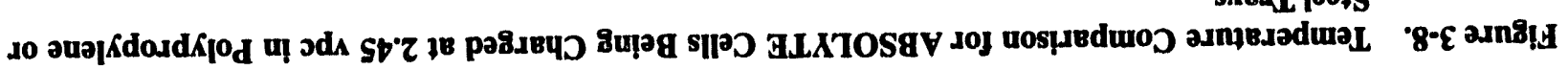
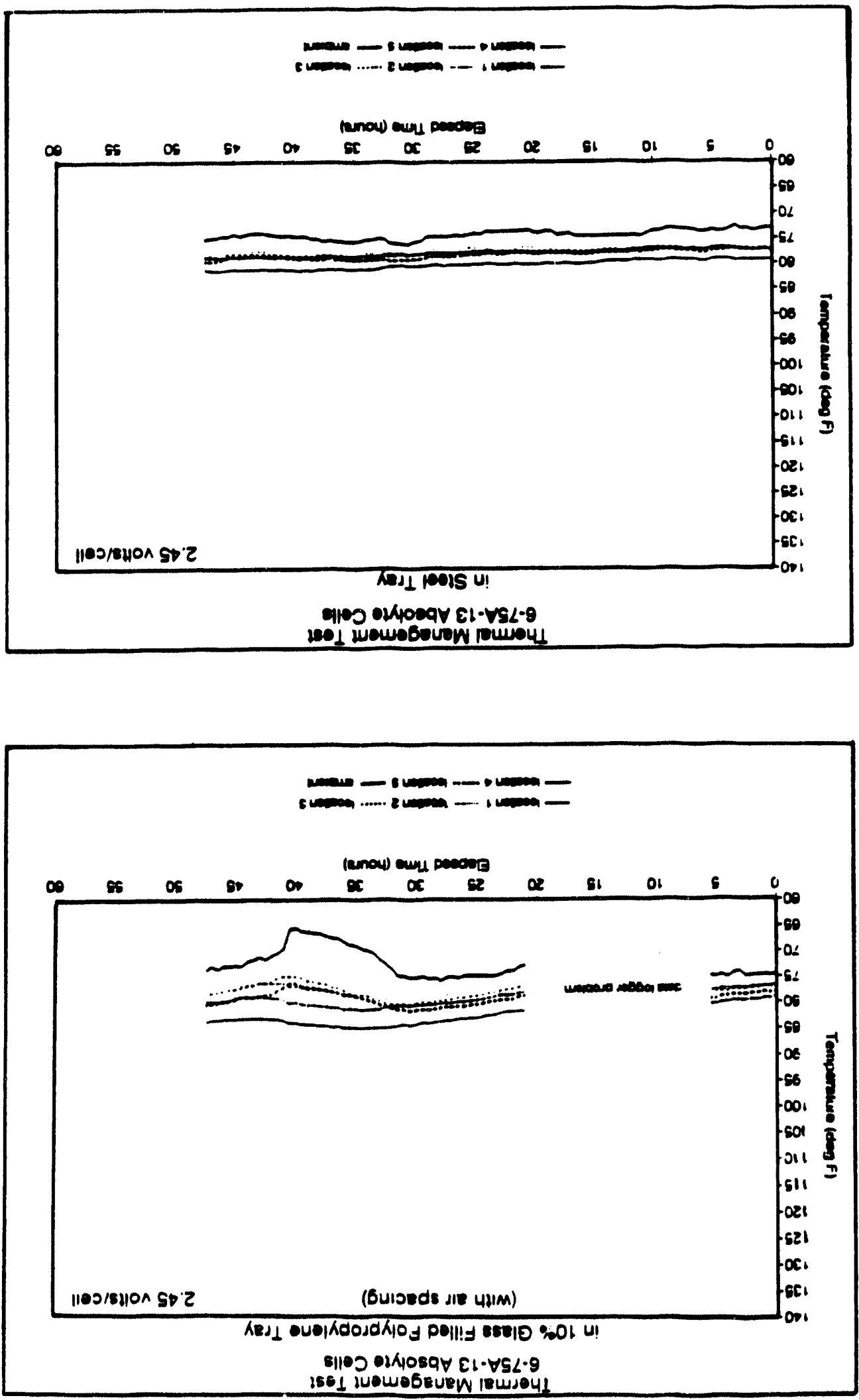
while the tests at $50^{\circ} \mathrm{C}$ have reached the equivalent of 5 yr. Both accelerated tests show the batteries operating above their rated capacities.

\section{Advanced Design (LSB)}

Present ABSOLYTE batteries are designed to provide sustained long-duration discharges typical of energy storage systems. These batteries offer significant reductions in battery footprint, space, and weight when compared to conventional flooded electrolyte lead-acid batteries. Yet, with a battery optimized for high-power applications, even greater savings in battery footprint, space, and weight can be achieved for power regulation applications. The advanced design battery has this as its objective.

High-power applications require batteries that have very low internal resistance. Accordingly, the advanced design battery seeks to reduce the resistance of cell components so that the total cell resistance is decreased. The battery components that were analyzed and redesigned included the intercell connectors, terminals, plate straps, plate lugs and grids as well as the active materials and the electrolyte absorbing separator system. The GNB advanced design uses a sleeve as the jar and two covers (one at each end of the sleeve) to form the cell container. The covers are sealed to the jar (sleeve) by a heat-sealing process. The cell terminals are at opposite ends, one through each of the two covers. It was proposed to mold the positive and negative plate straps into their respective covers. When the jar-to-cover closure was made, the plate lugs would fit into pre-made slots in the strap. The plate lugs would be subsequently fused to the strap, creating both the current conducting path and the electrolyte/gas seal.

Prototype cells were tested and demonstrated the ability to provide as much as a $66 \%$ capacity improvement over the ABSOLYTE IIP design at the 15-min discharge rate. These prototypes highlighted several process and assembly issues that had to be resolved before the design could be considered reliable enough for utility applications. Among these were leakage at the jarto-cover heat seal and at the interface between the cover and the terminal bushings. The primary cause of the jarto-cover heat seal leakage was determined to be the poor heat sealing characteristics of the plastic material used and interference during assembly between the plate lugs and the terminal bushing molded into the cover. The leakage at the terminal bushings was first thought to be related to the bushing geometry and variability in the molded cover and the bushing coating. However, changes to these parts and processes did not significantly reduce the leakage. GNB then conducted experi- ments to measure the amount of heat developed at the lead to plastic interface during the terminal welding process and to compare the heat developed on the LSB design to that developed on the ABSOLYTE IIP design, which does not exhibit terminal-post leakage.

Temperature measurements were recorded during the welding process for the three different LSB bushing designs. The maximum temperatures observed are listed in the following table:

Lead-Plastic Interface Temperature During Welding

\begin{tabular}{ccc}
$\begin{array}{c}\text { Bushing } \\
\text { Type }\end{array}$ & $\begin{array}{c}\text { Maximum } \\
\text { Temp }^{\circ} \mathrm{C}\end{array}$ & $\begin{array}{c}\text { Distance to } \\
\text { Intertace (in.) }\end{array}$ \\
\hline 3 Slot & $115-130$ & 0.425 \\
4 Slot & $193-213$ & 0.248 \\
5 Slot & $232-260$ & 0.223
\end{tabular}

The temperatures observed at the bushing to lead interface on the ABSOLYTE IIP design range from 122$185^{\circ} \mathrm{C}$.

The temperature at the interface between the lead bushing and the plastic cover is dependent on the distance from the weld area to the lead-to-plastic interface. Furthermore, since the melting point of the plastic being used was $220^{\circ} \mathrm{C}$, it became obvious why the interface on the 4 and 5 slot designs was being damaged by an excessive amount of heat developed during the welding process.

These findings have necessitated taking a new direction to solve the leakage issues of the advanced LSB design. A new plastic material, a clay-filled polypropylene, has been selected to replace the previously used plastic. This plastic is less temperature sensitive, more stable, and has better sealing characteristics than the previous material. The terminal bushing is being redesigned to accept two lead posts rather than the individual plate lugs. This design approach will require the battery to have an internal strap, but initial calculations indicate only minor effect on the overall cell resistance.

To verify that the revised design reduced the heat developed at the lead-to-plastic interface, a prototype of the proposed bushing design was molded into a cover and tested in a similar manner as described above. The maximum temperature rise observed at the lead-to-plastic interface was $118^{\circ} \mathrm{C}$. Modifications to the tooling and the various parts affected has started and early results on leakage and temperature measurements from 
fabricated cell assemblies are expected during the first quarter of calendar year (CY) 1994.

\section{2-V Modular Battery (MSB)}

Based on discussions with one of the host utilities on this project, the need for a modular battery suitable for "portable" applications was identified. Critical characteristics include minimum space and weight and flexibility of installation. To obtain these features, a reduction in operational lifetime was deemed necessary and acceptable (below that which could be achieved if life were the primary criterion). The operational life of this design in utility-type applications is projected to be $5-10$ yr depending on the extent of cycling the battery experiences.

A design based on a medium-sized modular battery package (approximately the size of a Group 27 automotive battery) was proposed. The module, however. would be a $2-\mathrm{V}$ unit that would be connected in series/ parallel to achieve the desired voltage and capacity. The modular approach would increase the flexibility of installation and would permit easy replacement of modules during the operational lifetime of the battery. The design would allow utilities to minimize their initial investment while evaluating battery energy storage in their system. In addition, this approach could be used where temporary, seasonal, or short-term conditions exist that could be resolved using battery energy storage.

GNB's initial design calculations indicated that this battery would have a nominal capacity of $500 \mathrm{Ah}$ at a 2 hr discharge rate. The expected cycle life for the battery would be in excess of 400 cycles to an $80 \%$ depth of discharge. The operational lifetime of the design in utility applications is expected to be 5-10 yr depending on the extent of cycling the battery experiences.

GNB has completed detailed designs for the container and the intermediate cover that provides the primary seal to the battery jar. Finite element analysis and prototype deflection tests are being conducted to determine dimensional stability while the module is operating with the internal pressures expected for this VRLA design. A sketch of this proposed $2-\mathrm{V}$ battery module is shown in Figure 3-9.

\section{Copper Negative Grid}

Historically, lead has been used as the material for the negative plate grid. The principal considerations in the selection of a lead alloy, or for that matter any material, to be used as the negative plate grid are over-poten- tial characteristics and strength; corrosion resistance is not a major consideration. Lead is a poor electrical conductor, and other materials, copper for example, with higher conductivities could improve the high rate discharge performance of the lead-acid battery. Although the copper substrate would have to be coated with lead to provide chemical corrosion resistance, the leadcoated copper grid would still significantly lower the cell's internal resistance, increase energy density, improve charge acceptance, achieve a more uniform current distribution over the length of the plate, reduce polarization, and improve active material utilization.

Copper is an ideal candidate as a negative grid substrate because it is an excellent conductor, is readily available, and can be worked and fabricated into forms that can be used in a battery configuration. Copper has a specific electrical resistance $1 / 12$ that of lead, and when compared on a per-weight basis, the electrical resistance is less than $1 / 16$ that of lead. Thus, cells incorporating lead-plated copper negative grids should have considerably better performance, especially at high discharge rates.

One risk of incorporating copper into a lead-acid cell, however, is the possibility of contamination. Copper is a known contaminant in reclaimed lead, and the deleterious effects of copper on the performance of leadacid batteries are well known. The rate of self-discharge of a lead-acid cell is greatly accelerated by the presence of copper in the electrolyte. A crucial technical aspect of any effort to incorporate a lead-coated copper grid in a lead-acid cell is to ensure the integrity and porosityfree nature of the lead coating.

Two concepts for producing a lead-coated copper negative grid were analyzed by GNB: (1) a copper stretch metal (expanded) technology and (2) a coextruded copper-cored wire concept. In the latter, a plastic supporting structure would be used with the coextruded wire to form a battery grid.

After evaluating both concepts, GNB selected the plastic grid supporting a current path of co-extruded copper wires for further investigation because of its lighter weight and flexibility in sizing the current collector path to meet a variety of application needs. Further, it was decided that the best application for the copper negative grid was in the advanced LSB design.

The proposed grid design (Figure 3-10) consists of a molded plastic frame with a series of lead-coated coextruded copper wires as the current collectors. The wires are encapsulated into the plastic frame during the molding process with about $1 / 4$ in. of each wire protruding beyond the upper grid frame to provice a connecting 


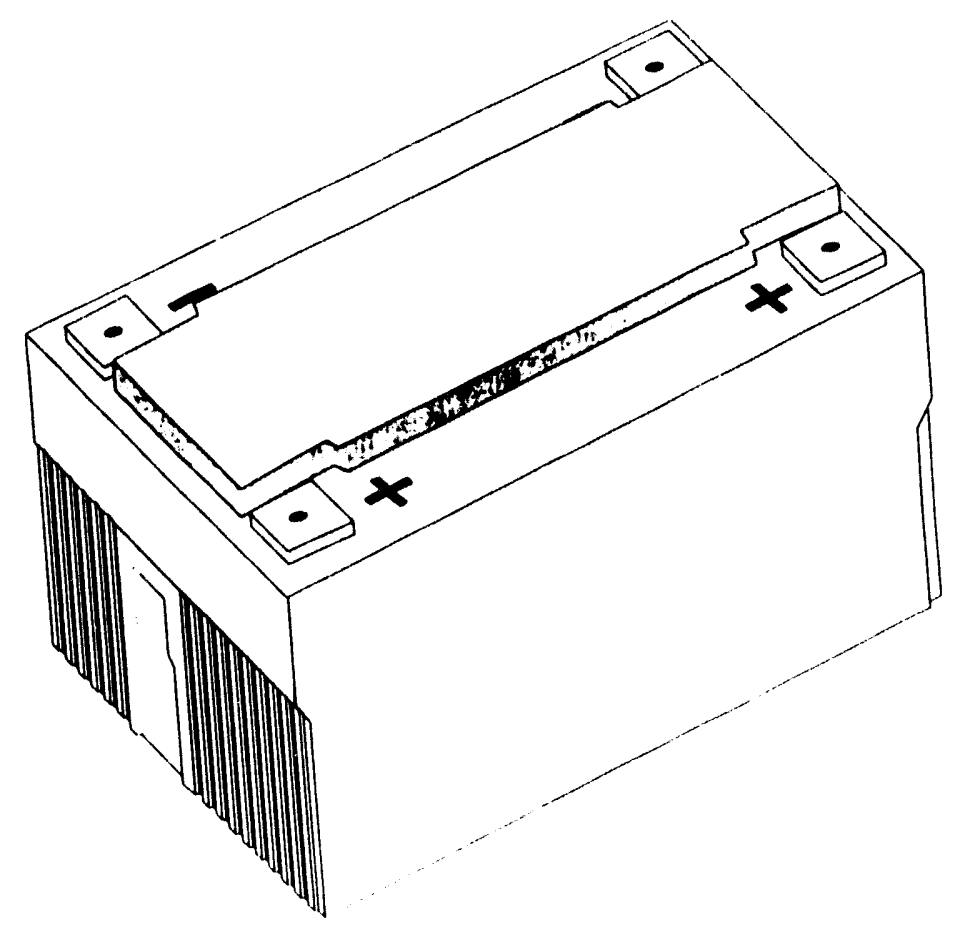

Figure 3-9. Sketch of Proposed 2-V Battery Module for Portable Utility Applications

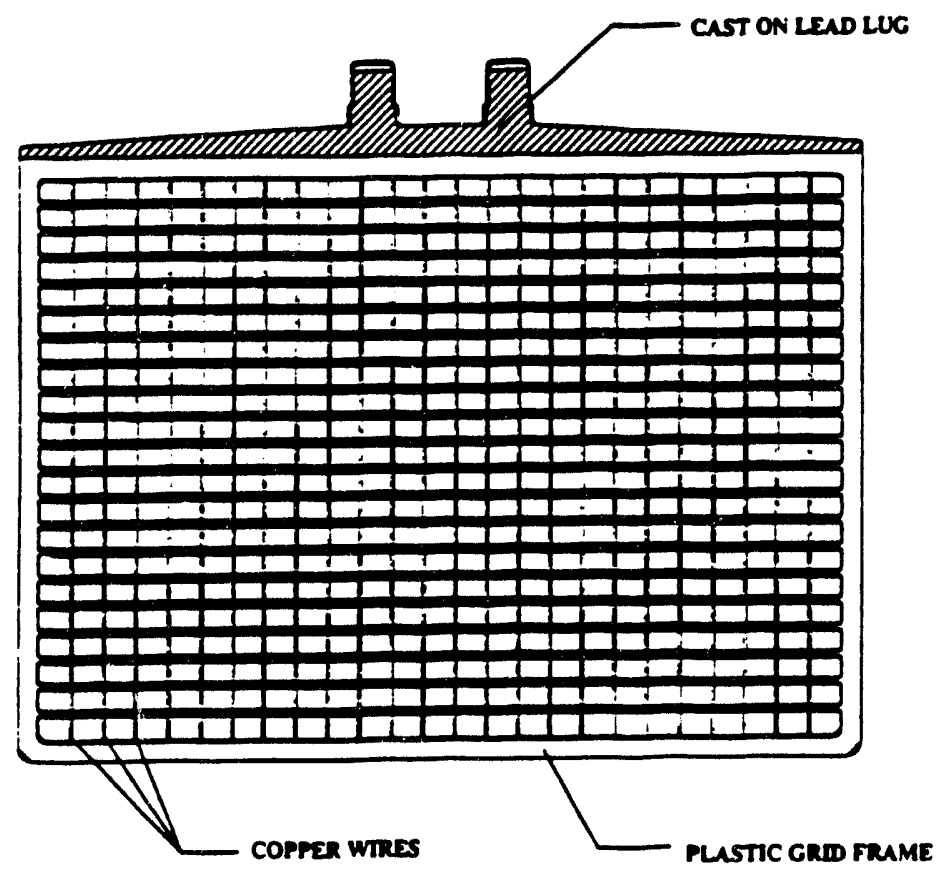

Figure 3-10. Conceptual Sketch of a Negative Grid Constructed from Copper-Cored, Lead-Coated Wires Molded into a Plastic Frame and Having a Cast-On Lead Lug and Top Frame as the Current Collector 
point for a cast lead current bar and grid lug. The proposed grid has a resistance of 134 mohms compared to a resistance of 294 mohms for the conventional lead grid. The proposed grid weighs only $167 \mathrm{~g}$ compared to $832 \mathrm{~g}$ for the conventional lead grid.

Because the integrity of the bond between the leadcoated copper wire and the cast on lead lug is critical, a small-scale experiment is being planned to demonstrate both the physical as well as the metallurgical bonding be' ween these two parts. Small lengths of the leadcoated copper wire will be cast into lead using a small open top mold. The samples will then be cut and polished to examine the bond areas. The prototype plastic mold has been ordered and is expected to arrive during January 1994, allowing GNB to fabricate prototype grids during the first quarter of CY94.

\section{Positive Plate Design}

Three of the most basic factors that limit a lead-acid cell's cycle and float life are positive grid corrosion, damaging changes in the positive active material (PAM) structure, and the formation of passivating films at the PAM-to-grid interface. This subtask explores changes in the positive grid alloy to lower positive grid corrosion, and the potential benefits of PAM additives to improve PAM stability and utilization.

\section{Positive Grid Alloys}

Selection of a positive grid alloy requires the evaluation of corrosion resistance, grid growth, tensile strength, and gassing characteristics, as well as its behavior in a cell to establish cycle and float performance and oxygen recombination efficiency when used in a VRLA design.

Several alloy compositions developed by GNB were bench tested in bare metal corrosion tests. Using these preliminary screening tests, nine alloy compositions were selected for further testing in actual batteries. The battery configuration selected was a mid-sized modular construction approximating a Group 24 automotive battery in size. A total of 1500 grids per alloy composition was cast and pasted. Using the ze plates, a total of $15412-\mathrm{V}$ batteries was assembled, filled, and formed.

Baseline characterization of the grids (weight, volume, width, height, and thickness) and the assembled batteries (weight, open circuit voltage, and impedance) has been completed. Cycle testing of experimental cells (not the assembled batteries) is providing preliminary evidence that dopant levels (less than $1 \%$ ) of additives to lead-tin alloys improve their $100 \%$ depth of discharge cycling capabilities. The assembled batteries should begin cycle testing during January 1994, as cycle test equipment becomes available.

\section{Plate Additives}

The purpose of a plate additive is to help stabilize the PAM structure during cycling. A stabilized structure will create a framework that allows an increased plate porosity and therefore permits an increase in active material utilization without sacrificing cycle life.

Based on a study of the literature of available additive materials, tin dioxide, fluoridated tin dioxide, a fluorocarbon polymer (PTFE or PVDF) and a conductive titanium suboxide ceramic were selected for further investigation. Sources for these materials are being identified and requests for sample lots of these materials are being made.

\section{Electrolyte Immobilization}

The present, ABSOLYTE design utilizes an absorbent glass mat that serves as a plate separator as well as the means of electrolyte immobilization. By and large, this glass mat has worked very well; however, there are some disadvantages. The most important disadvantage is Inaterial cost, which is the primary reason for the higher cost of VRLA cells. Another limitation is the wicking height of the glass mat, which limits overall cell height, as installed, to 24 in. or less. The objective of this task is to investigate lower cost alternatives to the fiberglass mat presently used in VRLA cells. These investigations involve the evaluation of vendor supplied samples and the performance testing of cells containing materials that have passed the initial screening tests.

GNB personnel met with the research staff of a potential separator material supplier to review the requirements for a nonglass material for VRLA type cells. As a result of that meeting, the vendor prepared an experimental polymer separator mat in the thickness used by GNB in its ABSOLYTE design. The material was then run through the ABSOLYTE assembly process to identify any areas that may require adjustment for the nonglass separator material. Principal concerns revolved around material handling and operation $\mathrm{c} n$ the ABSOLYTE production equipment. The processing trials identified improvements in controlling separator thickness that were required by the vendor, and changes to the material cutting operations would be required to handle the more elastic polymer separator material. Both of these appear to be feasible to accomplish. 
Because of these encouraging results, plans have been made to test small experimental cells to determine whether the material decomposes over time in the sulfuric acid and oxidizing environs of a lead-acid battery. In particular, the cells will be analyzed for the presence of extraordinary amounts of carbon dioxide, which indicates that some organic material in the cell is decomposing. Intermediate products, such as formic or acetic acid, form during the breakdown of organic materials, and these acids can severely attack the positive grid and increase positive grid corrosion. The material proposed by the vendor has passed the Electro Chemical Compatibility (ECC) test, indicating that undesirable impurities that could affect the plate potentials are not present in the material.

Full-size 100-Ah ABSOLYTE cells are planned to be assembled using experimental quantities of the nonglass separator in the next quarter, and the cells will be evaluated under accelerated float life test conditions at $60^{\circ} \mathrm{C}$.

\section{Task 2. Baseline Design and Economics Study}

In addition to the technical efforts to improve VRLA batteries for BES system installations, GNB is teamed with two host utilities. PREPA and PG\&E, to develop systems requirements and to conduct economic analyses relating to battery systems as part of their utility portfolio.

\section{Specifications and Design Requirements}

UMR has prepared specifications for BES systems for two different utility applications: (1) battery energy storage as an option for distributed storage, and (2) spinning reserve and area regulation. In the report that UMR prepared, the layout design, heating restictions, and economic analysis of a VRLA battery energy storage system were presented. Since the amount of land used in each of the designs is a large consideration (because of high real estate costs), the first problem addressed was the optimization of floor space in the layout design for each BES system. The second was the cooling and heating requirements for each building that are needed to keep the batteries within specified temperatures. The third and most important problem was the economic analysis of each BES system. The costs and benefits of each system were estimated and compared to determine the feasibility of the installation of each system.

\section{Battery Energy Storage As an Option for Distributed Storage}

The PG\&E objective is to evaluate energy storage as an option for distributed storage. The battery would be used at substation sites to shave the peak from the substation feeder during peak demand periods. This mode of operation extends the life of the substation transformer as well as contributing to reducing the overall utility system peak.

The battery module chosen to model this application is the 6-cell GNB VRLA MSB-2460. This battery module weighs $79 \mathrm{lb}$, measures $12.1 \times 8.7 \times 6.9 \mathrm{in}$. $(l \times w \times h)$, and consists of six $2-V$ cells connected in parallel. The cabinet designed by GNB for this battery module has eight shelves of five modules for a total of 40 battery modules per cabinet. Each 5 -module shelf is arranged in a horse-shoe fashion so that all terminals face the inside of the cabinet. The 40-module cabinet has overall dimensions of $39.5 \mathrm{in}$. deep by $31.5 \mathrm{in}$. wide by 69 in. tall, with a combined weight of $4,090 \mathrm{lb}$ (Figure $3-11$ )

This BES system is designed so that it can be located at a variety of substations, and since the required capacity varies with individual site specifications, a modular design has been adopted. The modular construction of the BES system allows individual "unit batteries" to be connected in parallel with others to obtain the capacity needed at each specific substation. Each "unit battery" consists of five parallel strings of the MSB-2460 battery modules, each string containing 327 modules. The unit battery therefore consists of 1,635 battery modules. Nine cabinets will be needed to hold each string of 327 battery modules; therefore, each unit battery will consist of 45 MSB battery cabinets. The unit battery provides $0.5 \mathrm{MW}$ for $2 \mathrm{hr}(1.0 \mathrm{MWh})$. The unit battery is matched with a $500-\mathrm{kW}$ power conditioning system (PCS) to interface to the utility system.

In their report, UMR offered five installation options requiring various amounts of floor space. The option recommended by UMR minimizes floor space requirements, allows accessibility for maintenance, and contains all of the components needed for a BES system in an organized manner. The layout arranges the battery cabinets in five rows of nine cabinets. One row is placed along the back wall of the building, and the remaining four rows are placed back-to-back and stacked two cabinets high in the center of the building. The PCS and control and data acquisition system (CDAS) are positioned along the remaining wall. There 


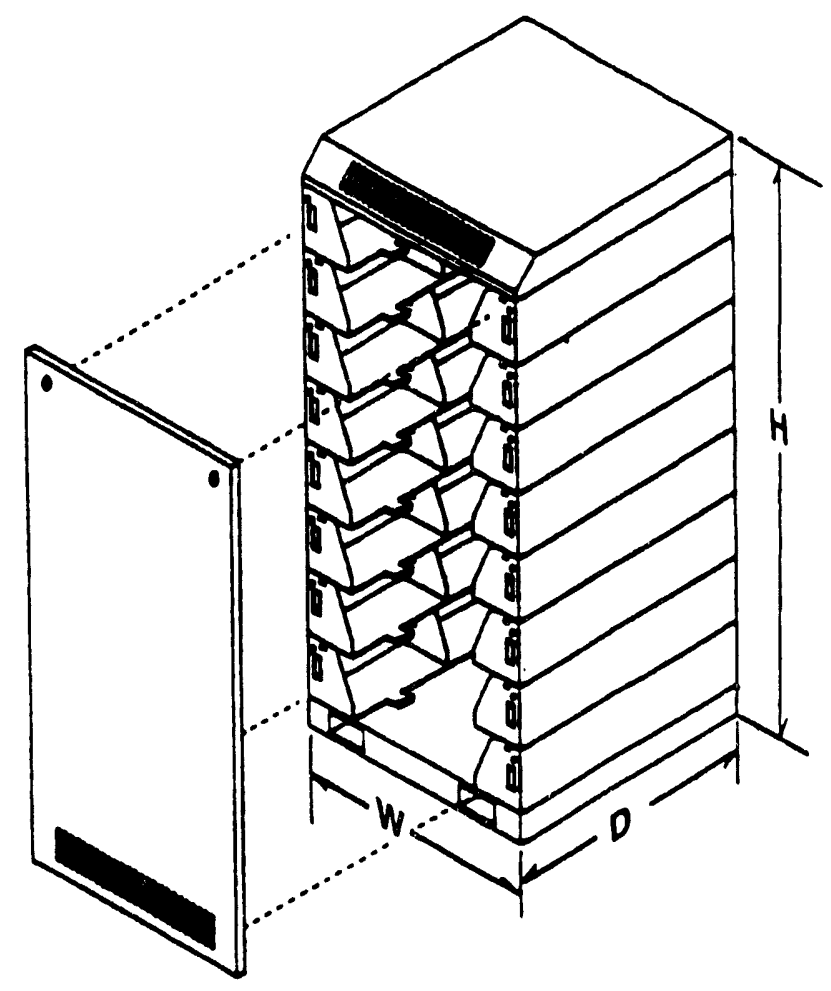

Figure 3-11. Cabinet Designed to Contain 40 GNB VRLA MSB-2460 Battery Modules

are two 5- $\mathrm{ft}$ aisles for access and maintenance as required. Figures 3-12 and 3-13 show the floor layout and the side view for this option and depict how the battery cabinets, PCS, and other control equipment would be contained in a single facility.

\section{Battery Energy Storage for Spinning Reserve and Area Regulation}

The PREPA application is spinning reserve and area regulation. PREPA is presently installing the first of several $20-\mathrm{MW}$ batteries that will eventually be needed to meet its network requirements. The battery has been sized to accommodate both the spinning reserve requirements as well as the area regulation requirements for this application.

The battery selected to model this application is GNB's advanced design VRLA LSB-1340. The LSB1340 is a single-cell battery that weighs $58 \mathrm{lb}$ and measures 15 in. long by 16.4 in. wide by 2.3 in. high. A cabinet designed for this battery contains a number of battery modules. Each module has two stacks of cells, either three or six cells high, totaling either six or twelve cells per module. Each cabinet consists of five 12-cell modules and one 6-cell module, which yields a total of
66 cells per cabinet. The cabinet measures 43 in. long by $16.9 \mathrm{in}$. wide by $89.4 \mathrm{in}$. tall, and weighs $4,600 \mathrm{lb}$ (Figure 3-14).

The proposed 20-MW design consists of 30 parallel strings of LSB-1340 cells. Each string contains 1,000 cells totaling 30,000 cells for the entire plant. The proposed design is similar to the first PREPA plant (PREPA \#1) in that the same PCS and basic building design are used. There are two 10-MW PCS units, each of which charges 15 strings of cells.

A critical element in the design is floor space utilization. Sixteen cabinets are required to contain each string of 1,000 cells. The total battery plant therefore wiil need 480 cabinets. The proposed battery layout consists of 15 rows of cabinets with each row separated by a 4-ft aisle. Each row consists of two strings of 16 cabinets arranged back-to-back, totaling 32 cabinets per row. The overall dimensions of this battery room are $85-\mathrm{ft}$ wide by $120-\mathrm{ft}$ long. The PCS room houses both PCS units and is sized the same as PREPA \#1. The PCS room is $85-\mathrm{ft}$ wide by $42-\mathrm{ft}$ long, yielding an overall building size of $162-\mathrm{ft}$ long by $85-\mathrm{ft}$ wide $\left(13,770 \mathrm{ft}^{2}\right)$ as shown in Figure 3-15. The building can be made of either steel or concrete to meet seismic zone four codes. 


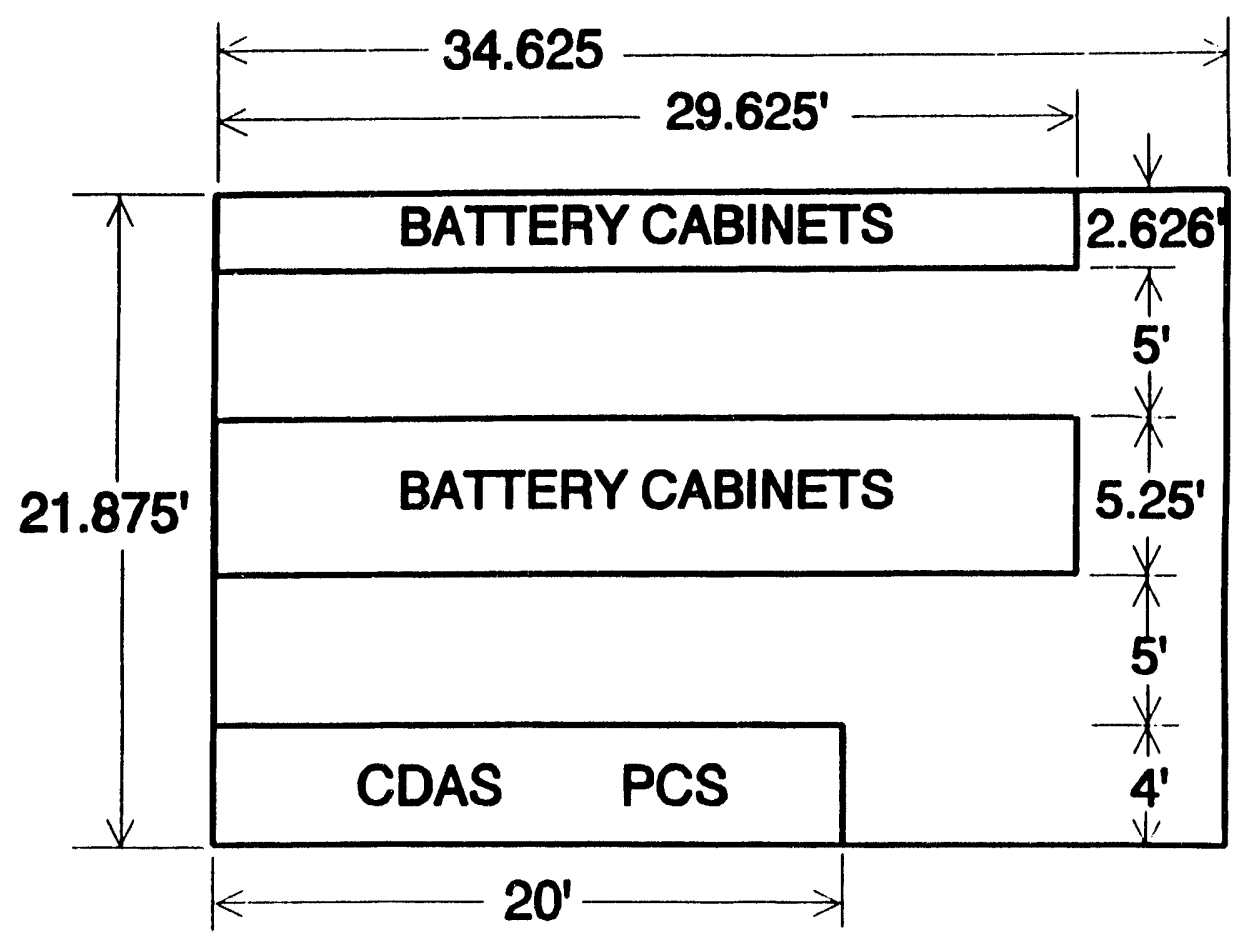

Figure 3-12. Floor Plan Proposed by UMR for a 0.5-MW, 2-hr (1.0-MWh) PG\&E BES System Facility

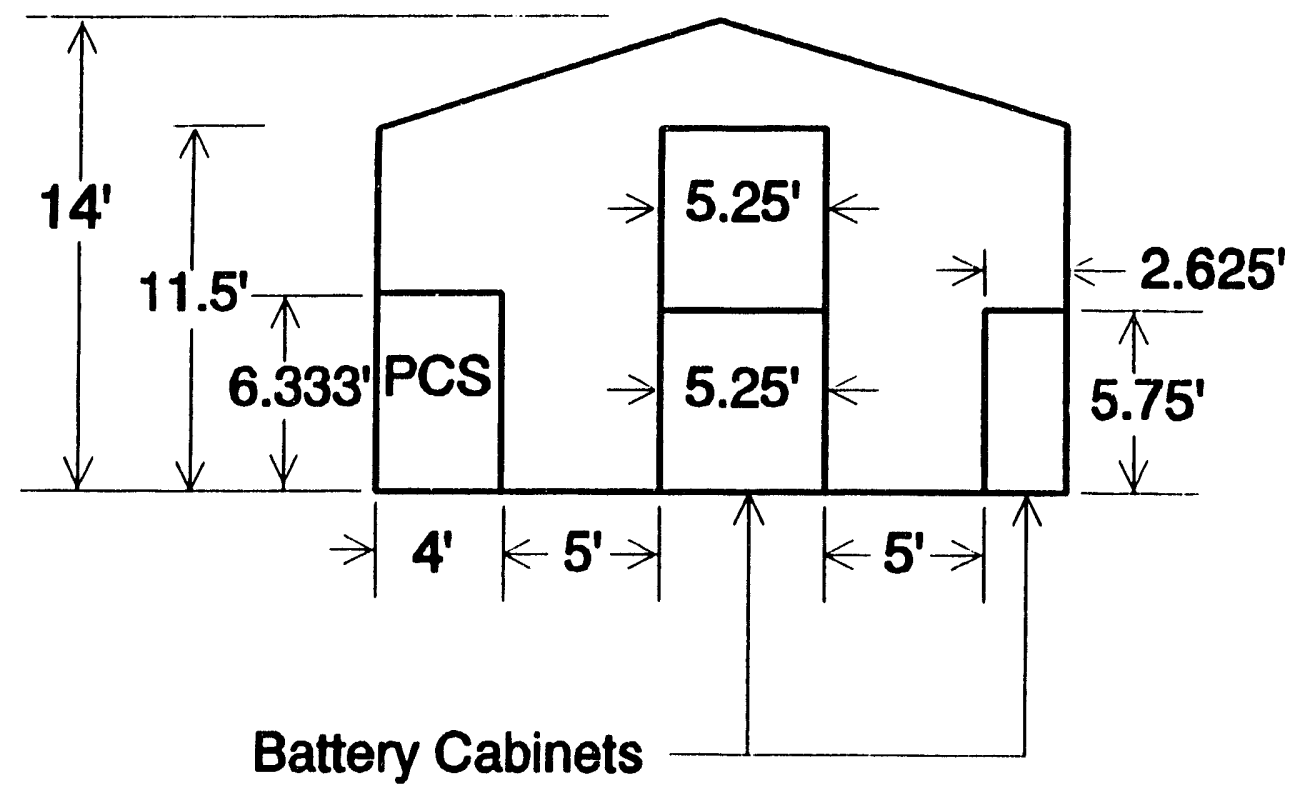

Figure 3-13. Side View of the UMR Floor Plan for the PG\&E BES System Facility Showing that Four of the Five Rows of Battery Cabinets Are Placed Back-to-Back and Stacked Two High in the Center of the Building 


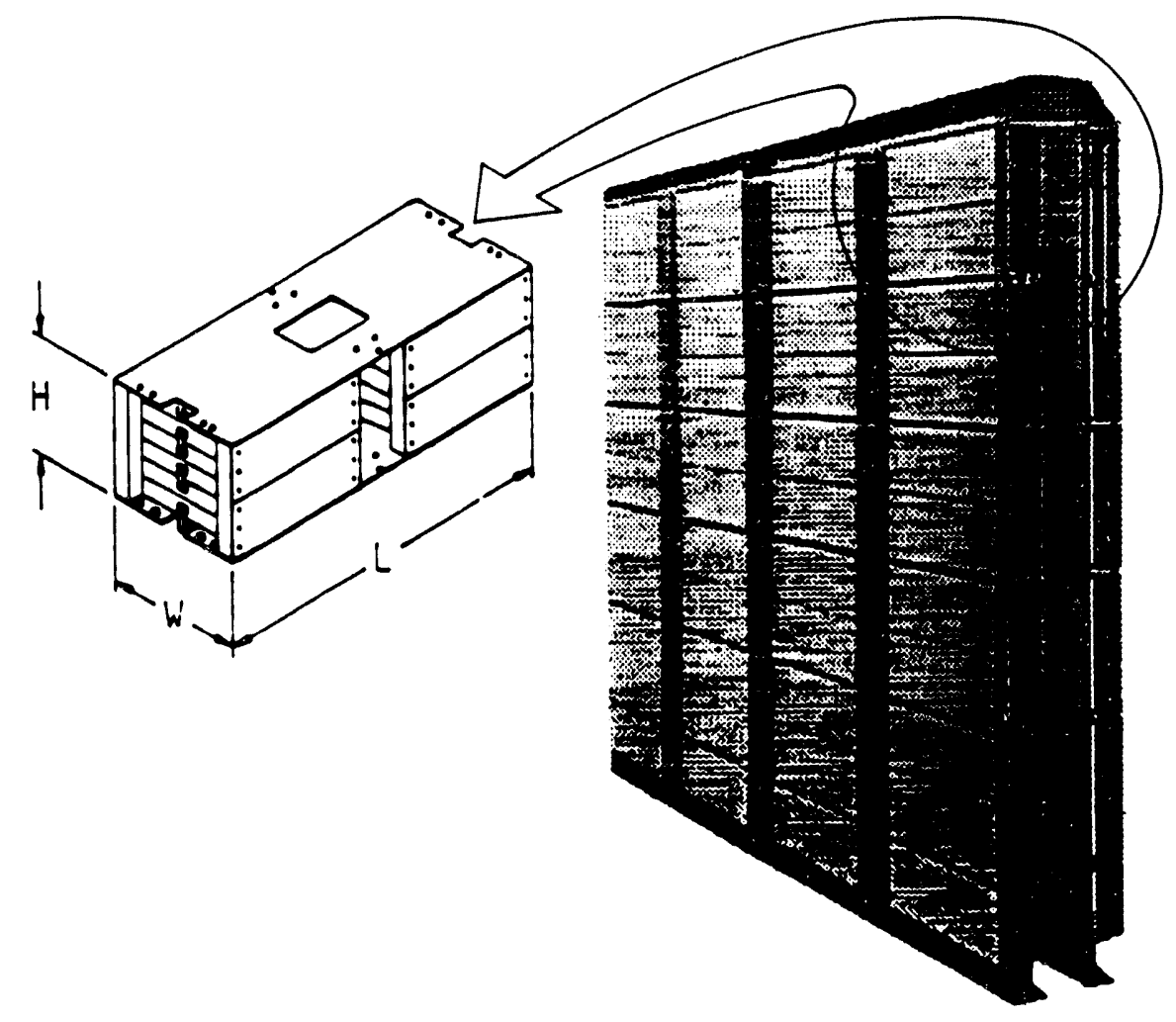

Figure 3-14. Cabinet Designed for the LSB-1340 Battery Selected for the PREPA Spinning Reserve and Area Regulation BES System Application

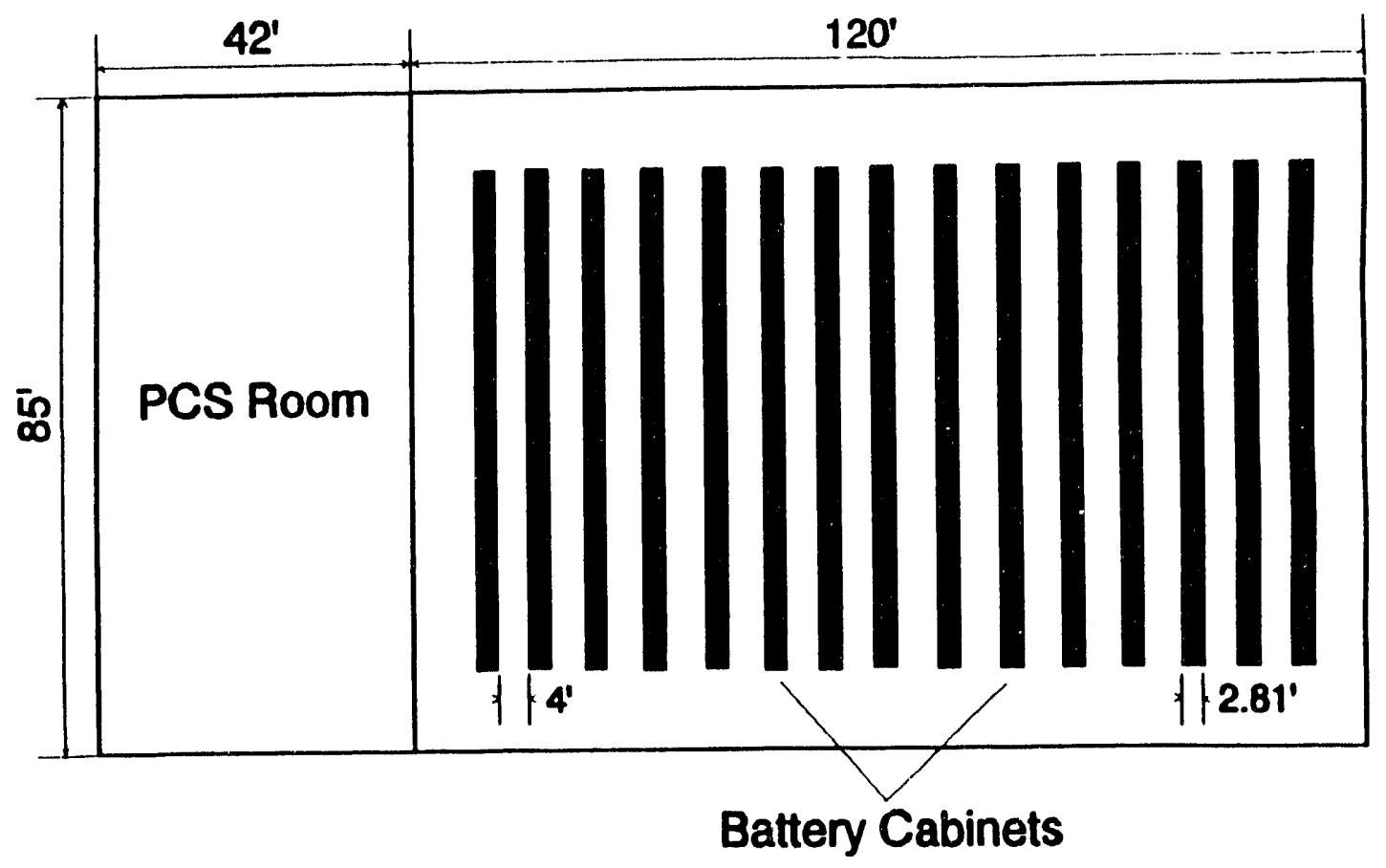

Figure 3-15. Floor Plan Proposed by UMR for the PREPA BES System Facility 
Therefore, requirements for this building are an aisle width of $4 \mathrm{ft}$, a battery room height of $16 \mathrm{ft}$, a PCS room height of $30 \mathrm{ft}$, an area of $13,770 \mathrm{ft}^{2}$, and an energy footprint of $20,000 \mathrm{~kW} / 13,770 \mathrm{ft}^{2}=1.45 \mathrm{~kW} / \mathrm{ft}^{2}$. Only one floor plan was proposed because stacking of the LSB cabinets is not possible, and because the large number of batteries and cabinets needed makes it fairly simple to locate them in an efficient manner. The side view of this BES system (Figure 3-16) shows how the battery and PCS rooms are arranged, as well as the sloped roof design. The slope of the roof is based on previous building designs and is sufficient for rain drainage.

\section{HVAC System Requirements}

In many battery energy storage systems, heating, ventilation, and air conditioning (HVAC) systems are not high cost items. Heating in most BES systems, including the ones being designed here, is not critical because the batteries generate enough heat in most instances. When cooling requirements are considered, generally the installation of ventilation fans proves to be adequate. Because the BES systems being discussed in this report differ from other systems installed to date in that they are designed around VRLA batteries, a detailed analysis of each system is required to assure that the optimum operating temperatures are maintained.

UMR calculated the largest possible temperature rise expected for each of the designed BES systems using procedures developed by Bechtel Group, Inc., and compared it with the recommended operating temperature for the batteries. The worst case scenario of temperature rise was used to determine the needs for the HVAC system. This occurs when the batteries are charged immediately after discharging so that there is no time for cool down between cycles. Normally there will be some downtime between these operations, so the worst case scenario provides a conservative estimate.

For the PG\&E application, the battery is expected to discharge for a maximum of $2 \mathrm{hr}$ and recharge for a maximum of $8 \mathrm{hr}$. The temperature rise calculated using the Bechtel approach was $3.2^{\circ} \mathrm{C}$ during the discharge segment and $4.6^{\circ} \mathrm{C}$ for the recharge segment of the cycle. Therefore, the maximum change in temperature was calculated to be $7.8^{\circ} \mathrm{C}\left(14^{\circ} \mathrm{F}\right)$. This temperature rise must be added to the maximum battery room temperature and compared to the recommended operating temperature for the battery. According to studies conducted at the Battery Energy Storage Test (BEST) facility in New Jersey, the highest average daily temperature
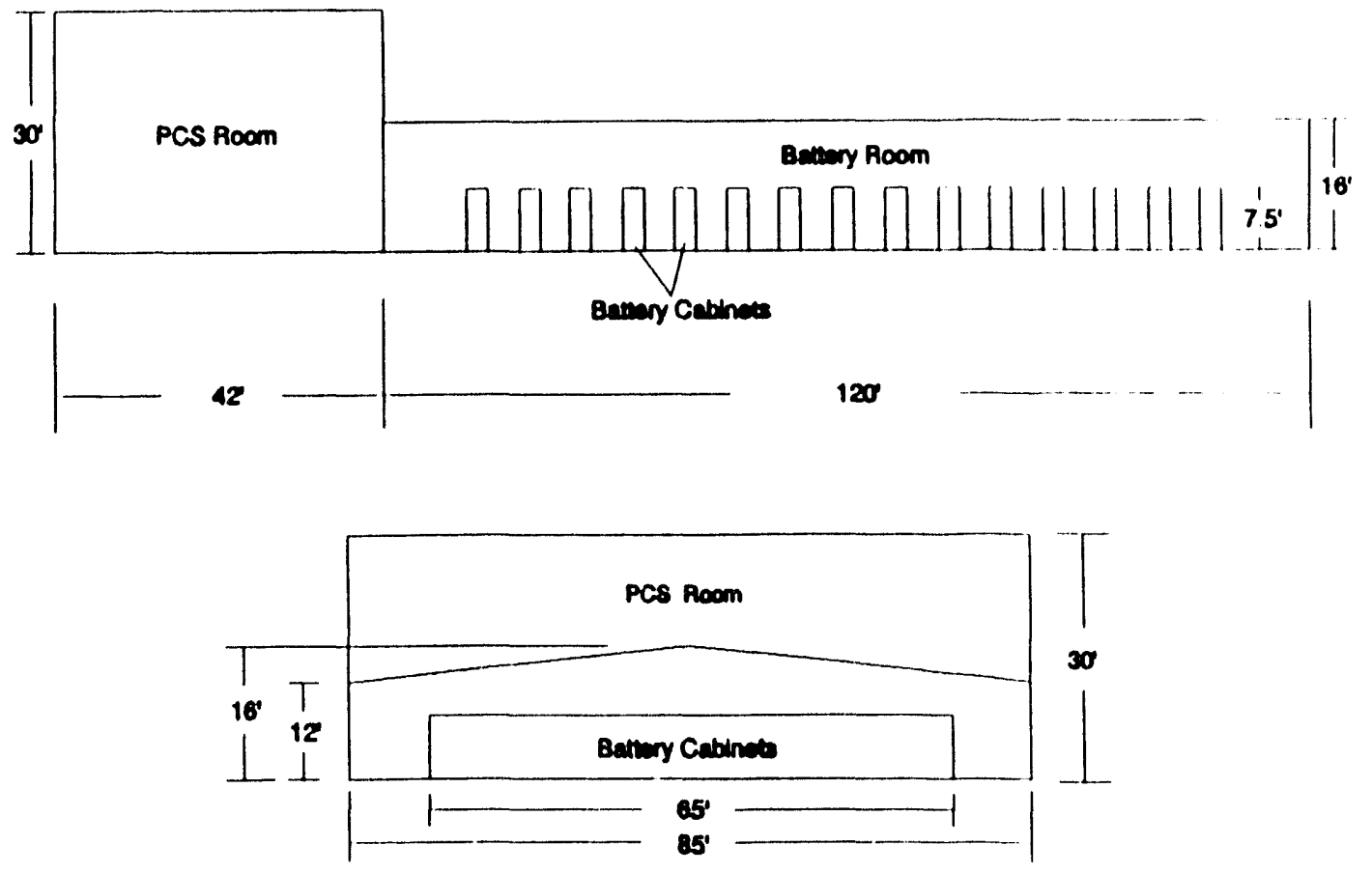

Figure 3-16. Side View of the UMR Floor Plan for the PREPA BES System 
should bc used instead of the peak temperature when calculating cell temperature characteristics.

For the PG\&E application, the highest average daily temperature expected is $95^{\circ} \mathrm{F}$; therefore, the maximum temperature the battery cells would be subjected to is $114^{\circ} \mathrm{F}$. Although operating at this temperature continuously would have a degrading effect on battery lifetime, this analysis is directed at identifying worst case conditions. The temperature rise calculated is $21^{\circ} \mathrm{F}$ below the maximum allowable operating temperature of $135^{\circ} \mathrm{F}$ recommended for the ABSOLYTE VRLA design and provides an adequate margin of safety to compensate for the estimates made in calculating the temperature rise.

The analysis suggests that free convection is sufficient to keep the batteries from overheating in the PG\&E application. The only requirement for HVAC is a ventilation fan used to keep the room within $5^{\circ} \mathrm{F}$ of the outside ambient temperature. The size and placement of the fan can be determined using existing BES installations. A 14,000 CFM fan mounted at the building's center ridge for maximum efficiency should be adequate. The fan would pull air through louvers placed on each side of the building so that the air is moved evenly across the battery cabinets, assuring that the room stays within $5^{\circ} \mathrm{F}$ above the outside ambient temperature.

For the PREPA application, the battery is required to discharge for a maximum of $0.5 \mathrm{hr}$ and charge for a maximum of $8 \mathrm{hr}$. The calculated temperature rise during discharge is $0.85^{\circ} \mathrm{C}$ and that during recharge is $4.7^{\circ} \mathrm{C}$, yielding an overall temperature rise of $5.5^{\circ} \mathrm{C}$ $\left(10^{\circ} \mathrm{F}\right)$. The average daily high temperature at PREPA's locale is $89^{\circ} \mathrm{F}$; therefore, the maximum temperature that the cells would be expected to be subjected to is $104^{\circ} \mathrm{F}$. As in the PG\&E analysis, the temperature rise expected is sufficiently below the maximum recommended operating temperature of the batteries to provide an adequate margin of safety for errors in estimations used in the calculation.

The analysis suggests that free air convection is adequate to keep the batteries from overheating and that forced air ventilation would adequately cool the system. The size and placement of the ventilating fans was based on the Chino BES system facility. The Chino plant uses one 35,000 CFM ridge-mounted ventilation fan for every $2.903 \mathrm{ft}^{2}$. The increased energy footprint for the PREPA installation warrants a more concentrated ventilation system, so UMR recommends that the $35,000 \mathrm{CFM}$ fans be placed every $24 \mathrm{ft}$ along the roof ridge, one fan for every $2,040 \mathrm{ft}^{2}$. As in the PG\&E design, the fans would draw air through louvers on each side of the building so that the air flows in the direction of the battery cabinets.

The analysis completes the HVAC system for the battery room but not for the PCS room. However, since a comparable system is already being installed at PREPA, the ventilation system designed for that PCS room should be used in this BES system design.

\section{Baseline Conceptual Designs}

The design proposals prepared by UMR served as the basis for an initial cost estimate for each of the applications developed. Systems costs consist of the three main components of a BES system: the batteries, the PCS, and the balance of plant (BOP). Determining the precise costs for these components is beyond the scope of UMR's effort under this contract, and therefore, costs were approximated using available, pertinent facility information; adding any additional costs unique to the design; and including a contingency factor deemed appropriate for the estimate. The UMR estimate used two methods to estimate systems cost: (1) normalizing the costs for existing systems to $\$ / \mathrm{kW}$ or $\$ / \mathrm{kWh}$ and multiplying it by the size of the systems designed, and (2) using applicable equations developed by Bechtel. UMR averaged the results from these two approaches for this report.

Average normalized costs were calculated from the published costs for six BES system facilities (Table 3-1). Crescent, JCBGI, and Chino are existing projects, while Bechtel-1, Bechtel-2, and the Reckrodt study involve theoretical designs analyzed by Bechtel Group, Inc. or UMR. The average normalized values for the main BES system cost categories are as follows:

$\begin{array}{ll}\text { Batteries } & 226.2 \$ / \mathrm{kWh} \\ \text { PCS } & 206.7 \$ / \mathrm{kW} \\ \text { BOP } & 151.3 \$ / \mathrm{kWh} \\ \text { Engineering } & 99.7 \$ / \mathrm{kWh}\end{array}$

In obtaining this list, the JCBGI and Chino BOP costs were excluded when calculating an average BOP normalized value. These two cases were considered to have artificially low BOP costs. The costs for the two BES systems designed in this study were then calculated using the sizing discussed in the design analysis. Note that the estimates for the PG\&E design are for a system that consists of four modular "unit batteries." These costs are listed in Table 3-2. 


\section{Table 3-1. Published Cost Data for Six Existing/Proposed BES System Installations}

\begin{tabular}{lcccccc}
\multicolumn{1}{c}{ Item } & Crescent & JCBGI & Chino & Bech.-1 & Bech.-2 & Reckrodt \\
\hline MW Capacity & 0.5 & 0.3 & 10 & 2.0 & 6.0 & 1.0 \\
MWh Capacity & 0.5 & 0.6 & 40 & 1.6 & 4.7 & 2.0 \\
Battery $(\$ / \mathrm{kWh})$ & 200 & 133.3 & 152 & 318.8 & 304.3 & 249 \\
PCS $(\$ \mathrm{~kW})$ & 220 & 200 & 180 & 210 & 148.3 & 282 \\
BOP $(\$ / \mathrm{kWh})$ & 160 & 33.3 & 30.0 & 184.4 & 137.2 & 123.8 \\
Engineering $(\$ / \mathrm{kWh})$ & & & 20.0 & 140 & 120 & 119.0
\end{tabular}

\section{Table 3-2. BES System Costs Estimated Using Existing Facility Costs}

\begin{tabular}{lcccc}
\multicolumn{1}{c}{ System } & & PG\&E & & PREPA \\
\cline { 1 - 1 } Size & & 2MW/4MWh & & 20MW/10MWh \\
Battery Cost & & $\$ 904,800$ & & $\$ 2,262,200$ \\
PCS Cost & & $\$ 413,400$ & & $\$ 4,134,000$ \\
BOP Cost & & $\$ 605,200$ & & $\$ 1,513,000$ \\
Engineering & & $\$ 398,800$ & & $\$ 997,000$ \\
Total Cost & & $\$ 2,322,200$ & & $\$ 8,906,000$
\end{tabular}

Using the Bechtel equations for costing of a BES system facility, UMR arrived at a cost for the PG\&E application of $\$ 2,091,000$ and a cost of $\$ 10,543,000$ for the PREPA design. When the results of the two cost estimating methods are compared, it can be seen that the estimates for the PG\&E design are similar; however, the cost estimates for the PREPA installation are significantly different. This is because the Bechtel cost equations are point fitting equations that were derived using data from smaller BES plants and therefore do not scale upward accurately to large plant designs. The only existing plant that compares in size with the PREPA installation is the Chino plant, so in developing final estimated costs for the PREPA plant, UMR weighted the costs for the Chino plant more heavily.
In addition, the final cost estimates for both designs were reduced to eliminate some required equipment that is typically included in the BOP costs for flooded cells but is not needed when the installation is based on a VRLA battery system. This includes the equipment used to water the flooded cells and hydrogen gas monitors, which are critical in a flooded battery installation.

For the PG\&E design, UMR averaged the results of the two calculation methods, reduced the cost for equipment not needed with VRLA batteries, and applied a contingency factor to arrive at a final estimated cost of $\$ 2.05 \mathrm{M}$. The PREPA costs were developed by averaging the Chino costs and the average of the costs calculated using the known cost and the Bechtel equation 
methods. The reduction for unnecessary equipment and a contingency were also included to arrive at an estimated cost for the PREPA BES system design of \$8.14M.

Since information on the costs of the internal systems of most utilities is not public, it was not possible for UMR to determine a dollar value for the benefits of the BES systems designed. However, it is possible to enumerate the potential benefits available to serve as the basis for the utility's justification for the system. The application for the PG\&E BES system is peak shaving, so its benefits would include deferral of generation and transmission lines. That is, by absorbing the increased demand at a substation, the system could delay the addition of generating units and/or transmission lines that would otherwise be needed to satisfy the increased demand.

The PREPA BES system application is spinning reserve and frequency regulation. When the load of a system changes suddenly and the generation stays the same, the frequency of the system changes to compensate for the difference. The frequency decreases when the load increases and increases when the load decreases. Normally, combustion turbines, which can react quickly to load changes, have to be kept on line to compensate for this frequency change. A BES system can perform this function with a much faster response time and efficiency thus eliminating the need to keep combustion turbines with high operating costs on line and operating at low efficiencies.

Secondly, when a generating unit fails, it takes a certain period of time to bring another generating unit on line. To maintain a constant supply of electricity to all customers, a utility must keep a backup generating unit, equivalent in size to the largest generating unit in use at the time, operating in reserve in case the largest generating unit should fail. This backup system is referred to as spinning reserve. The benefits of having a BES system act as the spinning reserve is that it can be brought on line at full power at any time, allowing sufficient time to start up other backup units and ramp them to the desired output power. Therefore, the backup units are not kept on line continuously. The economic benefit to the utility is the savings in not continuously running the reserve units as spinning reserve.

\section{Economic Analyses}

PG\&E completed an economic evaluation of distributed utility battery energy storage, which is expected to favor a transportable system concept. In anticipation of a follow-on demonstration project at PG\&E, the distribution engineers were surveyed to help estimate the market potential for such a system and to answer some remaining technical questions. One significant result of the survey was that the 24 survey respondents (representing one-third of PG\&E's service territory) believed that within the next $3 \mathrm{yr}, 461-\mathrm{MW}$ to $2-\mathrm{MW}$ battery energy storage systems could be sited in their respective planning areas.

In addition, PG\&E cumpleted the battery dispatch modeling for four case study sites in the PG\&E system. The modeling relied upon estimated 1990 load data from North Branch, Lodi, Lincoln, and Mountain Quarries planning areas. For each site, the top 10 days were first analyzed to determine the potential for peak load reduction. A dynamic battery state-of-charge model was applied to each day in 0.1-hr time increments by dispatching the battery to follow the load above a given estimated $\mathrm{kW}$ threshold. The threshold was adjusted iteratively with a $25-\mathrm{kW}$ resolution such that the battery would never drop below $0 \%$ state-of-charge for any of the ten test days. The lowest $\mathrm{kW}$ threshold that the battery could support defined the new peak.

This procedure was applied for a matrix of cases: battery ratings of $500 \mathrm{~kW}, 1 \mathrm{MW}, 1.5 \mathrm{MW}$ and $2 \mathrm{MW}$; battery ratings of $2 \mathrm{hr}$ and $3 \mathrm{hr}$; and at each of the four sites. The calculated threshold (and, equivalently, the peak load reduction) for each case was used to estimate the upgrade deferral time for each site.

A summary of the sites studied is provided in Figure 3-17. Included are the cost estimates to perform capacity increases, the peak load reductions from the dispatch modeling, and the growth rates as given by the respective planning engineers. For the economic study, a 1-MW/2-hr system was assumed to defer the average capacity upgrade cost of $\$ 1.6 \mathrm{M}$ each year over the service life of the battery system.

By comparing the traditional transmission and distribution upgrade options and the battery system option, including operation and maintenance, transportation, and generation capacity, the following results were obtained:

\begin{tabular}{|c|c|c|}
\hline & 5-Yr Life & 10-Yr Life \\
\hline $\begin{array}{l}\text { Savings from base } \\
\text { expansion plan }\end{array}$ & $\$ 484,000$ & $\$ 826,000$ \\
\hline
\end{tabular}

Allowable battery system cost:

$\begin{array}{lcc}\text { in } \$ & \$ 554,000 & \$ 694,000 \\ \text { in } \$ / \mathrm{kW} & \$ 554 & \$ 694 \\ \text { in } \$ / \mathrm{kWh} & \$ 277 & \$ 347\end{array}$




\begin{tabular}{|c|c|c|c|c|c|c|c|c|c|}
\hline Case study & $\begin{array}{c}\text { Upgrade } \\
\text { Cost } \\
(1993 \text { sk) }\end{array}$ & $0.5 / 2$ & $0.5 / 3$ & $1 / 2$ & $\begin{array}{l}\text { Iant Sk } \\
1 / 3 \\
\end{array}$ & 20 (MM & (urs) & $2 / 2$ & $2 / 3$ \\
\hline $\begin{array}{l}\text { Corral } \\
\text { Peak Loed Red. (kW) } \\
\text { Growh Rate (kW/yr) } \\
\text { Doferral (yrs) }\end{array}$ & 1520 & $\begin{array}{r}500 \\
830 \\
.\end{array}$ & $\begin{array}{r}500 \\
830 \\
.\end{array}$ & $\begin{array}{r}1000 \\
830 \\
1\end{array}$ & $\begin{array}{r}1000 \\
830 \\
1\end{array}$ & $\begin{array}{r}1186 \\
830 \\
1\end{array}$ & $\begin{array}{r}1386 \\
830 \\
1\end{array}$ & $\begin{array}{r}1411 \\
830 \\
1\end{array}$ & $\begin{array}{r}1736 \\
830 \\
2\end{array}$ \\
\hline $\begin{array}{l}\text { Lincoln } \\
\text { Peak Load Red. (kW) } \\
\text { Growth Rate (kW/yr) } \\
\text { Deferral (yrs) }\end{array}$ & 1631 & $\begin{array}{r}311 \\
570 \\
.\end{array}$ & $\begin{array}{r}436 \\
570 \\
.\end{array}$ & $\begin{array}{r}536 \\
570 \\
.\end{array}$ & $\begin{array}{r}811 \\
570 \\
1\end{array}$ & $\begin{array}{r}786 \\
570 \\
1\end{array}$ & $\begin{array}{r}1136 \\
570 \\
1\end{array}$ & $\begin{array}{r}986 \\
570 \\
1\end{array}$ & $\begin{array}{r}1436 \\
570 \\
2\end{array}$ \\
\hline $\begin{array}{l}\text { Mountain Quamies } \\
\text { Peak Load Red. (kW) } \\
\text { Growth Rate (kW/yr) } \\
\text { Deferral (yrs) }\end{array}$ & 1881 & $\begin{array}{r}500 \\
880 \\
.\end{array}$ & $\begin{array}{r}500 \\
880 \\
.\end{array}$ & $\begin{array}{r}880 \\
880 \\
1\end{array}$ & $\begin{array}{r}1000 \\
880 \\
1\end{array}$ & $\begin{array}{r}1136 \\
880 \\
1\end{array}$ & $\begin{array}{r}1488 \\
880 \\
1\end{array}$ & $\begin{array}{r}1361 \\
880 \\
1\end{array}$ & $\begin{array}{r}1786 \\
880 \\
2\end{array}$ \\
\hline $\begin{array}{l}\text { Valley Springs } \\
\text { Peak Loed Red. (kW) } \\
\text { Growth Rate (kW/yr) } \\
\text { Deforral (yrs) }\end{array}$ & 1224 & $\begin{array}{r}500 \\
830 \\
.\end{array}$ & $\begin{array}{r}500 \\
830 \\
.\end{array}$ & $\begin{array}{r}1000 \\
830 \\
1\end{array}$ & $\begin{array}{r}1000 \\
830 \\
1\end{array}$ & $\begin{array}{r}1186 \\
830 \\
1\end{array}$ & $\begin{array}{r}1388 \\
830 \\
1\end{array}$ & $\begin{array}{r}1411 \\
830 \\
1\end{array}$ & $\begin{array}{r}1736 \\
830 \\
2\end{array}$ \\
\hline
\end{tabular}

Figure 3-17. Summary of Site Data for the Cases Included in the PG\&E Battery Dispatch Modeling Study

A baseline expansion plan was constructed that included a series of traditional substation capacity upgrades such as replacement of transformer banks, installation of higher rated circuit breakers, and upgrade of the distribution circuit. One substation was assumed to be upgraded each year for the 10-yr study period. The total estimated cost of this baseline plan was compared to an alternative plan utilizing a 1-MW/2-hr battery system to defer each of the substation upgrades for one year. Costs for battery transportation, set up, and maintenance were included in the alternative plan and a credit was taken for the generation capacity value. The net savings compared to the baseline plan are shown below for both a 5- and a 10-yr battery system. An allowable battery cost, assuming a $20 \%$ salvage value, has also been calculated and is expressed as a total and as a normalized cost.

\section{Technology Evaluation - SNL}

The performance and operating characteristics, as well as service life and failure modes for VRLA batteries are determined in this SNL activity. This informa- tion is shared with the developer to improve the design and operation of the technology.

\section{Status}

During the first quarter of FY93, SNL received three present state-of-the-art VRLA batteries (Type 3-85A25) from GNB. These 6-V units have a rated nominal capacity of $1040 \mathrm{Ah}$ at the $\mathrm{C} / 8$ rate to an end of discharge voltage of $5.25 \mathrm{~V}(1.75 \mathrm{vpc})$. Because of problems with the battery cycler, initial testing of these batteries was delayed until the second quarter.

A total of seven capacity tests was performed on one of the batteries, while the other two batteries were sent to the photovoltaic (PV) group and integrated into a stand-alone PV/battery system for purposes of evaluation. Of the seven capacity tests performed on the first battery, five were run at a $C / 2$ rate and the other two were run at a $\mathrm{C} / 8$ rate. As expected, the capacity at the $\mathrm{C} / 2$ rate increased with each capacity test and ranged from $842.5 \mathrm{Ah}$ on cycle one to $893.6 \mathrm{Ah}$ on cycle five. The capacity of the battery, at the $\mathrm{C} / 8$ rate, was $1162 \mathrm{Ah}$, which exceeded its rated value of $1040 \mathrm{Ah}$. 


\section{Applied Research - SNL}

GNB is designing sealed lead-acid batteries that are optimized to meet the requirements of electric utility applications. A common feature of all sealed lead-acid batteries is some kind of vent to enable the battery to operate at a small positive pressure. The pressure must be positive to prevent loss of the limited electrolyte in the system and ingress of oxygen, which would increase self-discharge rates. However, the pressure must not be so high as to put undue strain on the battery case components, which could cause venting and electrolyte leaks. The GNB vent assembly presently contains a molded plug of ethylene-propylene-diene monomer (EPDM) rubber. Although in general the performance of this material has been acceptable, there have been instances in which the valves appeared to stick, presumably from chemical attack on the rubber by the battery electrolyte. SNL has investigated the potential for surface treatments of the plug to improve the reliability of the vent operation.

Plasma processing was used at SNL to apply a thin, pinhole-free coating to three sets of vent plugs provided by GNB. In two cases, another material that was believed to be more chemically resistant (siloxane or fluorocarbon) was introduced along with the plasma. For the third set of samples, the plasma alone was used in an attempt to crosslink the surface of the plug. These samples were returned to GNB where they were built into vent assemblies and cycled repeatedly by being attached to a continuously overcharged battery. Testing and analysis of the data have occupied the greater part of this fiscal year.
Performance of vents containing the coated plugs showed progressive changes during the first $50 \mathrm{hr}$ of the cycle test, with the pressure inside the batteries first increasing and then starting to decrease. Thereafter, the pressure became very uniform, particularly for the samples coated with siloxane and the ones that were only crosslinked. In the latter stages of the 500-hr experiment, the repeatability of vent opening was better than typically observed for the baseline uncoated plugs. The only performance of the coated plugs that was not acceptable was that the opening pressure of the vent decreased below 3 psi for the coatings that gave the most uniform operation. It may be possible to correct the lower opening pressure by adjusting the dimensions of the vent assembly to put more pressure on the plug, but this was not actually tried in these experiments.

GNB is now in the process of reevaluating the design of the vent since it has been decided that the valves should operate at a higher pressure range than previously selected because of the recharge conditions likely to be encountered in utility applications. This shift may be achieved using the ABSOLYTE vent design, but other concepts are also being pursued. Since the coated plugs shifted vent operation to lower pressures, it is not clear without more tests whether this approach can meet the new requirements. GNB is presently considering what vent designs to test for this new requirement, and SNL will furnish additional coated plugs for inclusion in the test matrix if requested to do so. These discussions should be concluded during the first quarter of FY94. 


\section{Subsystems Engineering - Zinc/Bromine}

Zinc/bromine batteries are attractive candidates for utility applications because they offer two to three times the specific energy of lead-acid batteries, have sufficient power, operate at near room temperature, are capable of being recycled, can be built at low cost, and have potentially long lifetimes. The zinc/bromine battery is composed of three parts: the cell stack, the reservoirs, and the auxiliary pumps, controls, and piping. The electrolyte solutions are continuously pumped in separate circulation systems through the anode and cathode chambers of the cell stack. During charge, zinc is plated on one side of a bipolar electrode, while bromine is formed on the other side. The bromine quickly forms a complex with quaternary ammonium ions in the electrolyte, and this complex separates, forming a second, denser phase. During discharge, the electrode reactions are reversed. The cell stack is composed of a number of bipolar electrodes and cell separators with monopolar terminal electrodes on each end. The electrodes are made from electrically conducting carbon plastic and are thermally welded into a flow frame. The flow frame contains the channeis and openings used to carry the electrolyte to and from the electrodes. The flow frames are thermally welded together, forming a hermetically sealed cell stack. Rigid endblocks are placed outside the terminal electrodes to minimize the deflection when electrolyte is pumped through the stack under pressure.

\section{Technology Development - JCBGI}

The objective of the zinc/bromine technology development is to develop and evaluate low-cost, longlife prototype modules that demonstrate the performance required for utility applications. This project is being conducted primarily through a cost-sharing contract with an industrial partner, JCBGI. The objective of the JCBGI program is to extend its technology from mobile designs to a utility design and to develop, fabricate, and evaluate a $100-\mathrm{kWh}$ utility battery system. SINL is responsible for technical direction of the development contract and, in addition, performs evaluations of contract deliverables. The $39-\mathrm{mo}, \$ 3.2 \mathrm{M}$ contract program with JCBGI was initiated in August 1990 and organized into two 18-mo technical phases followed by a 3-mo reporting period. Because satisfactory technical progress was made during the first phase, the second phase was initiated during the second quarter of FY92. In FY93, component development and design of the $100-\mathrm{kWh}$ deliverable was completed. In FY94, the $100-\mathrm{kWh}$ will be built and tested.

\section{Tasks}

The major goals of the JCBGI contract are to:

1. Demonstrate leak-free battery stacks

2. Demonstrate steady long-term operation by achieving over 100 cycles with a $<10 \%$ drop in energy efficiency

3. Achieve energy efficiencies of $\sim 75 \%$

4. Demonstrate adequate performance with six consecutive, no-strip cycles

5. Verify battery cost of $\$ 150 / \mathrm{kWh}$ or less

6. Address safety issues associated with the battery

7. Build and test $100-\mathrm{kWh}$ deliverable.

\section{Status}

\section{Battery Testing}

\section{Eight-Cell Batteries}

The performance of recently built batteries and batteries constructed at the start of the contract are compared in Table 4-1. The increase in performance and cycle life are due to improvements in material properties and processing techniques. The efficiencies of the last two builds, V1-78 and V1-79, were not expected to be significantly better than the V1-72 to V1-77 builds, but the cycle life is expected to increase.

\section{$\underline{V 1-67}$}

This 8-cell battery has been used primarily for nostrip cycling tests. The results are listed in Table 4-2. As in previous studies, the results demonstrate that nostrip cycle regimes afforded a significant increase in efficiency by reducing residual losses.

After completing 105 cycles, testing of battery V1-67 has been suspended so that other batteries with improved performance could be cycled. A plot of baseline cycle efficiencies for V1-67 is given in Figure 4-1. 


\section{Table 4-1. Improvements in Battery Performance}

\begin{tabular}{cccc}
$\begin{array}{c}\text { Batteries } \\
\text { Tested }\end{array}$ & $\begin{array}{c}\text { Manufacture } \\
\text { Dates }\end{array}$ & $\begin{array}{c}\text { Average } \\
\text { Cyclo Lite }\end{array}$ & $\begin{array}{c}\text { Average } \\
\text { Energy } \\
\text { Efficlency (\%) }\end{array}$ \\
\hline V1-53 & 3/91 to 4/91 & 298 & 71.8 \\
V1-54 & & & \\
V1-55 & & & \\
V1-57 & $10 / 92$ to 3/93 & 378 & 75.0 \\
V1-72 & & & \\
V1-76 & $6 / 93$ & 138 & 75.0 \\
V1.77 & $6 / 93$ & 21 & 76.7 \\
V1-78* & & & \\
V1.79* & & &
\end{tabular}

- Indicates tests still in progress. V1-78 will be sent to SNL for testing.

\section{Table 4-2. Efficiencies (\%) for V1-67}

\begin{tabular}{|c|c|c|c|c|c|}
\hline Cycle Type & CE & VE & EE & $\begin{array}{l}\text { Transport } \\
\text { Inefficlency }\end{array}$ & $\begin{array}{c}\text { Residual } \\
\text { Inofficiency }\end{array}$ \\
\hline Baseline Cycle & 88.1 & 80.1 & 70.6 & 6.0 & 5.9 \\
\hline No-Strip Cycles 47-52 & 92.7 & 79.6 & 73.7 & 5.8 & 1.5 \\
\hline No-Str ycles 53-58 & 93.1 & 79.5 & 74.1 & 5.3 & 1.6 \\
\hline No-Strip Cycles 59-64 & 92.7 & 79.4 & 73.5 & 5.7 & 1.6 \\
\hline
\end{tabular}

\section{V1-68}

Initial testing gave efficiency levels such as $\mathbf{8 8 . 7 \%}$ coulombic efficiency (CE), $80.7 \%$ voltaic efficiency (VE), $71.6 \%$ energy efficiency (EE), with $5.9 \%$ transport inefficiency and $5.4 \%$ residual inefficiency at 21 cycles. An experimental electrolyte was then introduced in an attempt to prolong the life of the porous carbon layer. However, the new electrolyte did not cycle well. The battery voltage rose on charge to the set limit (1.99 vpc) and then declined. Gas was observed in the anolyte and the efficiencies for this cycle were $47.6 \% \mathrm{CE}$, $77.4 \% \mathrm{VE}$, and $36.8 \% \mathrm{EE}$, with $32.5 \%$ transport and $19.0 \%$ residual inefficiencies. When replaced with standard load leveling electrolyte, the performance returned to normal.

A second experimental electrolyte was put into the battery, but the battery cycled poorly again. This time the performance did not return to normal efficiency levels when replacing the electrolyte. 


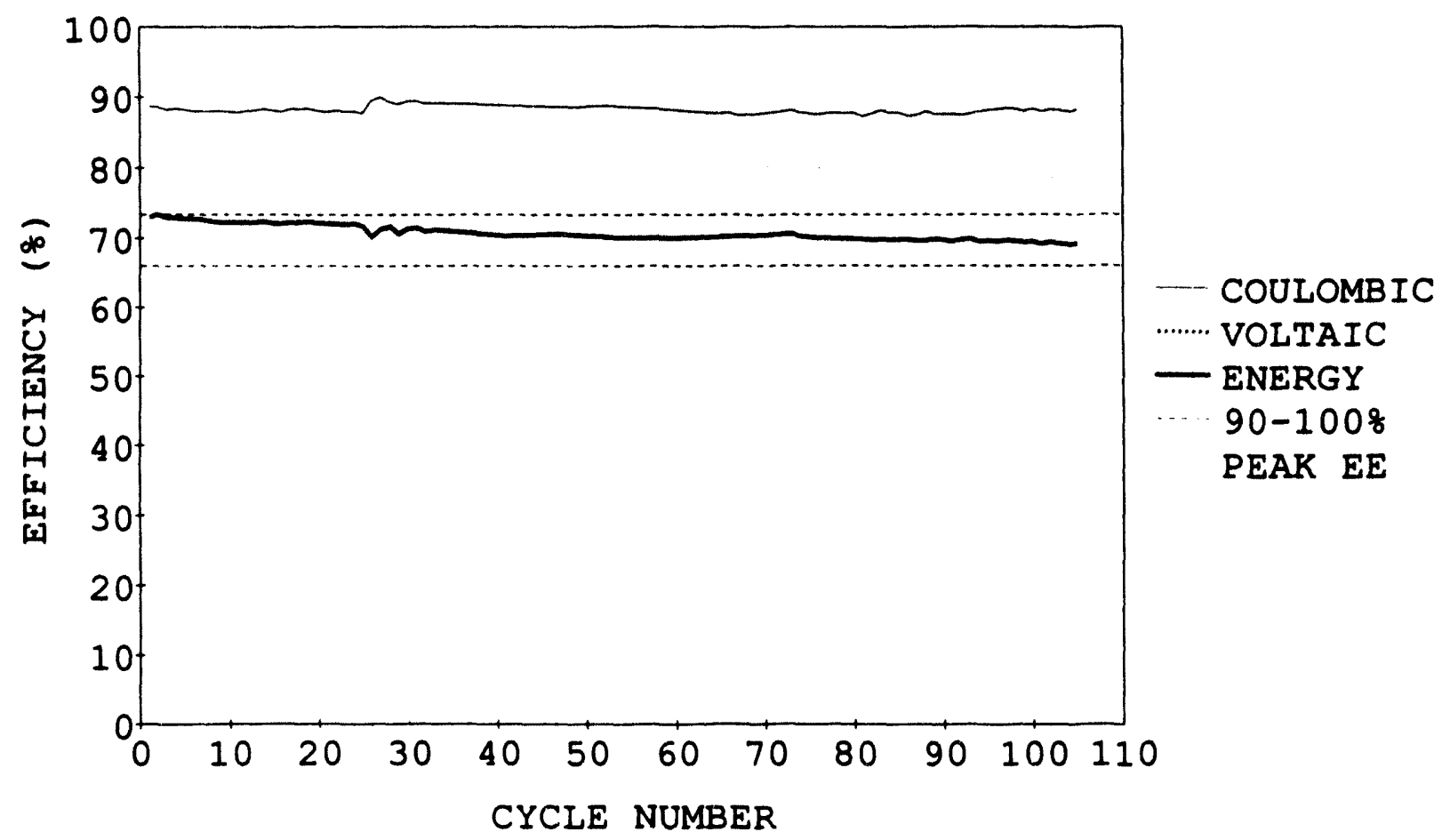

Figure 4-1. V1-67 Baseline Cycle Efficiencies (1-kWh, 8-Cell Battery Stack)

When torn down, the battery was found to have been damaged by localized heating in a small portion of one of the cells. The electrode, separator, and spacing mesh also showed some degree of melting. Adjacent cells had heat damage in the same area but to a lesser extent. Although no dendrites were observed, it appeared that some shorting dendrites might have formed when the experimental electrolyte was used leading to localized overheating.

\section{V1-69}

Battery V1-69 has completed 39 cycles and performs at $87.6 \% \mathrm{CE}, 79.8 \% \mathrm{VE}, 69.9 \% \mathrm{EE}$, with $5.5 \%$ transport, and $6.9 \%$ residual inefficiencies. The battery was taken off test to make room for batteries with improved performance.

\section{V1-71}

The energy efficiency for battery V1-71 decreased by over $10 \%$ from the peak after 195 cycles, but the stack was used to examine a modified utility type cycling regime. The baseline cycle performance for the first 200 cycles, before the modified cycling, is shown in Figure 4-2.
For the modified cycles, the battery is initially charged for $4.5 \mathrm{hr}$ at $20 \mathrm{~mA} / \mathrm{cm}^{2}$, followed by a repetitive sequence of $60-\mathrm{min}$ discharges at $21 \mathrm{~mA} / \mathrm{cm}^{2}$ and 65 -min charges at $20 \mathrm{~mA} / \mathrm{cm}^{2}$. The charge steps need to be longer than the discharge steps to compensate for transport losses and the difference between charge and discharge rates so that the battery is always at $100 \%$ state of charge (SOC) at the start of each short cycle. The short charge/discharge steps continue until the voltage on discharge falls below $1.0 \mathrm{vpc}$.

The last test ran 78 consecutive short charge/discharge cycles. The previous runs of this test reached 52 , 56 , and 69 cycles respectively. During the last test, V1-71 developed a slow but steady leak and has therefore been removed from testing. By the end of testing, baseline performance had declined to $83.5 \% \mathrm{CE}, 74.4 \%$ $\mathrm{VE}$, and $62.1 \% \mathrm{EE}$, with $6.6 \%$ transport and $10.0 \%$ residual inefficiencies. The stack will be torn down to pinpoint the location of the leak. A total of 551 cycles was completed including those under the modified test regime.

\section{V1-72}

The performance of V1-72 had declined by more than $10 \%$ from the peak energy efficiency of $75 \%$ by 460 cycles. The efficiencies at that time were $84.4 \%$ 


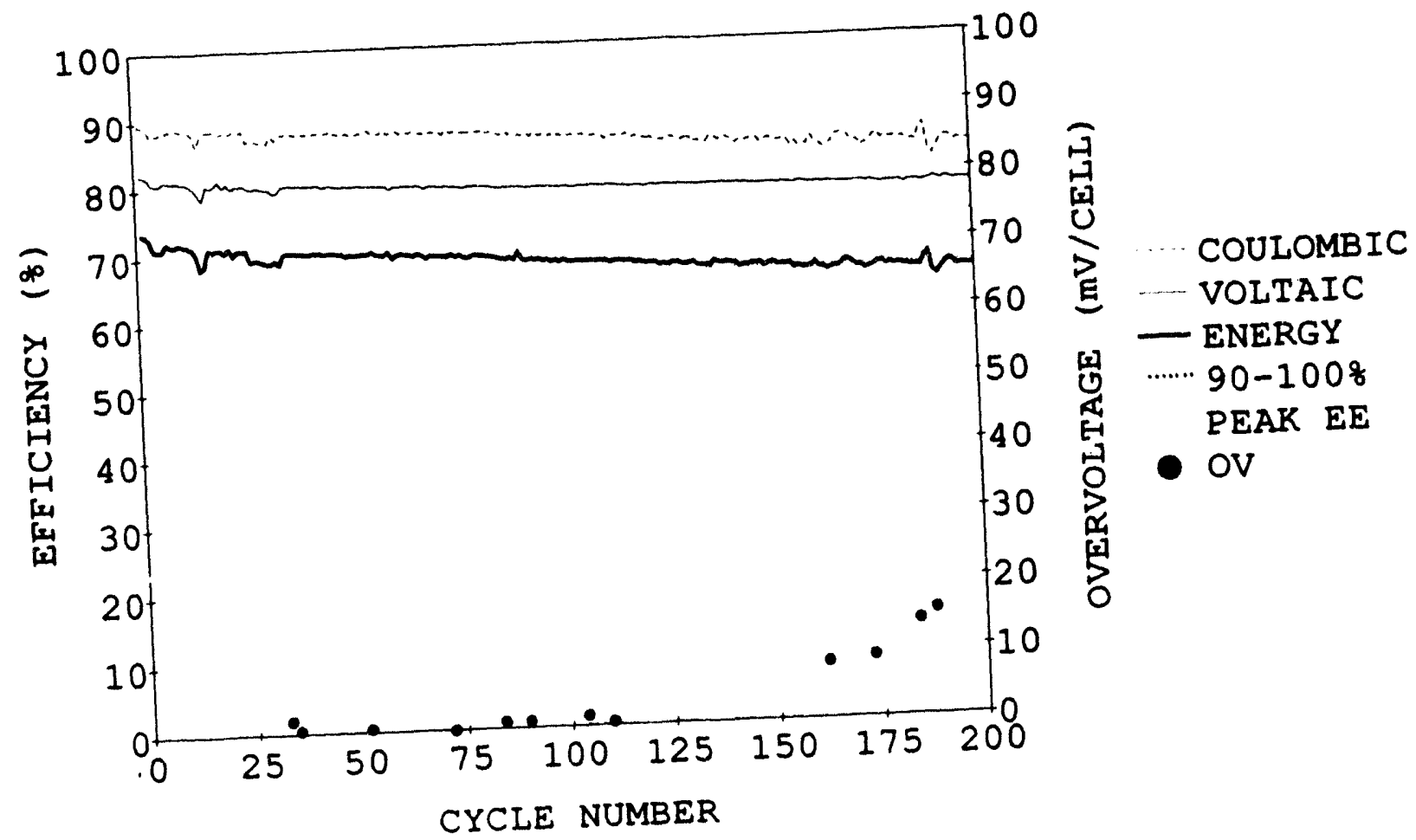

Figure 4-2. V1-71 Baseline Cycle Efficiencies (1-kWh, 8-Cell Battery Stack)

coulombic, $79.7 \%$ voltaic, and $67.3 \%$ energy, with $7.3 \%$ transport and $8.2 \%$ residual inefficiencies. At this point an electrode reconditioning process was run on V1-72. This process was found to significantly improve efficiencies on the subsequent cycle and this battery continued cycling for a total of 504 cycles as seen in Figure 4-3. The efficiencies at the end of testing were 88.4\% CE, $79.1 \% \mathrm{VE}$, and $70.0 \% \mathrm{EE}$, with $5.5 \%$ transport and $6.1 \%$ residual inefficiencies.

Following the 504th cycle, the second phase solenoid valve became inoperable during a series of six consecutive baseline cycles. This caused the battery to become severely overcharged, since only a limited amount of bromine was available during the discharge portions of each cycle. In an attempt to discharge the battery more rapidly so that the faulty valve could be replaced, second phase catholyte was introduced into the anolyte reservoir, causing the electrolyte temperature to reach $64^{\circ} \mathrm{C}$. The reservoir was drained and refilled with deionized water in order to slow the reaction and cool the battery down. Following the incident, a leak was observed from the right anode stud. Because of the leak, the battery was torn down.

\section{$v 1-73$}

The energy efficiency of V1-73 had dropped $10 \%$ from the peak value by 146 cycles. Testing for cross- flow in the cell stack indicated no internal leakage. However, polarization had increased starting at about cycle 110 and causing a decline in voltaic efficiency as shown in Figure 4-4. The battery teardown showed moderately rough zinc plating and some indication that dendrite activity had occurred.

Two events might be responsible for the decline in performance. The electrolyte was found to be slightly contaminated with nickel from cracked pump impellers, which could possibly cause poor zinc plating. Also the battery had been accidentally overcharged to about $90 \%$ total zinc utilization during no-strip cycling at about cycle 62 . Baseline cycles run immediately afterward showed no indication of a problem at that time, but the overcharge may have partially damaged the bromine electrode.

\section{Y $1-74$}

Battery V1-74 was manufactured using electrodes with a different type of carbon than V1-72, V1-76, and V1-77. The testing regime for battery V1-74 consisted primarily of consecutive sets of six no-strip cycles during the first 230 cycles. After 240 cycles, the energy efficiency had declined by $10 \%$ from the peak values (Figure 4-5). The main failure mode again appeared to be a rapid increase in polarization from degradation of the cathode layer. 


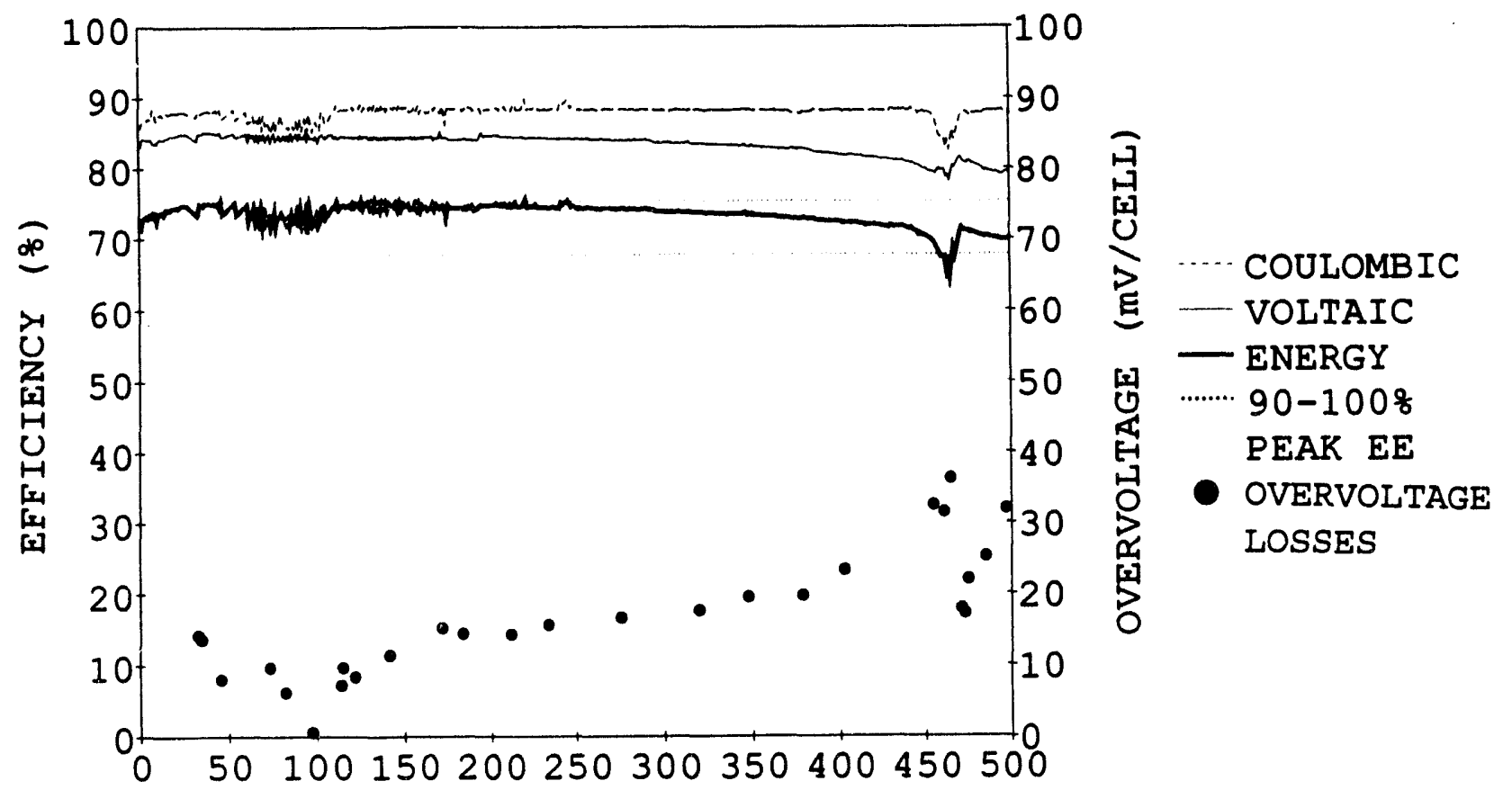

CYCLE NUMBER

Figure 4-3. V1-72 Baseline Cycle Efficiencies (1-kWh, 8-Cell Battery Stack)

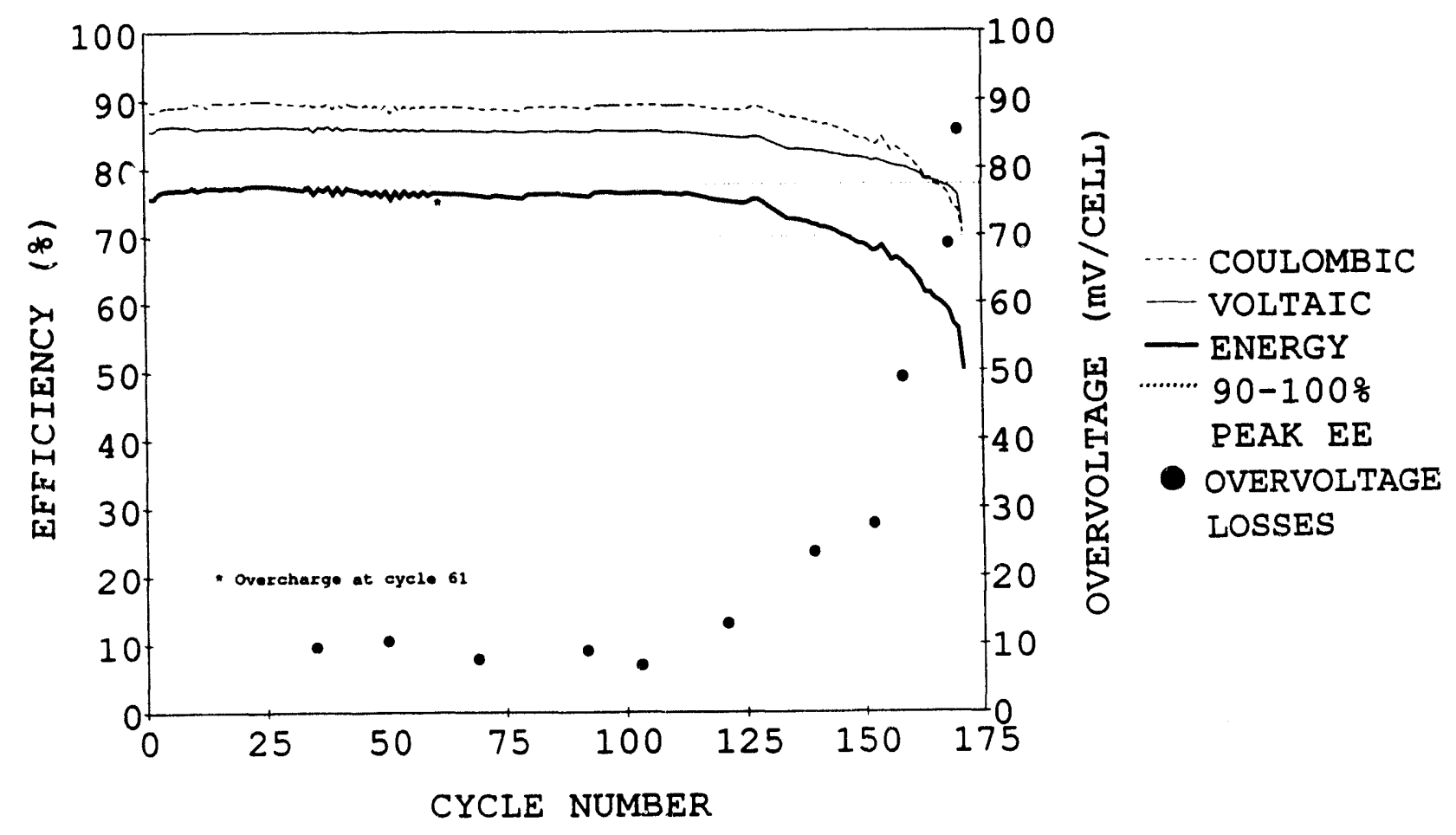

Figure 4-4. V1-73 Baseline Cycle Efficiencies (1-kWh, 8-Cell Battery Stack) 


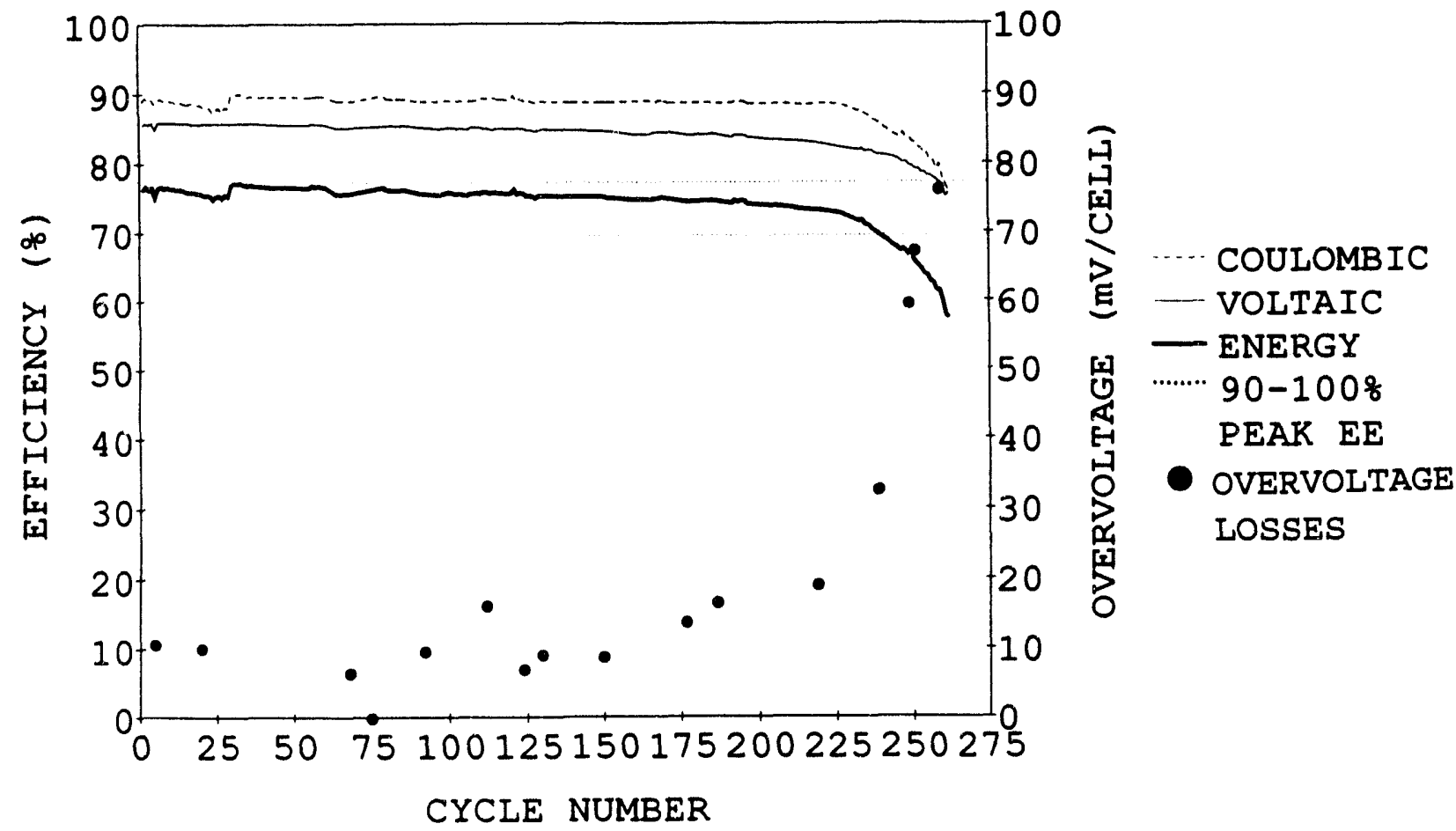

Figure 4-5. V1-74 Baseline Cycle Efficiencies (1-kWh, 8-Cell Battery Stack)

This battery was torn down at a full SOC after 264 cycles. The terminal anodes generally had uniform plating, but there were a few rough areas. On the right anode terminal, there was a small section of dendritic plating that had grown into the adjacent separator. Moderate-to-severe blistering on the cathode side of the separator because of previous zinc penetration on the anode side was present on a number of the separators. On the right side of the stack, the 6th and 7th bipolar electrodes were severely warped, which caused rough plating that had grown into the adjacent separators. Similar warpage and zinc plating were observed on the 7th left bipolar electrode. Other than what has been indicated, the zinc plating was uniform and fairly smooth, and the warpage of the remaining bipolar electrodes was typical.

\section{$\underline{V 1-75}$}

Battery V1-75 developed a sudden drop in performance at 16 cycles as seen in Figure 4-6. By the last cycle $(\$ 24)$, the coulombic efficiency had fallen to $78.7 \%$ and the energy efficiency to $65.9 \%$. Some red bromine complex was observed in the anolyte as well indicating internal leakage.

On tearing the battery down, a 2-in. region of the separator was found to be heavily covered with dendrites in one cell, and the adjacent anode was bare of zinc at the same location. A specific cause for the problem was not uncovered, but an internal leak near the center of the stack is suspected.

\section{V1-76}

The performance of V1-76 had declined by more than $10 \%$ at 325 cycles and continued to drop rapidly through cycle 341 (Figure 4-7). The residual inefficiency increased $100 \%$ during this decline. Figure 4-7 also shows a dramatic increase in overvoltage for battery V1-76, which appears to be the primary reason for the declining efficiencies. This rapid increase in polarization occurred similarly in battery V1-73, which has been confirmed by postmortem evaluation to have a severely degraded cathode layer.

After cycle 341 , an electrode reconditioning process was performed on the battery, which caused significant improvements in performance. A number of attempts to recondition the electrodes have been made without bringing the performance back into the $10 \%$ degradation range for this battery as seen in Figure 4-7. It appears that the electrode reconditioning process is more successful if it is done before the performance of the battery deteriorates beyond $10 \%$. Battery V1-76 has at this time completed 414 cycles, and efficiencies are at 


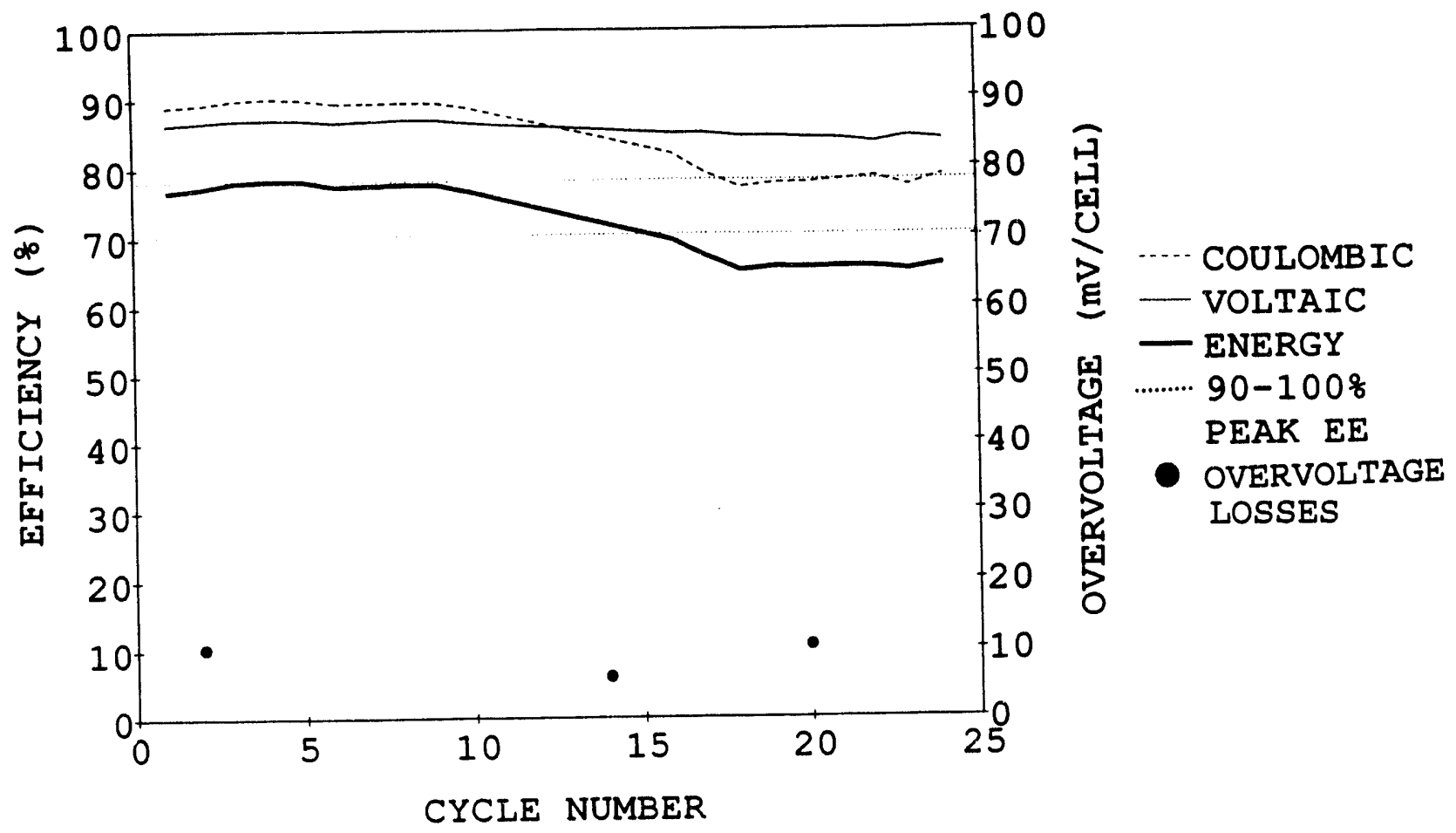

Figure 4-6. V1-75 Baseline Cycle Efficiencies (1-kWh, 8-Cell Battery Stack)

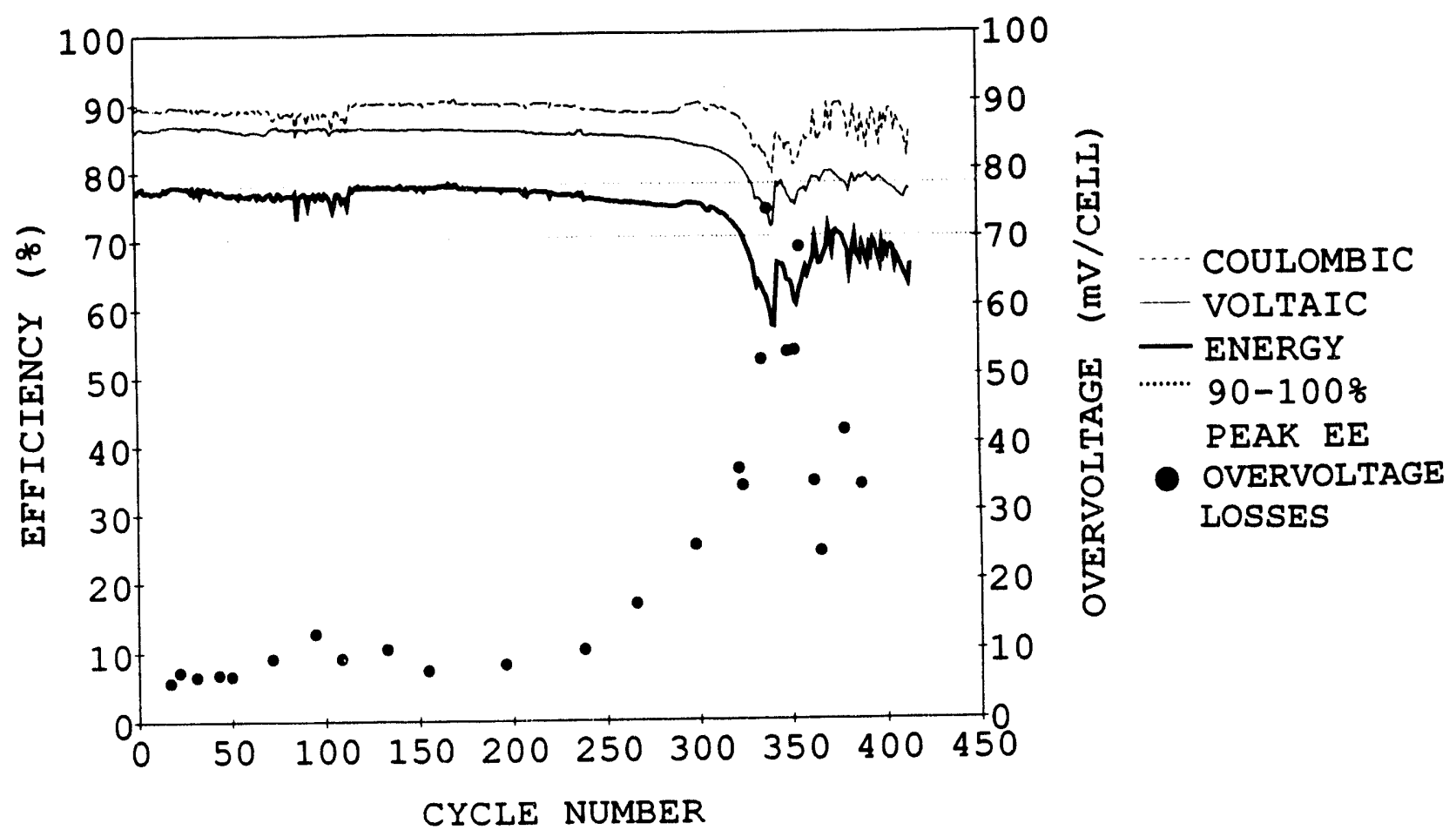

Figure 4-7. V1-76 Baseline Cycle Efficiencies (1-kWh, 8-Cell Battery Stack) 
85.9\% CE, $76.8 \%$ VE, and $66.0 \% \mathrm{EE}$, with $7.3 \%$ transport and $6.7 \%$ residual inefficiencies.

\section{$\underline{V 1-77}$}

Battery V1-77 had completed 350 baseline cycles, but the efficiencies were decreasing fairly rapidly as seen in Figure 4-8. The cycle performance was at $86.4 \% \mathrm{CE}, 81.4 \% \mathrm{VE}$, and $70.3 \% \mathrm{EE}$, with $6.2 \%$ transport and $7.4 \%$ residual inefficiencies when an attempt to recondition the electrodes was made. Following one reconditioning cycle, the efficiencies increased to $90.0 \%$ $\mathrm{CE}, 83.3 \% \mathrm{VE}$ and $75.0 \% \mathrm{EE}$. This was the third battery to observe a significant improvement in performance following the electrode reconditioning process.

The electrode reconditioning process has been performed twice on battery V1-77 at cycles 351 and 379 . It has completed 400 cycles and is currently performing at 89.7\% CE, $82.0 \% \mathrm{VE}$ and $73.6 \% \mathrm{EE}$, with $6.0 \%$ transport and $4.2 \%$ residual inefficiencies. From Figure 4-8, it can be seen that the electrodes need to be reconditioned after about 25 baseline cycles for this battery.

\section{$\underline{V 1-78}$}

Twenty-one baseline cycles were run on V1-78 with very consistent results. The cycle efficiencies aver- aged $89.6 \%$ coulombic, $85.6 \%$ voltaic, and $76.7 \%$ energy, with $5.4 \%$ transport and $5.0 \%$ residual inefficiencies. V1-78 has been removed from testing, and it will be sent to SNL for testing. Figure 4-9 is a graph of the cycle efficiencies for V1-78.

\section{$\underline{\mathrm{V} 1-79}$}

Battery V1-79 has completed 263 cycles, with the most recent cycle giving $90.5 \% \mathrm{CE}, 83.4 \% \mathrm{VE}$, and $75.5 \%$ EE. Figure 4-10 is a plot of cycle efficiencies for V1-79. Baseline cycling of this battery is continuing.

\section{Series Stacks (V25-01-08)}

Battery V25-01-08, the first eight-cell stack produced with $2500-\mathrm{cm}^{2}$ electrodes, has completed 10 cycles with very inconsistent performance. The energy efficiencies for this battery ranged from $10.7 \%$ to $64.9 \%$. Some of the cycles had charge voltages below the open circuit voltage of the battery. The inconsistent results may indicate a flow problem, but this will be determined when the battery is torn down. Cycle efficiencies for V25-01-08 are shown in Figure 4-11. The electrolyte has been circulating under 1.5 times the designed operating pressure for $1500 \mathrm{hr}$ without any leaks from the stack.

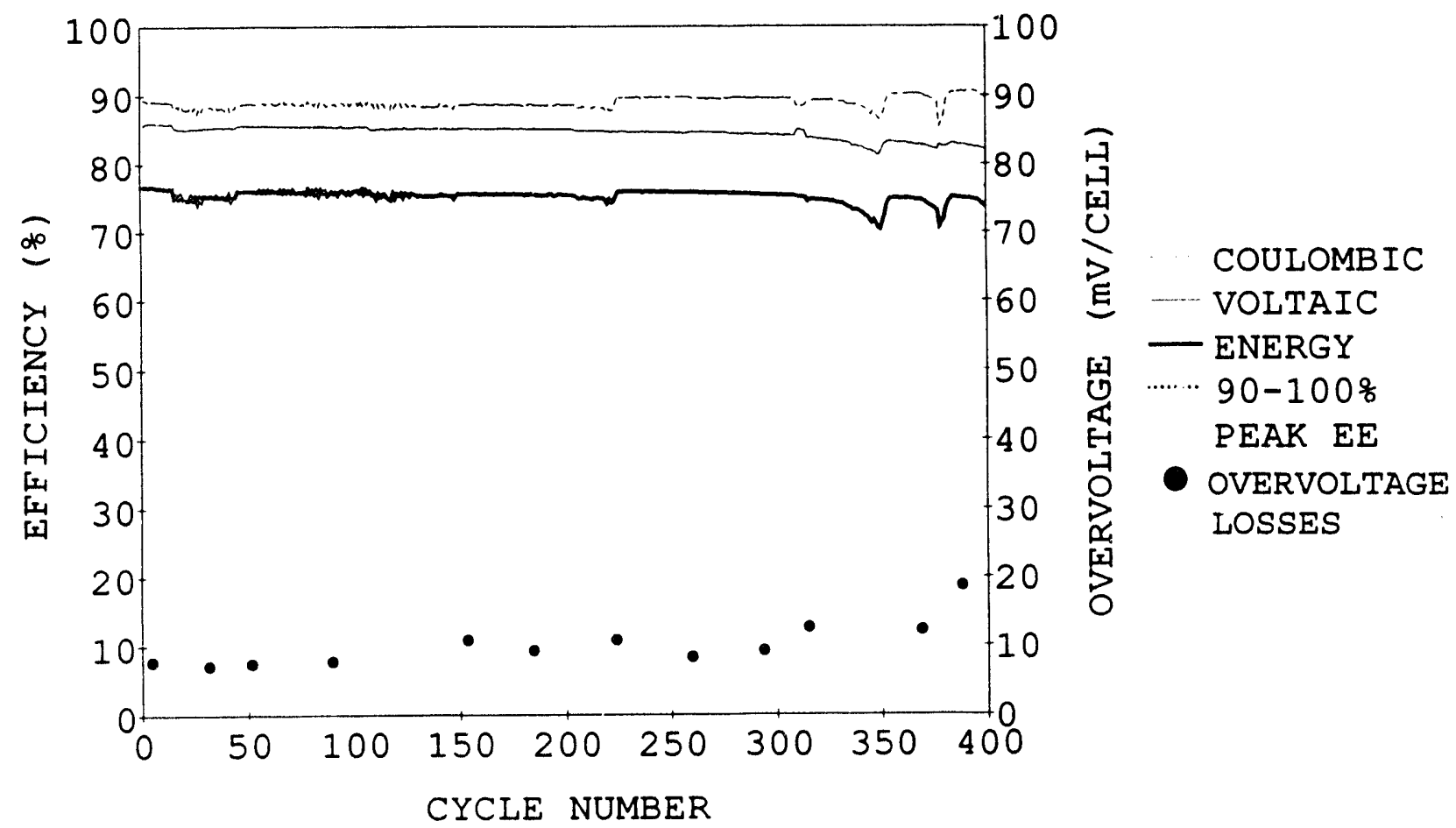

Figure 4-8. V1-77 Baseline Cycle Efficiencies (1-kWh, 8-Cell Battery Stack) 


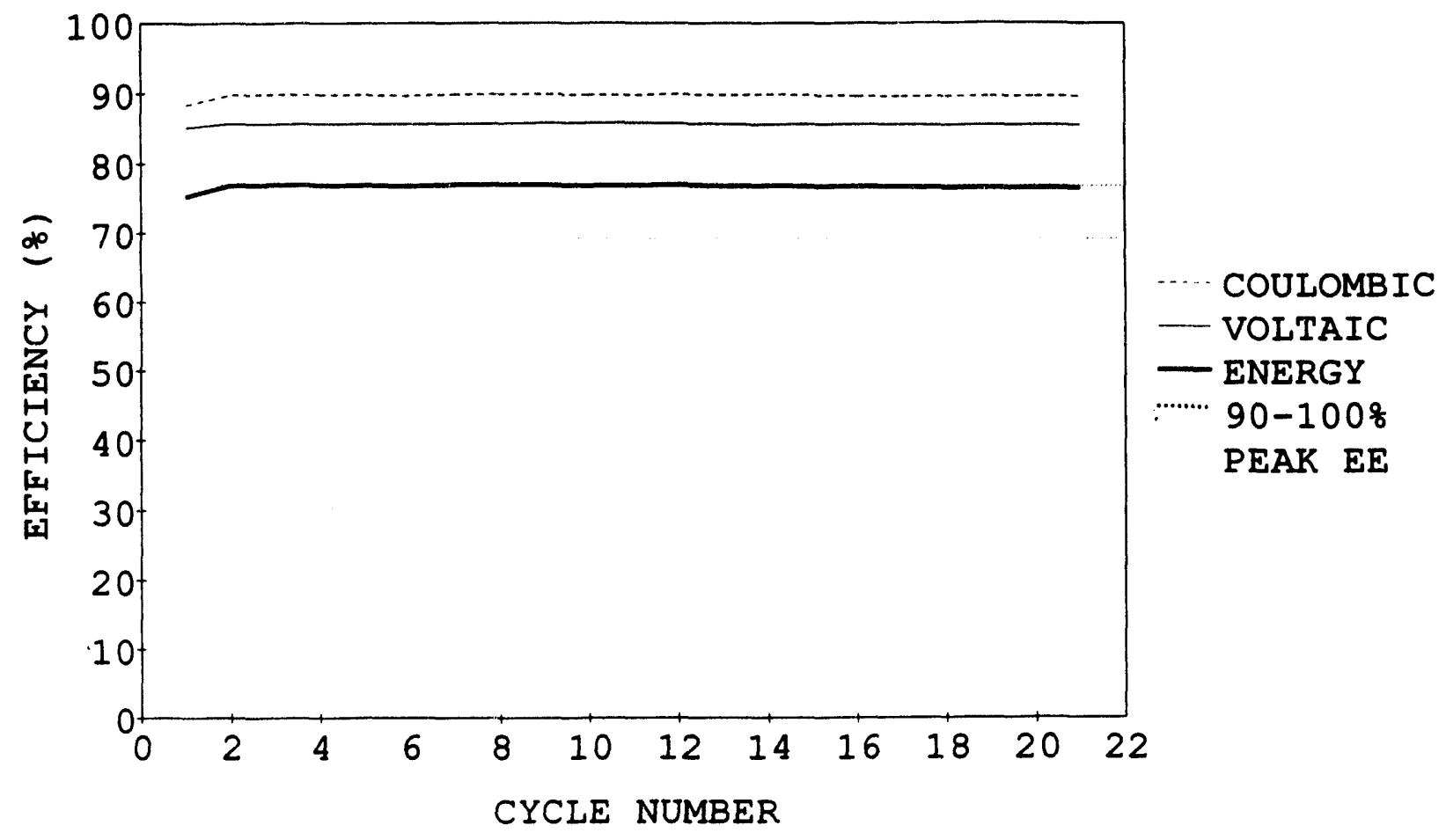

Figure 4-9. V1-78 Baseline Cycle Efficiencies (1-kWh, 8-Cell Battery Stack)

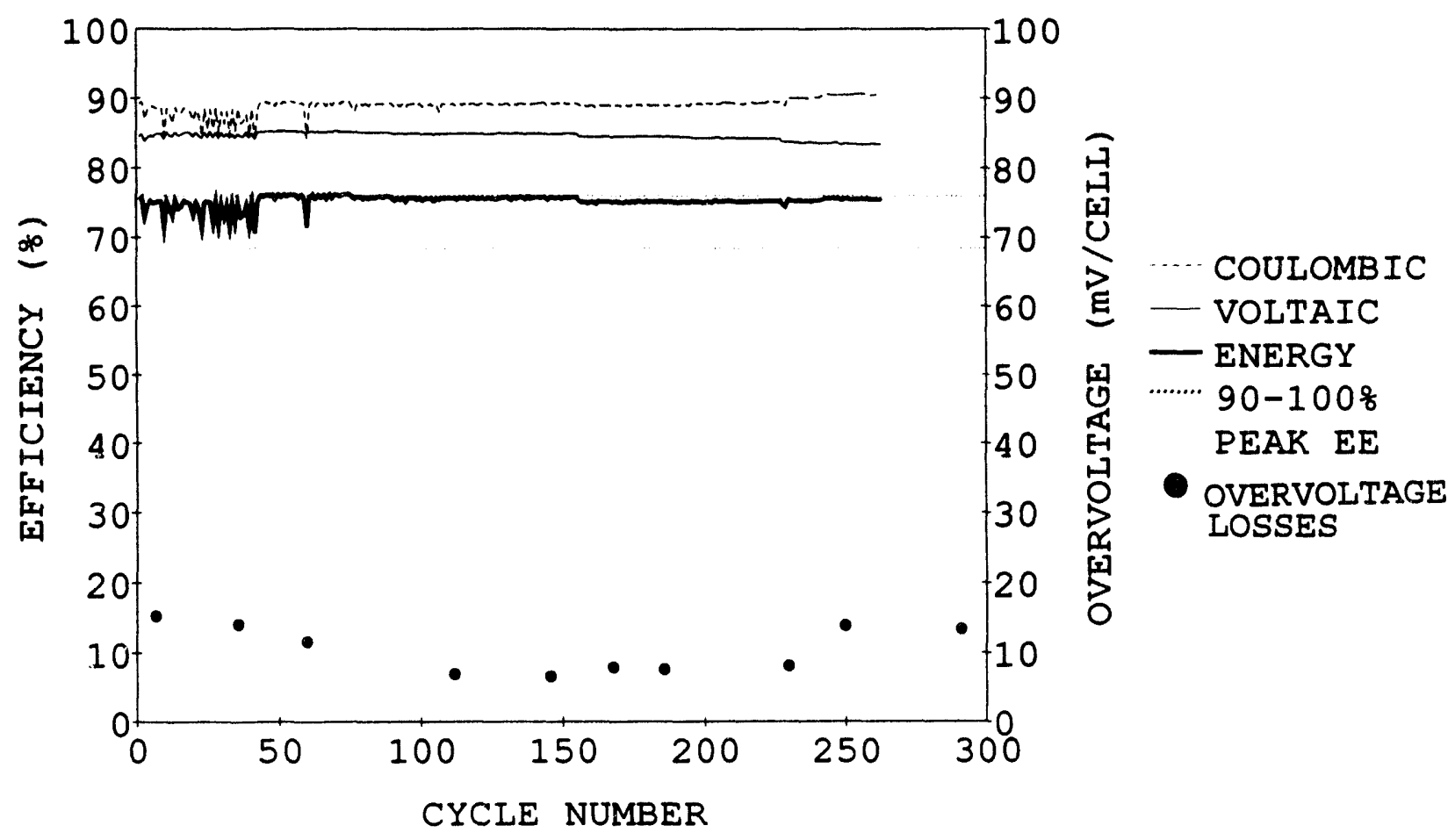

Figure 4-10. V1-79 Baseline Cycle Efficiencies (1-kWh, 8-Cell Battery Stack) 


\section{Deliverable Battery Status}

\section{Battery Teardown (SNL \#526)}

The 15-kWh SNL deliverable, SNL \#526(VL-19/ VL-20), was dismantled at $0 \%$ SOC with the assistance of SNL personnel. Each separator in the two stacks was cracked and brittle. Many of the cells showed the effects of localized heating, which caused melting of the screen, separator, and bipolar electrodes. Several cells had holes through the electrodes. Many of the bipolar electrodes were grossly wrinkled or warped, apparently from high temperature. Some separators also had a characteristic dendrite rash. The conclusions from the teardown are that excessive heating occurred while cycling in the absence of electrolyte flow, and this was the major cause of failure for this battery.

\section{Other Test Results}

\section{Electrode Reconditioning}

In the past, failure of the zinc/bromine batteries has usually been associated with a very rapid increase in polarization, which causes the efficiencies to drop very quickly near the end of cycle life. This trend can be seen in Figure 4-4 for battery V1-73. Recent tests have indicated that the high polarization of a poorly performing battery can be at least partially reversed. An electrode reconditioning technique has been used to lower polarization significantly and improve efficiencies of three eight-cell batteries as seen in Table 4-3. The effects of the reconditioning can also be seen from the baseline cycle efficiency plots for batteries V1-72, V176, and V1-77 given in Figures 4-3, 4-7, and 4-8 respectively. Examination of the potential reversibility of the cathode layer degradation is continuing.

\section{Polarization Testing}

All eight-cell batteries are monitored for overvoltage and internal resistance (IR) loss on a regular basis during the course of testing. A current interrupt method, which allows a measurement of the IR-Free polarization as well as the IR drop during discharge, is performed approximately every 50 cycles to examine deterioration of the battery. The current interrupt method places a low-resistance power supply with a fast on/off transistor in series with the battery. The power is turned on and off every $20 \mu \mathrm{s}$ with a measurement being taken every $10 \mu \mathrm{s}$. When the power is off, there is no IR drop because there is no current, but the polarization remains from the electrode kinetics. When the power is on, both the polarization and IR drop can be measured.

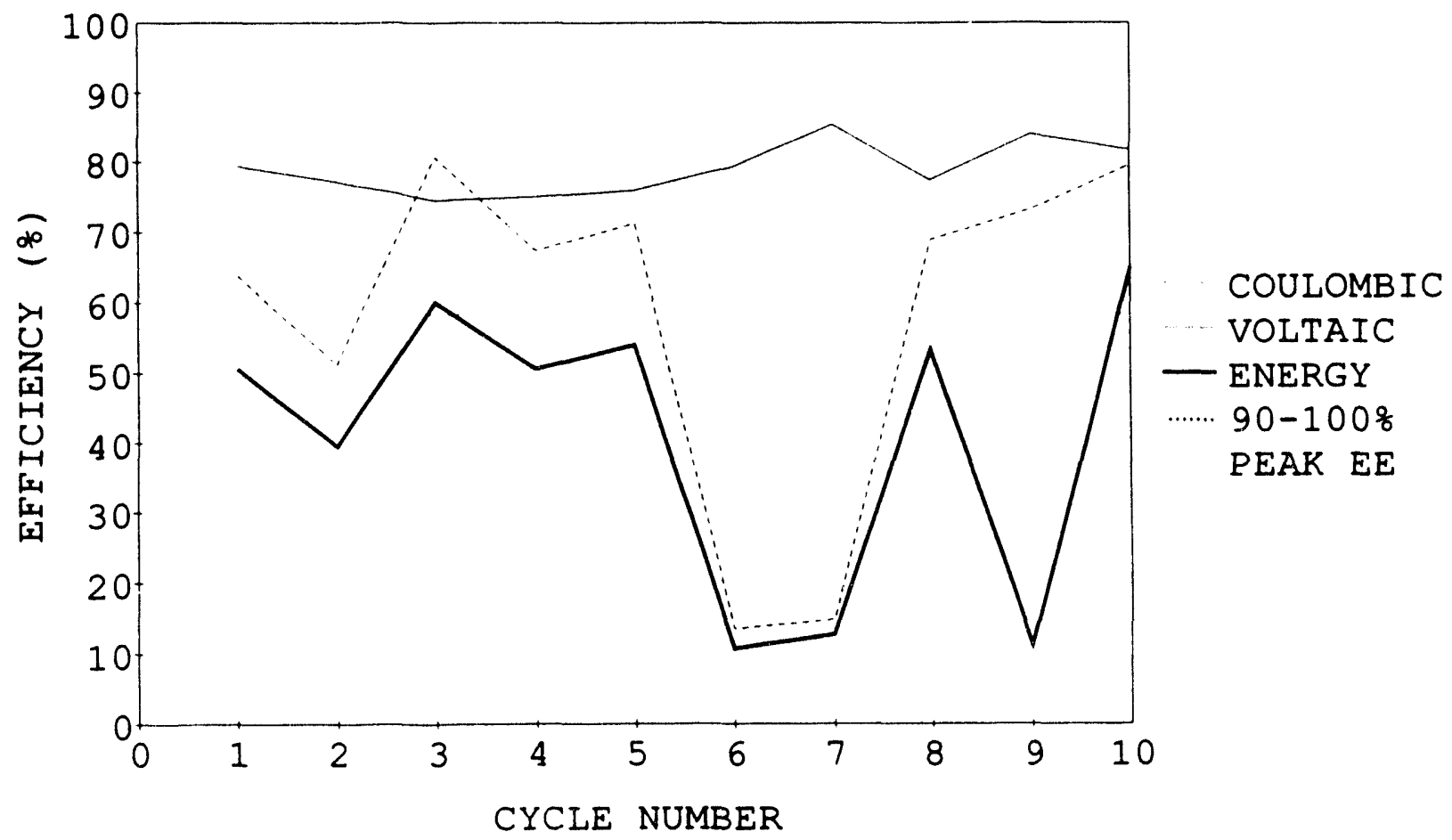

Figure 4-11. V25-01-08 Baseline Cycle Efficiencies (2-kWh, 8-Cell Battery Stack) 


\section{Table 4-3. Baseline Cycle Efficiencies Before and After Electrode Reconditioning}

\begin{tabular}{cccccc} 
Battery & & Cycle & Coulombic (\%) & Voltaic (\%) & Energy (\%) \\
\hline V1-72 & Before & 465 & 82.6 & 78.1 & 64.5 \\
& After & 467 & 85.4 & 80.4 & 68.7 \\
V1-76 & Before & 341 & 79.3 & 71.8 & 57.0 \\
& After & 343 & 84.9 & 78.0 & 66.2 \\
V1-77 & Before & 350 & 86.4 & 81.4 & 70.3 \\
& After & 355 & 90.0 & 83.3 & 75.0
\end{tabular}

On a more frequent schedule, rough measurements of electrode polarization are made using $\mathrm{AC}$ resistance alone. The polarization is determined from the open circuit voltage, voltage on load, the current and the AC resistance. Very good correlation has been observed between the two methods; therefore, the AC resistance method is used because it is simpler.

Figures 4-12 and 4-13 demonstrate the overvoltage and IR drop for V1-74 measured with the current interrupt test procedure. Figure 4-12 shows a significant increase in overvoltage between cycles \#184 and \#241, which suggests cathode layer degradation. Figure 4-13 indicates that the resistance of the battery has also gradually increased during the life of this battery. Figure 4-14, which represents results determined using AC resistance and baseline current density $(21 \mathrm{~mA}$ $\mathrm{cm}^{2}$ ), also shows that V1-74's overvoltage began to increase significantly around 200 cycles. A normal value for the overvoltage is about $10 \mathrm{mV}$ for an 8 -cell battery.

\section{Stand Tests}

While a battery is in stand, the bromine remaining in the cell stack will slowly diffuse to the zinc electrode and chemically react. This affects both the capacity and temperature of the battery. Since the electrolyte is usually not circulated during stand in order to limit the amount of bromine in the cell stack, the temperature inside the stack will increase.

The capacity loss effect of stand has been measured previously for 8-cell stacks. However, in cell stacks with only a few cells, the temperature increase will be less than in full-size stacks. Therefore, further tests are being done with 50-cell stacks where the temperature increase during stand will be measured.
A 50-cell stack was cycled and put into stand several times. At the end of the stand period, a warm pulse of electrolyte was observed at the electrolyte outlet of the cell stack when the circulation was resumed. Two tests showed temperature pulses of $9.5^{\circ}$ and $3.7^{\circ} \mathrm{C}$ indicating that the temperature inside the stack was increasing. The temperature of the warmer electrolyte was probably somewhat less than the temperature of the interior of the battery, and the measurement was complicated by the presence of a gas bubble at the connections. Sometimes it appeared that the electrolyte was actually displaced from the thermocouple by the bubble. Further tests are planned with a new 50-cell stack that will have a higher efficiency.

During the tests, the average transport loss was calculated in terms of a pseudo-current. This value was lower than during a normal baseline cycle as expected because the quantity of bromine is slowly being depleted during the stand. The transport current during stand was about $0.05 \mathrm{~A}$, while in a baseline cycle such as cycle 2 for $\mathrm{V} 1-71$, the value was $0.084 \mathrm{~A}$. In other tests, the self-discharge during stand was found to be about two times higher for a battery stack in the horizontal orientation as compared to the vertical position.

\section{Gas Generation at the Anode}

Since $\mathrm{H}_{2}$ gas accumulation has sometimes been observed in the sealed anolyte flow lines of test batteries, a beaker-scale test was carried out to quantify the normal $\mathrm{H}_{2}$ gassing rates on zinc electrodes. The beakerscale tests were conducted using zinc/zinc metsi electrode pairs in $0 \% \mathrm{SOC}$ (no $\mathrm{Br}_{2}$ ) load-leveling electrolyte at a $\mathrm{pH}=3.7$. All gassing rate volumes were measured at atmospheric pressure. 


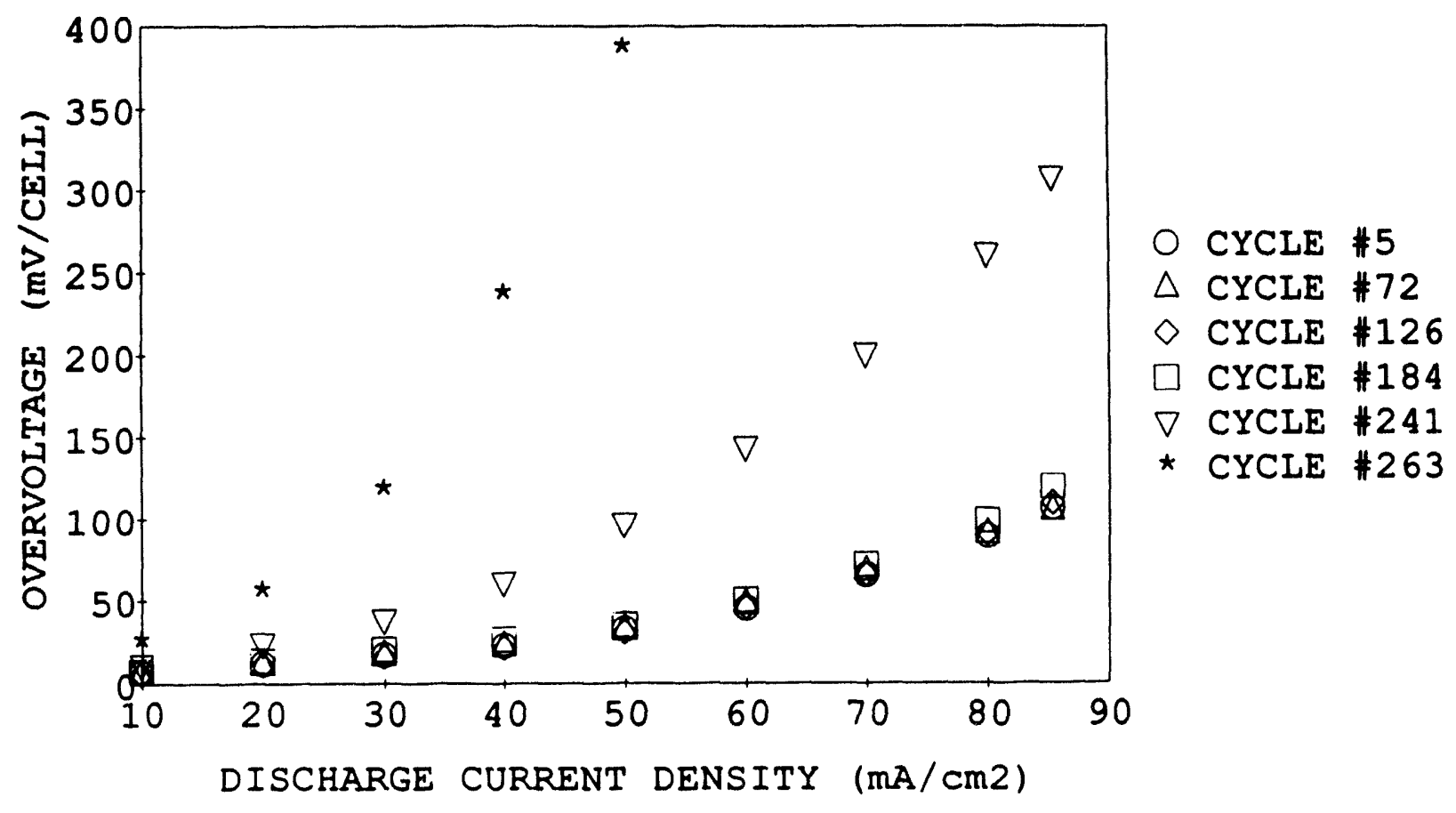

Figure 4-12. Overvoltage Losses for V1-74 Measured by the Current Interrupt Method (1-kWh. 8-Cell Battery Stack)

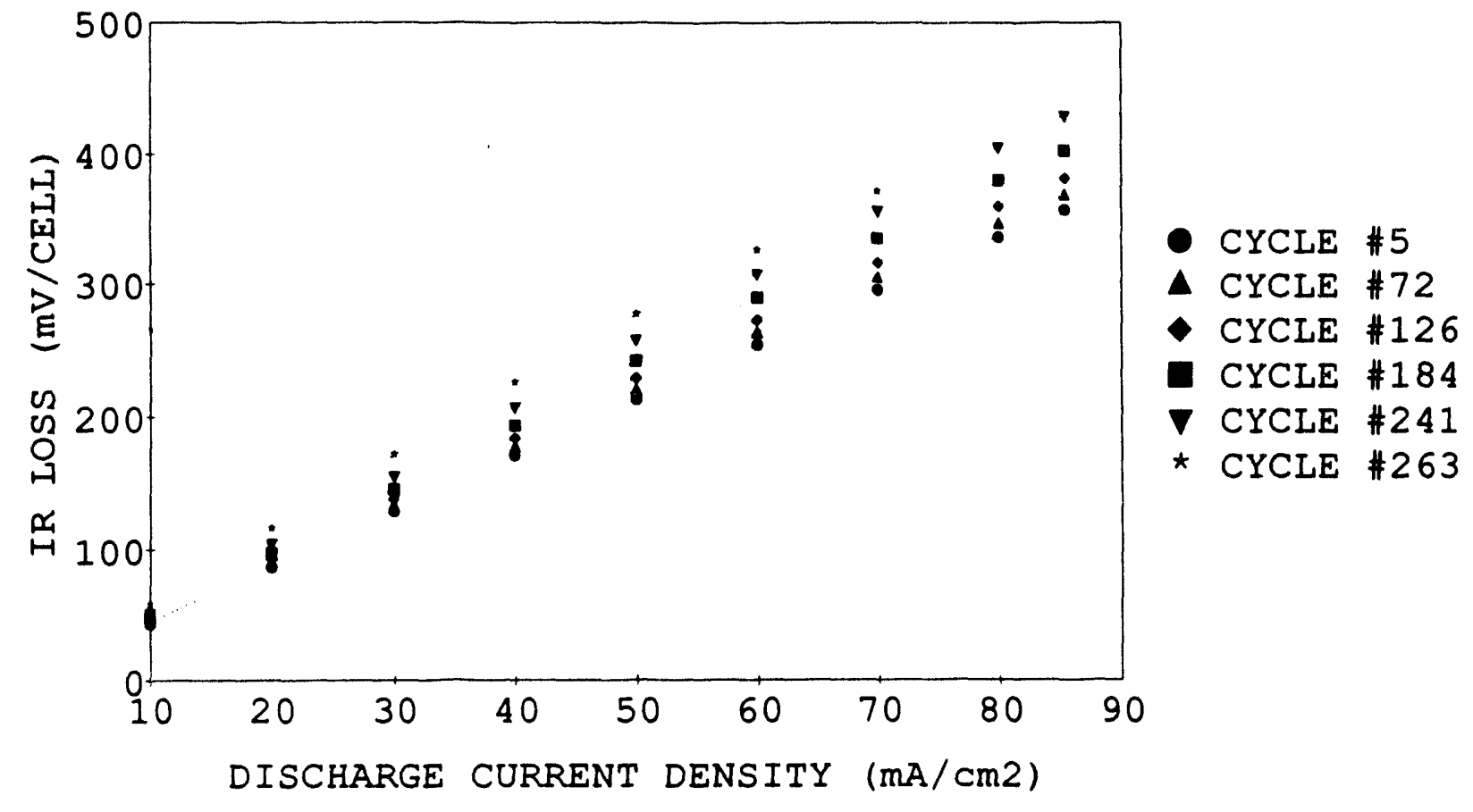

Figure 4-13. IR Losses for V1-74 Measured by the Current Interrupt Method (1-kWh, 8-Cell Battery Stack) 


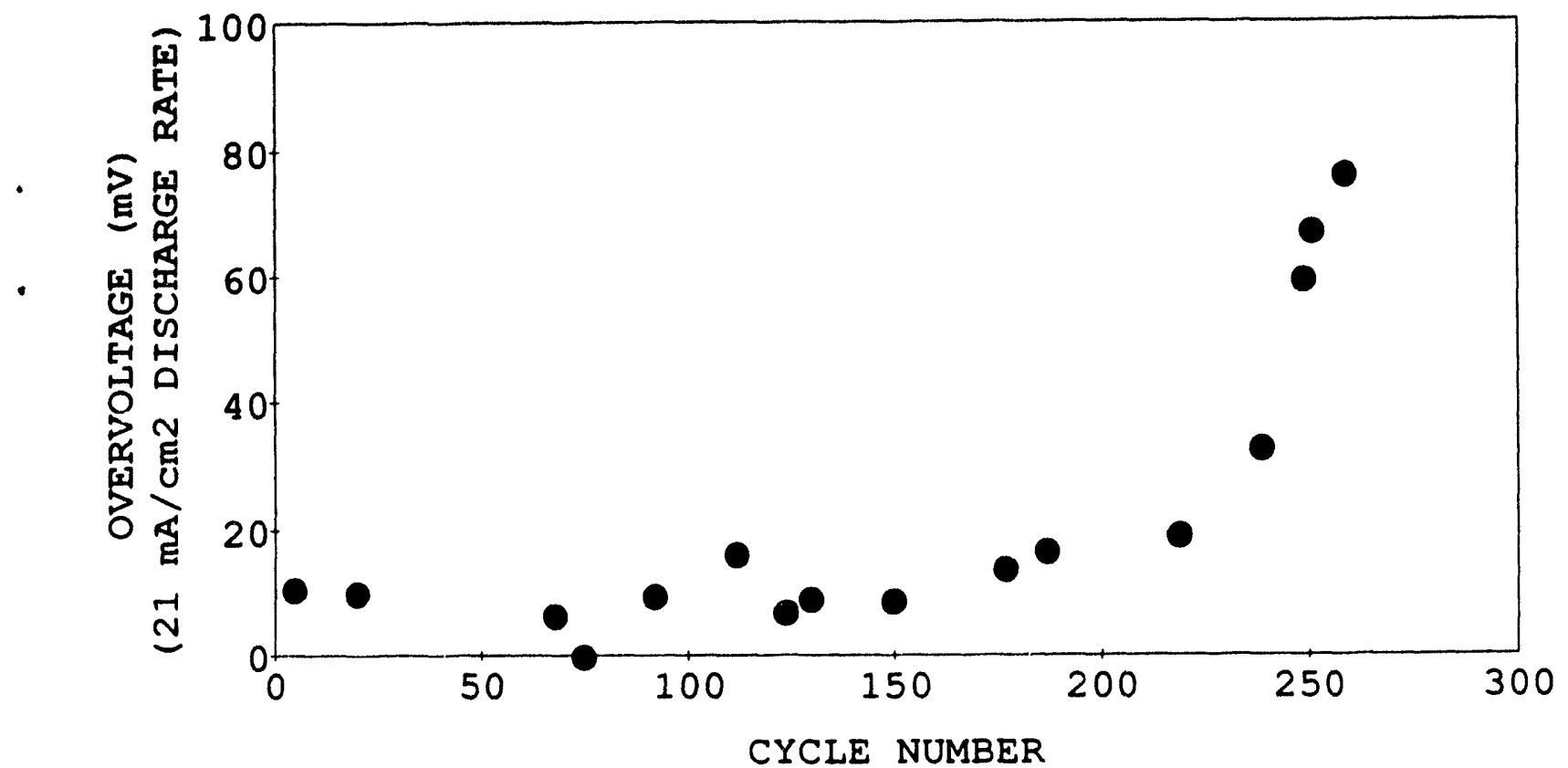

Figure 4-14. Overvoltage Losses for V1-74 Measured by the AC Resistance Method (1-kWh, 8-Cell Battery Stack)

The open-circuit $\mathrm{H}_{2}$ gassing rate on fresh zinc metal electrodes was found to be $3.2 \times 10^{-3} \mathrm{~m} / \mathrm{hr}-\mathrm{cm}^{2}$. This would translate into a gassing rate of $189 \mathrm{mi} / \mathrm{hr}$ for a 50-cell battery stack consisting of $1175-\mathrm{cm}^{2}$ electrode area. A charge current density of $20 \mathrm{~mA} / \mathrm{cm}^{2}$ was then imposed across a pair of zinc electrodes, and this resulted in a 17 times greater gassing rate of $5.5 \times 10^{-}$ $2 \mathrm{ml} / \mathrm{hr}-\mathrm{cm}^{2}$. This would correspond to a fairly significant gas generation rate of $3200 \mathrm{ml} / \mathrm{hr}$ for a full-size 50 cell battery stack. The most likely source of this enhanced $\mathrm{H}_{2}$ gassing is from the slightly inefficient zinc electrodeposition current. As a result, a parasitic reduction reaction of water to hydrogen is also present on the electrode. However, visual inspection seemed to indicate that some of the $\mathrm{H}_{2}$ gassing was also occurring at the discharging zinc electrode. This may have been the result of a chemical reaction between freshly exposed high surface area zinc and water.

Factors that would be expected to increase gassing rates in batteries include areas of bare, exposed carbon plastic on zinc electrodes; electrolyte impurities; shunt current induced gassing; or elevated temperatures (beaker scale tests were conducted at room temperature).

The gassing rates measured in the beaker-scale test indicate that the zinc electrode is capable of producing a large amount of gas. This would also imply that water would have to be periodically added to the electrolyte. Each one liter of hydrogen gas would require the electrochemical reduction of $1.6 \mathrm{ml}$ of water. However, this is generally not required. Therefore, the unexpected high gassing rate results from the beaker-scale test will need to be examined using other tests.

\section{Nonflow Zinc/Bromine Battery}

A 16-run, designed experiment to investigate the important parameters for nonflowing zinc/bromine batteries has been completed. The factors studied included quat type (MEP or Quat B), amount of carbon in the catholyte gap, charge rate, discharge rate, and zinc loading. Results indicated that none of the factors had a significant effect on the energy efficiency of the battery; however, some of these factors did influence hydrogen gas evolution. The factors that minimize hydrogen formation indicate that the cell should perform at $80 \%$ energy efficiency and would be expected to give off $1.8 \mathrm{ml}$ of hydrogen during a cycle.

The self-discharge of a single-cell nonflow battery was examined by allowing a fully charged battery to stand for various lengths of time before discharging. A thermocouple was introduced into the anolyte gap to 
determine the amount of heat generated during stand. Results of the stand tests are given in Table 4-4. The battery temperature increased by less than $1^{\circ} \mathrm{C}$ during each of the stand loss tests.

\section{Core Technology Advances}

\section{Electrode Substrate}

An electrode substrate material has been developed with low expansion to bromine, improved processibility, and lower resistance. This has produced significant improvements in battery performance and terminal electrode and cathode layer processibility.

\section{Terminal Electrodes}

Terminal electrodes are prepared by imbedding a metal screen between layers of conductive carbon plastic. The resistance from the electrical connection to the face of the electrode has in the past been found to be higher than predicted, indicating high resistance at the plastic/screen interface. A number of methods to reduce this interfacial resistance have been attempted, with mixed results. A conductive coating on the surface of the plastic or the metal screen has been found to reduce this effect significantly.

Test specimens were prepared by imbedding two pieces of copper screen in carbon plastic, separated by two layers of carbon plastic. The resistance from one screen to the other was measured and is given in Table 4-5 for uncoated samples and samples with two different coatings. In this case, the coatings were applied to the carbon plastic before hot pressing the samples.

Table 4-5 indicates that coating \#1 significantly reduced the resistance between the two screens by over
$50 \%$ as compared to the sample with no coating. This would indicate a significant reduction in the resistance at the screen/plastic interface.

Coating \#1 was then applied to carbon plastic sheets before preparing terminal electrodes. In one case, only the piece of plastic facing the screen was coated, and in the other case, all of the carbon plastic sheets were coated. The results of these tests are given in Table 4-6. The face-to-stud resistance is the resistance from the electrical connection to the face of the electrode, whereas the face-to-face resistance is the resistance through the part.

The results in Table 4-6 show that the coating at the plastic/screen interface reduces the face-to-stud resistance of the terminal electrode by about $33 \%$. It also indicates that the coating applied at the plastic/plastic interface decreases the resistance even more. Using this coating for preparing terminal electrodes has consistently given lower resistance terminal electrodes than without using the coating.

\section{Cathode Activation Layer}

The main cause of failure during long-term battery cycling appears to be aging of the cathode activation layer. Therefore, preparation of the porous carbon layer has received renewed attention, and efforts are being made to both discover the failure mechanism and improve the production process.

\section{Performance of Cycled Battery Electrodes}

The polarization and surface area measurements for electrodes taken from recently torn-down batteries are given in Table 4-7. The results show that the polarization increases and the surface area decreases during cycling. It is also clear from the trend of the data in Tabie 4-7 that cycled battery electrodes with lower sur-

Table 4-4. Efficiencies (\%) for Single-Cell Nonflow Battery During Stand Loss Cycling

\begin{tabular}{cccccc}
$\begin{array}{c}\text { Stand } \\
\text { Time (hr) }\end{array}$ & $\begin{array}{c}\text { Coulomblc } \\
\text { Efficiency }\end{array}$ & $\begin{array}{c}\text { Voltaic } \\
\text { Efficlency }\end{array}$ & $\begin{array}{c}\text { Energy } \\
\text { Efflcioncy }\end{array}$ & $\begin{array}{c}\text { Transport } \\
\text { Inofficioncy }\end{array}$ & $\begin{array}{c}\text { Residual } \\
\text { Inofficlency }\end{array}$ \\
\hline 0 & 88.0 & 90.0 & 79.2 & 10.3 & 1.7 \\
24 & 56.4 & 84.1 & 47.4 & 38.5 & 5.1 \\
61.3 & 21.6 & 78.4 & 16.9 & 70.7 & 7.8
\end{tabular}




\section{Table 4-5. Interface Carbon Test Samples}

\begin{tabular}{ccc} 
Sample & Coating & $\begin{array}{c}\text { Realetance } \\
\text { (mohm) }\end{array}$ \\
\hline$\# 1$ & none & 36.5 \\
$\# 2$ & Coating $\$ 1$ & 16.3 \\
$\# 3$ & Coating $\# 2$ & 44.5
\end{tabular}

Table 4-6. Terminal Electrode Samples

\begin{tabular}{cccc}
$\begin{array}{c}\text { Sample } \\
\text { Number }\end{array}$ & $\begin{array}{c}\text { Plastlc Pleces } \\
\text { Coated }\end{array}$ & $\begin{array}{c}\text { Resiatance } \\
\text { Face-to-Stud } \\
(\mathbf{m o h m})\end{array}$ & $\begin{array}{c}\text { Resistance } \\
\text { Face-to-face } \\
\text { (mohm) }\end{array}$ \\
\hline TE-1 & None & 0.65 & 1.38 \\
TE-2 & All & 0.44 & 1.14 \\
TE-3 & Facing Screen & 0.46 & 1.24
\end{tabular}

face areas also give poor polarization results. This trend can also be observed in Figure 4-15 for cycled battery electrodes.

\section{Recent Improvements in Processing}

Since polarization and battery performance depend on the active surface area of the bromine electrode, it is important to obtain the highest initial surface area possible. Recent studies in cathode layer processing methods with the new carbon plastic have produced low polarization as well as significantly higher surface areas than seen previously with other carbon plastic materials. Bipolar electrodes have been produced with $52-\mathrm{mV}$ polarization@ @ $250 \mathrm{~mA} / \mathrm{cm}^{2}$ and surface areas of $3600 \mathrm{~cm}^{2} / \mathrm{cm}^{2}$. Terminal electrodes have been prepared with $43-\mathrm{mV}$ polarization @ $250 \mathrm{~mA} / \mathrm{cm}^{2}$ and surface areas of $5500 \mathrm{~cm}^{2} / \mathrm{cm}^{2}$. Polarization of less than $100 \mathrm{mV} @ 250 \mathrm{~mA} / \mathrm{cm}^{2}$ is considered good. The highest surface areas in the past have been $2500 \mathrm{~cm}^{2} / \mathrm{cm}^{2}$ for bipolar electrodes, and $2000 \mathrm{~cm}^{2} / \mathrm{cm}^{2}$ for terminal electrodes. The combination of higher surface areas and low-resistance carbon plastic has resulted in longer lifetimes and better performance for recent battery builds.

\section{High-Surface-Area Carbon}

Electrode samples have also been produced by using a new type of carbon that has a higher surface area. The new carbon has about twice the active surface area (as measured by BET apparatus) as the standard carbon used in the cathode layer. However, when tested for area and polarization in the laboratory, the electrode samples actually showed slightly less active area and higher polarization than those made by the standard process.

\section{Separator Development}

\section{Recent Advances}

The separator used for the zinc/bromine battery is an extruded microporous silica-filled plastic material. The objective of separator development is to obtain a material with better properties than the standard zinc/ bromine battery separator. Resistivity and bromine flux of experimental separator samples (prepared in the JCBGI laboratories) are compared to the standard separator in Table 4-8. 
Table 4-7. Polarization and Surface Area for Cycled and Uncycled Bromine Electrodes

\begin{tabular}{cccccc} 
& & \multicolumn{2}{c}{ Blpolar Electrodes } & \multicolumn{2}{c}{ Torminal Electrodes } \\
\cline { 2 - 6 } $\begin{array}{c}\text { Battery } \\
\text { Number }\end{array}$ & $\begin{array}{c}\text { Number of } \\
\text { Cycles }\end{array}$ & $\begin{array}{c}\text { Polarization } \\
20 \mathrm{~mA} \mathrm{~mm}^{2} \\
(\mathrm{mV})\end{array}$ & $\begin{array}{c}\text { Surface Area } \\
\left(\mathrm{cm}^{2} / \mathrm{cm}^{2}\right)\end{array}$ & $\begin{array}{c}\text { Polarization } \\
\mathbf{2 0} \mathrm{mA} \mathrm{cm}^{2} \\
(\mathrm{mV})\end{array}$ & $\begin{array}{c}\text { Surface Area } \\
\left(\mathrm{cm}^{2} / \mathrm{cm}^{2}\right)\end{array}$ \\
\hline V1-54 & 279 & $27(4)$ & $1664(2197)$ & 54 & 938 \\
V1 57 & 279 & $67(4)$ & $1657(2197)$ & 108 & 516 \\
V1-62 & 128 & $108(4)$ & $644(2479)$ & 100 & 775 \\
V1-66 & 15 & $123(4.5)$ & $686(1542)$ & 113 & 635 \\
V1.68 & 32 & $21.8(5.5)$ & $766(1641)$ & 20.5 & 2063 \\
V1-73 & 171 & $36.5(2.5)$ & $1524(3097)$ & 151 & 860 \\
V1-75 & 24 & $8.3(2.5)$ & $2625(3097)$ & 12.5 & 4141
\end{tabular}

Note: Polarization and surface area of bipolar electrodes prior to cycling are given in parentheses.

S

250

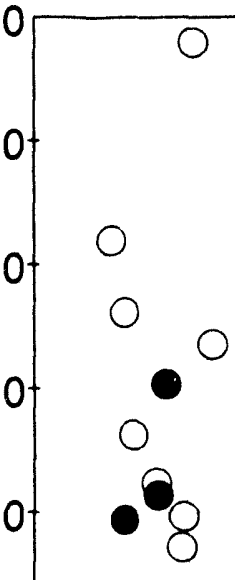

0

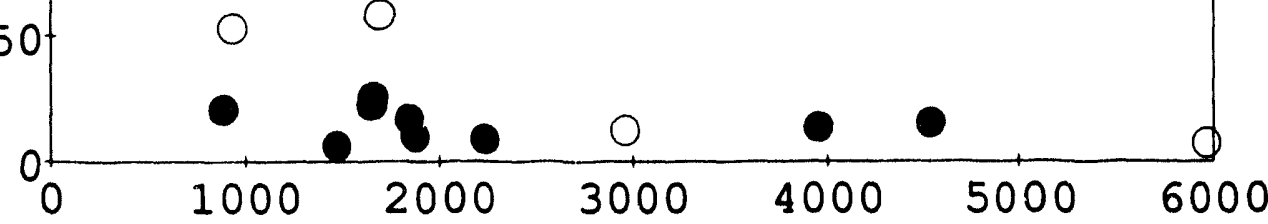

SURFACE AREA (cm2/cm2)

Figure 4-15. Polarization vs Surface Area for Cycled Battery Electrodes 


\section{Table 4-8. Separator Properties}

\begin{tabular}{ccc} 
Sample & $\begin{array}{r}\text { Resistivity } \\
\text { (ohm-cm) }\end{array}$ & $\begin{array}{c}\text { Bromine Flux } \\
\text { (Mole/e/cm }\end{array}$ \\
\hline$\# 115-\mathrm{A}$ & 18.2 & $3.0 \mathrm{E}-9$ \\
$\# 115-\mathrm{B}$ & 18.1 & $2.5 \mathrm{E}-9$ \\
$\# 115-\mathrm{C}$ & 19.5 & $3.0 \mathrm{E}-9$ \\
$\# 115-\mathrm{D}$ & 17.4 & $3.5 \mathrm{E}-9$ \\
$\# 115-\mathrm{E}$ & 17.3 & $2.5 \mathrm{E}-9$ \\
Standard & 23.1 & $3.3 \mathrm{E}-9$
\end{tabular}

Table 4-8 indicates that all of the experimental separators had lower resistivity than the standard, and all but \#115-D had lower bromine diffusion rates than the standard. Sample \#115-E gave the greatest improvements in separator properties over the standard material, and these improvements are projected to increase the energy efficiency of the batteries by 3 or $4 \%$. An extrusion run to produce a separator with the same formulation as \#115-E is scheduled in the near future.

\section{Brittleness of Cycled Battery Separators}

A number of 50-cell batteries have been observed to develop brittle separators over the course of cycling. Most of these batteries were overheated at some point during cycling, which may have caused the problem. Embrittlement of fresh separators could only be achieved by heating the separator material above $130^{\circ} \mathrm{C}$. Placing a sample in boiling water did not cause the separator to become brittle.
The apparent cause of the brittle separators appears to be a decrease in the molecular weight of the polymeric material during cycling or overheating as seen in Table 4-9. The weight average molecular weight (Mw) of the samples was determined by Gel Permeation Chromatography. The cycled separator sample was found to have a lower molecular weight than a separator sample treated for $1 \mathrm{hr}$ at $160^{\circ} \mathrm{C}$. It is unknown whether the interior of the battery actually reached these high temperatures or whether another factor also contributes to the reduction in molecular weight of the cycled battery separator.

\section{Now Battery Design}

\section{$2500-\mathrm{cm}^{2}$ Battery Stack Manufacturing}

A larger battery stack was deemed desirable to reduce costs for a large utility battery. The development of a larger stack design began in late 1992. The stack

Table 4-9. Molecular Weight of Separator Materials

\begin{tabular}{lc}
\multicolumn{1}{c}{ Separator Treatment } & Mw \\
\hline Noncycled Separator & 114,100 \\
Cycled Separator & 52,270 \\
Treated for $1 \mathrm{hr} @ 160^{\circ} \mathrm{C}$ & 98,280
\end{tabular}


features $2500-\mathrm{cm}^{2}$ active area, and was designed for ease of manufacturing to reduce part count and to improve resectability. The weld bead design, vibration welding parameters, and material composition were all optimized to ensure simple manufacture of the battery stacks. The design features improved fluid flow, and rigid plastic endblocks that require no further stiffening.

The $2550-\mathrm{cm}^{2}$ flow frame design was developed through a combination of computer-aided design and flow tests. Initial samples of flow frames, end blocks, and end block covers were produced. Vents were added to the flow frame mold along the outer edges of the frame, and the inner edge at the top of the insert infrared weld bead in order to fill the mold more evenly.

Burst tests were conducted to verify design integrity of the battery stacks prior to testing their electrochemical performance. The test stack consists of about six flow frames welded between two end blocks. Initial samples failed at $6 \mathrm{psi}$. In both cases, the first flow frame to end block center weld bead was insufficiently welded.

More recent battery stacks held up to 25 psi before bursting, and the failure was attributed to tooling misalignment in the center of the battery. However, despite this misalignment, the burst pressure was within the range required for actual battery operation. Cycling will begin once stacks are assembled.

\section{System Controller}

A microprocessor controller is being developed to coordinate the operation and safety monitoring of the zinc/bromine battery system. The controller monitors battery stack voltages and currents, electrolyte levels and pressures, battery SOC, electrolyte temperatures, and liquid and vapor leak sensors. It also controls the circulation of the complexed bromine through the stack during charge and discharge, and shuts the system down if the current during charge or discharge exceeds the safe operating limits. Additionally, the battery can be monitored, and the system can be re-programmed over standard phone lines.

\section{2-kWh Deliverable Station}

The deliverable station for the 8 -cell, $2500-\mathrm{cm}^{2}$ design battery will use three pumps with $\mathrm{AC}$ motors; one for control of the second phase, one for circulating the aqueous catholyte and one for circulating the anolyte. The second phase will be delivered by the control pump to the intake of the aqueous catholyte pump during discharge and will be shut off during charge. Most of the plumbing components will be made of rigid
Kynar and flexible viton. The reservoirs for the deliverable are being constructed from rectangular polyethylene tanks.

A microprocessor controller will coordinate the operation and safety monitoring of the system. Presently, voltage, current, liquid level, and leak data are converted to $24-\mathrm{V}$ signals and sensed by the programmable logic controller (PLC). Temperature data could be converted in a similar manner, but will be monitored by a commercially available electronic package.

Charge and discharge currents are controlled by power mosfets which are switched either on or off by the PLC. The mosfets are also capable of controlling the direction of the current. Therefore, a fully charged battery does not need to be electrically isolated because the discharge circuit would be enabled allowing only discharge to occur.

Liquid levels are adjusted by modifying the speeds of the anolyte and catholyte motors. The second phase motor is also controlled by the PLC. The pumps are mounted on the top of the reservoirs to eliminate any leaks that may occur because of fittings below the liquid level. A liquid leak sensor will also be incorporated into the system.

\section{0-kWh Deliverable Station}

The final goal of the contract is to deliver a 100-kWh zinc/bromine battery system.

The design objectives for the proposed $100-\mathrm{kWh}$ battery station are that it operate independently of external controls. This means it will be a stand-alone system with internal controls and safeguards that will ensure fail-safe cycling. The battery system should be wholly self-contained. The pump rates and electrolyte levels will be self-adjusting. Power for all of the parasitic systems such as cooling, controls, and electrolyte circulation will be taken from the battery system itself. If any electrolyte should leak, it should be contained within an outer shell and collect in a watertight basin at the bottom.

The station will have a built-in controller that will oversee the operation of the battery, such as setting the pump rates, and will monitor the battery for upset conditions, leaks, or high temperature and shut the battery down safely if necessary.

The 100-kWh station will be housed in a haz-mat building as shown in Figure 4-16. The station, chiller, and scrubber will all be contained in this $8 \times 10 \mathrm{ft}$ building. 

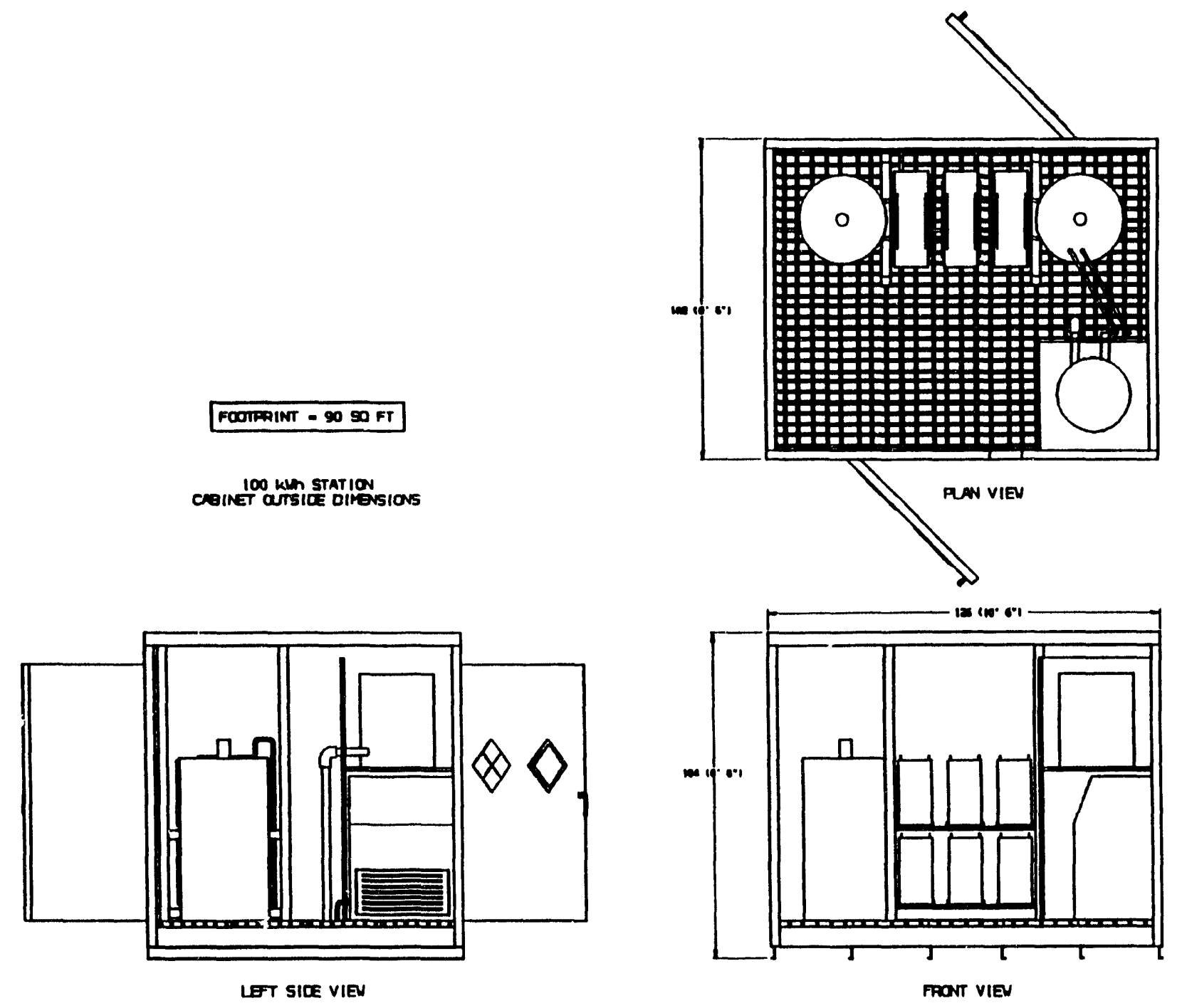

Figure 4-16. 100-kWh Station

\section{Technology Evaluation - SNL}

The objective of the battery technology evaluation element is to evaluate advanced rechargeable cells, modules, and batteries from developers working under OEM contracts. Performance and operating characteristics, as well as cycle life data and failure modes, are determined. This information is used to improve the design and operation of all battery technologies.

\section{Tasks}

The tasks planned under this SNL activity for FY93 included:

1. Evaluate 8-Cell Zinc/Bromine Battery Stack 1.1 - Perform several series of no-strip cycles on battery
1.2 - Conduct life-cycle tests using UES test profile and monitor performance

Funding stretch-out to JCBGI delayed the deliverable into FY94.

\section{Status}

Testing of the JCBGI $15-\mathrm{kWh}$ battery which consisted of two 50-cell stacks assembled into a parallel configuration was completed during the 4th quarter of FY92 and reported in the FY92 annual report. These stacks have been returned to JCGBI and a post-test analysis was performed on them (see p. 4-10).

Testing of the 8-cell battery from JCBGI has been delayed. 


\section{Applied Research - Complexing Agents for Zinc/Bromine Battery Electrolyte}

\section{Background}

This project was requested by JCBGI and is being carried out as a cooperative project between SNL and JCBGI. The objective is to reformulate the electrolyte for the zinc/bromine battery using bromine complexing agents that will allow further improvements in safety in the event of accidental exposure to electrolyte and also in operating efficiency. Several quaternary ammonium bromide salts (quats) have been identified as candidate complexing agents, but these compounds are not commercially available. Therefore, the first task of this project is synthesis of the candidate compounds. This work is being carried out at the UNM Chemistry Department under SNL direction. The second task is evaluation of the candidate compounds. This work is being carried out at SNL and JCBGI. The compounds are tested for bromine complexation at SNL. Electrochemical performance is evaluated at JCBGI, and measurements of bromine evaporation rate are also made. Specific identity of the quats is not disclosed in this report because the quats are potentially patentable materials.

\section{Synthesis}

Fourteen candidate complexing agents were synthesized at the UNM Department of Chemistry. The status of this work is shown in Table 4-10. Structure was confirmed for all quats except Quats E and J. Quat E is probably the correct structure, and difficulty in purification is most likely the cause of the incorrect elemental analysis. Quat $\mathrm{J}$ is probably a mixture of quaternary ammonium bromide salts. Most of the quats were made using commercially available tertiary amines and organic bromides. The reaction occurred in refluxing tetrahydrofuran over 10-12 hr. The product precipitated as a white solid that was filtered and then purified by washing with diethyl ether, dissolving in acetone, and reprecipitating with diethyl ether. The solid was then dried in a vacuum desiccator for $8 \mathrm{hr}$ at $65^{\circ} \mathrm{C}, 10 \mathrm{~mm}$ Hg. As shown in Table 4-10, yields range from 35 to $82 \%$. The tertiary amines needed to make Quats B, H, and $\mathrm{M}$ are not commercially available, and thus were synthesized also. This results in a longer process and, as shown in Table 4-10, lower overall yields. Work to raise the yield of Quat B resulted in almost doubling the yield to $45 \%$ compared to $24 \%$ reported previously.
Quat A was made both with and without solvent. The reactants were the same in either case, and as Table 4-10 shows, the yield is higher for the reaction without solvent. The reasons for the different yields were not thoroughly investigated because Quat A is not a suitable candidate, for reasons given later in this report. Nevertheless, the reaction without solvent required special pressure flasks and did not appear to give as clean a product as the reaction using solvent. Except for Quat $\mathrm{E}$, the materials used to make the candidate quats are comparable in price to those used in making MEP (N-methyl-N-ethylpyrrolidinium bromide), the quat currently used in zinc/bromine battery electrolyte.

The amount synthesized during FY93 includes $618 \mathrm{~g}$ of Quat B, $243 \mathrm{~g}$ of Quat C, $233 \mathrm{~g}$ of Quat D, and $260 \mathrm{~g}$ of Quat $\mathrm{G}$ for evaluation at JCBGI. All of these samples were prepared by repeating several runs of 30 to $40 \mathrm{~g}$ each. Quats B, C, and $\mathrm{G}$ have been tested at JCBGI, and the results are reported in the section entitled Evaluation - JCBGI.

\section{Evaluation - SNL}

The goal of the evaluation work at SNL is to screen candidate quats so that a few quats can be recommended for further evaluation at JCBGI. Important factors include aqueous phase bromine concentration, the possibility of solid formation, and electrolyte resistivity. Tests were performed at three simulated states of charge (discharged, half-charge, and full charge) and at three temperatures (ice bath, ambient, and $50^{\circ} \mathrm{C}$ ).

Bromine complexation tests were performed with the following procedure:

1. Aqueous zinc bromide/quat samples were made that simulate a specific battery SOC. The formulations can be found in Table 4-11.

2. Bromine was added as indicated in Table 4-11, and the sample was stirred in a sealed flask for $1-1.5 \mathrm{hr}$ at either ambient temperature or in a warm water bath at $50^{\circ} \mathrm{C}$.

3. The volumes of the aqueous phase and brominequat complex phase were measured using a graduated cylinder.

4. The aqueous phase and a portion of the complex phase were centrifuged.

5. If the sample had originally been at $50^{\circ} \mathrm{C}$, it was placed back in the water bath in a sealed centrifuge tube to re-equilibrate at this temperature for $1 \mathrm{hr}$.

6. Excess potassium iodide was added to a sample of aqueous phase (either ambient or $50^{\circ} \mathrm{C}$ ). An 
Table 4-10. Status of the Quat Synthetic Work

\begin{tabular}{|c|c|c|c|c|c|c|c|}
\hline \multirow[b]{2}{*}{ Quat } & \multirow[b]{2}{*}{$\begin{array}{l}\text { Overall } \\
\text { Yield \% }\end{array}$} & \multicolumn{2}{|c|}{ Structure Confirmed by: } & \multicolumn{4}{|c|}{ Amount Synthesized During Each Quarter of FY93 } \\
\hline & & NRM' & $\begin{array}{l}\text { Elemental } \\
\text { Analysis }\end{array}$ & First & Second & Third & Fourth \\
\hline$A^{* 2}$ & 60 & Yes & Yes & $61 \mathrm{~g}$ & - & - & - \\
\hline A & 35 & Yes & Yes & - & $41 \mathrm{~g}$ & 一 & - \\
\hline B & $45(56)^{3}$ & Yes & Yes & $52 \mathrm{~g}$ & $242 \mathrm{~g}$ & $25 \mathrm{~g}$ & $396 \mathrm{~g}$ \\
\hline C & 56 & Yes & Yes & $38 \mathrm{~g}$ & $23 \mathrm{~g}$ & $268 \mathrm{~g}$ & - \\
\hline $\mathbf{D}$ & 80 & Yes & Yes & - & $55 \mathrm{~g}$ & - & $233 \mathrm{~g}$ \\
\hline E & 40 & In Progress & No & - & $13 \mathrm{~g}$ & - & - \\
\hline$F$ & 80 & Yes & Yes & - & $34 \mathrm{~g}$ & - & - \\
\hline $\mathbf{G}$ & 75 & Yes & Yes & - & - & $310 \mathrm{~g}$ & - \\
\hline $\mathrm{H}$ & $25(60)^{3}$ & Yes & Yes & - & - & $48 \mathrm{~g}$ & - \\
\hline 1 & 58 & Yes & Yes & - & - & $37 \mathrm{~g}$ & $5 \mathrm{~g}$ \\
\hline$J$ & - & No & No & - & - & $36 \mathrm{~g}$ & - \\
\hline$K$ & 50 & Yes & Yes & - & - & $33 \mathrm{~g}$ & - \\
\hline$L$ & 80 & Yes & Yes & - & - & $35 \mathrm{~g}$ & $57 \mathrm{~g}$ \\
\hline$M$ & $45(56)^{3}$ & Yes & Yes & - & - & - & $36 \mathrm{~g}$ \\
\hline$N$ & 82 & In Progress & In Progress & - & - & - & $27 \mathrm{~g}$ \\
\hline \multicolumn{8}{|c|}{$\begin{array}{l}1 \text { Nuclear Magnetic Resonance - proton and carbon- } 13 \text {. } \\
2 A^{*}=\text { Quat A synthesized without using a solvent. } \\
3 \text { The yield in parentheses is for tertiary amine plus organic bromide only }\end{array}$} \\
\hline
\end{tabular}

amount of iodine was produced which was equivalent to the amount of bromine originally present, and the sample was then titrated with sodium thiosulfate.

7. Remaining ambient sample was placed in an ice bath to equilibrate at this temperature for $1 \mathrm{hr}$, and a sample of the aqueous phase was titrated as in step 6.

8. If the bromine-quat complex was a low viscosity liquid, it was dissolved in $1 \mathrm{M}$ acidic, aqueous potassium bromide solution and then treated as in Step 6.
The set of data collected during FY93 is shown in Table 4-12. Discussion of the main points of these data follows. Aqueous phase bromine concentration is important because a lower concentration is expected to result in higher coulombic efficiency. Bar graphs of the aqueous phase bromine concentration data are shown in Figures 4-17 (a-d) for the simulated states of charge and temperatures. Ambient aqueous phase bromine concentrations can be lowered by a factor of 10 relative to MEP in the discharged state (Figure 4-17a), and by a factor of 4 in the half-charge state (Figure 4-17b). At full charge (Figure 4-17c), the results are puzzling because there seems to be no differentiation between the quats, nor do 


\section{Table 4-11. Electrolyte Formulations for the Simulated States of Charge Used in Testing Quats}

\begin{tabular}{ccccc} 
& $\mathrm{ZnBr}_{2}$ & $\mathrm{ZnCl}_{2}$ & Quat & Bromine \\
\cline { 2 - 5 } Discharged & $3 \mathrm{M}$ & - & $1 \mathrm{M}$ & $0.49 \mathrm{M}$ \\
Hall Charge & $2 \mathrm{M}$ & - & $1 \mathrm{M}$ & $1.47 \mathrm{M}$ \\
Full Charge & $1 \mathrm{M}$ & - & $1 \mathrm{M}$ & $2.45 \mathrm{M}$ \\
Full Charge-JCBGI & $0.45 \mathrm{M}$ & $0.5 \mathrm{M}$ & $1.6 \mathrm{M}$ & $1.95 \mathrm{M}$
\end{tabular}

some of the results repeat very well (Quat A). Perhaps this test involved too much bromine, so the formulation JCBGI uses to simulate full charge in its load-leveling electrolyte was tried. This formulation was able to differentiate between quats and was used in place of the $1 \mathrm{M} \mathrm{ZnBr}, 1 \mathrm{M}$ quat full charge formulation. Ambient aqueous phase bromine concentrations can be lowered by a factor of 4 to 5 relative to MEP in the JCBGI full charge state (Figure 4-17d).

An important factor in choosing a quat is the possibility of solid formation. Solids are undesirable because they plug delivery channels in the battery stack. All of the quats are water soluble, but in the presence of zinc salts, solids are produced at ambient temperature when Quats A, F, and M are present. Most of the quats give either a solution or oil/aqueous mixture, however, in the presence of zinc salts (see Table 4-12). The complexes of most of the quats with bromine are oils at ambient temperature or above at all the simulated states of charge. The exceptions are Quats $A, L$, and $M$. The bromine complex with each of these quats forms a solid at certain states of charge at ambient temperature.

Of the bromine complexes that are oils, most are denser than the aqueous phase. The one exception is the complex with Quat $\mathrm{K}$ under discharged conditions. This complex is less dense at all temperatures tested. At half charge and JCBGI full charge, however, the complex is denser than the aqueous phase. Since the system is designed to work with gravity storage of the bromine complex, a complex that floats at one state of charge and sinks at another is not desirable.

Quat J was deliberately left out of these discussions because it does not have the structure that was intended. It is probably a mixture of quaternary salts. Limited data were collected at half-charge conditions with the idea that if favorable data were obtained, more work could be done to characterize it. Aqueous phase bromine concentrations show little advantage over MEP, however, and the complex with bromine is quite different than the other quats in that it takes up about three times the volume as other complexes. The complex with Quat $J$ is also a putty-like material at ambient temperature that would not be suitable in a flowing system. No more work is planned with Quat J at this time.

Resistivity of the electrolyte is an important factor since this correlates with the voltaic efficiency. Measurements of resistivity were made with electrolyte of the following composition $\left(2.25 \mathrm{M} \mathrm{ZnBr}_{2}, 0.5 \mathrm{M} \mathrm{ZnCl}_{2}\right.$, and $0.8 \mathrm{M}$ quat) using a Hanna Instruments Portable Conductivity meter (HI 8733). Measurements were not made on electrolyte that contained solid or oil. The results are shown in Table 4-13, and all of the electrolytes made with experimental quats show higher resistivity than electrolyte made with MEP. Quats C, G, H, and $M$ could not be measured because electrolyte made with these quats does not form a solution under these test conditions.

For possible application in cold climates, data were also collected at low temperatures. At ice bath temperature, the bromine complexes with Quats A, F, L, and M are solids at certain SOCs. To determine the temperatures that other complexes solidify, samples were placed in an aluminum block and equilibrated at $-5^{\circ} \mathrm{C}$ and then $-13^{\circ} \mathrm{C}$ (within a degree) by circulating cold polypropylene carbonate through the block. The samples consisted of complex alone and complex/aqueous mixtures at various SOCs. The results are shown in Table 4-14. At $-13^{\circ} \mathrm{C}$ most of the quats had samples that contained solid at some SOC, and many of the quats had samples that contained solid at $-5^{\circ} \mathrm{C}$. In a number of cases, the complex solidified when exposed to air but remained liquid when covered with aqueous phase. All of the 


\section{Table 4-12. Quat Screening Data - FY93}

\begin{tabular}{|c|c|c|c|c|c|c|c|c|c|}
\hline \multirow[b]{2}{*}{$\begin{array}{l}\text { Simulated } \\
\text { State of } \\
\text { Charge }\end{array}$} & \multirow[b]{2}{*}{ Quat } & \multirow[b]{2}{*}{$\begin{array}{l}\text { Temp } \\
{ }^{\circ} \mathrm{C}\end{array}$} & \multirow[b]{2}{*}{$\begin{array}{l}\text { Electrolyte } \\
\text { State }\end{array}$} & \multicolumn{2}{|c|}{ Aqueous Phase } & \multicolumn{2}{|l|}{ Complex } & \multirow[b]{2}{*}{ state $^{2}$} & \multirow[b]{2}{*}{$\begin{array}{l}\text { Bromine } \\
\text { Cloud }^{3}\end{array}$} \\
\hline & & & & $\begin{array}{l}\text { Volume } \\
\text { ml }\end{array}$ & $\begin{array}{l}{\left[\mathrm{Br}_{2}\right]} \\
\text { Molar }\end{array}$ & $\begin{array}{l}\text { Volume } \\
\text { mi }\end{array}$ & $\begin{array}{l}{\left[\mathrm{Br}_{2}\right]} \\
\text { Molar }\end{array}$ & & \\
\hline Discharged & MEP4 $^{4}$ & 2 & - & - & 0.057 & - & 4.3 & Oll & No \\
\hline Discharged & Quat $A^{.5}$ & 2 & - & - & 0.004 & - & - & Solid & No \\
\hline Discharged & Quat A & 2 & - & - & 0.010 & - & - & Solid & No \\
\hline Discharged & Quat B & 2 & - & - & 0.016 & - & 2.6 & Oil & No \\
\hline Discharged & Quat C & 2 & - & - & 0.007 & - & - & Oil & No \\
\hline Discharged & Quat D & 2 & - & - & 0.011 & - & - & Oil & No \\
\hline Diecharged & Quat E & 2 & - & - & 0.013 & - & - & Oll & No \\
\hline Diecharged & Quat F & 2 & - & - & 0.000 & - & - & Wax & No \\
\hline Discharged & Quat G & 2 & - & - & 0.009 & - & - & Oil & No \\
\hline Discharged & Quat H & 2 & - & - & 0.007 & - & - & Oll & No \\
\hline Discharged & Quat I & 2 & - & - & 0.009 & - & - & Oll & No \\
\hline Discharged & Quat K & 2 & - & - & 0.004 & - & - & Oilt & No \\
\hline Discharged & Quat L & 2 & - & - & 0.018 & - & - & Oll & No \\
\hline Discharged & Quat M & 2 & - & - & 0.007 & - & - & Solid & No \\
\hline Discharged & Quat N & 2 & - & - & 0.049 & - & - & Oil & No \\
\hline Discharged & MEM $^{6}$ & 25 & Solution & 19 & 0.19 & 1 & 8.0 & Oil & - \\
\hline Discharged & MEP & 25 & Solution & 18 & 0.076 & 2 & 4.0 & Oil & - \\
\hline Discharged & MEP & 20 & Solution & 18 & 0.081 & 2 & 3.8 & Oil & No \\
\hline Discharged & Quat A* & 20 & Slurry & 19.5 & 0.016 & 3 & - & Oil & No \\
\hline Discharged & Quat A & 22 & Slurry & 16.5 & 0.024 & 3.5 & 2.4 & Oil & No \\
\hline Discharged & Quat B & 22 & Solution & 15.5 & 0.023 & 4 & 2.4 & Oll & No \\
\hline Discharged & Quat C & 22 & Oillsoiution & 14.5 & 0.007 & 5 & 1.6 & OH & No \\
\hline Discharged & Quat D & 22 & OIVSolution & 15 & 0.017 & 4.5 & 2.1 & On & No \\
\hline Discharged & Quat E & 22 & Solution & 16 & 0.029 & 4 & 2.6 & OII & No \\
\hline Discharged & Quat F & 22 & Precipitate & 13 & 0.009 & 5 & 1.6 & Oil & No \\
\hline Discharged & Quat G & 22 & Oivsolution & 15 & 0.010 & 5 & 1.8 & Oil & No \\
\hline Discharged & Quat $\mathrm{H}$ & 22 & Oilvsolution & 14 & 0.008 & 5.5 & 1.9 & Oil & No \\
\hline Discharged & Quat I & 22 & Oiv/solution & 15 & 0.012 & 4.5 & 2.0 & Oll & No \\
\hline Dlecharged & Quat K & 22 & Oilsolution & 12.5 & 0.004 & 7 & - & Oî & No \\
\hline Dlecharged & Quat L & 22 & Solution & 17 & 0.030 & 3 & 2.8 & Oll & No \\
\hline Discharged & Quat M & 22 & Wax & - & 0.009 & - & - & Wax & No \\
\hline Discharged & Quat N & 22 & Solution & 16.5 & 0.068 & 3 & 2.4 & Oll & No \\
\hline Discharged & MEP & 50 & - & 18.5 & 0.10 & 1.5 & 5.3 & Oil & Yes, Light \\
\hline Discharged & Quat A* & 50 & - & 21 & 0.027 & 2.5 & 2.7 & Oil & No \\
\hline Discharged & Quat A & 50 & - & 17.5 & 0.047 & 2.5 & 2.7 & On & No \\
\hline Discharged & Quat B & 50 & - & 16.5 & 0.029 & 3.5 & 2.7 & OII & No \\
\hline Discharged & Quat C & 50 & - & - & 0.017 & - & - & On & No \\
\hline Discharged & Quat D & 50 & - & 16 & 0.019 & 4 & - & OA & No \\
\hline Discharged & Quat E & 50 & - & 16.5 & 0.036 & 3.5 & - & Oil & Yes, Light \\
\hline Discharged & Quat F & 50 & - & 14 & 0.013 & 5.5 & - & Oll & No \\
\hline Discharged & Quat G & 50 & - & 14.5 & 0.015 & 4.5 & - & Oil & No \\
\hline Discharged & Quat H & 50 & - & 14 & 0.010 & 5.5 & - & Oil & No \\
\hline Discharged & Quat I & 50 & - & 14.5 & 0.017 & 4.5 & - & Oil & No \\
\hline Discharged & Quat K & 50 & - & 12.5 & 0.008 & 7 & - & Oilt & No \\
\hline Discharged & Quat L & 50 & - & 17.5 & 0.038 & 2.5 & - & Oil & No \\
\hline Discharged & Quat M & 50 & - & 15.5 & 0.008 & 5.5 & - & Oil & No \\
\hline Discharged & Quat N & 50 & - & 17 & 0.089 & 2.5 & - & Oil & No \\
\hline
\end{tabular}




\section{Table 4-12. Quat Screening Data - FY93 (Continued)}

\begin{tabular}{|c|c|c|c|c|c|c|c|c|c|}
\hline \multirow{2}{*}{$\begin{array}{l}\text { Simulated } \\
\text { State of } \\
\text { Charge }\end{array}$} & \multirow[b]{2}{*}{ Quat } & \multirow[b]{2}{*}{$\begin{array}{l}\text { Temp } \\
\cdot c\end{array}$} & \multirow[b]{2}{*}{$\begin{array}{l}\text { Electrolyte } \\
\text { State }^{1}\end{array}$} & \multicolumn{2}{|c|}{ Aqueous Phase } & \multicolumn{3}{|l|}{ Complex } & \multirow[b]{2}{*}{$\begin{array}{l}\text { Bromine } \\
\text { Cloud }^{3}\end{array}$} \\
\hline & & & & $\begin{array}{l}\text { Volume } \\
\mathrm{ml}\end{array}$ & $\begin{array}{l}\left.\mathrm{Br}_{2}\right] \\
\text { Molar }\end{array}$ & $\begin{array}{l}\text { Volume } \\
\text { ml }\end{array}$ & $\begin{array}{l}{\left[\mathrm{Br}_{2}\right]} \\
\text { Molar }\end{array}$ & state $^{2}$ & \\
\hline Half Charge & MEP4 & 2 & - & - & 0.028 & - & 6.9 & Oil & No \\
\hline Half Charge & Quat A.5 & 2 & - & - & 0.008 & - & - & Solid & No \\
\hline Half Charge & Quat A & 2 & - & - & 0.011 & - & - & Solid & No \\
\hline Hall Charge & Quat B & 2 & - & - & 0.017 & - & 5.5 & Oil & No \\
\hline Hall Charge & Quat C & 2 & - & - & 0.008 & - & 4.4 & Oil & No \\
\hline Half Charge & Quat D & 2 & - & - & 0.018 & - & - & Oll & No \\
\hline Half Charge & Quat E & 2 & - & - & 0.025 & - & - & Oil & No \\
\hline Hatf Charge & Quat F & 2 & - & - & 0.014 & - & - & Solid & No \\
\hline Hall Charge & Quat G & 2 & - & .. & 0.018 & - & - & Oil & No \\
\hline Hall Charge & Quat H & 2 & - & - & 0.014 & - & - & Oil & No \\
\hline Hall Charge & Quat I & 2 & - & - & 0.013 & - & - & Oil & No \\
\hline Hall Charge & Quat J & 2 & - & - & 0.035 & - & - & Solld & No \\
\hline Hall Charge & Quat K & 2 & - & - & 0.012 & - & - & Oil & No \\
\hline Hall Charge & Quat L & 2 & - & - & 0.019 & - & - & Oil & No \\
\hline Half Charge & Quant M & 2 & - & - & $0 ., 012$ & - & - & OII & No \\
\hline Haif Charge & Quat N & 2 & - & - & 0.028 & - & - & Oil & No \\
\hline Half Charge & MEP & 25 & Solution & 16 & 0.043 & 4 & 6.1 & Oil & - \\
\hline Half Charge & MEP & 25 & Solution & 16 & 0.043 & 4 & 6.7 & Oil & No \\
\hline Half Chargo & MEP & 20 & Solution & 16 & 0.043 & 4.5 & 6.5 & Oil & No \\
\hline Half Charge & Quat $A^{*}$ & 20 & Slumy & 15.5 & 0.019 & 4.5 & - & Oll & No \\
\hline Half Charge & Quat A & 22 & Slurry & 16 & 0.020 & 5 & - & Oil & No \\
\hline Half Charge & Quat B & 20 & Slurry & 15.5 & 0.023 & 5 & 6.5 & Oil & No \\
\hline Half Charge & Quat C & 22 & Clumps & 15 & 0.011 & 6.5 & 5.1 & Oil & No \\
\hline Half Charge & Quat D & 22 & Solution & 15.5 & 0.024 & 5 & 5.2 & Oil & No \\
\hline Half Charge & Quat E & 22 & Soapy Solid & 16 & 0.038 & 5 & 6.1 & Oil & No \\
\hline Hall Charge & Quat F & 22 & Precipitate & 14.5 & $0 . r^{-}$ & 5.5 & 5.2 & Oil & No \\
\hline Haff Charge & Quat G & $\overline{22}$ & Precipitate & 15.5 & 0.023 & 5 & 5.4 & Oil & No \\
\hline Half Charge & Quat $H$ & $\overline{22}$ & OlvSolution & 15 & 0.016 & 5.5 & 5.0 & Oil & No \\
\hline Half Charge & Quat I & $\overline{22}$ & OIVSolution & 15.5 & 0.018 & 5 & 5.2 & Oil & No \\
\hline Half Charge & Quat J & $\overline{22}$ & Precipltate & 5 & 0.035 & 15 & - & Putty & No \\
\hline Half Charge & Quat K & 22 & Oivsolution & 14.5 & 0.012 & 6 & 4.7 & Oil & No \\
\hline Half Charge & Quat L & $\overline{22}$ & Precipltate & 16 & 0.032 & 4.5 & 6.1 & Oil & No \\
\hline Half Charge & Quat M & $\overline{2}$ & OIVSolution & 14 & 0.014 & 6 & 4.8 & Oil & No \\
\hline Half Charge & Quat N & 22 & OivSolution & 14 & 0.045 & 5 & 5.2 & Oil & No \\
\hline Haff Charge & MEP & 50 & - & 16 & 0.050 & 4 & 6.2 & Oil & Yes \\
\hline Hall Charge & Quat $A^{\circ}$ & 50 & - & 12.5 & 0.034 & 4 & - & - & Yes, Light \\
\hline Hall Charge & Quat A & 50 & - & 16 & 0.025 & 5 & 5.4 & Oil & No \\
\hline Half Charge & Quat B & 50 & - & 18 & 0.033 & 5 & 6.1 & Oll & No \\
\hline Hall Charge & Quat C & 50 & - & 17 & 0.015 & 5 & - & Oll & No \\
\hline Half Charge & Quat C & 50 & - & 15.5 & 0.019 & 5.5 & 5.6 & Oll & No \\
\hline Half Charge & Quat D & 50 & - & 15.5 & 0.026 & 5 & - & Oll & Yes, Light \\
\hline Hall Charge & Quat E & 50 & - & 16 & 0.050 & 5 & - & OH & Yee \\
\hline Half Charge & Quat F & 50 & - & 14.5 & 0.028 & 5.5 & - & Oll & Yes \\
\hline Half Charge & Quat G & 50 & - & 15 & 0.027 & 5.5 & - & OH & No \\
\hline Half Charge & Quat H & 50 & - & 15 & 0.020 & 5.5 & - & Oll & No \\
\hline Hall Charge & Quat I & 50 & $\ldots$ & 15 & 0.022 & 5.5 & - & Oll & Yes, Light \\
\hline Half Charge & Quat K & 50 & - & 14.5 & 0.017 & 6 & - & Oil & Yes, Light \\
\hline Half Charge & Quat L & 50 & $\ldots$ & 16 & 0.037 & 4.5 & - & Oil & Yes \\
\hline Half Charge & Quat M & 50 & - & 14 & 0.019 & 6 & - & Oil & No \\
\hline Hall Charge & Quat N & 50 & - & 16 & 0.049 & 4.5 & - & OII & Yes \\
\hline
\end{tabular}


Table 4-12. Quat Screening Data - FY93 (Continued)

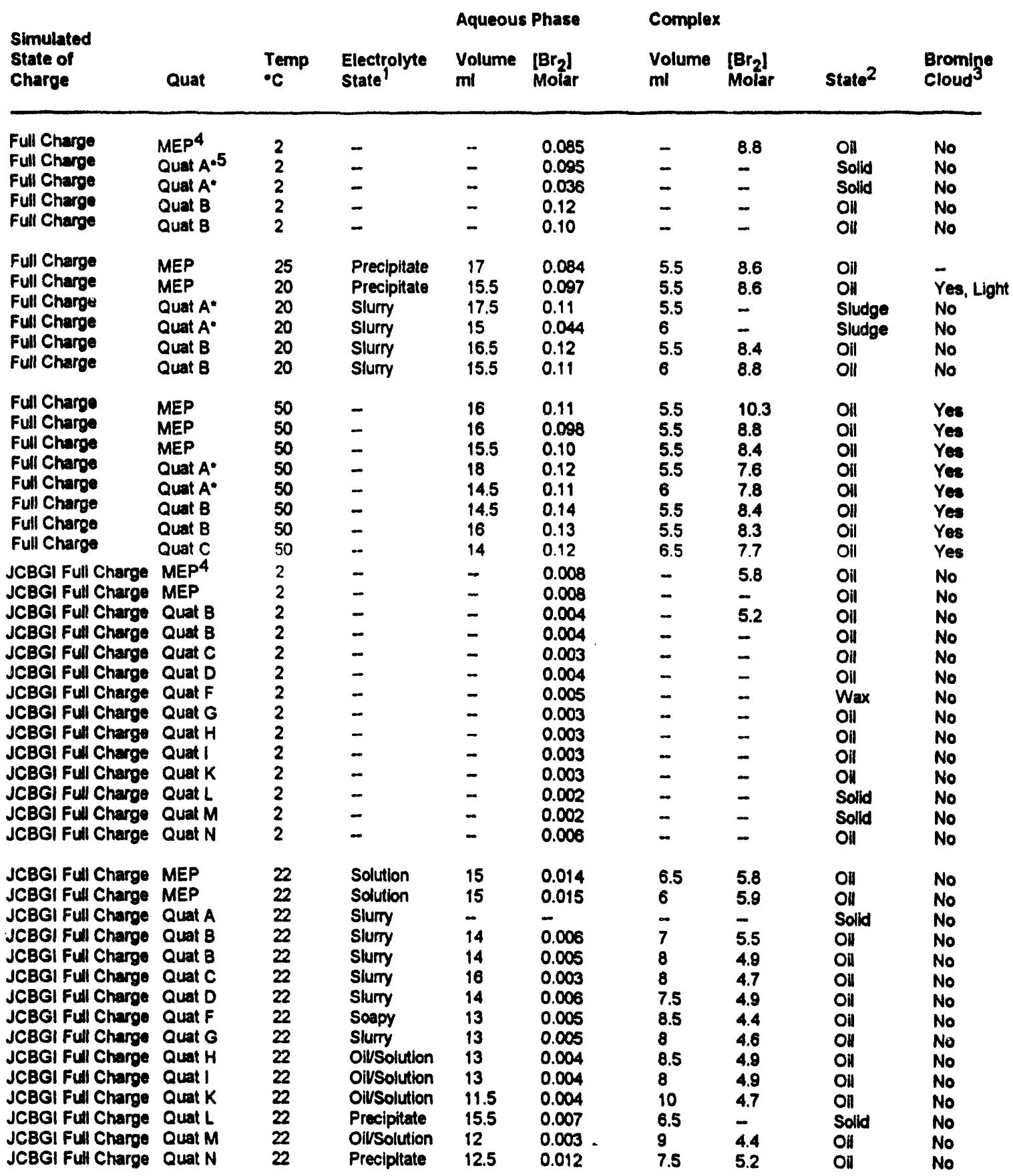


Table 4-12. Quat Screening Data - FY93 (Continued)

\begin{tabular}{|c|c|c|c|c|c|c|c|c|c|}
\hline \multirow{2}{*}{$\begin{array}{l}\text { Simulated } \\
\text { State of } \\
\text { Charge }\end{array}$} & \multirow[b]{2}{*}{ Quat } & \multirow[b]{2}{*}{$\begin{array}{l}\text { Temp } \\
\cdot C\end{array}$} & \multirow[b]{2}{*}{$\begin{array}{l}\text { Electrolyte } \\
\text { State }^{1}\end{array}$} & \multicolumn{2}{|c|}{ Aqueous Phase } & \multicolumn{2}{|c|}{ Complex } & \multirow[b]{2}{*}{ Stote 2} & \multirow[b]{2}{*}{$\begin{array}{l}\text { Bromine } \\
\text { Cloud }^{3}\end{array}$} \\
\hline & & & & $\begin{array}{l}\text { Volume } \\
\mathrm{ml}\end{array}$ & $\begin{array}{l}{\left[\mathrm{Br}_{2}\right]} \\
\text { Molar }\end{array}$ & $\begin{array}{l}\text { Volume } \\
\text { mi }\end{array}$ & $\begin{array}{l}{\left[\mathrm{Br} \mathbf{r}_{2}\right]} \\
\text { Molar }\end{array}$ & & \\
\hline $\begin{array}{l}\text { JCBGI Full Charge } \\
\text { JCBGI Full Charge } \\
\text { JCBGI Full Charge } \\
\text { JCBGI Full Charge } \\
\text { JCBGI Full Charge } \\
\text { JCBGI Full Charge } \\
\text { JCBGI Full Charge } \\
\text { JCBGI Full Charge } \\
\text { JCBGI Full Charge } \\
\text { JCBGI Full Charge } \\
\text { JCBGI Full Charge } \\
\text { JCBGI Full Charge } \\
\text { JCBGI Full Charge } \\
\text { JCBGI Full Charge } \\
\text { JCBGI Full Charge } \\
\text { JCBGI Full Charge } \\
\text { JCBGI Full Charge }\end{array}$ & $\begin{array}{l}\text { MEP } \\
\text { MEP } \\
\text { MEP } \\
\text { Quat A } \\
\text { Quat A } \\
\text { Quat B } \\
\text { Quat B } \\
\text { Quat C } \\
\text { Quat D } \\
\text { Quat F } \\
\text { Quat G } \\
\text { Quat H } \\
\text { Quat I } \\
\text { Quat K } \\
\text { Quat L } \\
\text { Quat M } \\
\text { Quat N }\end{array}$ & $\begin{array}{l}45 \\
50 \\
50 \\
50 \\
50 \\
45 \\
50 \\
50 \\
50 \\
50 \\
50 \\
50 \\
50 \\
50 \\
50 \\
50 \\
50\end{array}$ & $\begin{array}{l}- \\
- \\
- \\
- \\
- \\
- \\
- \\
- \\
- \\
- \\
- \\
-\end{array}$ & $\begin{array}{l}15 \\
15 \\
14.5 \\
14 \\
14 \\
14.5 \\
13.5 \\
- \\
14 \\
14 \\
13 \\
13 \\
13 \\
11.5 \\
15.5 \\
12 \\
13.5\end{array}$ & $\begin{array}{l}0.018 \\
0.025 \\
0.024 \\
0.009 \\
0.008 \\
0.009 \\
0.009 \\
0.006 \\
0.008 \\
0.006 \\
0.007 \\
0.004 \\
0.005 \\
0.004 \\
0.013 \\
0.004 \\
0.018\end{array}$ & $\begin{array}{l}6.5 \\
6.5 \\
- \\
7.5 \\
7.5 \\
7 \\
7.5 \\
- \\
7.5 \\
8.5 \\
8 \\
8.5 \\
8 \\
8.5 \\
7 \\
8.5 \\
7.5\end{array}$ & $\begin{array}{l}6.0 \\
- \\
- \\
- \\
\overline{5} .4 \\
- \\
- \\
- \\
- \\
- \\
- \\
- \\
- \\
-\end{array}$ & $\begin{array}{l}\text { Onl } \\
\text { Oll } \\
\text { Onl } \\
\text { Onl } \\
\text { Onl } \\
\text { Oll } \\
\text { Oil } \\
\text { Oll } \\
\text { Oil } \\
\text { Oil } \\
\text { Oll } \\
\text { Oll } \\
\text { Oll } \\
\text { Oll } \\
\text { Onl } \\
\text { Onl } \\
\text { Oll }\end{array}$ & $\begin{array}{l}\text { No } \\
\text { No } \\
\text { Yes, Light } \\
\text { No } \\
\text { No } \\
\text { No } \\
\text { No } \\
\text { No } \\
\text { No } \\
\text { No } \\
\text { No } \\
\text { No } \\
\text { Yes, Light } \\
\text { No } \\
\text { No } \\
\text { No } \\
\text { No }\end{array}$ \\
\hline
\end{tabular}

\footnotetext{
1 Electrolyte appearance at ambient temperature before addition of bromine.

2 All cils and solids are more dense than the aqueous phase excest the marked oils ( $\uparrow$, Quat $K$, discharged) which are leas denes. 3Presence or absence of bromine vapor in a sealed flask containing electrolyte plus bromine.

$4 N$-Mothyl-N-ethytpyrrolidinium Bromide.

5 Quat A made without solvent.

6 N-Methyl-N-ethylmorpholinium Bromide
}

complexes that remain liquid at these low temperatures become viscous, however, and would probably require more pumping power than is available for practical operation.

In the section Evaluation-JCBGI, data show that Quats $C$ and $G$ do not perform well in a minicell test. Bromine complexation tests were performed on electrolyte containing a mixture of Quat $\mathrm{C}$ and MEP to determine if Quat $\mathbf{C}$ would provide any advantages in this mode of usage. A mixture of 33\% Quat $\mathrm{C}$ and $67 \%$ MEP was chosen because this proportion gives electrolyte (2.25M $\mathrm{ZnBr}_{2}, 0.5 \mathrm{M} \mathrm{ZnCl}_{2}$, and $0.8 \mathrm{M}$ quat) that is a solution :ather than an oil/aqueous mixture. Electrolyte that contains a larger proportion of Quat $C$ to MEP forms oil/aqueous mixtures as does any mixture of Quat C with Quat B; however, it is not clear whether the presence of a second phase before bromine has been added affects electrochemical performance. Results of the mixture tests are given in Table 4-15. For comparison purposes, values for MEP and Quats B and C are also given. The use of Quat $C$ in a mixture shows little advantage at half charge, and at both simulated SOCs the use of Quat B is a better choice because it provides lower aqueous phase bromine concentration and good electrochemical performance in the minicell.

\section{Evaluation - JCBGI}

Quaternary ammonium salts form complexes with bromine which lowers the vapor pressure and reduces the activity of the bromine. Improving the complexing capabilities of the quaternary salts can enhance battery performance in two ways. The self-discharge of the battery will be reduced by lowering the aqueous bromine concentration, and the safety of the system will be improved by reducing the bromine evaporation rate.

\section{Compiexing Ability of Experimental Quats}

The complexing ability of various quaternary compounds was determined using two test methods. First, the concentration of bromine in the aqueous layer of a synthetic $50 \%$ SOC electrolyte was determined by titration with a thiosulfate solution. Second, a bromine evaporation rate from the complex phase was determined by putting a small amount of complex in a poly- 
a) Discharged

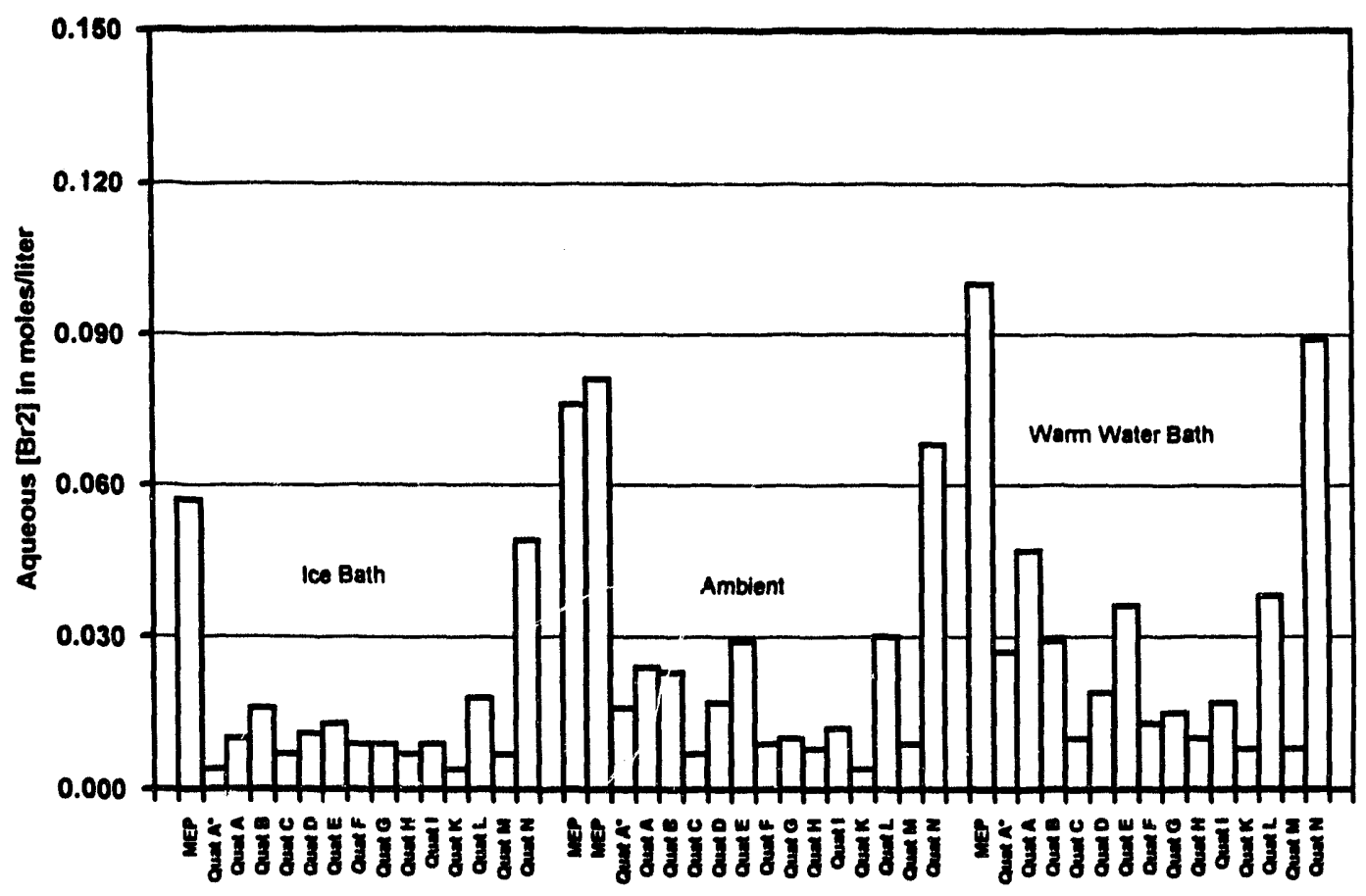

b) Half Charge

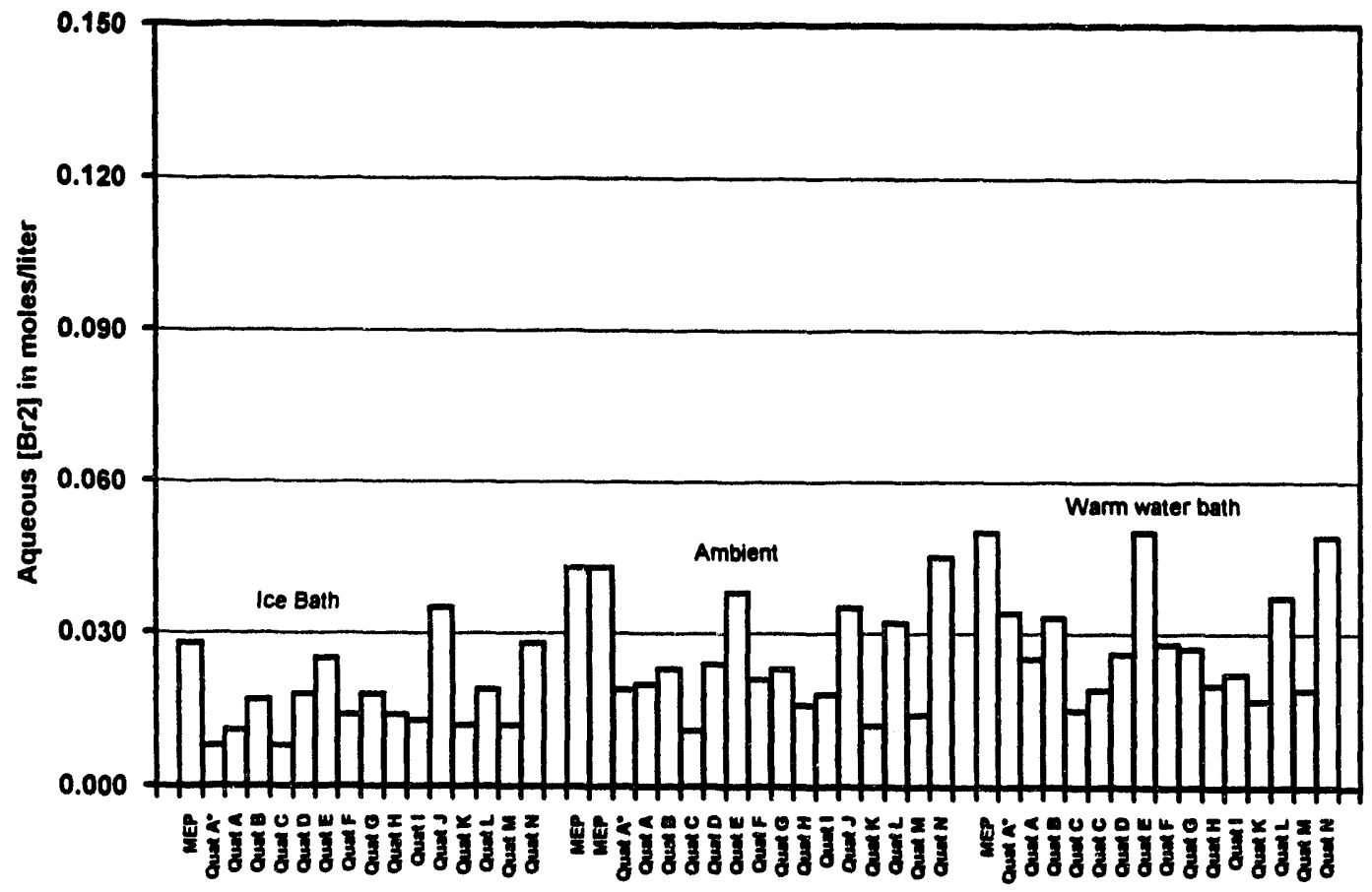

Figure 4-17. Bar Graphs of Aqueous Phase Bromine Concentration Data for Candidate Bromine Complexing Agents (page 1 of 2) 
c) Full Charge

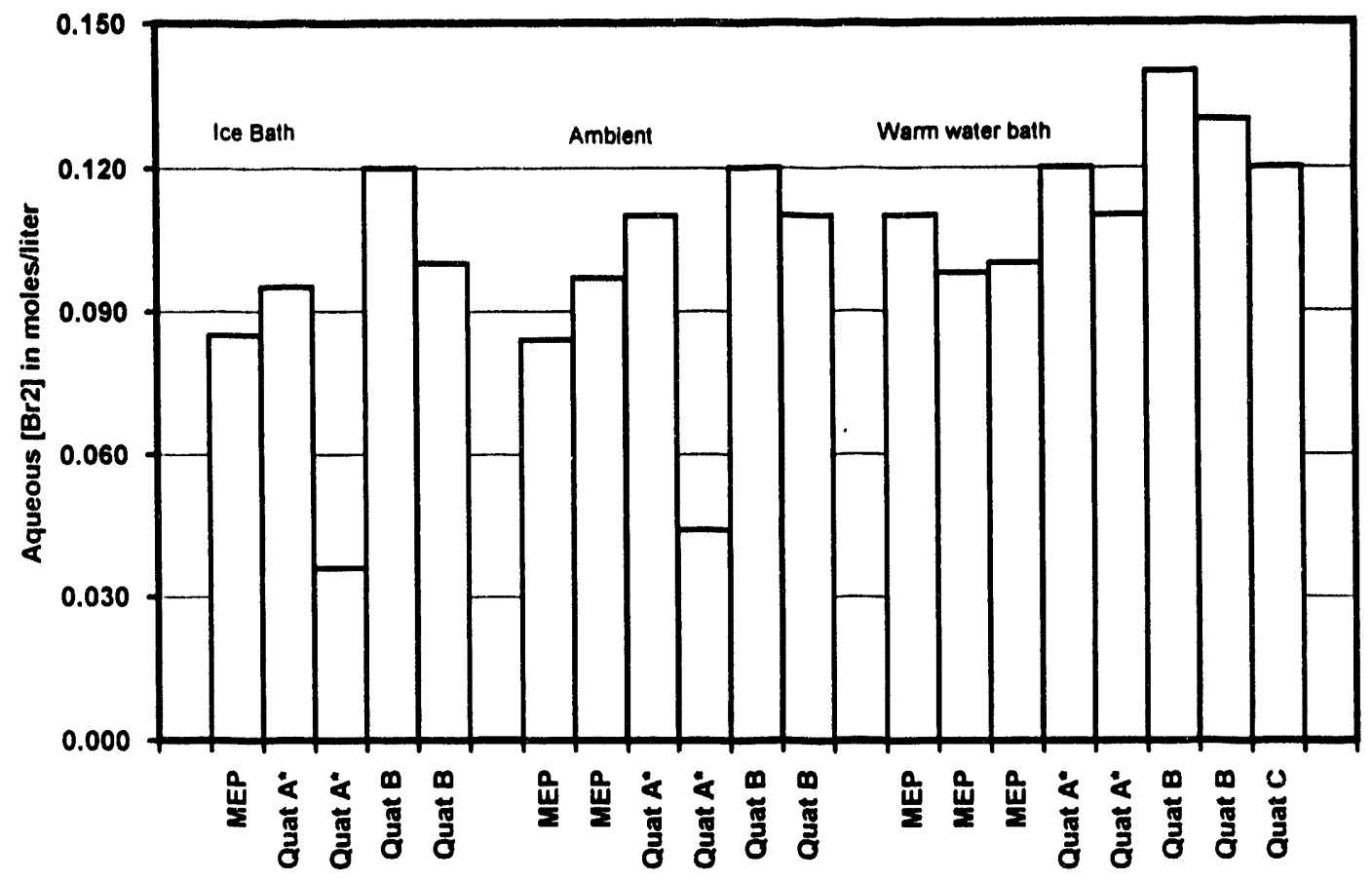

d) JCBGI Full Charge

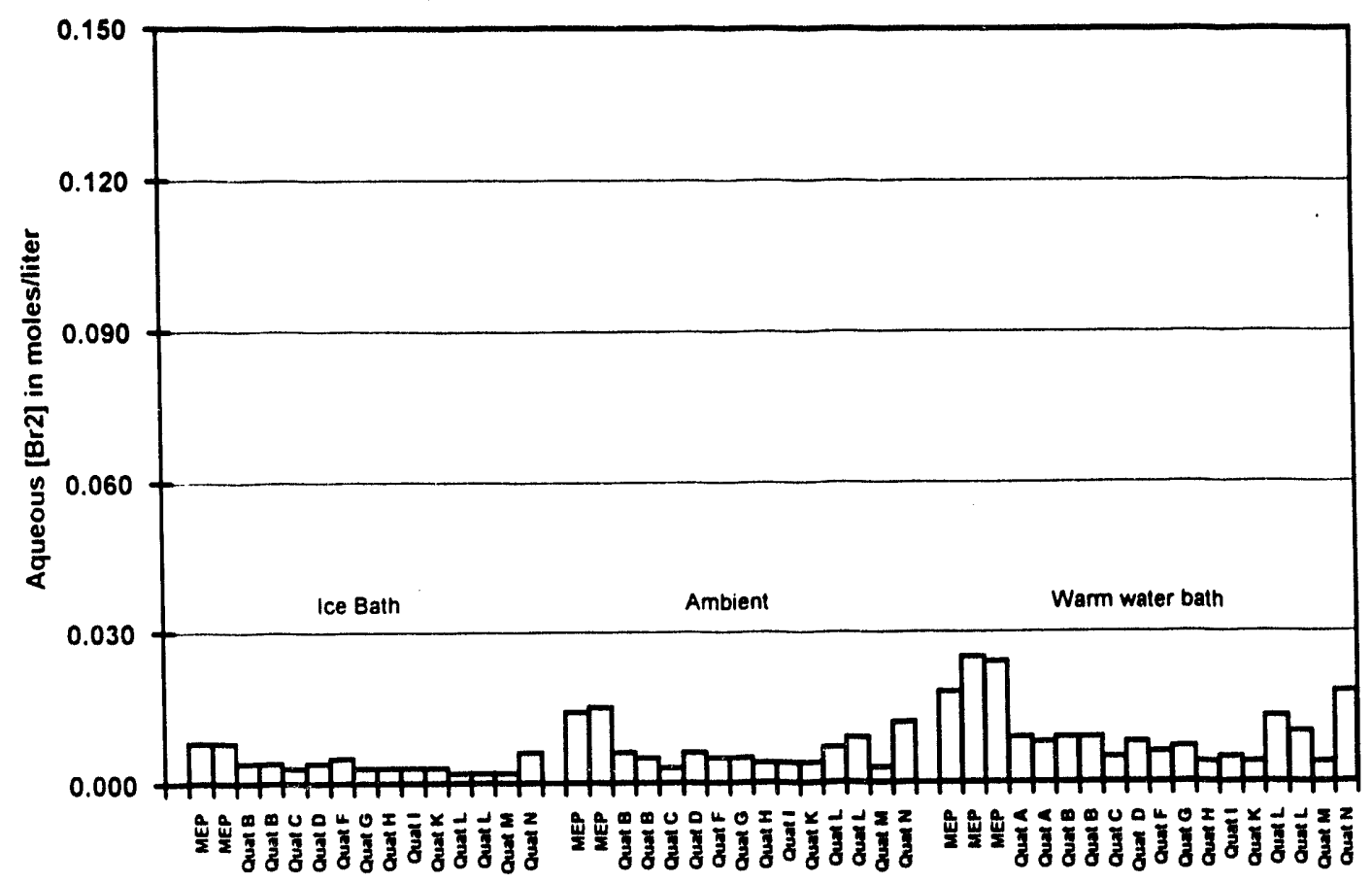

Figure 4-17. Bar Graphs of Aqueous Phase Bromine Concentration Data for Candidate Bromine Complexing Agents (page 2 of 2) 
Table 4-13. Electrolyte Resistivity (Ohm-Cm)

\begin{tabular}{cccc} 
& ICe Bath & $25^{\circ} \mathrm{C}$ & $50^{\circ} \mathrm{C}$ \\
\cline { 2 - 4 } MEP & 23.4 & 14.0 & 9.9 \\
Quat B & - & 17.0 & 11.0 \\
Quat C & - & - & - \\
Quat D & - & - & 11.8 \\
Quat G & - & - & - \\
Quat H & - & - & - \\
Quat I & - & - & 13.1 \\
Quat L & - & 15.0 & 10.5
\end{tabular}

tetrafluoroethylene (PTFE) cup, which in turn was placed in a one liter flask. Air was drawn through the flask at a rate of $0.5 \mathrm{~L} / \mathrm{min}$. and sent to an instrument that measured bromine concentration. The evaporation rate was then calculated from the air flow rate, exposed surface area, and the measured bromine concentration.

Results in Table 4-16 indicate that a number of experimental complexing agents v/ere found to have stronger bromine complexing ability than the standard N-Methyl-N-ethylpyrrolidinium Bromide (MEP).

\section{Performance in a Battery}

Based on the improved complexing ability of these experimental quats, battery performance was anticipated to increase because of reduced bromine concentration in the aqueous phase catholyte, which in turn would reduce self discharge. However, the results in Table 4-17 for cycles run on single-cell batteries showed that only Quat B gave a satisfactory energy efficiency, primarily because of a significant increase in the coulombic efficiency over the standard MEP.

Beaker scale polarization tests showed that all the experimental complexing agents gave significantly higher polarization and higher electrical resistance than the standard MEP. Other than Quat B, the experimental quats were found to complex the bromine too tightly to be effective in an actual battery. Even reducing the amount of experimental quat in the electrolyte by $50 \%$ did not increase the battery performance to the same level as that obtained with the standard MEP quat electrolyte.

\section{Molecular Modeling}

Molecular modeling of the quat-bromine complex was performed to try to gain an understanding of why some quats complex bromine better than others. If there was such an understanding, proposal of candidate quats could be a less empirical process. The molecular modeling was done at the UNM Chemistry Department using PC-based software named PCMODEL distributed by Serena Software. When bromine forms a complex with a quat, polybromide $\left(\mathrm{Br}_{3}{ }^{-}\right)$is formed. The complex consists of a quaternary cation and polybromide anion. This software package had no way to build a polybromide anion directly, so one was built by bonding two bromine atoms to an oxygen atom. The resultant entity was then given attributes of polybromide anions from the literature.

The modeling software places the quaternary cation and the polybromide anion in the lowest energy (most stable) conformation. A space-filling model can be drawn that depicts the space taken up by each atom as a sphere. One view of the model for the complex between MEP and bromine is shown in Figure 4-18. Similar models were created for the complexes with Quats B, C, $G$, and $K$. It seems reasonable to expect that the shape 


\section{Table 4-14. State of Aqueous Phases and Quat-Bromine Complexes at Low Temperatures}

\begin{tabular}{|c|c|c|c|c|c|}
\hline QUAT & $\begin{array}{l}\text { SIMULATED } \\
\text { BTATE OF } \\
\text { CHARQE }\end{array}$ & COMPLEX & COMPLEXAQUEOUS & $\begin{array}{l}-13^{\circ} \mathrm{C} \\
\text { CoMPLEX }\end{array}$ & COMPLEXIQUEOUS \\
\hline MEP & Half Charge & Ilquid & Houid & Mould & liquid \\
\hline MEP & JCBGI FullCha & liquid & liquid & eolld & solidniquid \\
\hline & & & & & \\
\hline Quat B & JCBGI FullChg & Navid & liquid & solid & solldiliquid \\
\hline Quat C & Diecherged & semi-ealid & liquid & eolid & solidnliquid \\
\hline Quat C & JCBGI FullChg & liguid & liquid & Hquid & liquid \\
\hline & & & & & \\
\hline Quat D & JCBGI Full Charge & liquid & liquid & Iquid & Ilquid \\
\hline Ouat E & Diecharoed & solid & solld & solld & solld \\
\hline Quat E & Hali Charge & Ilquid & llquid & liquid & liquid \\
\hline & & & & & \\
\hline Quat F & Discharged & solid & solid/lituid & colid & solid/iquid \\
\hline Quat F & JCBGI Full Charge & solid & solid/liquid & solid & solid \\
\hline & & & & & \\
\hline Qual G & Discharged & semi-solid & semi-solld/iguid & solid & solld/semi-solid \\
\hline Puat G & Hall Charge & llquid & liquid & solid & solid/liquid \\
\hline Quat G & JCBGI Full Charge & liquid & liquid & liquid & liquid \\
\hline & & & & & \\
\hline Quat H & Discharred & liquid & liquid & liguid & liquid \\
\hline Quat $\mathrm{H}$ & Half Charge & liquid & liquid & solid & solid/liquid \\
\hline Quat $\mathrm{H}$ & JCBGIFull Charge & liquid & liquid & Ifquid & liquid \\
\hline & & & & & \\
\hline Qual I & Discharged & semi-solid & liquild & semteolid & liquid \\
\hline Quat I & Haff Charge & Hevid & liquid & liquid & liquid \\
\hline Qual 1 & JCBGI Full Charge & liquid & liquid & liquid & liquid/solid \\
\hline & & & & & \\
\hline Quat K & Discharged & cemtedld & liquid & solid & liquid \\
\hline Quat K & Half Charge & liguid & liquid & liquid & liquid \\
\hline Quat K & JCBGI Full Charge & liguid & liquid & Equid & liquid \\
\hline & & & & & \\
\hline Quat L & Discharged & liguid & liquid & solid & solidhiquid \\
\hline Quat L & Half Charge & liquid & liquid & liguid & solid/semi-solld \\
\hline & & & & & \\
\hline Quat M & Half Charge & solid & solid/liquid & solid & solid/liquid \\
\hline Quat N & Discharged & Tiquid & liquid & solid & solid/iquid \\
\hline Quat N & Half Charge & liguid & liquid & liquid & liquid \\
\hline
\end{tabular}

Table 4-15. Aqueous Phase Bromine Concentration (M) for Electrolyte with $33 \%$ Quat $C$ and $67 \%$ MEP at Ambient Temperature

\begin{tabular}{lcccc} 
& Mixture & MEP & Quat B & Quat C \\
\cline { 2 - 5 } Discharged & 0.040 & 0.078 & 0.023 & 0.007 \\
Half Charge & 0.037 & 0.043 & 0.023 & 0.011
\end{tabular}


Table 4-16. Aqueous Bromine Concentration and Evaporation Rates for Experimental Quaternary Complexing Agents

\begin{tabular}{ccc} 
Quat Type & $\begin{array}{c}\text { Aqueous } \mathrm{Br}_{2} \\
\text { (Molelliter) }\end{array}$ & $\begin{array}{c}\mathrm{Br}_{2} \text { Evaporation } \\
\left(\mu \mathrm{g} / \mathrm{cm}^{2}-\mathrm{min}\right)\end{array}$ \\
\hline MEP & 0.024 & 33.0 \\
$\mathrm{JCl}-1$ & 0.0205 & 27.0 \\
Quat B & 0.010 & 17.6 \\
Quat C & 0.0037 & 11.0 \\
Quat G & 0.006 & 13.0
\end{tabular}

\section{Table 4-17. Single-Cell Battery Efficiencies for Experimental Quaternary Complexing Agents (\%)}

\begin{tabular}{cccccc}
\hline Quat Type & $\begin{array}{c}\text { Coulombic } \\
\text { Efficiency }\end{array}$ & $\begin{array}{c}\text { Voltaic } \\
\text { Efficiency }\end{array}$ & $\begin{array}{c}\text { Energy } \\
\text { Efficiency }\end{array}$ & $\begin{array}{c}\text { Transport } \\
\text { Inefficiency }\end{array}$ & $\begin{array}{c}\text { Residual } \\
\text { Inefficiency }\end{array}$ \\
\hline MEP & 87.8 & 83.1 & 73.0 & 7.2 & 5.1 \\
JCl-1 & 84.5 & 76.0 & 64.2 & 8.5 & 7.0 \\
Quat B & 91.5 & 79.9 & 73.1 & 4.9 & 3.6 \\
Quat C & 64.5 & 77.2 & 49.7 & 8.6 & 27.0 \\
Quat G & 65.4 & 75.9 & 49.6 & 8.2 & 26.4 \\
\hline
\end{tabular}

of the cation may influence the stability of the complex; however, no clear-cut topographical features could be identified that would consistently identify a particular quat as a good complexing agent. Likewise, other factors such as energy and nitrogen-bromine bond distance did not result in trends that are useful in identifying specific quats as good complexing agents.

\section{Conclusion}

The most promising candidate at this point is Quat B. Use of Quat B can reduce aqueous phase bromine concentration and bromine evaporation rate in half compared to MIEP with no penalty in energy efficiency. The use of additives may raise voltaic efficiency and is being investigated. Quats A, F, J, K, L, and $M$ are not good candidates for a flow battery based on solids formation, and Quat $E$ is expensive and shows little advantage over MEP. Quat N shows no advantage over MEP with respect to aqueous phase bromine concentration. Quats $C$ and $G$ appear to complex bromine too well. This leaves Quats D, H, and I. Based on their aqueous phase bromine concentrations, Quats $\mathrm{H}$ and $\mathrm{I}$ could be expected to show similar performance to Quats $C$ and $G$. Quat $D$ is expected to show similar performance to Quat B, but Quat D can be made in $80 \%$ overall yield with one reaction rather than $24 \%$ overall yield for two reactions for Quat B. Minicell testing of Quat D is planned for FY94. 


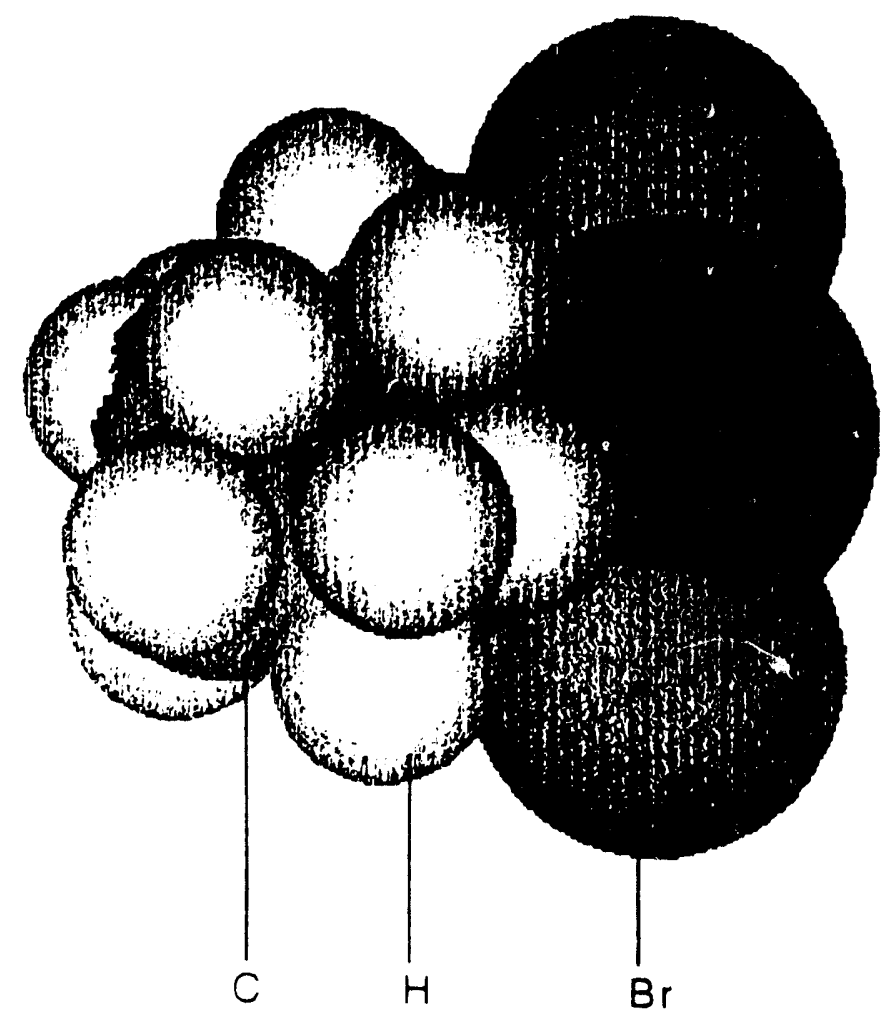

Figure 4-18. One View of the Space-Filling Model of the Complex Between Bromine and N-MethylN-ethylpyrrolidinium Bromide 


\section{Subsystems Engineering - Sodium/Sulfur}

The sodium/sulfur technology is being developed for UES applications primarily because of two advantages: (1) lower life-cycle costs are possible compared to conventional battery options and (2) a relatively low footprint system with excellent mechanical durability can be produced. The potential cost advantage results from projected lower capital costs, less required maintenance, longer service life, and higher energy efficiency. Given the sodium/sulfur technology's excellent energy density, a low system footprint is possible. Because the UES cell and battery designs share many characteristics with their electric-vehicle counterparts, sodium/sulfur battery systems are expected to be easily transportable. Other benefits of this technology include the capability to accommodate multiple applications with a single battery plant and insensitivity to changes in ambient conditions. Based on system analyses performed to date, sodium/sulfur battery systems could be used in many utility battery-storage applications including customer peak shaving, deferral of distribution facilities, area/frequency regulation, spinning reserve, and load leveling. Those requiring frequent use, having siting limitations, and/or needing portability are the most attractive.

The long-term goal of this project is to ensure that a viable sodium/sulfur technology will be available for utility applications such that the markets that will be or are being served by conventional batiery technologies will be enhanced. During FY93, the primary hardware development activity is being performed under a contract with SPI. Additionally, the performance of the SPI technology is being evaluated at SNL.

\section{Technology Development - SPI}

The development of the UES sodium/sulfur technology is following a structured and phased strategy. Successful completion of this long-term effort will yield a system suitable for commercial marketing. The phases specific to this program are as follows: (1) component engineering that permitted the construction of effective and safe battery modules, in turn allowing the odium/sulfur concept to be proved (1985-1990); (2) preliminary battery engineering and design for a single load-leveling application that demonstrated the advantages of the technology (1989-1990); (3) iteration of component engineering to resolve specific utility-battery feasibility issues and identify long-term develop- ment requirements (1991-1993); (4) conceptual battery engineering to provide the basis for entering into relatively expensive battery-system level engineering development (1993-1994); (4) prototype battery engineering to qualify the production processes and final product configuration (1995-1996); and (5) product engineering to scaleup production to commercial levels and satisfy institutional and regulatory requirements (1997-2000). A very important part of the two latter phases involves the comprehensive evaluation and demonstration of complete battery systems at customer locations.

The development of the UES sodium/sulfur technology was continued past the component engineering and preliminary battery engineering steps for two reasons: (1) during the last few years utility systems analyses have shown a true need for battery storage and (2) the benefits of the sodium/sulfur technology in these applications became recognized and substantiated. Based on the status of the technology, a 3-yr, $\$ 3.1 \mathrm{M}$ cost-shared contract was placed in mid-1991 with SPI to complete the activities described in Categories 3 and 4 in the preceding paragraph. In this contract, relevant "':'., applications are being identified, specific cell and ardware developed, preliminary engineering of ttery modules completed, and, finally, a fullutery plant concept designed. An integral part of this work is the formulation of a solid definition of battery requirements, an activity, that with increased involvement of the utility industry, can finally be progressed. The continued need to reduce capital (first) cost and improve service life at the battery level is the focus of the development activity because these two areas remain the key issues impeding commercialization. In addition, attention is being focused on battery configuration and maintenance strategies, effective thermal management systems, battery safety both under intended and accident situations, and ultimately on reclamation.

Of relevance, development of the sodium/sulfur technology for mobile applications at SPI's sister organization SPL, is proceeding along a similar but accelerated path. Those improvements that are applicable to voth types of end-uses (e.g., manufacturing technology, some materials and components, safety features) are incorporated in this effort. Work under this project is focusing solely on the specific needs for UES applications. 


\section{Tasks}

The tasks that are being performed under the Silent Power contract include the following:

1. Assessment of UES Applications

2. UES Cell and Battery Component Development

3. Design and Fabrication of UES Modules

4. Full-Scale Battery Plant Design

The remainder of this section contains a description of the results obtained during FY93.

\section{Status}

\section{Task 1. UES Applications Assessment}

The conceptual design of an integrated $300-\mathrm{kW}$ sodium/sulfur system called NAS- $P_{\text {ac }}$ (shown schematically in Figure 5-1), was developed to minimize the costs associated with the site preparation, transportation and deployment, and maintenance. Recognizing that battery energy storage offers considerable benefit when fully transportable, NAS- $\mathrm{P}_{\mathrm{ac}}$ was designed for compatibility with truck carriers and to fit conveniently within a standard seabox.

Some of the activities supported by this task include SPI's active participation at the UBG meetings in Albuquerque, Valley Forge, and Indianapolis during this time period. In addition to observing firsthand some of the ongoing projects, these meetings have been a convenient forum to have a dialogue with utilities and manufacturers involved in BES, and to obtain updates on existing and planned progress. They have also tended to set the stage for future interests and have allowed manufacturers to gauge the near-term market.

A role scenario (Figure 5-2) for advanced batteries in utility energy storage was developed based on a costeffective solution to rated power duration. With superconductive magnetic energy storage (SMES) and perhaps ultra-capacitors providing the short duration power pulse needs, and with compressed air energy storage (CAES) and pumped hydro satisfying the long-duration application $(5+h r)$, batteries can fill the intermediate niche of the $1 / 2$ to $4 \mathrm{hr}$ discharge duration. Within the battery role, lead-acid batteries offer excellent power capabilities, and manufacturing is well established; but frequent deep cycling can be deleterious to battery life. Conversely, advanced batceries, such as sodium/sulfur, cater to delivering higher energy (longer duration) at medium power levels.
The relative first cost of a sodium/sulfur BES system, ignoring site engineering and assuming a mature market, can be divided between power electronics equipment and batteries, as demonstrated in Figure 5-3. The short duration applications have costs that are dominated by the power electronics, while the longer duration costs are principally from the batteries. A balanced equipment cost occurs for applications rated at $\sim 2 \mathrm{hr}$.

The average discharge period for BES applications (existing, planned, and expressed interest) appears to be around this 2-hr duration. Coupled with the fact that the performance of current state-of-the-art sodium/sulfur batteries tends to fall off at rates of $1 \mathrm{hr}$ and faster, the NAS- $\mathrm{P}_{\mathrm{ac}}$ unit design was rated for $2 \mathrm{hr}$ of continuous full-power operation. This rating only specifies the limits of capability; it does not define how the system might be used in an actual application (e.g., it could load-follow up to its rated capacity, or it could deliver half of its power over a 4-hr duration).

Because demand-side management may be the strongest initial incentive for the U.S. market, a benefits analysis was performed for the NAS- $P_{a c}$ system against a demand charge of $\$ 12 / \mathrm{kW}$ per month (i.e., what a utility might charge its larger customers). The assumptions behind the analysis include a 30 -yr equipment life, power conditioning costs of $\$ 300 / \mathrm{kW}$, and a NAS-P $\mathrm{P}_{\mathrm{ac}}$ cost of $\$ 147 / \mathrm{kWh}$ with maintenance costs of $\$ 7.14 / \mathrm{kWh}$ associated with replacement of battery packs at their end of life. These figures are considered to be mature component costs to the user. Figure 5-4 presents the benefitto-cost $(B / C)$ ratio for a range of system designs (having excess capacity) and for specific cell service life (characterized by the stated Weibull parameters). The design point selected for the NAS- $\mathrm{P}_{\mathrm{ac}}$ unit, employing UES cells, achieves a benefit to cost ratio of 2 . A cell population with a higher characteristic life ( 6000 cycles) but a lower Weibull shape factor (1.4), however, would not offer as good B/C because of more frequent battery replacements. In that case, there is an advantage to installing more initial capacity. The importance of this study is to demonstrate an excellent B/C for future investment and a life-cycle-cost sensitivity of the system to the achievement of certain cell reliability figures. The latter was projected as a basis for characterizing the 50-Wh UES cell under development in this contract. In fact, achievement of this statistical result produces a NAS-P $P_{a c}$ battery pack with a 5-yr, no-maintenance battery. 


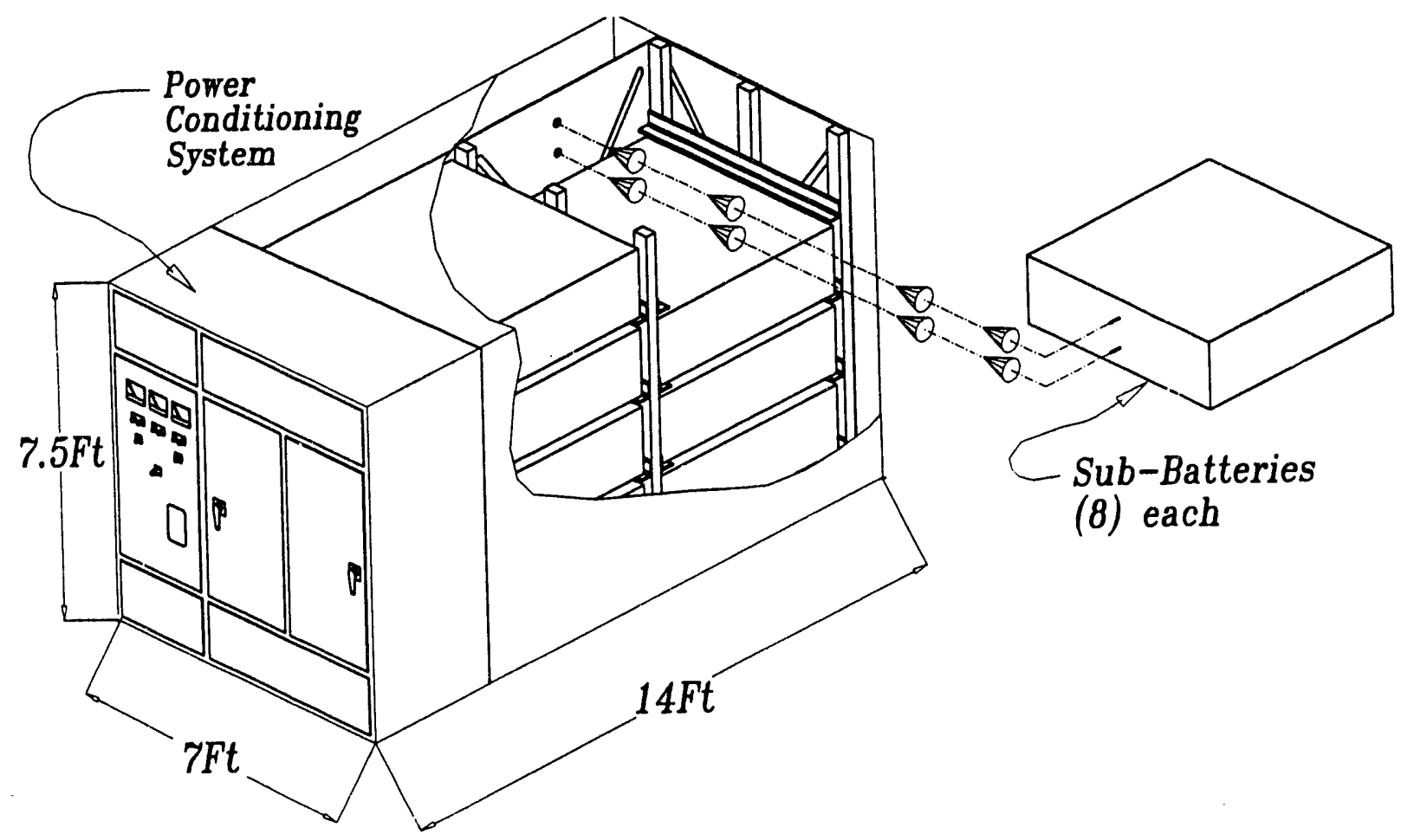

Figure 5-1. 300-kW NAS-P $P_{a c}$ Transportable System

RATEd POWER DURATION (hOURS):
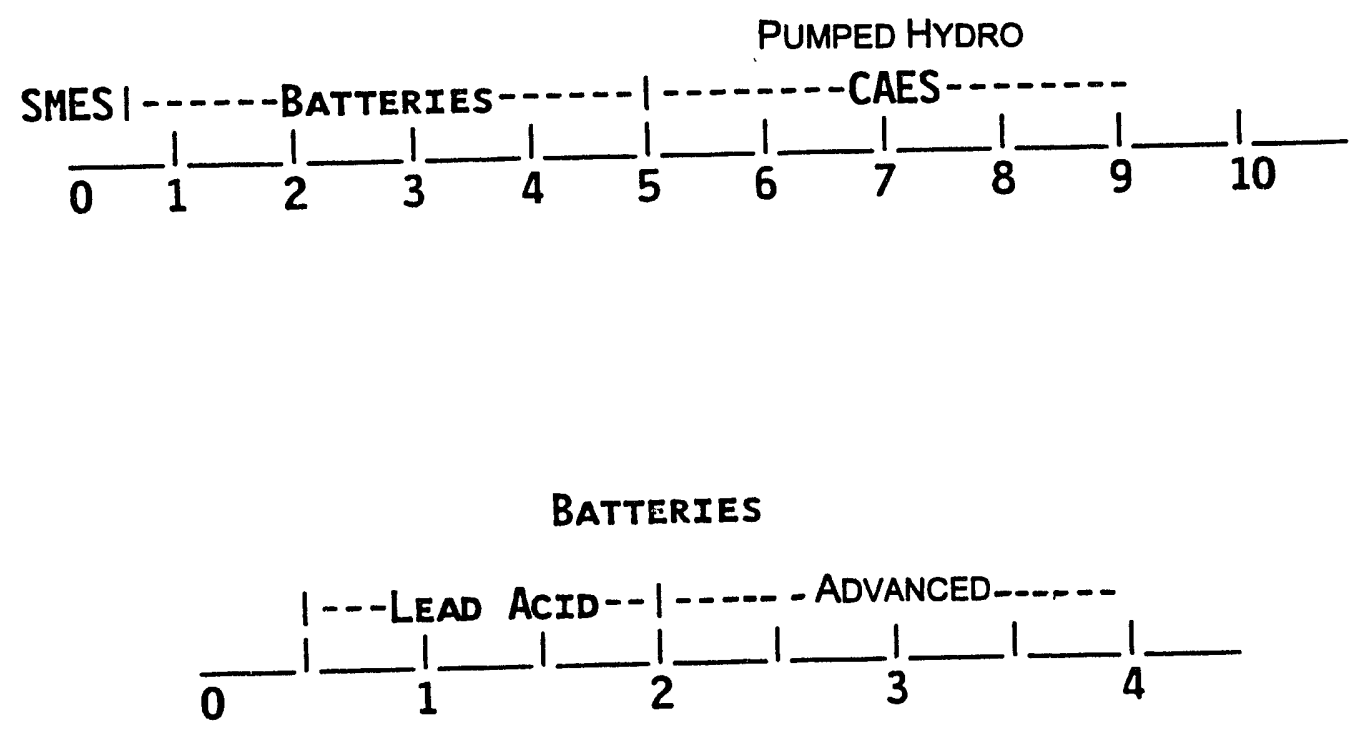

Figure 5-2. Role of $A$ tvanced Batteries in Utility Energy Storage 
중

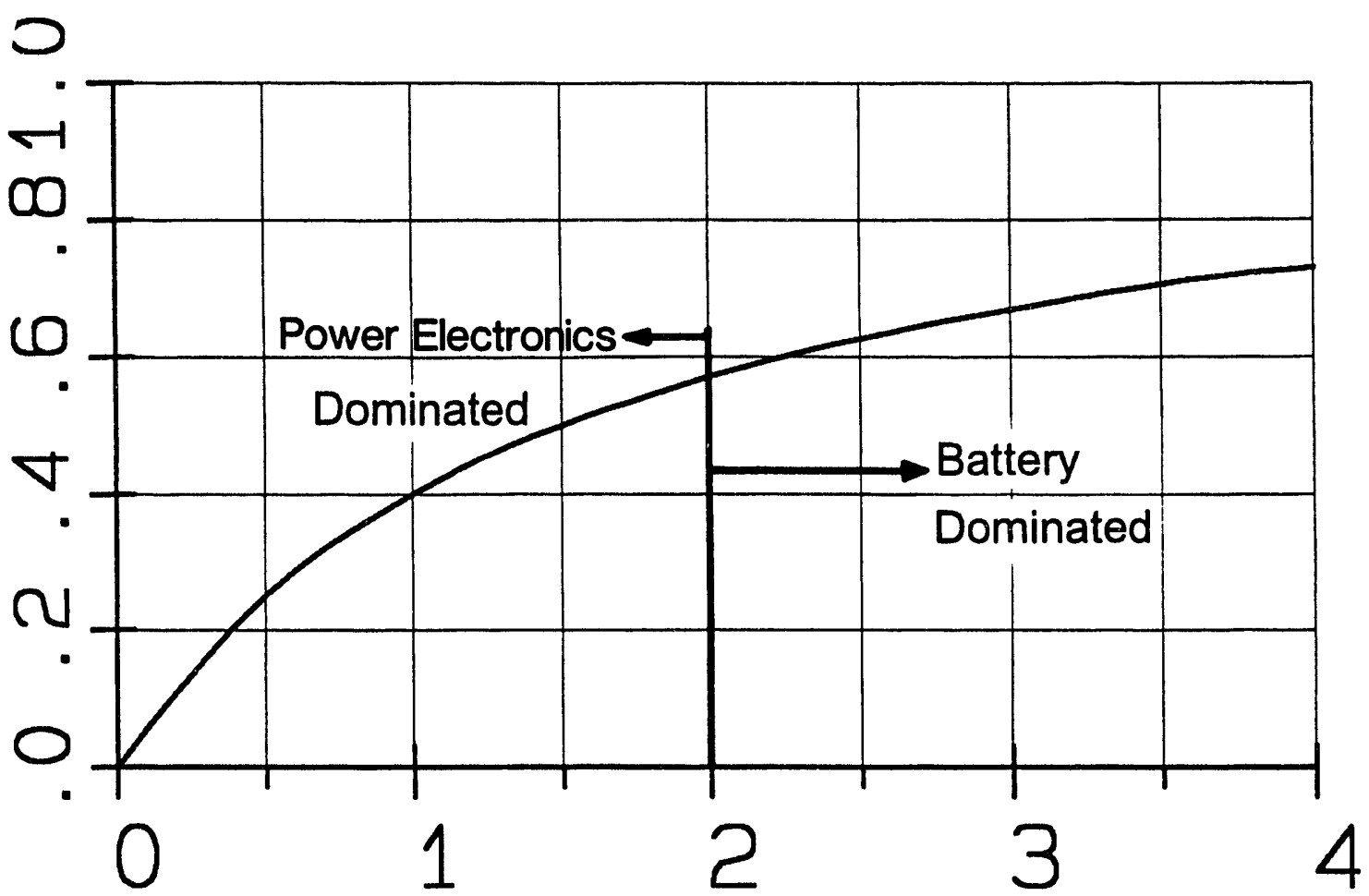

Power Duration (hr)

Figure 5-3. Battery Energy Storage Relative Capital Costs

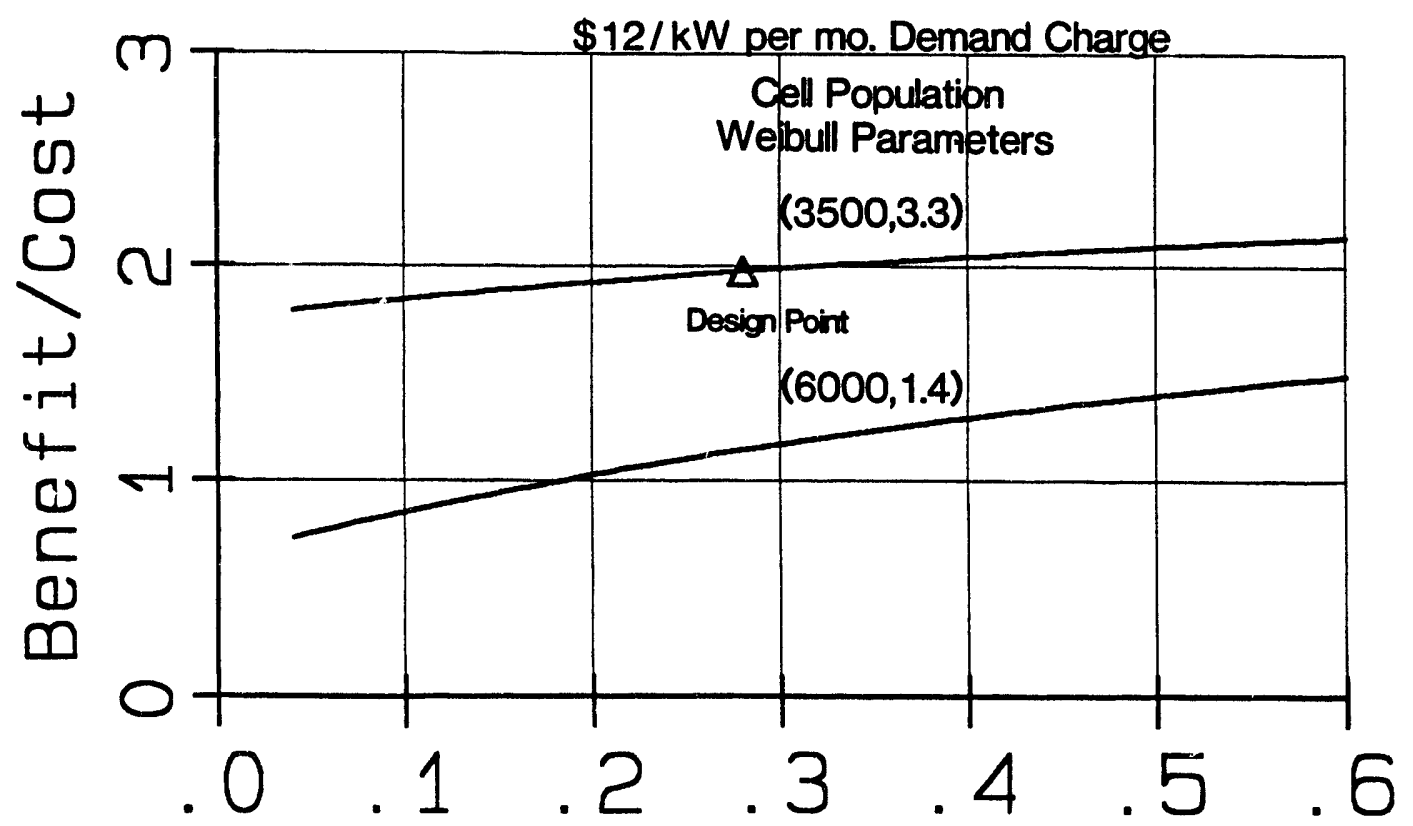

Excess Capacity (Fraction of rated)

Figure 5-4. NAS-P ${ }_{a c}$ Battery System Demand Charge Savings 


\section{Task 2. UES Cell \& Battery Component Development}

The majority of the hardware development activities in this contract are performed within this task. Its primary objective is the development and qualification of a sodium/sulfur cell and associated battery hardware for the selected UES applications. In past years, considerable effor was expended on Sub-Task 2.1 to allow these development activities to be efficiently progressed. During FY93, work focused on hardware development.

\section{Task 2.1 UES Battery Design Study}

The design of an integrated battery system is based on the use of replaceable sodium/sulfur batteries with a 480-VAC, 3-phase, 300-kW line commutated converter. In this design, the maximum battery voltage is limited to $500 \mathrm{VDC}$. However, restrictions relative to the use of this converter topology have not been made; rather, a line commutated version was deemed to offer the lowest cost and to require the lowest DC voltage (a distinct benefit for sodium/sulfur batteries). The battery for this converter is composed of two parallel strings of four series (eight total) sub-batteries. The NAS- $P_{a c}$ battery is rated for 2-hr continuous discharge at full power. The design life of the battery is 1500 cycles to complete discharge. No maintenance is planned up to the point of sub-battery replacement. Thermal management has been designed to be passive and intrinsic to the battery module design. The thermal enclosure utilizes a standard, nonevacuated, thermal insulation to minimize cost and maintenance. Heat loss is expected to be approximately $12 \mathrm{~W} / \mathrm{kWh}$, which amounts to a $6-8 \%$ impact on system efficiency for the majority of diurnal applicitions. This could be halved with an evacuated enclosure, albeit a more expensive option, for applications that require longer stand times.

The battery has been designed to fit behind the 7.5-ft height and 7-ft width dimensions of the existing converter. As shown in Figure 5-1, the total depth of the NAS-P $P_{\text {ac }}$ unit is $14 \mathrm{ft}$, which allows modules to be arranged in tandem 4 series tiigh. The overall package is completely transportable by truck or seabox.

\section{Task 2.2.1 Cell Component Development}

The cell configuration selected for this program is a c/S cell, designed around SPL's XPB electrolyte. A c/S cell was selected because of its potential for long service life, a projection based on demonstrated results achieved at SPL using a similar design. The metal-ceramic seals were designed to use TCB techniques that have been used routinely by SPL for many years. Having the cathode contained inside the electrolyte permits the elimination of the expensive and often ineffective coated corrosion resistant container.

During the past year, the cell development effort has addressed four major cell components: (1) the sodium seal, (2) the sulfur seal, (3) the sodium electrode, and (4) the sulfur electrode and current collector.

\section{Sodium Seal Development}

The c/S TCB seals, although similar in design, are three times larger in this cell than the largest seal in a PB cell. The 10-Ah PB cell is the current cell being produced by Silent Power in its automated pilot-plant production facility for electric vehicle batteries. The XPB cell is an extended version of the PB cell having a capacity of $30 \mathrm{Ah}$. Because of the large size of the seals in the $\mathrm{c} / \mathrm{S}$ cell, significant development effort has been required and is continuing. Beta-alumina durability during freeze/thaw $(F / T)$ has long been a concern with $\mathrm{c} / \mathrm{S}$ cell designs. Work early in the program, using simple sulfur electrodes sealed inside electrolytes, yielded encouraging results relative to freeze/thaw capability. With the correct current collector diameter, these assemblies could be thermally cycled without electrolyte fracture. However, in order to fully access the F/T durability issue, thermal cycling needs to be performed on a population of fully functional cells. Much of the cell building activity that took place this year was aimed at developing a cell that could be thermally cycled.

At the end of last year, functional cells were routinely being fabricated, but there was still a problem in obtaining and maintaining a leak-tight sodium seal. A decision was made to chrome plate the metal components, a change that offers two potential benefits:

1. The safety tube/seal member could be made thinner, thus reducing the thermal stresses generated in the seal during thermal cycling and

2. From an environmental perspective, using less chrome is preferred.

Several early cells were fabricated with chromeplated seals; however, none could be fabricated that were hermetic. Careful evaluation of the chrome plate and TCB seals made with chrome-plated components revealed that microcracks within the chromium layer itself were allowing leakage under the thermocompression bonds. Several different plating vendors and types of chrome were tried, but leak rates were not reduced.

However, by adopting a thicker chromide-coated safety tube component, hermetic sodium seals could be 
routinely formed. The baseline cell design currently uses a chromide-coated steel safety tube joined to the alpha-alumina ring using an aluminum interlayer, as shown in Figure 5-5. Once incorporated into the build routine, the use of chromide-coated safety tubes yielded good results. Typically, there was no detectable leakage in the seal using the coated safety tubes. This modification allowed cells to be built that have achieved in excess of 750 electrical cycles. To date, 72 cells have been assembled since the chromide coating was incorporated.

During the initial heat-up to operating temperature, approximately $10-20 \%$ of the cells failed. Further, with additional thermal cycling, no cell survived more than three thermal cycles from room temperature to operating temperature. As more cells were assembled and tested, a pattern began to emerge. The cells always failed on heat-up, and whether it was the initial heat up or a subsequent heat-up, failure always became apparent at $290^{\circ} \mathrm{C} \pm 10^{\circ} \mathrm{C}$ and was manifested as a short circuit. Further, the electrolyte always remained intact. Upon examination of the failed cells, it appeared that in each case the initiation of cell failure was in the sodium seal. This allowed sodium to leak out of the cell into the well formed by a cuff on the safety tube and to bridge across to the cathode sealing ring, thus shorting the cell. In all cases, the failure of the seal had occurred at the interface between the alpha-alumina header and the aluminum interlayer.

Several possible contributors to, or causes of, the seal failures were hypothesized:

1. The stress induced by the mismatch in thermal expansion coefficients between the steel and the alumina is sufficiently high to cause mechanical failure of the seal;

2. Liquid metal embrittlement of aluminum by soöum;

3. Metallurgical changes (undefined) occurring in the heat-treatable aluminum alloy used for the bonding interlayer that adversely affect its mechanical properties; and

4. Heating the cells in a temperature gradient such that sodium melts at the top of the cell first and has no free space into which it can expand pushes the seal apart.

To test the first three hypotheses, an experimental matrix was devised. The matrix consisted of the following variables:

1. The final thickness of the aluminum interlayer after bonding,

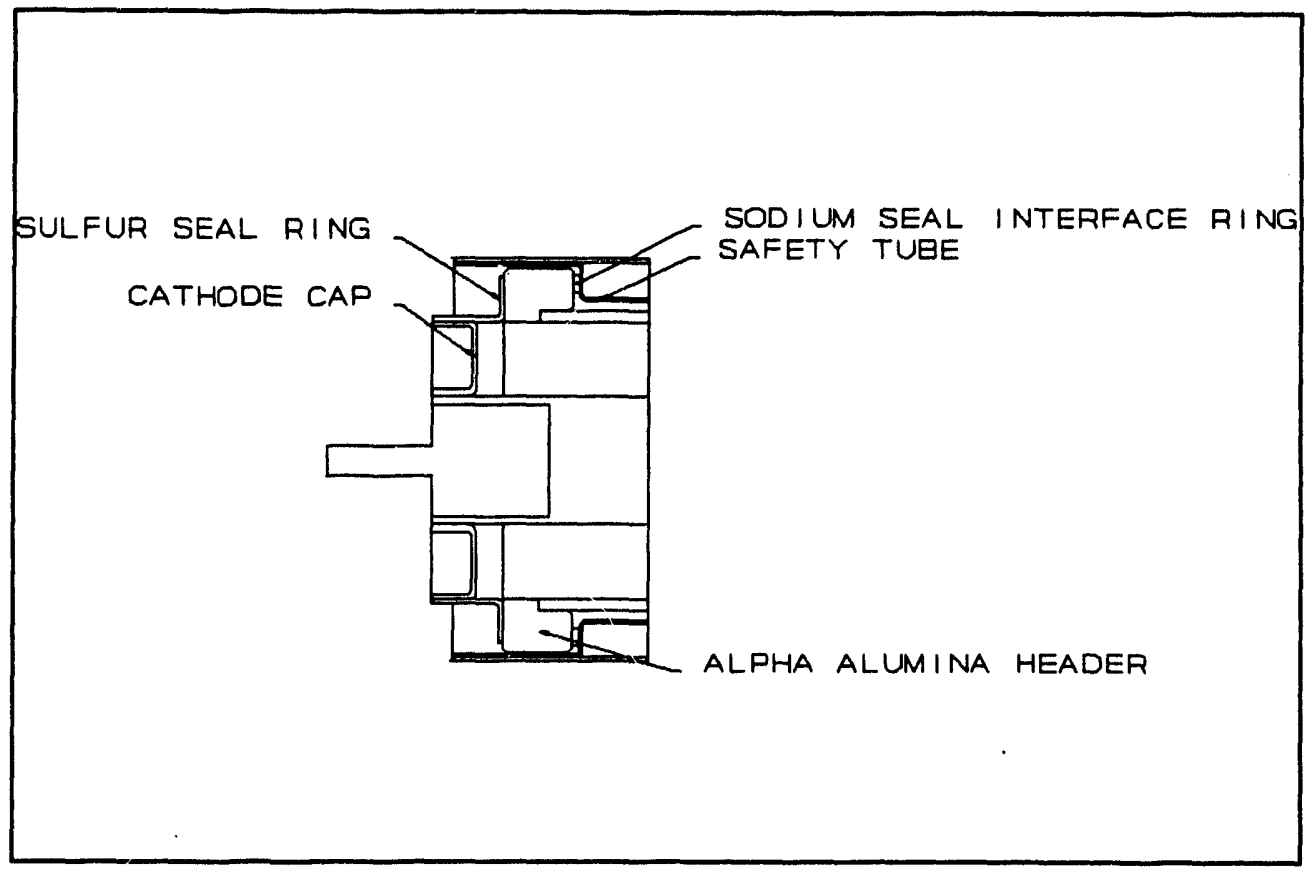

Figure 5-5. c/S Cell Top Section Showing Baseline TCB Seal Design 
2. The alloy of aluminum for the interlayer, heattreatable vs. non-heat-treatable,

3. The use of a Kovar backing ring,

4. The alloy of the safety tube as a ternary variable (1020 mild steel, Kovar, or 410 stainless steel), and

5. The presence of sodium or lack thereof in the sealed assembly.

The rationale for this matrix of experiments is as follows. By doubling the thickness of the aluminum seal component, the shear stress in the aluminum is effectively halved. Because the baseline alloy is heat treatable and therefore subject to temperature and aging effects, an alternate aluminum alloy was selected as part of the matrix. By using a backing ring, as shown in Figure 5-6, the higher expansion portion of the seal, the mild steel, is now constrainec' between two members with lower, closely matched expansions, thus reducing the stress applied at the alumina/aluminum interface. This is a potentially undesirable effect. Therefore, a non-neat-treatable aluminum alloy with a similar eutectic temperature and bonding temperature was chosen as a replacement. Using an alloy with a lower thermal expansion coefficient than mild sisel will result in lower stresses in the bonded seal. During early seal trials, which were conducted to evaluate the feasibility of TCB seals with the diameter required for $\mathrm{c} / \mathrm{S}$ cells, several TCB seals with planar elements were thermally cycled with no sodium and with no loss of hermeticity.

To test the durability of the seal, the cells (or partial cell assemblies in some cases) were heated to the cell operating temperature of $330^{\circ} \mathrm{C}$ at standard heating rates, subjected to three electrical cycles (in the cases of incomplete cells, thermal cycles between $330^{\circ} \mathrm{C}$ and $375^{\circ} \mathrm{C}$ were performed), and cooled to room temperature at normal cooling rates. This regime was repeated until failure of the cell or assembly occurred.

The results of the testing are shown in Table 5-1. Thus far, the only dramatic improvement in seal durability has been obtained for the partial cell assemblies in which sodium was removed from the seal environment.

To evaluate the possible influence of non-uniform melting of sodium in the cells, two cells were assembled using the baseline configuration and were well insulated over the top $2 / 3$ of their outer containers to insure that their lower ends were at a higher temperature during heat-up than their tops. Thermocouples attached to both ends of the cells confirmed that this was the case. During testing, both of these cells had failed by the second F/T cycle.

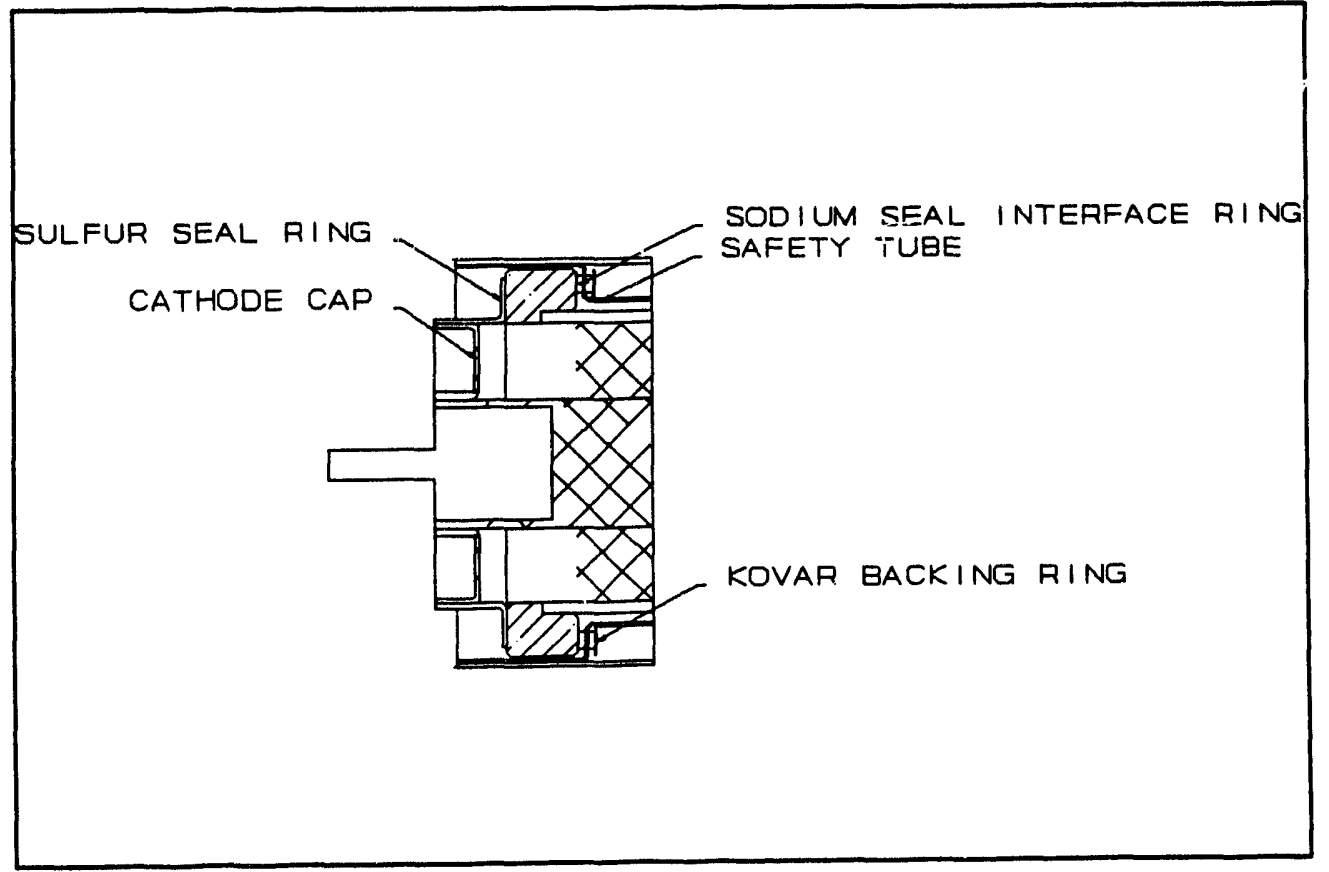

Figure 5-6. Cross Section of Seal Variant Using Kovar Backing Ring 
Table 5-1. Freeze/Thaw Results on Sodium Seals

\begin{tabular}{ccccccc} 
Trial \# & $\begin{array}{c}\text { Aluminum } \\
\text { Thickness } \\
\text { (in) }\end{array}$ & $\begin{array}{c}\text { Aluminum } \\
\text { Alloy }\end{array}$ & $\begin{array}{c}\text { Sodium } \\
\text { Presence }\end{array}$ & S.T. Alloy & Backing Ring & $\begin{array}{c}\text { Cycles } \\
\text { Survived }\end{array}$ \\
\hline 1,2 & 0.010 & $6061-T 6$ & Yes & 1020 & No & 3 \\
3 & 0.020 & $6061-T 6$ & Yes & 1020 & No & 1 \\
4 & 0.020 & $6061-T 6$ & Yes & 1020 & No & 3 \\
5 & 0.010 & $5086-\mathrm{H} 111$ & Yes & 1020 & No & $-(+)$ \\
6,7 & 0.010 & $6061-\mathrm{T} 6$ & No & 1020 & No & $10\left(^{*}\right)$ \\
8 & 0.010 & $6061-\mathrm{T} 6$ & Yes & 1020 & Yes & 2
\end{tabular}

(+) Failed during initial heat-up

(*) Removed from test after 10 cycles, seals still intact.

Looking for plausible explanations, an investigation was conducted into the possibility of liquid metal embrittlement of aluminum in sodium. It has been shown that under the right conditions liquid sodium does embrittle aluminum (Rostoker, McCaughery, Markus, Reinhold, Embrittlement by Liquid Metals; Reinhold, New York, 1960). To eliminate aluminum embrittlement as the cause of seal failures, an effort has begun to build cells employing brazed seals between the outside diameter of the alpha-alumina collar, as shown in Figure 5-7. Cusil ABA was selected as the braze alloy because of its excellent wetting properties to both metal and ceramic. This design allows the seal to be in compression at cell operating temperature. If the seal is attacked by sodium, a compressive stress state is a desirable feature because there will be no mechanism to propagate cracks through the seal. However, the seal components need to be designed in such a manner that stresses transmitted to the beta-alumina are minimized.

Brazed sodium seals are probably not a viable option for commercial production because of high cost and the long-term durability of the brazed joints in liquid sodium is also suspect. However, cells with brazed seals that can survive thermal cycling will allow the more critical aspects of the central sulfur cell configuration to be assessed; that is, cell safety and electrolyte F/T durability.

\section{Sulfur Seal Development}

Concurrent with the sodium seal development, a similar effort was initiated for the sulfur seal. The alloy initially chosen for fabricating the sulfur sealing ring was 6061-T6 aluminum. This alloy was selected for its machinability and weldability. During the course of early cell builds, cracking of the sealing ring was a problem. The 6061 aluminum is susceptible to hot cracking when the metal is constrained while cooled during welding. For this reason, 5086-H111 aluminum alloy was selected as a replacement alloy for manufacturing the sulfur seal rings. This alloy is readily weldable and does not suffer from hot cracking. Cells were assembled using this alloy, and the cracking problem ceased.

At this point, 5086-H111 cathode caps were then introduced into the design because of prublems encountered in achieving consistently leak tight weld using 6061-T6. The difficulty in welding was also related to the hot cracking behavior of the 6061 alloy. Once this change was made, uniform hermetic welds were achieved.

\section{Sodium Electrode Deveiopment}

Work was initiated during this year to develop a more reliable, less time-consuming method of sodium filling the cells. As shown in Figure 5-8, this new method involves filling the cell through a small tube in 


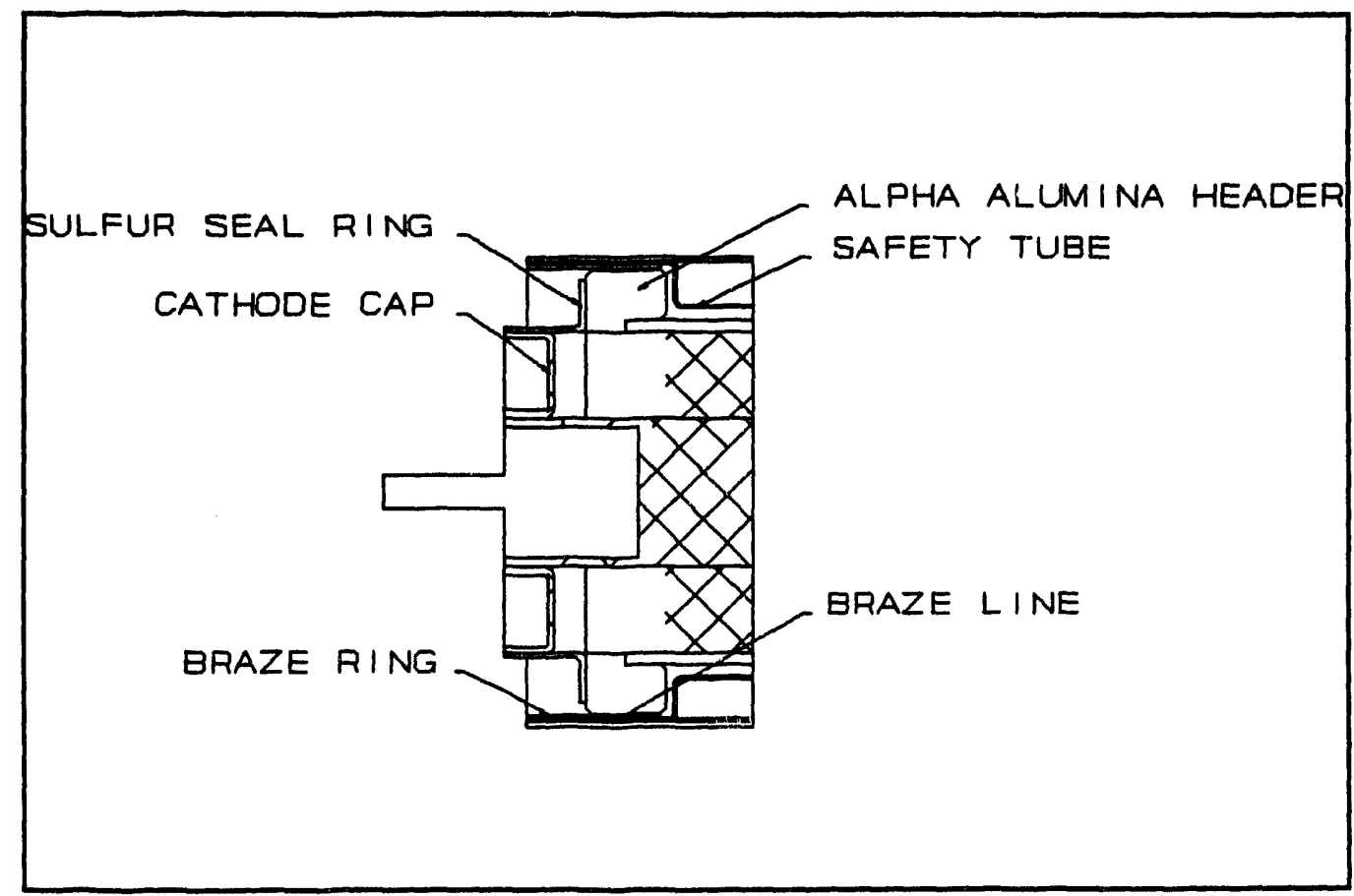

Figure 5-7. Cross Section of Brazed Seal Assembly

the base of the one-piece outer container. The tube is sealed using an o-ring so that, after filling, the tube can be withdrawn and a tapered plug resistance welded into the hole to seal the cell. This method eliminates several potential sources of sodium contamination during the filling operation. The method has been tested and is ready for cell build trials.

\section{Sulfur Electrode and Current Collector Development}

The sulfur electrodes used in cells fabricated as part of this contract have been of a dual mat type. The basic design of the electrode structure has remained the same with two minor changes. The first was a reduction in the mass of sulfur to eliminate the possibility of breaching the sulfur seal in the event of a cell short circuit. The second was a reduction in the length of the electrode to eliminate some problems with current focusing and resultant electrolyte failure near the alpha- to beta-alumina glass seal. Both changes were fully effective in resolving the problems noted.

Three different flame-sprayed coatings on an aluminum substrate have been utilized for the central current collector. The result of these various current collector/ electrode combinations is discussed in Task 2.2.3, Cell Design Verification.

\section{Task 2.2.2 Battery Component Development}

Battery components being developed under this contract include the thermal management system, cell interconnects, busplates, and electrical isolation design. In addition, some fundamental studies in search of a viable failure device are being performed.

To verify the preferred passive thermal management design (using a $\mathrm{LiCl}-\mathrm{KCl}$ eutectic salt as a latent heat storage medium), a small battery composed of ten 3 cell series strings (10 Ah PB cells) was assembled. This module contained 11 thermal energy storage (TES) capsules in a tightly bundled array as shown in Figure 5-9. Two experiments were run consecutively to determine a preferred assembly procedure. The first module used mica sheet separators $(0.2 \mathrm{~mm}$ thick) as isolation between cells and TES capsules. Tight packing was maintained throughout testing by constraining the assembly from the outside, mimicking the assembly plan for the large $75-\mathrm{kWh}$ NAS- $\mathrm{P}_{\mathrm{ac}}$ sub-battery packs. The second battery was assembled by cementing cells and TES capsules together using a ceramic-based cement, after first coating all components to assure isolation. While the thermal performance of the first assembly proved to be perfectly acceptable, the cemented array offered better thermal conductance between cells and TES capsules and, even more impor- 


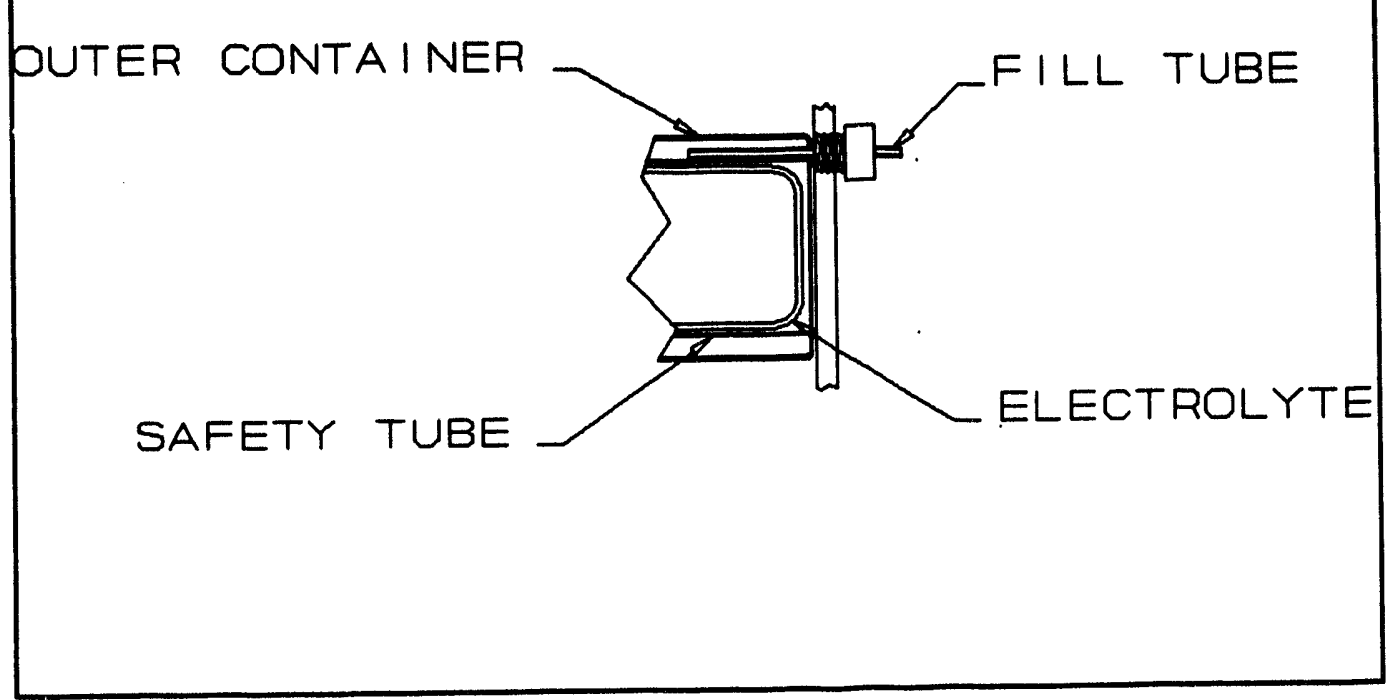

Figure 5-8. Alternate Sodium Filling Design

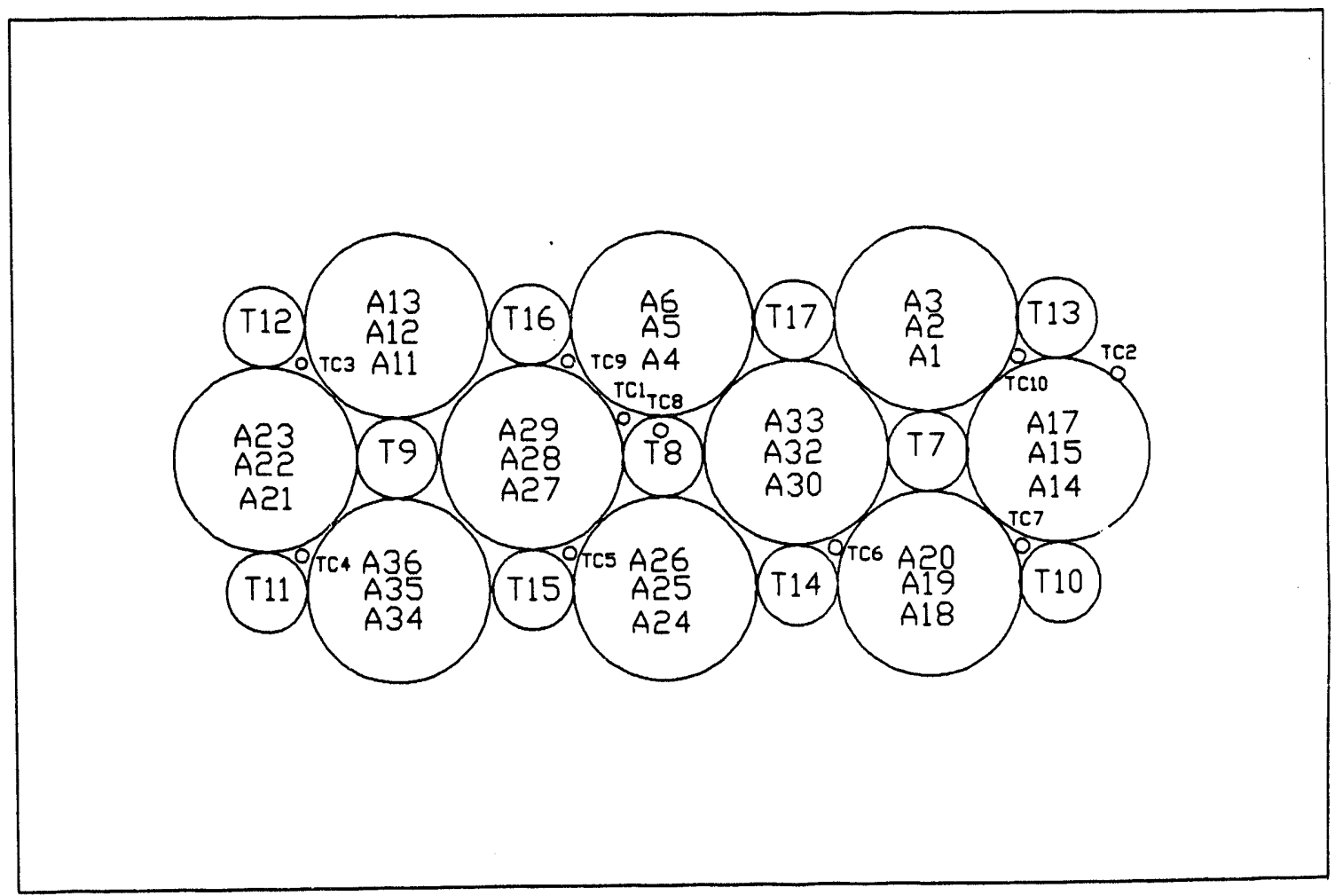

Figure 5-9. 30-Cell TES Experiment Plan View. ("The "A" notation denotes 3-cell strings and the "T" denotes the TES capsules.) 
tantly, provided protection against potential corrosion by the hot salt, should a leak develop in a TES container. After carefully reviewing the performance data, the salt leak trials, and the assembly plan for each of these design approaches, a recommendation was made to proceed with the cemented assembly. This assembly technique will be utilized for the 13-kWh prototype battery to be delivered to SNL. The subsequent information in this section demonstrates the performance of the module that used this preferred assembly technique.

Figures 5-10 to 5-12 show constant power cycles of $240-W, 300-W$, and 400-W discharges, respectively, followed in each case by a $150-\mathrm{W}$ charge. These conditions correspond to operation of the NAS-P $\mathrm{P}_{\mathrm{ac}}$ battery system at the beginning-of-life (BOL), mid-life and endof-life (EOL) conditions. In the latter two cases, 20\% and $38 \%$ of the strings have failed in a bank, respectively. The maximum rated temperature excursion is $330-375^{\circ} \mathrm{C}$ during normal operation of the UES battery. This testing was intended to follow the procedures and practices established for the large NAS- $\mathrm{P}_{\mathrm{ac}}$ battery pack as closely as possible. At the lower power, however, the starting temperature was raised by approximately $10^{\circ} \mathrm{C}$, to achieve a sufficient amount of salt melting to verify performance. The utilization of latent-heat energy storage was intended primarily to handle the
EOL conditions. The data presented in the figures are from a thermocouple attached to the bottom cell, designated A27 in Figure 5-9. At all power loadings, it was observed by the change in thermal response that the salt began to melt around $354^{\circ} \mathrm{C}$ and absorbed heat from the cell during the remainder of the discharge portion of the cycle. The cell temperature continued to increase through the melting transition at a rate dependent upon the power loading. As shown in Figure 5-13, analysis of the cycle data showed that the maximum cell temperature attained was reduced by approximately $15^{\circ} \mathrm{C}$ with the salt vs no salt. During the charge period, the heat flow is reversed from the salt into the cell matrix effectively extending the time at temperature. Because the enclosure design utilizes a conventional insulation system to reduce cost and enable component recycling, the extended time at temperature is useful in offsetting heat loss that would otherwise have to be made up by internal heaters connected to the utility grid.

Careful analysis of the data has accounted for $85 \%$ of the expected $2610 \mathrm{~J}$ latent heat store of the salt associated with a cell. It should be noted that the salt capsules used in this test were approximately $20 \%$ shorter than the 3-cell string length, and, furthermore, they were raised from the bottom bankplate by an electrical standoff. This provides an explanation for the $85 \%$ account-

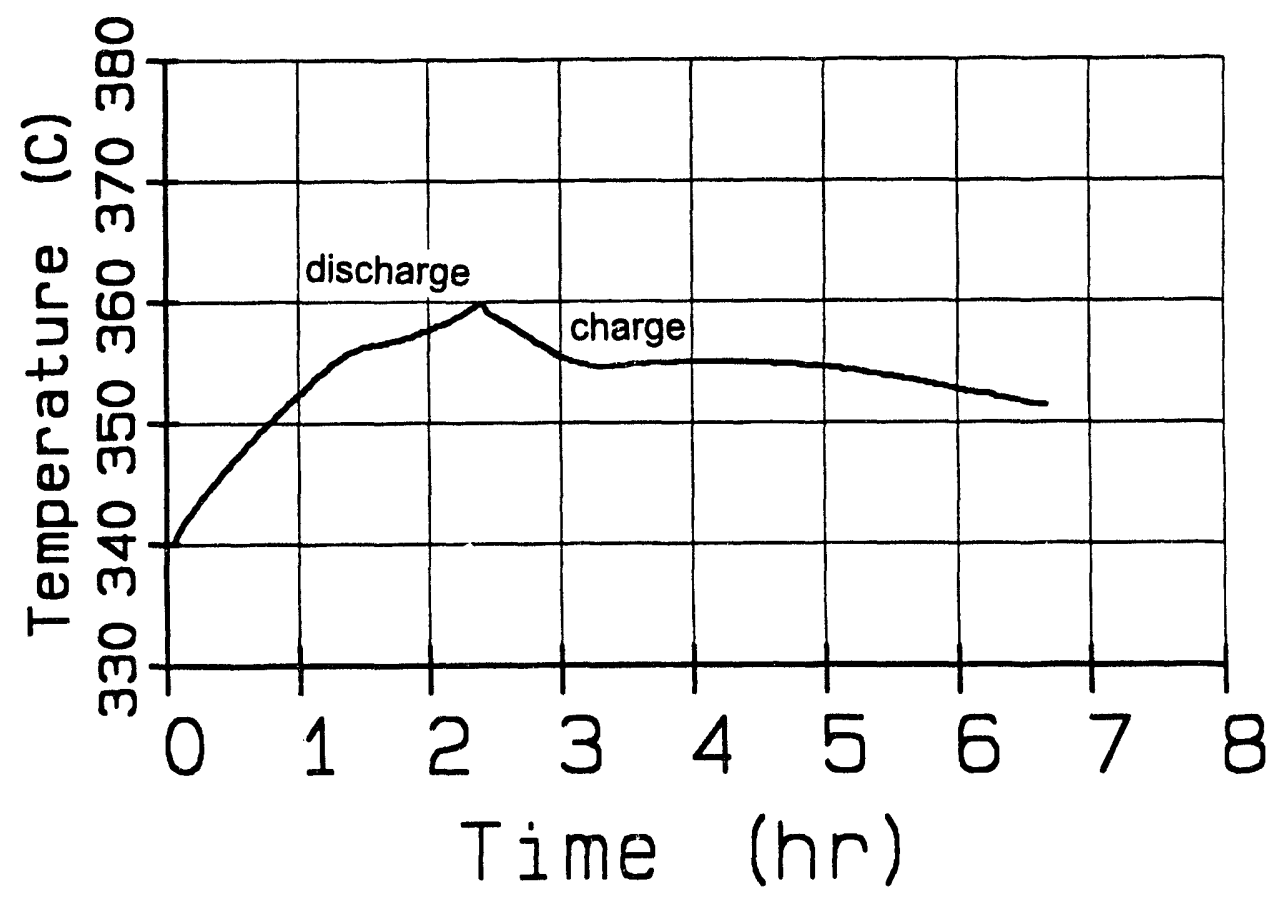

Figure 5-10. 30-Cell TES Experiment 240-W Discharge /150-W Charge (Ceramic Cement) 


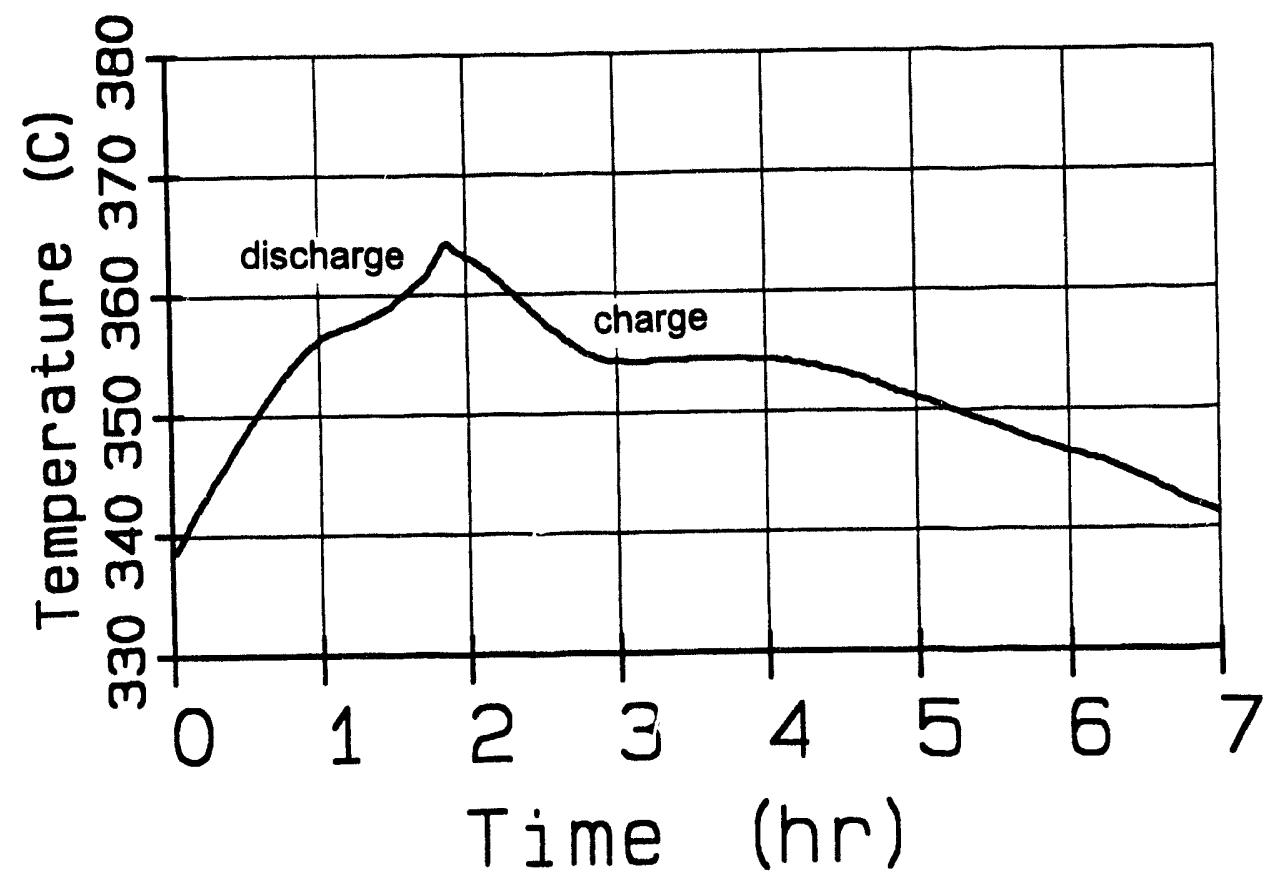

Figure 5-11. 30-Cell TES Experiment 300-W Discharge /150-W Charge (Cemented)

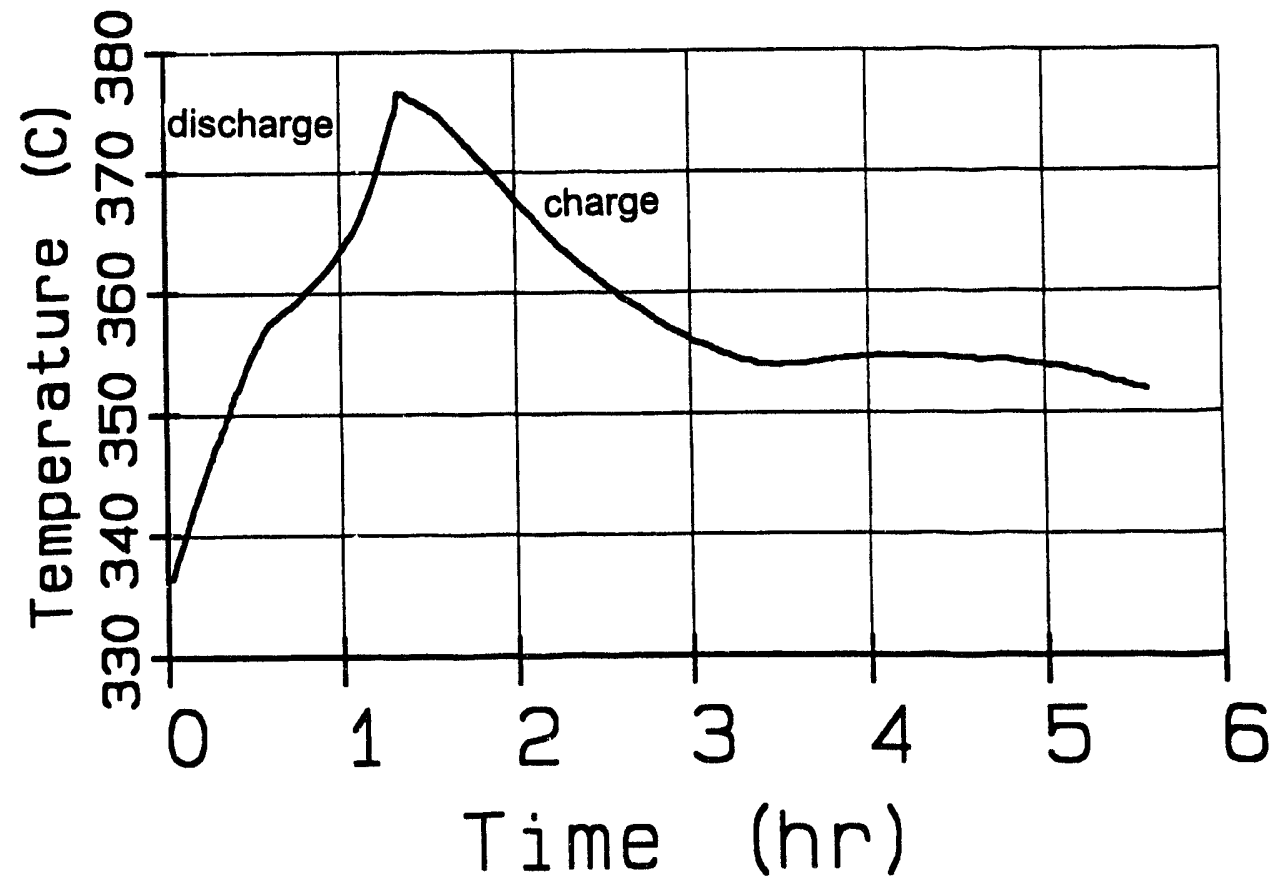

Figure 5-12. 30-Cell TES Experiment 400-W Discharge /150-W Charge (Cemented) 


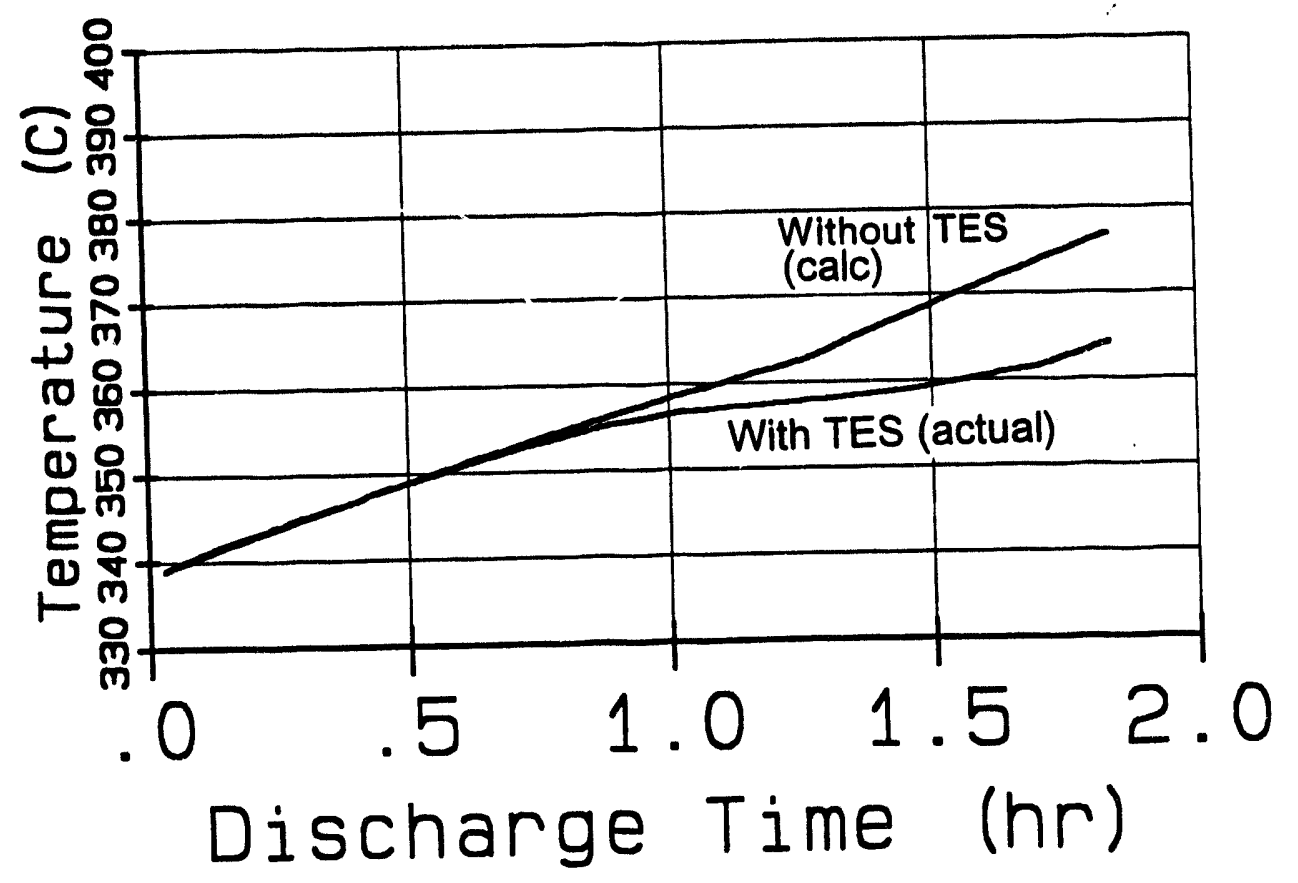

Figure 5-13. 30-Cell TES Experiment 300-W Discharge

ing because the subject thermocouple monitors the bottom cell (A27) of the string. As a final note, the amount of TES material in this experiment wis only $60 \%$ of that planned for the large NAS- $\mathrm{P}_{\mathrm{ac}}$ battery (based on the PB to UES $\mathrm{c} / \mathrm{S}$ cell capacity ratio).

In a separate series of tests, TES capsules were subjected to an extreme temperature anomaly sufficient to melt the aluminum containment for the salt. This test was to assess the worst possible case in an accident or other event in which a number of cells may be shorted resulting in a thermal excursion above the melting point of aluminum. The thin steel jacket surrounding the capsule then was required to contuin fully the molten aluminum. The salt, on the other hand, was known to aggressively corrode ferrous alloys at elevated temperatures. With the ceramic cement aprlied to the exterior of the mild steel jacket, the jacket remained intact and retained all of the molten aluminum in the bottom of the jacket. This was not the casc for the trial with a bare steel jacket, in which the jacket was essentially corroded away. This testing clearly demonstrates the benefit of the cemented array in providing an extra margin of safety to a prototype battery design that has been complicated by the use of PB strings with TES capsules.

Several trial assemblies have verified the ability of the cemented array to withstand freeze/thaw $(F / T)$ cycling. The final check was done with the 30-cell experiment described above. In addition to $F / T$, one of the 10 strings was purposely shorted to determine what effect, if any, the cemented assembly would have on the observed temperature excursion. The string with cells designated $\mathrm{A} 27-\mathrm{A} 29$, having separate terminations, was shorted $(60 \mathrm{~A})$ over a sufficient period of tirne to cause cell reversal and loss of voltage for that string. The maximum temperature rise was $70^{\circ} \mathrm{C}$, occurring at the failed string. Some $10 \mathrm{~min}$ subsequent to this, surrounding cells experienced a $25^{\circ} \mathrm{C}$ temperature rise, indicative of thermal exchange with the failed string. The conclusion was that nothing serious happened as a result of completely shorting a string and that, if anything, the improved thermal contact of the cemented assembly appears to have limited the temperature rise.

All of the testing that has been discussed here reffects the efforts taken to ensure a safe and good performing deliverable battery, a battery that can be used as a showpiece for the sodium/sulfur advanced UES battery technology.

\section{Task 2.2.3 Cell Design Verification}

A total of 87 cell assemblies has been built since the start of the contract. Of these, 13 were partial cell assemblies, and 10 were used in the first UES module 
experiment. Of the remaining 64 cell assemblies, 40 cells were successfully fabricated and subjected to electrical and thermal cycling. Eight UES cells are presently on test. A testing summary for the cells remaining on test is shown in Table 5-2. The last column of this table, "Unrecoverable," refers to the percentage of the theoretical capacity that cannot be recovered during charging.

\section{Testing Conditions}

All of the cells tested were instrumented with voltage sense leads and a single K-type thermocouple. Heating was achieved at a rate of $15^{\circ} \mathrm{C} / \mathrm{hr}$ to a temperature of $330^{\circ} \mathrm{C}$. Following application of a resistive load, the discharge current was increased to $2 \mathrm{~A}$ until approximately $70 \%$ of the theoretical capacity was removed. Charge was initiated at a current level of 1-2 A until a voltage of $2.3 \mathrm{~V}$ was reached. Several break-in cycles were performed with discharge currents of 5-7 A until $70 \%$ of theoretical capacity was removed. Charge currents were typically 4-5 A during break-in cycles.

\section{Early Electrical Performance}

The initial projected $\mathrm{BOL}$ electrical performance of the UES cell is shown in Table 5-3. The actual performance of early UES cells could not be accurately determined because many cells failed before testing started or after completing only a few electrical cycles. The "learning" curve and assembly problems are partially responsible for the initially high failure rate observed with this cell. However, a few cells did survive testing long enough for early performance data to be taken. Cells 004 and 009 were the best performing cells built early in this program.

In terms of electrical behavior, both cells showed stable resistance values less than 13 mohms. While the usable capacity for both cells was over $27 \mathrm{Ah}$ for both cells, a specific energy of $150 \mathrm{Wh} / \mathrm{kg}$ was less than the predicted value, primarily because the cell weight was higher than projected. Unfortunately, cell 004 failed during the third F/T cycle after completing only 32 electrical cycles. Cell 009 failed near the top of charge, after completing one $\mathrm{F} / \mathrm{T}$ and 25 electrical cycles.

\section{Table 5-2. UES Central Sulfur Cell Testing Summary}

\begin{tabular}{|c|c|c|c|c|c|c|c|}
\hline \multirow[b]{2}{*}{$\begin{array}{c}\text { Cell } \\
\text { Number }\end{array}$} & \multirow[b]{2}{*}{$\begin{array}{c}\text { Ah } \\
\text { Capacity }\end{array}$} & \multirow[b]{2}{*}{$\begin{array}{l}\text { Current } \\
\text { Collector } \\
\text { Cathode }\end{array}$} & \multirow[b]{2}{*}{$\begin{array}{l}\text { Total } \\
\text { Cycles }\end{array}$} & \multicolumn{2}{|c|}{$\begin{array}{l}\text { Resistance } \\
\text { (mohm) }\end{array}$} & \multicolumn{2}{|c|}{$\begin{array}{l}\text { Unrecoverable } \\
\text { Capacity }(\%)^{c}\end{array}$} \\
\hline & & & & Nominal" & Slope ${ }^{b}$ & Nominal & Slope \\
\hline 023 & 29.13 & $\mathrm{Ni} / \mathrm{Cr}$ & 759 & +16.73 & +1.56 & +26.43 & +0.89 \\
\hline 027 & 29.84 & $\mathrm{Ni} / \mathrm{Cr}$ & 761 & +15.84 & +0.85 & +37.05 & +0.17 \\
\hline 058 & 29.48 & NVCr-5086 & 481 & +11.23 & -0.07 & +24.76 & -0.20 \\
\hline 060 & 29.59 & Ni/Cr-5086 & 483 & +26.43 & -0.08 & +25.80 & -0.10 \\
\hline 062 & 29.91 & $\mathrm{Ni} / \mathrm{Cr}-5086 \mathrm{~s}$ & 246 & +12.02 & -0.01 & +10.41 & -0.01 \\
\hline 063 & 29.54 & $\mathrm{Ni} / \mathrm{Cr}-5086 \mathrm{~s}$ & 246 & +12.95 & -0.07 & +11.34 & -0.03 \\
\hline 064 & 29.40 & $\mathrm{Ni} / \mathrm{Cr}-5086 \mathrm{~s}$ & 246 & +12.54 & -0.10 & +10.35 & -0.02 \\
\hline 066 & 29.77 & $\mathrm{Ni} / \mathrm{Cr}-5086 \mathrm{~s}$ & 246 & +12.53 & -0.01 & +15.22 & +0.02 \\
\hline
\end{tabular}

Notes:

a The nominal cell resistance is expressed in milliohms.

b The slope of the resistance is expressed in micro-ohms per cycle.

c The nominal and slope values are expressed in percent of theoretical capacity to $\mathrm{Na}_{2} \mathrm{~S}_{3}$. 


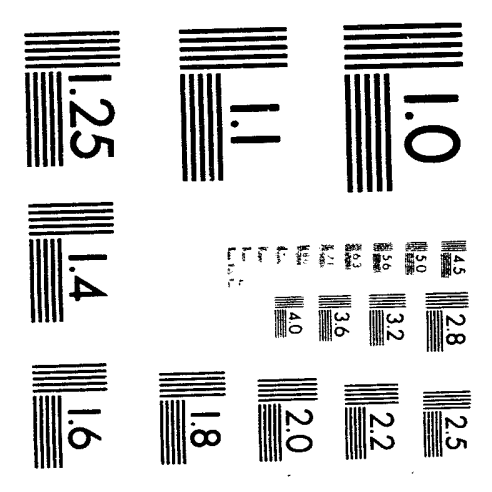



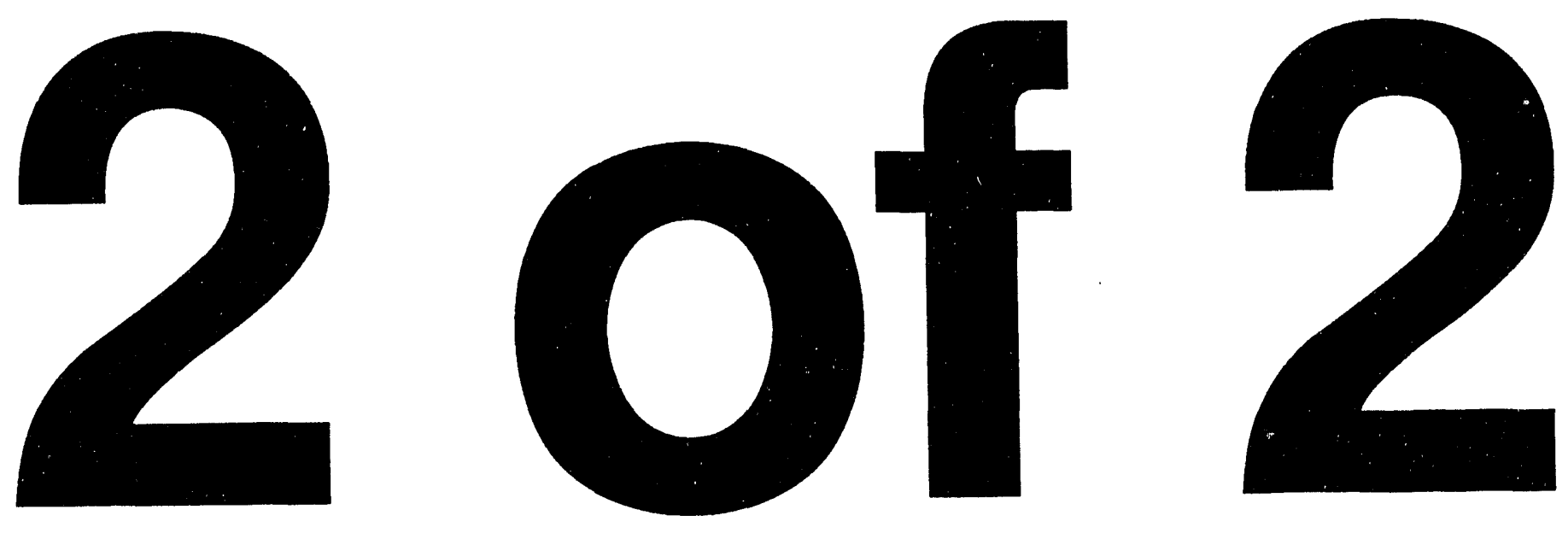
experiment. Of the remaining 64 cell assemblies, 40 cells were successfully fabricated and subjected to electrical and thermal cycling. Eight UES cells are presently on test. A testing summary for the cells remaining on test is shown in Table 5-2. The last column of this table, "Unrecoverable," refers to the percentage of the theoretical capacity that cannot be recovered during charging.

\section{Testing Conditions}

All of the cells tested were instrumented with voltage sense leads and a single $\mathrm{K}$-type thermocouple. Heating was achieved at a rate of $15^{\circ} \mathrm{C} / \mathrm{hr}$ to a temperature of $330^{\circ} \mathrm{C}$. Following application of a resistive load, the discharge current was increased to $2 \mathrm{~A}$ until approximately $70 \%$ of the theoretical capacity was removed. Charge was initiated at a current level of 1-2 A until a voltage of $2.3 \mathrm{~V}$ was reached. Several break-in cycles were performed with discharge currents of 5-7 A until $70 \%$ of theoretical capacity was removed. Charge. currents were typically 4-5 A during break-in cycles.

\section{Early Electrical Performance}

The initial projected BOL electrical performance of the UES cell is shown in Table 5-3. The actual performance of early UES cells could not be accurately determined because many cells failed before testing started or after completing only a few electrical cycles. The "learning" curve and assembly problems are partially responsible for the initially high failure rate observed with this cell. However, a few cells did survive testing long enough for early performance data to be taken. Cells 004 and 009 were the best performing cells built early in this program.

In terms of electrical behavior, both cells showed stable resistance values less than 13 mohms. While the usable capacity for both cells was over 27 Ah for both cells, a specific energy of $150 \mathrm{Wh} / \mathrm{kg}$ was less than the predicted value, primarily because the cell weight was higher than projected. Unfortunately, cell 004 failed during the third $F / T$ cycle after completing only 32 electrical cycles. Cell 009 failed near the top of charge, after completing one $\mathrm{F} / \mathrm{T}$ and 25 electrical cycles.

\section{Table 5-2. UES Central Sulfur Cell Testing Summary}

\begin{tabular}{|c|c|c|c|c|c|c|c|}
\hline \multirow[b]{2}{*}{$\begin{array}{c}\text { Cell } \\
\text { Number }\end{array}$} & \multirow[b]{2}{*}{$\begin{array}{c}\text { Ah } \\
\text { Capacity }\end{array}$} & \multirow[b]{2}{*}{$\begin{array}{l}\text { Current } \\
\text { Collector } \\
\text { Cathode }\end{array}$} & \multirow[b]{2}{*}{$\begin{array}{l}\text { Total } \\
\text { Cycles }\end{array}$} & \multicolumn{2}{|c|}{$\begin{array}{l}\text { Resistance } \\
\text { (mohm) }\end{array}$} & \multicolumn{2}{|c|}{$\begin{array}{l}\text { Unrecoverable } \\
\text { Capacity }(\%)^{c}\end{array}$} \\
\hline & & & & Nominala & Slope ${ }^{b}$ & Nominal & Slope \\
\hline 023 & 29.13 & $\mathrm{Ni} / \mathrm{Cr}$ & 759 & +16.73 & +1.56 & +26.43 & +0.89 \\
\hline 027 & 29.84 & $\mathrm{Ni} / \mathrm{Cr}$ & 761 & +15.84 & +0.85 & +37.09 & +0.17 \\
\hline 058 & 29.48 & Nicr-5086 & 481 & +11.23 & -0.07 & +24.76 & $\cdot 0.20$ \\
\hline 060 & 29.59 & $\mathrm{Ni} / \mathrm{Cr}-5086$ & 483 & +26.43 & -0.08 & +25.80 & -0.10 \\
\hline 062 & 29.91 & $\mathrm{Ni} / \mathrm{Cr}-5086 \mathrm{~s}$ & 246 & +12.02 & -0.01 & +10.41 & -0.01 \\
\hline 063 & 29.54 & $\mathrm{Ni} / \mathrm{Cr}-5086 \mathrm{~s}$ & 246 & +12.95 & -0.07 & +11.34 & -0.03 \\
\hline 064 & 29.40 & $\mathrm{Ni} / \mathrm{Cr}-5086 \mathrm{~s}$ & 246 & +12.54 & -0.10 & +10.35 & -0.02 \\
\hline 066 & 29.77 & $\mathrm{Ni} / \mathrm{Cr}-5086 \mathrm{~s}$ & 246 & +12.53 & -0.01 & +15.22 & +0.02 \\
\hline $\begin{array}{l}\text { Notes: } \\
\text { a The ne } \\
\text { b The sl } \\
\text { c The no }\end{array}$ & not & are & - & tit & & & \\
\hline
\end{tabular}




\section{Table 5-3. Projected BOL. Electrical Performance for the UES Central Sulfur Cell}

$\begin{array}{lc}\text { Cell Resistance } & 14.0 \mathrm{mohms} \\ \begin{array}{l}\text { Theoretical Capacity (to } \\ \mathrm{Na}_{2} \mathrm{~S}_{3} \text { ) }\end{array} & 35.5 \mathrm{Ah} \\ \text { Nominal Capacity } & 27.0 \mathrm{Ah} \\ \text { Power at C-rate } & 46.0 \mathrm{~W} \\ \text { Specific Energy @ C/2 } & 155.0 \mathrm{Wh} / \mathrm{Kg} \\ \text { Energy Density @ (C/2) } & 296.0 \mathrm{Wh} / \mathrm{L}\end{array}$

The target theoretical capacity for the first 32 UES cells was $35.5 \mathrm{Ah}$ with a sulfur load of $63 \mathrm{~g}$. Upon inspection after several failures, it was realized that, during a cell failure or deep discharge, the available volume in the cathode compartment was not sufficient to hold all of the reaction products of sodium and sulfur. The compartment would therefore rupture if over-discharged. Cells fabricated subsequent to cell 032 utilized a smaller sulfur load of $53 \mathrm{~g}$ to eliminate this condition. This change reduced the theoretical cell capacity to 29.5 Ah.

\section{General and Long-Term Performance}

UES cells fabricated during the past year can be categorized into two current collector groups: molybdenum and nickel-chromium. Cells 017 and 033 through 036 utilized an aluminum current collector with a flame sprayed molybdenum coating, and all of the remaining cells (037 through 087) were fabricated with a flame sprayed nickel-chromium coating on aluminum.

Molybdenum Current Collector. Molybdenum was selected as a cathode current collector primarily because of its stability in the polysulfide melt. Cell 017 was assembled using a thin (0.005-0.006 in.) coating of molybdenum, applied to an aluminum pole piece, using flame spray equipment.

Initial testing revealed good performance from cell 017 , but resistance and unrecoverable capacity (f1) steadily increased as testing progressed. The rate of change for the resistance rise (at BOD) was nearly linear at about 62 mohms/cycle, 25 times higher than expected (calculated from the cell design). Figure 5-14 shows results from three different cycles for cell 017 . While the degradation in relative performance is clearly evi- dent between each cycle, the position and slope of the single-phase region of each charge curve is nearly identical. This observation strongly suggested that the cause of the increase in cell resistance and $\mathrm{f} 1$ was not due to a loss of sulfur but due to some other mechanism. One explanation for the loss of charge acceptance could be that the "catalyzing agent" in the cathode, allowing charge in the two-phase region, was reaching depletion.

The sulfur electrodes of cells 033 through 036 contained additives intended to catalyze the recharge reaction in the cells. Cell 034 failed during the initial heatup after reaching a temperature of $280^{\circ} \mathrm{C}$. The remaining three cells were discharged at a current of $13 \mathrm{~A}$ until $18 \mathrm{Ah}$ were removed (75\% DOD). Charge was accomplished at a current level of $4 \mathrm{~A}$ until a voltage of $2.3 \mathrm{~V}$ was reached. This cycling regime continued through 550 electrical cycles, where the charge current was reduced to $2 \mathrm{~A}$ with a slight improvement in $\mathrm{f} 1$.

All three cells showed good initial performance, but the resistance change for cell 035 was higher than that of the other two and roughly took the form of two linear segments. The first segment lasted from cycle 1 through cycle 330 and had a slope of about $30 \mu \Omega$ /cycle. Following cycle 330 the slope increased to $48 \mu \Omega$ /cycle through the end of testing where the resistance was over $40 \mathrm{~m} \Omega$. Cell 035 was removed from test, but the posttest analysis is not complete.

The behavior of the resistance over the life of testing for cells 033 and 036 was reasonably consistent, and a plot of the resistance vs. cycle number for cell -036 , shown in Figure 5-15, is typical for both cells. Resistance for cells 033 and 036 remained relatively fiat following a short rise and fall observed in the first $\mathbf{5 0}$ cycles. After cycle 330 , a slight upturn in the slope 


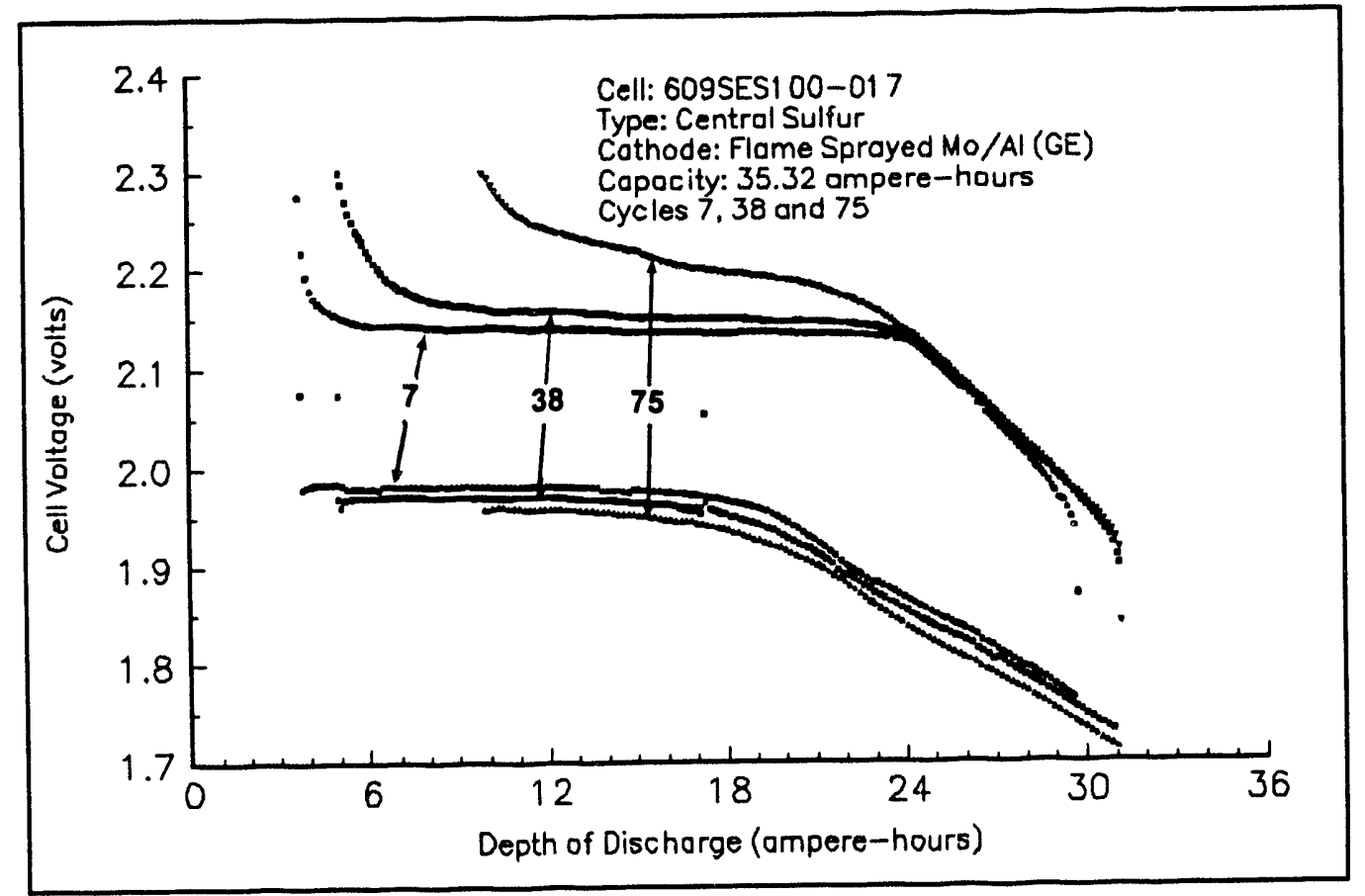

Figure 5-14. DOD Plots of Cycles 7, 38, and 75 for Cell 017. Charge and discharge currents were $5 \mathrm{~A}$ and $7 \mathrm{~A}$, respectively.

occuried, primarily affecting the beginning of discharge resistance. The cause in the slope change is unknown but may be related to an inadvertent discharge to $80 \%$ DOD near cycle 330 . Cell resistance continued to rise smoothly through cycle 600 where an unscheduled discharge to $92 \%$ DOD occurred. Cycling conditions recovered to normal within the next eight cycles, but a step change in cell resistance at the beginning of charge and at the beginning of discharge is clearly visible at cycle 600 in Figure 5-15. A decrease in the energy delivered during discharge of $0.5-1.0 \mathrm{Wh}$ was observed following cycle 600 . Other characteristics of the cell, like the usable capacity and $\mathrm{fl}$, did not appear to be affected by the high state of discharge at cycle 600 as shown in a plot of the depth of discharge and $f 1$ for cell 036 in Figure 5-16. The cause of the resistance change is likely attributable to an increase in the production of corrosion products in the polysulfide melt at high states of discharge.

\section{$\mathrm{Ni} / \mathrm{Cr}$ Current Collector}

Cells 037 through 087 were all fabricated with a $80 \%$ nickel $/ 20 \%$ chrome thin layer (0.007-0.12") applied to the aluminum pole piece using flame spray equipment. Differences in the cells fabricated in lots 10 through 21 that appear to have affected cell performance within the $\mathrm{Ni} / \mathrm{Cr}$ current collector group included sensitivity to how the $\mathrm{Ni} / \mathrm{Cr}$ coating was applied to the aluminum pole piece.

Electrical performance of cells utilizing a $\mathrm{Ni} / \mathrm{Cr}$ current collector was generally equivalent to cells fabricated with a molybdenum current collector and $\mathrm{Ni} / \mathrm{Cr}$ additive for 300 to 400 cycles. Beyond 400 cycles, however, charge acceptance tended to degrade at a higher rate, and the effects of deep discharge were more severe for the $\mathrm{Ni} / \mathrm{Cr}$ cells. The effect of deep discharge on $\mathrm{fl}$ can be seen in Figure 5-17, which shows a plot of $\mathrm{DOD}$ and $\mathrm{f} 1$ vs cycle number for cell 060 . During the first 330 cycles, the slope of the unrecoverable capacity was essentially monotonic and had a slope of $+1.8 \mathrm{mAh} /$ cycle. Following a deep discharge to $98 \%$ of theoretical (cycle 330 ), the f1 fell to around $10 \%$, but the slope changed to over $20 \mathrm{mAh} / \mathrm{cycle}$.

Performance of cells using $\mathrm{Ni} / \mathrm{Cr}$ current collectors that were applied by flame spraying wire showed significant differences in resistance behavior, especially during the first 100 cycles, over cells using $\mathrm{Ni} / \mathrm{Cr}$ current collector that were applied by flame spraying powder. Figures 5-18 and 5-19 show a plot of cell resistance at the beginning of discharge and charge vs cycle number for cells 040 and 062 , respectively. In both cases, the 


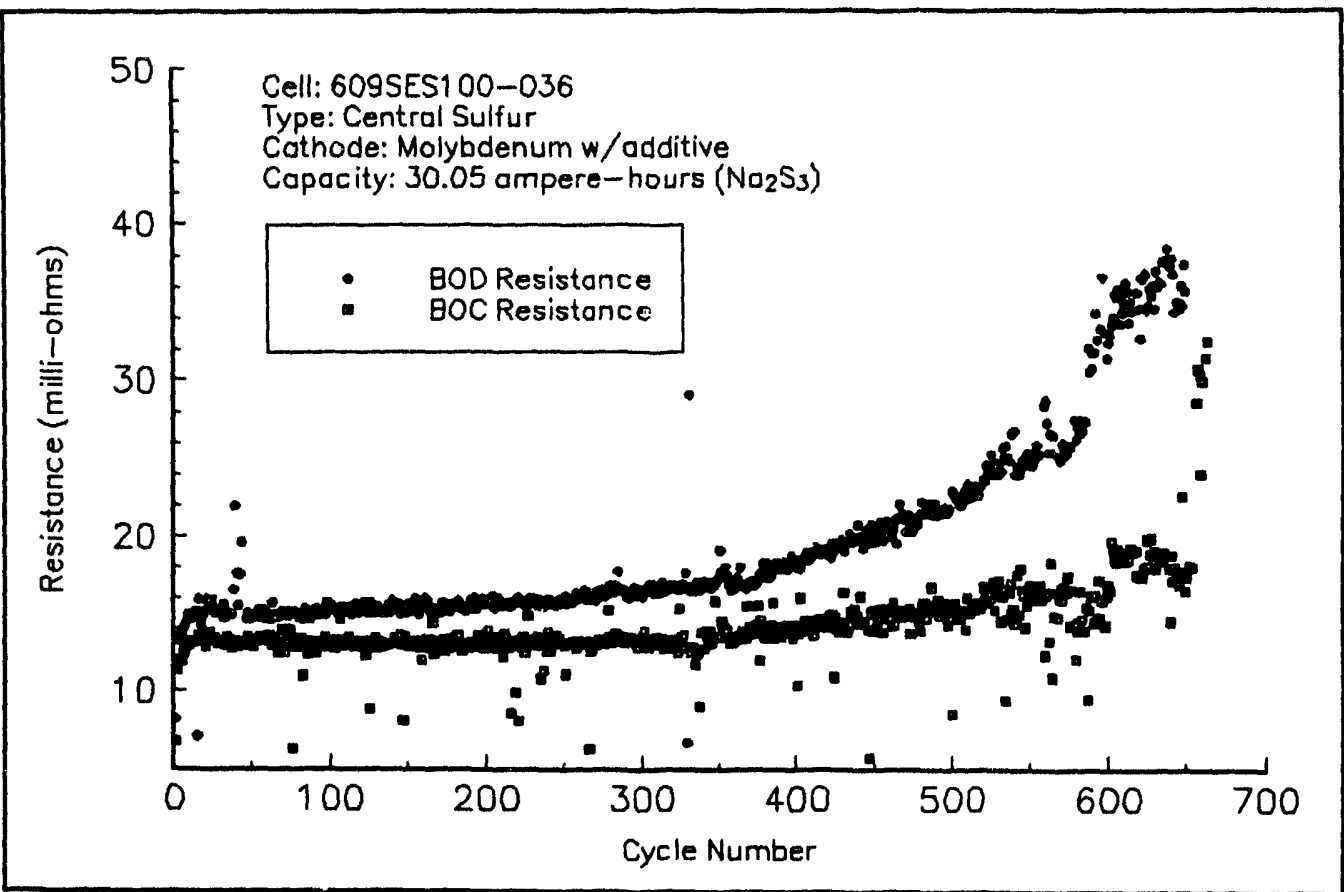

Figure 5-15. Cell Resistance at the Beginning of Discharge and Charge for a Molybdenum UES Cell

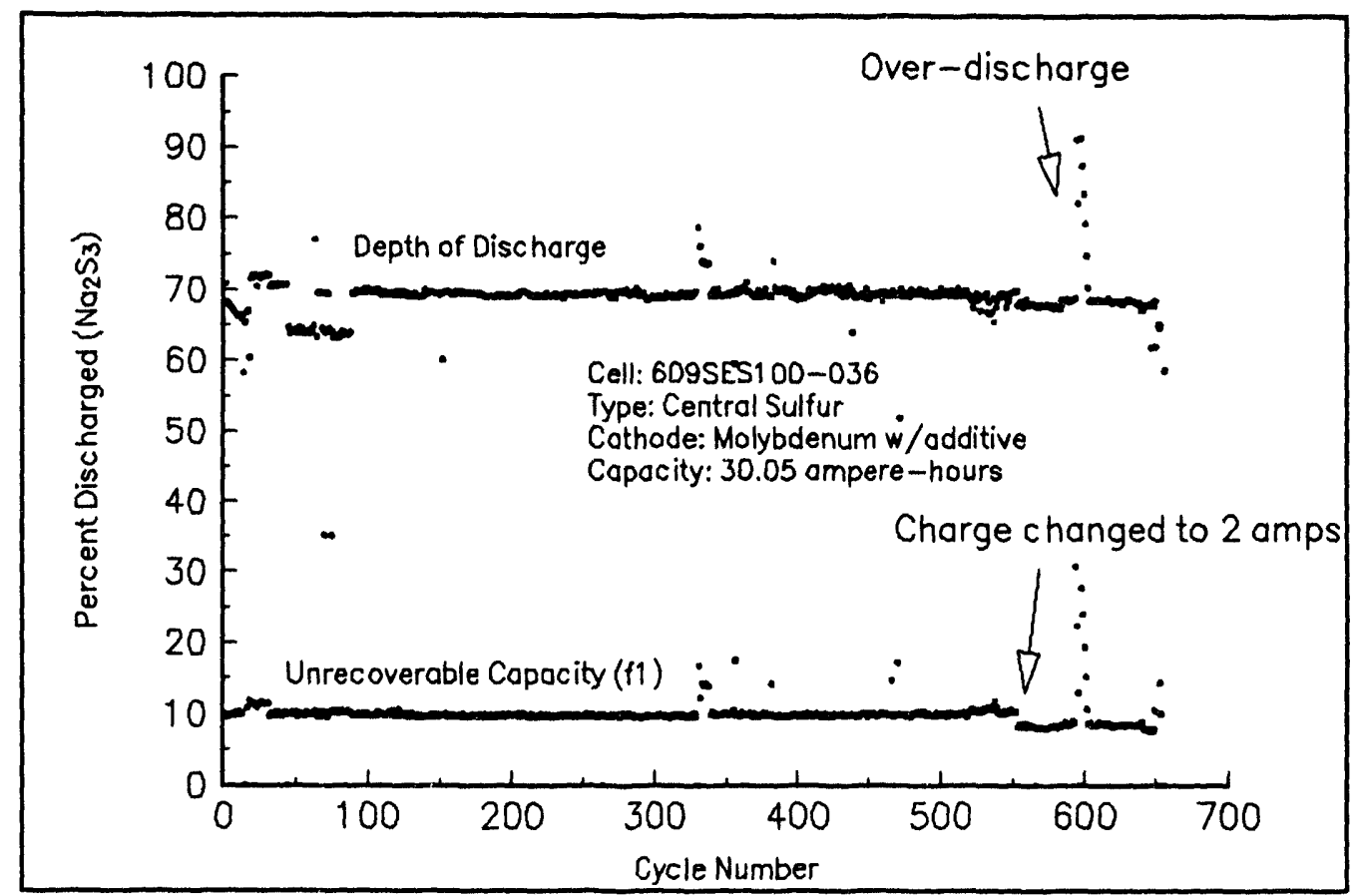

Figure 5-16. Effect of Changing Discharge and Charge Conditions on Cell Capacity and Unrecoverable Capacity 


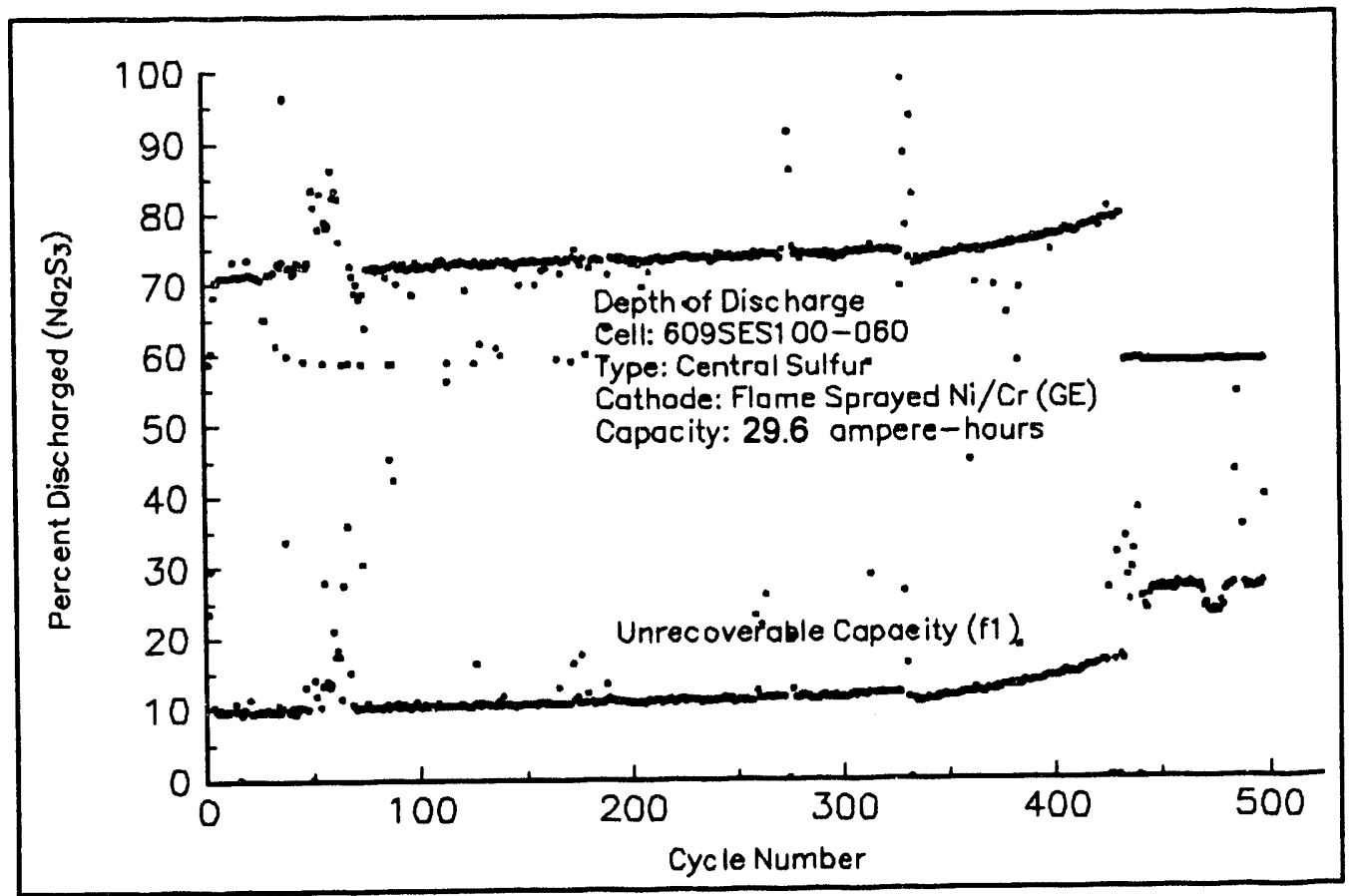

Figure 5-17. Depth of Discharge and $f($ for Ni/Cr UES Cell Showing Effects of a Deep Discharge

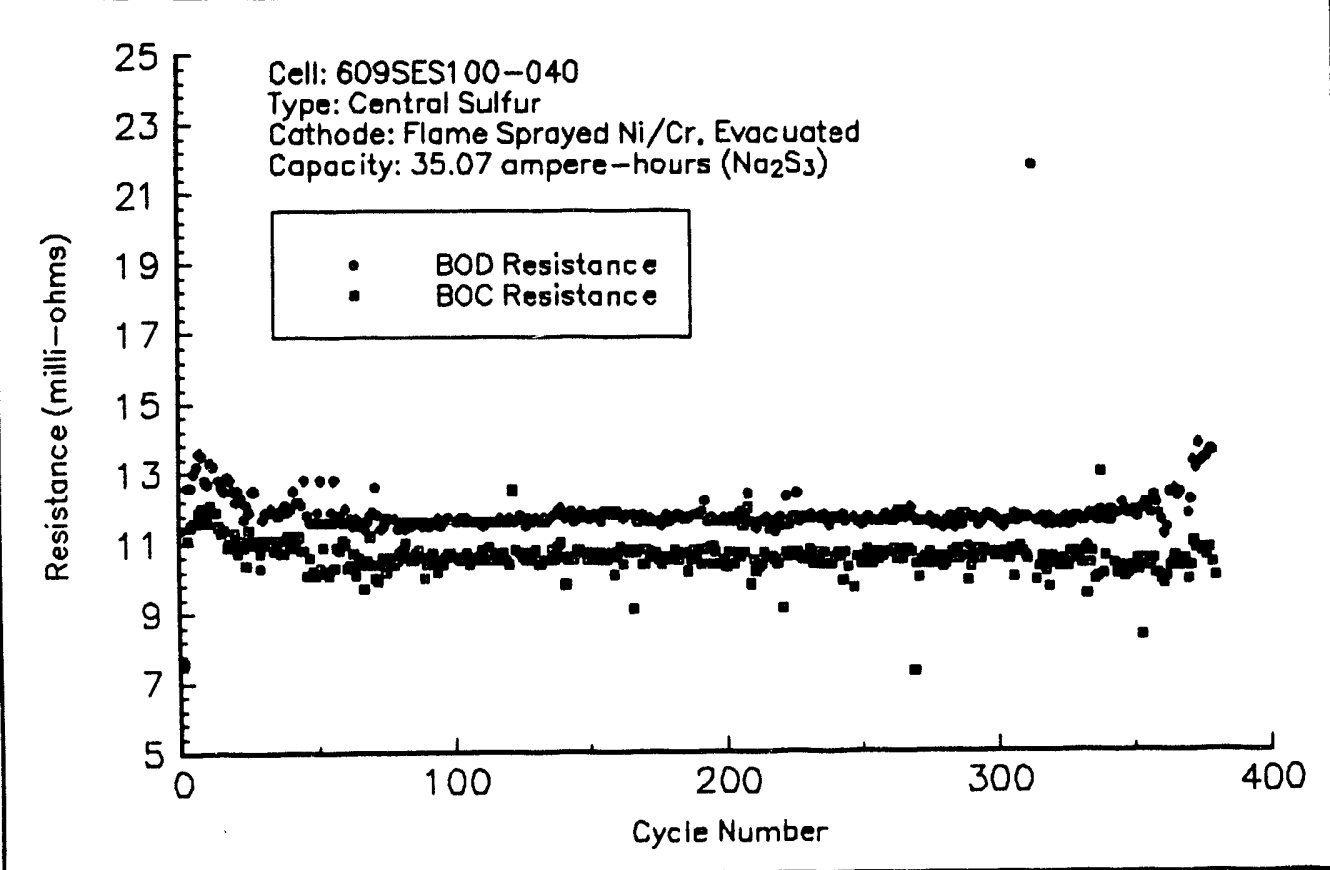

Figure 5-18. Resistance of UES Cell \#40 (Nichrome Coated from Wire Stock) 


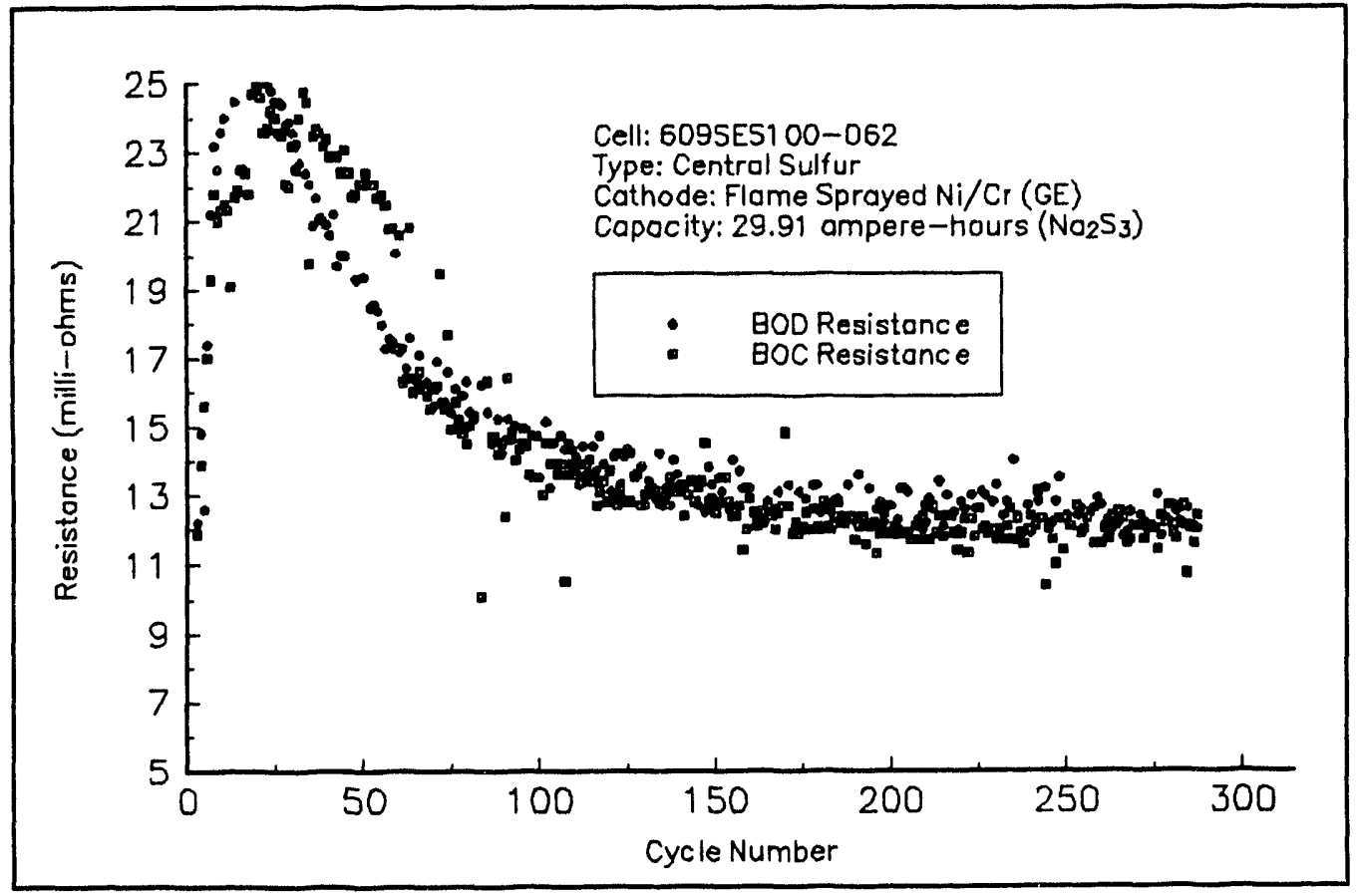

Figure 5-19. Resistance of UES Cell \#62 (Nichrome Coated from Metal Powder)

resistance at the beginning of testing was between 11 and 13 mohms. For cell 040 the resistance increased to a peak near cycle 10 and then decreased to around 12 mohms in 50 cycles. The resistance for cell 062 showed the same tendency to increase but reached a peak of about 25 mohms near cycle 25 and slowly decreased over the next 75 cycles to a value of 12 mohms where it remained constant through cycle 275 . The magnitude of the resistance peak appears to be related to the coating application method, but the direct cause is unknown and is under investigation.

\section{Cell Test Summary}

Performance of the cells assembled and tested were consistent with initial expectations. Cell resistance was generally lower than the predicted value of 14 mohms. Cell resistance and $\mathrm{f} 1$ show some sensitivity to depth of discharge, especially in cells utilizing the $\mathrm{Ni} / \mathrm{Cr}$ current collector. Additional fabrication and testing of cells utilizing both molybdenum and $\mathrm{Ni} / \mathrm{Cr}$ current collectors is scheduled and will further assist in the determination of an appropriate UES cell design.

\section{Task 3. Design \& Fabrication of UES Module}

Work is progressing toward assembly of the deliverable battery. This assembly will represent one-sixth of a full size NAS-P $P_{\text {ac }}$ sub-battery. In its envelope of approximately $700 \mathrm{~mm} \times 900 \mathrm{~mm}$ planform $\times 400 \mathrm{~mm}$ height are four banks connected in series. The electrical rating of the deliverable unit is $13 \mathrm{kWh}$ for $2-\mathrm{hr}$ continuous service at $32 \mathrm{VDC}$. The final configuration of the deliverable battery combines design elements from Silent Power's batteries as well as new approaches developed specifically for UES applications. The bank configuration is a modification of Silent Power's standard electric-vehicle design with the primary deviation being substitution of TES capsules and multilayer ceramic cement coatings as cell separators. The TES capsules, containing a lithium chloride/potassium chloride $(\mathrm{LiCl} / \mathrm{KCl})$ eutectic mixture, utilize the latent heat capacity of the salt to reduce temperature rise of the cells. The steel jacketed aluminum wall of each TES container, located in the interstitial space among cell strings, offers the benefit of increased vertical heat transfer local to each cell string. The cemented matrix enhances electrical isolation, structural rigidity and heat transfer, while minimizing potential safety concerns in 
the event of overtemperature fault conditions by fully encapsulating all components. In general, because of improved thermal conductance, both horizontally and vertically, the battery core should be able to take advantage of the increased heat loss from the enclosure during discharge periods without imposing large temperature gradients within the battery. The enclosure/thermal insulation system utilizes multilayer ceramic board and blankets in a single wall sheet metal box. This design minimizes the cost of this aspect of $\mathrm{NaS}$ battery technology by taking advantage of the continuous connection of a UES battery to an active power grid to make up the heat loss. Figure 5-20 presents a cut-away view of the deliverable battery.

\section{Task 4. Full-Scale Battery Plant Design}

The full-scale integrated NAS-P ${ }_{\mathrm{ac}}$ system, first referenced in Figure 5-1, is a $300-\mathrm{kW} / 600-\mathrm{kWh}$ BES system, which includes the power converter and battery management system. The battery is composed of 2 strings of 4 series sub-battery packs, achieving 500 VDC input to a line-commutated converter (480 VAC, 3 phase). The initial choice of converter topology was selected not only for its low cost and availability, but also because it requires the lowest $\mathrm{DC}$ voltage from the battery, an advantage for sodium/sulfur because of its open circuit failure mode.

Table 5-4 is a list of the electrical specifications of the NAS-P $\mathrm{P}_{\mathrm{ac}}$ system. The power wiring and disconnect switches between battery packs are displayed in Figure 5-21, as viewed from the left hand side of Figure 5-1. The switches provide isolation for battery replacement. Note that, other than replacement, no maintenance is planned for battery packs at the site. The electrical compartment contains the battery management system (BMS) and the interface boxes from the battery packs to the BMS, the heater controllers for each battery pack, and the current sensors for monitoring the current in each battery string.

The BMS monitors battery operation, provides a status for charge/discharge control and provides records of system operation. Progress this year on BMS development is described in the succeeding paragraphs. A prototype BMS will be delivered as part of the deliverable battery hardware.

The UES BMS is connected to the battery in two significant ways. First, critical voltages, temperatures, and currents are interfaced from the battery to the BMS. Second, a disconnect device, which is a contactor, is connected between the battery and load. In the event

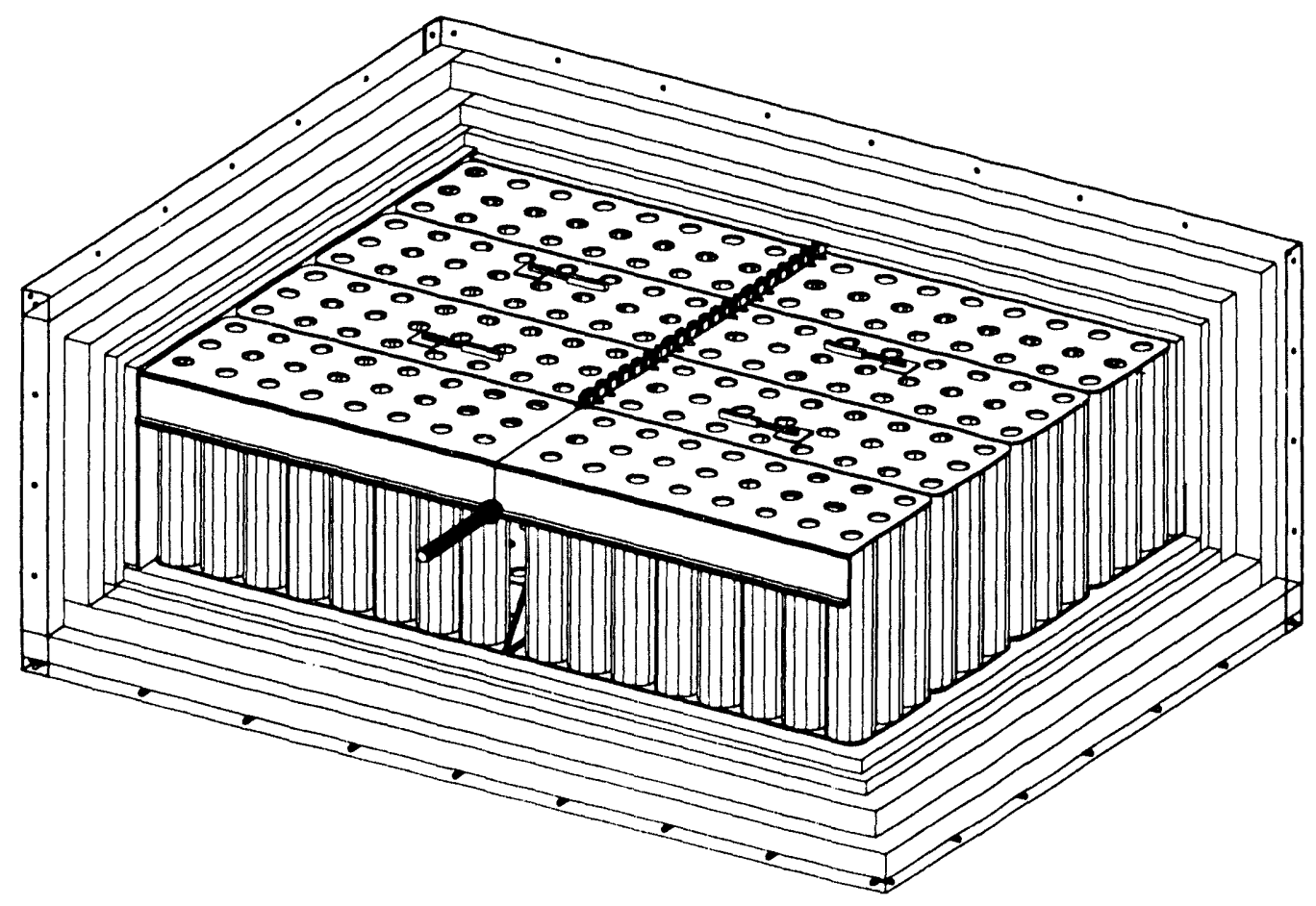

Figure 5-20. Cutaway of 13-kWh Deliverable Battery 


\title{
Table 5-4. NAS-P $\mathrm{ac}_{\mathrm{ac}}$ Battery Energy Storage System Specifications
}

\author{
- PCS Characteristics \\ $300 \mathrm{~kW}$ (max) \\ - Command and Control \\ Charge/Discharge Remote Signal from Dispatcher Battery \\ Management System: \\ Maintains Operating Temperature \\ End of Charge/Discharge Signal \\ Battery Readiness/Fault Status Conditions \\ Data Acquisition/Storage \\ - System Efficiency (AC-AC): $\quad 84 \%$ BOL \\ System Weight: $\quad 23,000 \mathrm{lb}$
}

that unsafe operating conditions are detected by the BMS, it controls the disconnect device in order to limit the use of the battery by the load (the PCS in this application).

The BMS is also required to save specific cycle data and allow retrieval of this information via a remote computer. With the exception of data retrieval, the BMS is designed to be independerit and fault-tolerant. The BMS described here is shown schematically in Figure 5-22 in a typical configuration with the proposed UES battery and load device.

\section{BMS - Capability}

The BMS has the capability to monitor a battery made up of eight sub-batteries or modules arranged in two parallel, four series strings. Each module may have up to 16 input channels (voltages, temperatures, and currents) for a total of 128 channels for the entire battery. During use of the battery, if the BMS detects a battery condition that is outside the defined operating limits, it will signal the load device to terminate use of the battery. If, after an appropriate amount of time, this sig- nal is ignored by the load device, the BMS will force the battery "off-line" by opening the contactor. The battery will then be placed back "on-line" once the BMS has determined that the battery can be safely operated.

Other features include the capability to detect peripheral hardware failures, thermocouple, and voltage sense lead failures. Additionally, the BMS has the capability to monitor, record, and download cycle data to a remote computer for analysis.

\section{Control Algorithm}

The control algorithm is based on the rated and theoretical capacity of the battery. Under most conditions, the BMS will allow the load device access to the battery if the remaining available capacity is within the rated capacity.

Specifically, the BMS will determine the absolute SOC of the battery based on theoretical capacity, open circuit voltages, temperatures, and the amount of charge removed during each discharge segment. Then, following a complete charge, the available capacity will be calculated and saved in nonvolatile memory. All of the 


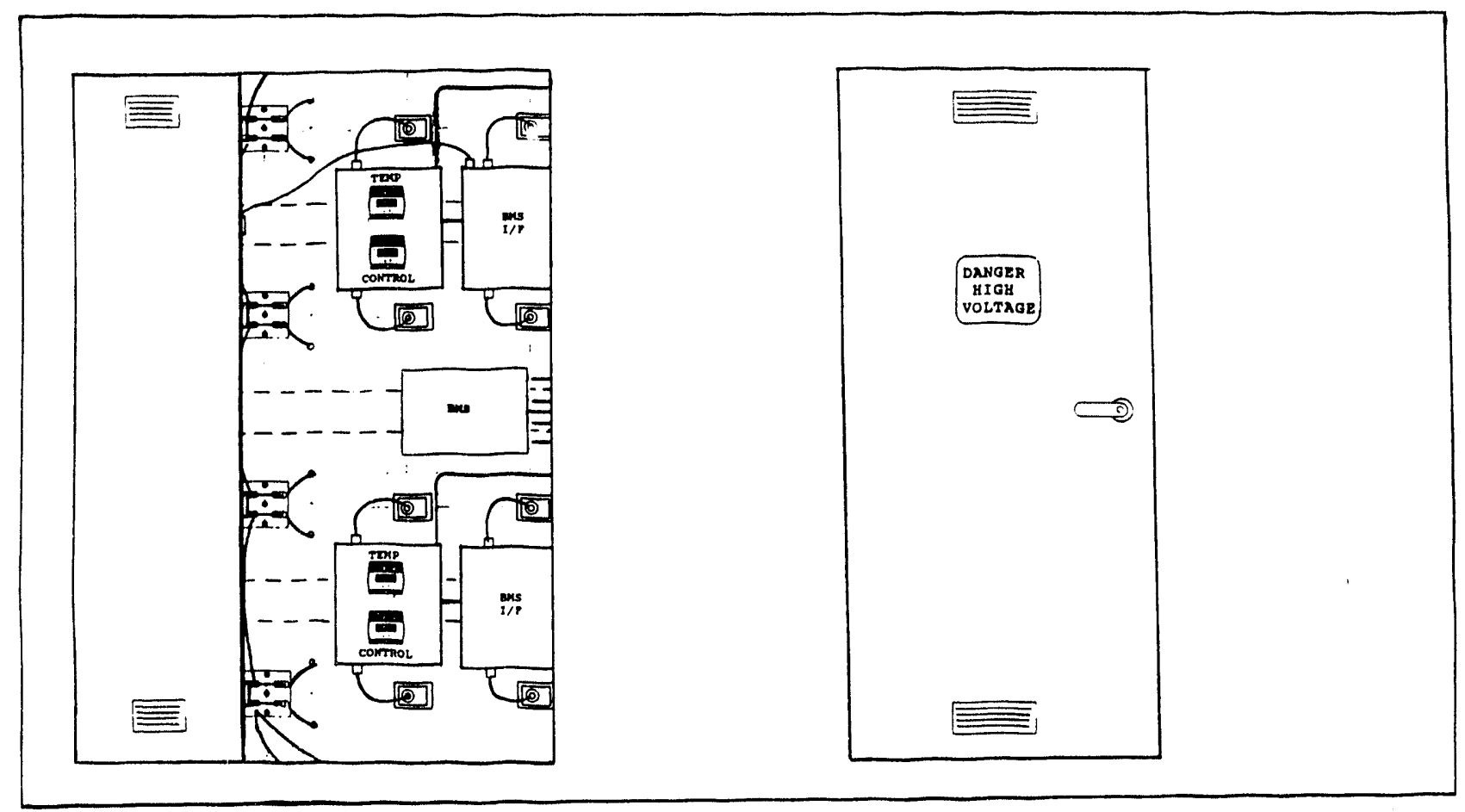

Figure 5-21. NAS- $P_{a c}$ Battery Electrical Compartment

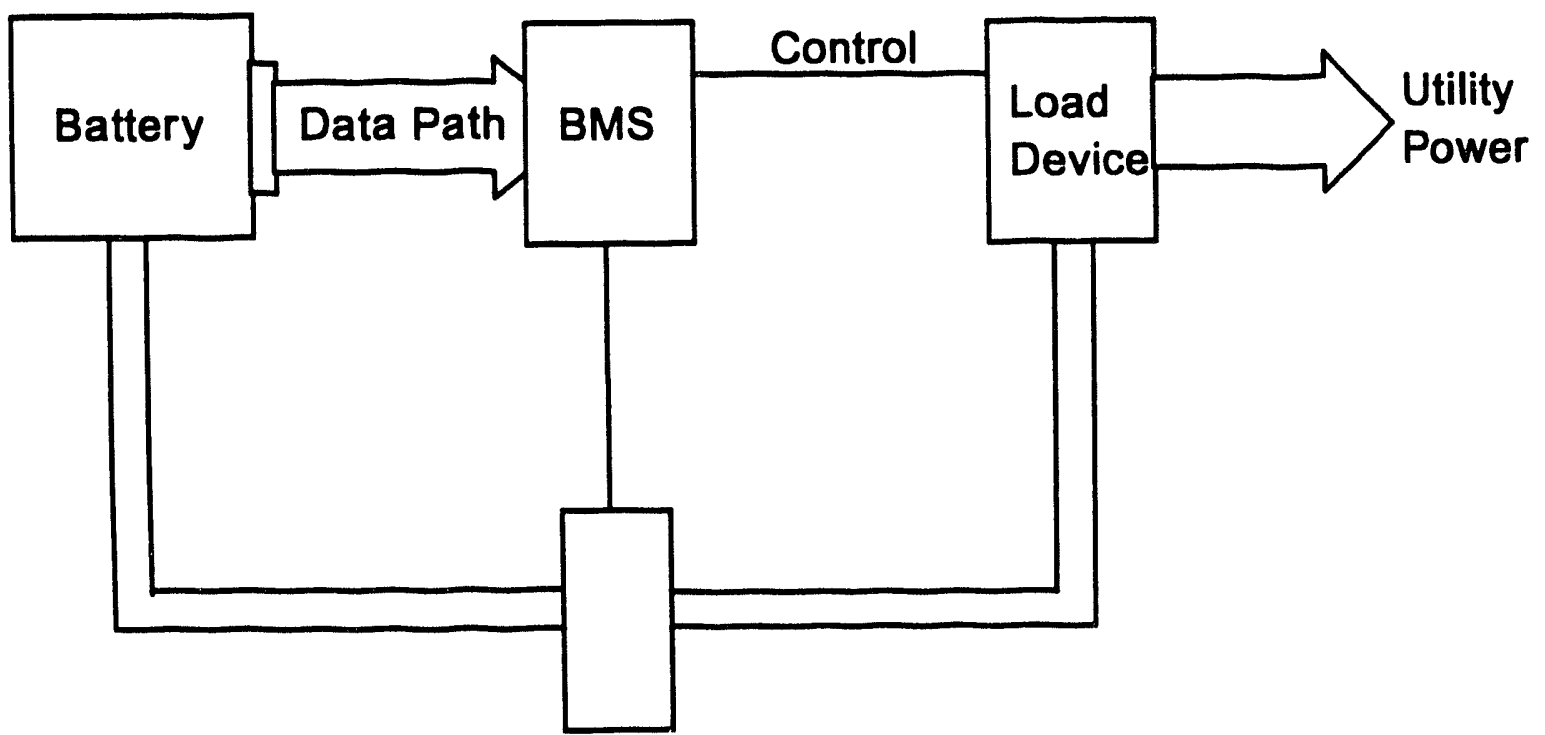

Disconnect Device

Figure 5-22. System Block Diagram 
available capacity will then be accessible to the load during the subsequent discharge as long as the temperature, current, and power levels for each module are maintained within the rated limits. This process will be repeated for each cycle until the battery can no longer supply the rated capacity (end of life).

This control algorithm has the advantage of allowing operation of the battery within limits that are easily determined and measured; these include current, power, and temperature. Other algorithms, specifically those that attempt to calculate real time open circuit voltages, require complex battery models that are sensitive to current levels, temperature, SOC, and age of the battery.

\section{Hardware Description}

The BMS consists of two main sections: Battery Interface Electronics and a Data Acquisition System. These two main sections are shown in a system block diagram in Figure 5-23. The battery interface electronics will be located immediately outside each battery module and will convert all bank voltages, temperature, and currents to Frequency Modulated (FM) light pulses. The light will then be transmitted to the Data Acquisition System over fiber optic cable for conversion back to 12-bit digital format.
The Data Acquisition System consists of a Frequency Converter and a Single Board Computer. The Frequency Converter is made up of 16, 12-bit counters connected to a specific battery input (voltage, tempera-

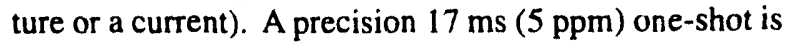
common to each of the 16 counters. The one-shot is triggered by the Single Board Computer and enables counting for the 17-ms time period. Upon completion of the counting period, 12-bit data for each of the 16 channels is latched and can be read by the Single Board Computer.

During normal operation, the BMS will function without human intervention and will supply a Battery Trip Request (go/no-go) signal to the load device as necessary to prevent damage to the battery. Interaction between the load device and the BMS will include no less than two signals: 1) a Discharge Request signal and 2) a Charge Request signal. Other input/output signals may include analog values that corresponded to the instantaneous power, total eriergy, and Ah supplied by the load device to the end user.

Data Acquisition System

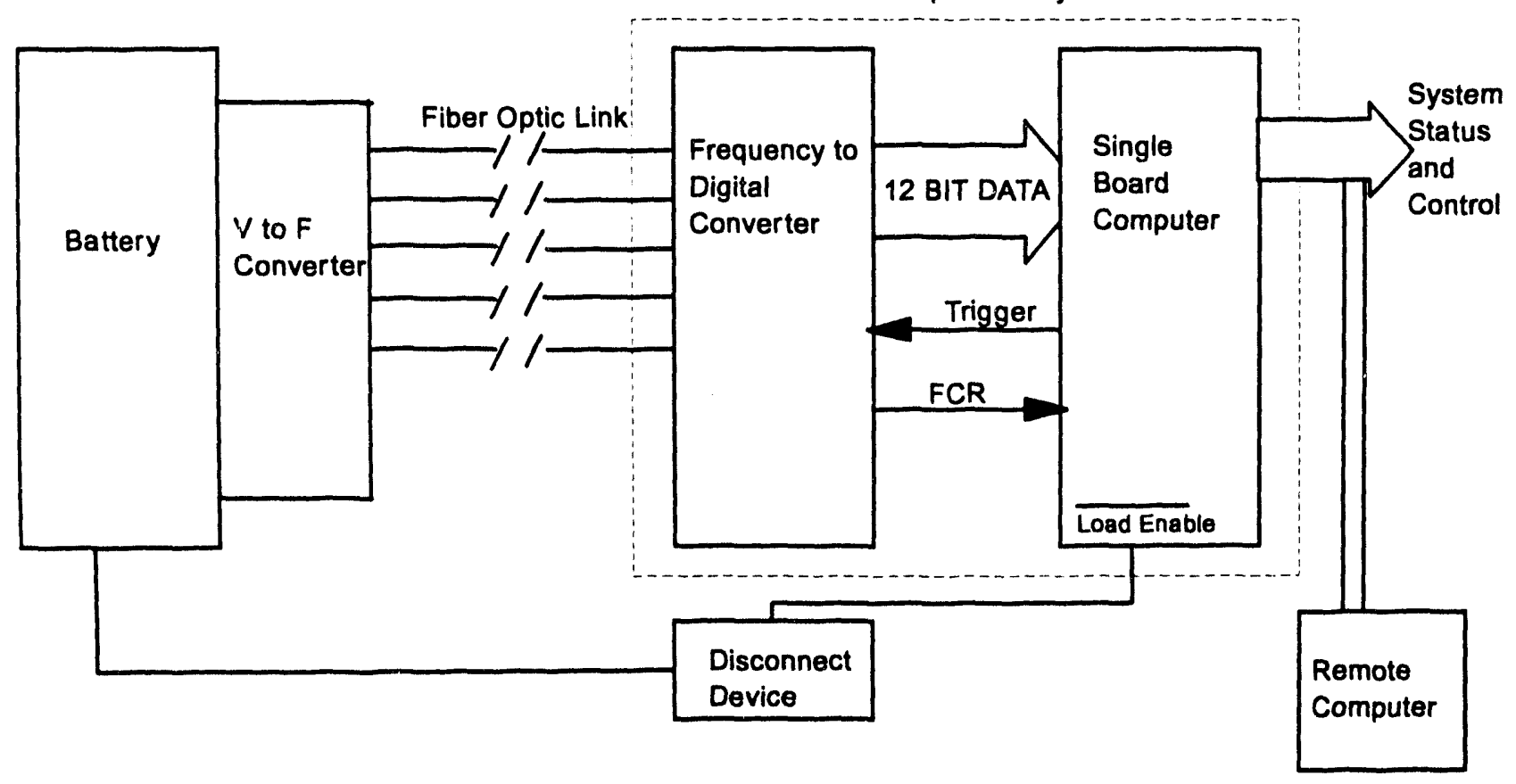

Figure 5-23. Battery Interface and BMS Diagram 


\section{Technology Evaluation - SNL}

The performance and operating characteristics, as well as service life data and failure modes for sodium/ sulfur cells and modules are determined in this SNL activity. This information is shared with the developer to improve the design and operation of the technology. FY93:

Three types of hardware were evaluated during

1. 40-Cell XPB Module

2. Single XPB Cells

3. Two 4-cell strings

\section{Status}

\section{Task 1. 40-Cell XPB Module}

Testing of a second 40-cell XPB sodium/sulfur module was completed during the first quarter of FY93. This module represented a portion of a single tray of an earlier UES battery design. This module was part of the deliverable agreement from the 5-yr Core Technology contract with SPL and was a duplicate of the unit that was previously tested at SNL. The cells used in this module were designed for utility applications and have a rated capacity of 30-Ah. Four of these cells placed in series make up an 8.28-V string, and ten 4-cell strings placed in parallel make a 300 -Ah rated module. This module was instrumented with seven thermocouples (strategically located at positions selected by SPL) and a current shunt was connected to each of the 10 strings. The module was placed in a convection furnace and heated at a rate of $6^{\circ} \mathrm{C} / \mathrm{hr}$ to $340^{\circ} \mathrm{C}$. Battery voltage, string currents, battery temperatures, and furnace temperature were monitored.

Initial testing started in August 1992. Several break-in cycles were attempted at a reduced charge/discharge rate to a shallow DOD. This was done to allow reactants to properly wet the electrolyte surface and lower the module resistance to less than 6 mohms. Because the module resistance remained high $(>13$ mohms), the temperature of the module was raised until the resistance dropped to approximately 9 mohms.

Three capacity tests were successfully performed on the module at different discharge rates. These discharge rates varied between $60 \mathrm{~A}$ and $105 \mathrm{~A}$. At the lower rates, the module capacity was $305 \mathrm{Ah}$ and at the higher rate, the capacity decreased only slightly to $287 \mathrm{Ah}$.
Testing continued on the module by placing it on the SNL/UES test profile. However, only the simplified frequency regulation portion was utilized. The principal purpose of this activity was to determine its thermal response to this continuous type of cycling. Initially, software control problems prevented the module from being regularly cycled. Once testing resumed, the average temperature increased after several UES segments were completed. Eventually, the test was terminated because of an overtemperature condition and not due to the normal end-of-discharge condition. The same test was repeated several times with similar results. Thermal problems prevented a full life-cycle characterization from being completed as was done with the first 40-cell module. Because the decision was made to use SPL's "PB" cell in the principal battery deliverable for this contract, testing was terminated, and the module was returned to SPL.

\section{Task 2. XPB Single Cells}

Two 30-Ah XPB cells from the present technology development contract with SPI were placed on test during FY92. These cells have been designated as SNL $\# 527$ and \#528. The test plan called for one cell (\#527) to be operated at $350^{\circ} \mathrm{C}$, while cell \#528 was operated at $330^{\circ} \mathrm{C}$. All of the electrical performance characterization tests were performed during FY92.

The FY93 activity, as defined in the test plan, was to determine response to a continuous Simplified Frequency Regulation (SFR) regime to $80 \%$ DOD (open circuit $=2.0 \mathrm{~V}$ ). This regime is symmetric: equal number of equivalent charge and discharge pulses are performed in each 160-min segment. When the cell energy was finally expended (80\% DOD), immediate recharging occurred at the 6-hr (5-A) rate. Cycling was interrupted at the end of each month to run three baseline capacity tests.

Figure 5-24 is a plot of the net Ah removed for each SFR cycle completed on each cell. Because of the symmetric discharge/charge nature of the SFR regime and the high electrical efficiency of the cell, each full discharge to $80 \%$ DOD takes an extended period of time (4-5 days). The method chosen to report the length of the discharge was to accumulate net Ah removed. As shown in Figure 5-24, the net Ah removed is greater than 10 times the cell's actual capacity.

For cell \#527, the capacity continuously decline until the cell failed (possible electrolyte fracture) on cycle 104 . The reason for the capacity decline and eventual failure was probably the higher operating temperature and the fact that the cell was sitting at a low 


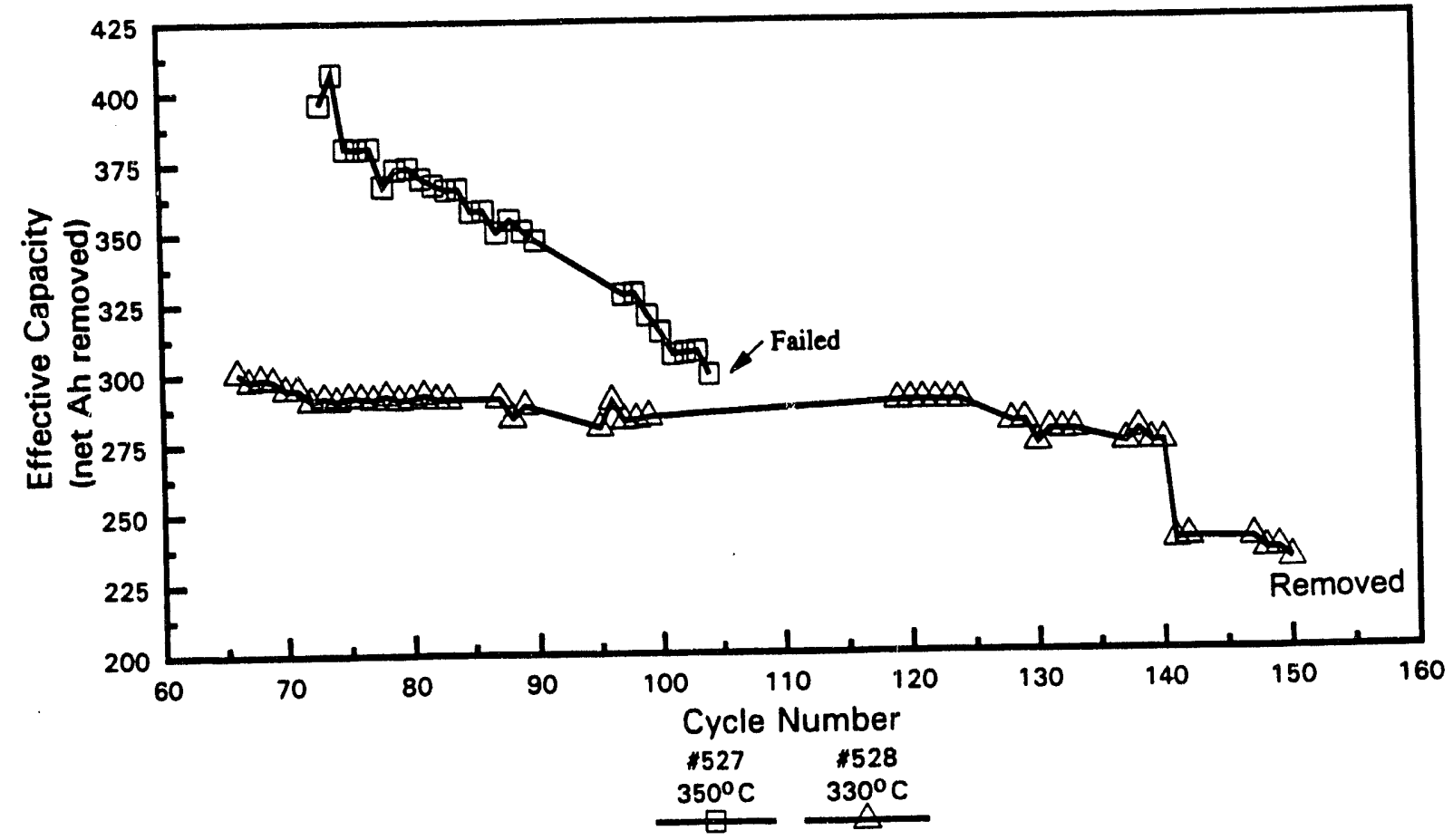

Figure 5-24. Total Ah Discharged per SFR Cycle for XPB Cells \#527 and \#528

SOC for extended periods of time while performing the SFR test profile. During this time, large amounts of corrosion products are generated that could have caused the cell to fail.

For cell \#528, a gradual decline in effective capacity was observed between cycles 125 and 140 . A sudden drop in effective capacity was observed at cycle 140 . The effective capacity of this point was about 230 net Ah removed-a loss of $70 \mathrm{Ah}$. Three sets of baseline capacity tests were performed. The average capacities were $30.6 \mathrm{Ah}, 31.0 \mathrm{Ah}$, and $31.0 \mathrm{Ah}$ as compared to its initial value of $31.3 \mathrm{Ah}$. A plot of all the baseline capacities for cell $\# 528$ is shown on Figure 5-25. The cell was removed from tests at this time because the effect of temperature and the SFR characterization were complete.

\section{Task 3. Four-Cell Strings}

Two 4-cell strings were placed on test in August 1993. The objectives of this testing include the determination of:

- baseline performance (electrical and thermal, including variation between strings)
- pulse discharge and recharge capability as function of DOD

- response to prime candidate applications (e.g., peak shaving, frequency regulation, spinning reserve)

These evaluations are being performed in preparation for the testing of a 13-kWh UES battery presently being fabricated by SPI using similar 4-cell PB strings.

The strings were heated to $350^{\circ} \mathrm{C}$ in order to achieve good wetting of the electrolyte. They were kept at this temperature while three break-in cycles were performed. A measure of how well the electrolyte was wetted can be seen in the end-of-discharge resistance. String 550 had an end-of-discharge resistance of 108 mohms ( $27 \mathrm{mohms} / \mathrm{cell})$, while string 551 had a slightly higher end-of-discharge resistance of $123 \mathrm{mohms}$ ( 30.8 mohms/cell). The temperature of the strings was then reduced to $330^{\circ} \mathrm{C}$, and three baseline capacity tests were performed. The average capacity of string $\mathbf{5 5 0}$ was 10.24 Ah and the average capacity of string 551 was 10.27 Ah. Actual parametric testing will be performed during FY94. 


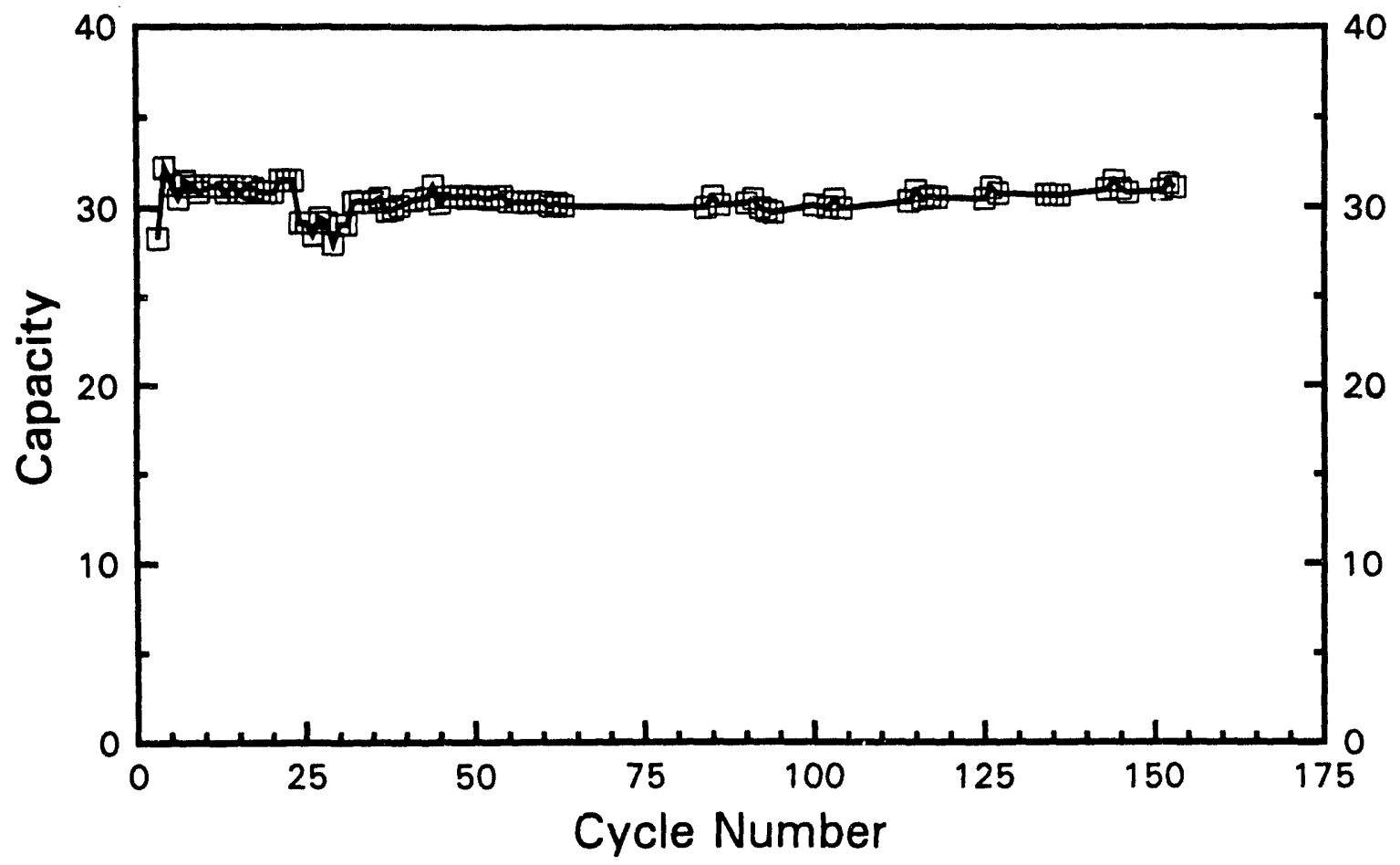

Figure 5-25. Baseline Capacity of Cell \#528 at $330^{\circ} \mathrm{C}$ (C/3 discharge, $\mathrm{C} / 5$ charge $)$ 


\section{System Integration}

The System Integration element is aimed at developing totally integrated battery energy storage systems. The objective is to develop several battery system designs that can meet the various application requirements in the utility operating environment. A modular system design approach is being promoted in all the UBS system engineering and system integration activities to reduce production costs as well as one-of-a-kind engineering and design costs. Omnion Power Engineering is under contract to develop the AC Battery. PG\&E will be the host utility to field-test the first AC Battery prototype container.

\section{AC Battery Development - Omnion}

The AC Battery is a patented, modular battery system concept proposed by Omnion Power Engineering. The concept embodies several of the design features that are desirable for utility operations. It offers redundancy at several levels, ease of maintenance, portability, and unattended remote operation. It also relies on mass manufacturing production techniques to realize the maximum potential of reducing the cost of battery energy systems. Upon completion of a successful development phase, the AC Battery will be able to meet application requirements in the $250-\mathrm{kW}$ to $3-\mathrm{MW}$ size ranges.

In its present form, the AC Battery is a $250-\mathrm{kW} /$ 167-kWh BES system packaged in factory-integrated containers. Each container houses several "modules" that contain the batteries as well as an on-board power conversion system. This enables the modules to accept $\mathrm{AC}$ power and convert it to $\mathrm{DC}$ to charge the batteries. In the discharge mode, the DC output of the batteries is converted to $\mathrm{AC}$ power that is aggregated from all the modules to equal the rated power capaci of the container.

Although the concept is simple and relies on proven battery and power conversion technology, it still combines these technologies in a manner that has not been attempted previously and places the battery in a potentially stressful environment that makes it difficult to predict performance. This uncertainty underscores the need to demonstrate the concept with a prototype container under field conditions.
During FY93, the AC Battery prototype was successfully completed, and field demonstration will begin in early FY94.

\section{Tasks}

The tasks in the AC Battery prototype development contract are described below:

1. PCS Design and Development - Includes the design and control software development of the PCS, design and test of a prototype unit, and design of a production board.

2. Module Design and Development - Includes the design of the module that will house the battery and the PCS boards. Includes the fabrication of a prototype module that will be replicated for the eight modules of the AC Battery container.

3. Container Development - Includes the structural and thermal design of the container to house the modules and meet all the transportability and operating requirements.

4. Production Cost Estimate - Comprises a study to estimate the cost of producing the commercial design of the AC Battery, assuming various rates of production. Also identifies changes in design that might be necessary for economic manufacturability at higher production rates.

5. AC Battery Testing - Includes preparation for the field test of the prototype unit at PG\&E. It is expected that the unit will initially be tested in a laboratory setting and moved to a substation site upon satisfactory checkout.

\section{Status}

\section{Container Design}

During the second quarter FY93, structural design of the container was completed, and a steel fabrication contract was placed with Schmidt Engineering of New Berlin, WI. The Container was delivered to Omnion in July, and final assembly of the unit and installation of the internal wiring were initiated. Following the discovery of a design weakness that could result in damage to the container's vertical corner beams during lifting operations, a structural design modification was finalized and implemented with the installation of removable cross-braces running from the upper corners (at the ends 
of the container) of each door set to the lower opposite corner (middle of the container). These cross-braces will be installed only for lifting and transportation operations and will be removed and stored internally in the container for field operations.

Installation of the internal wiring, air conditioning units, and hydrogen purging system was completed in August. The container was then fully prepared for installation of the modules.

Figure 6-1 is a photograph of the closed AC Battery Container. Figure 6-2 shows the orientation of the modules inside the container.

\section{Module Design}

Module design was finalized in the first quarter FY93, and fabrication of the eight modules was started shortly thereafter. During the second quarter of FY93, several minor design revisions were implemented during the battery rack-and-stack activities at DelcoRemy. Following the assembly of the modules, all eight units were transported to Omnion for the final assembly and cabling of the PCS components. All fabrication activities were completed in early July. During July, operational testing of the eight modules was completed. No major problems were enciuntered, and all module subsystems functioned as specified.

\section{PCS Design}

Most of the design activity was completed in parallel with the module design and fabrication efforts. Mechanical design considerations were emphasized to address the maintainability aspects of the PCS chassis. Cooling of the components was also considered in the positioning of the various high-energy electronic components and printed circuit boards that make up the control subsystem for the PCS. A DC-isolation strategy was implemented with the installation of a manual contactor system, which allows for managing DC voltages in the PCS. The removal and installation of the manual contactors permits the controlled charging and discharging of the PCS capacitors when the DC bus is connected and disconnected from the unit.

On July 8, a review of the power conversion design was held. Under an SNL contract, the University of Wisconsin performed an in-depth overview study of the PCS design to determine if all safety requirements had been met and to determine if the design needed improvements. No significant issues were brought out during the review.

Figure 6-3 is a photograph of the PCS layout on the module. Prior to installation in the container, a shroud is placed over the electronics for both safety and thermal management purposes.

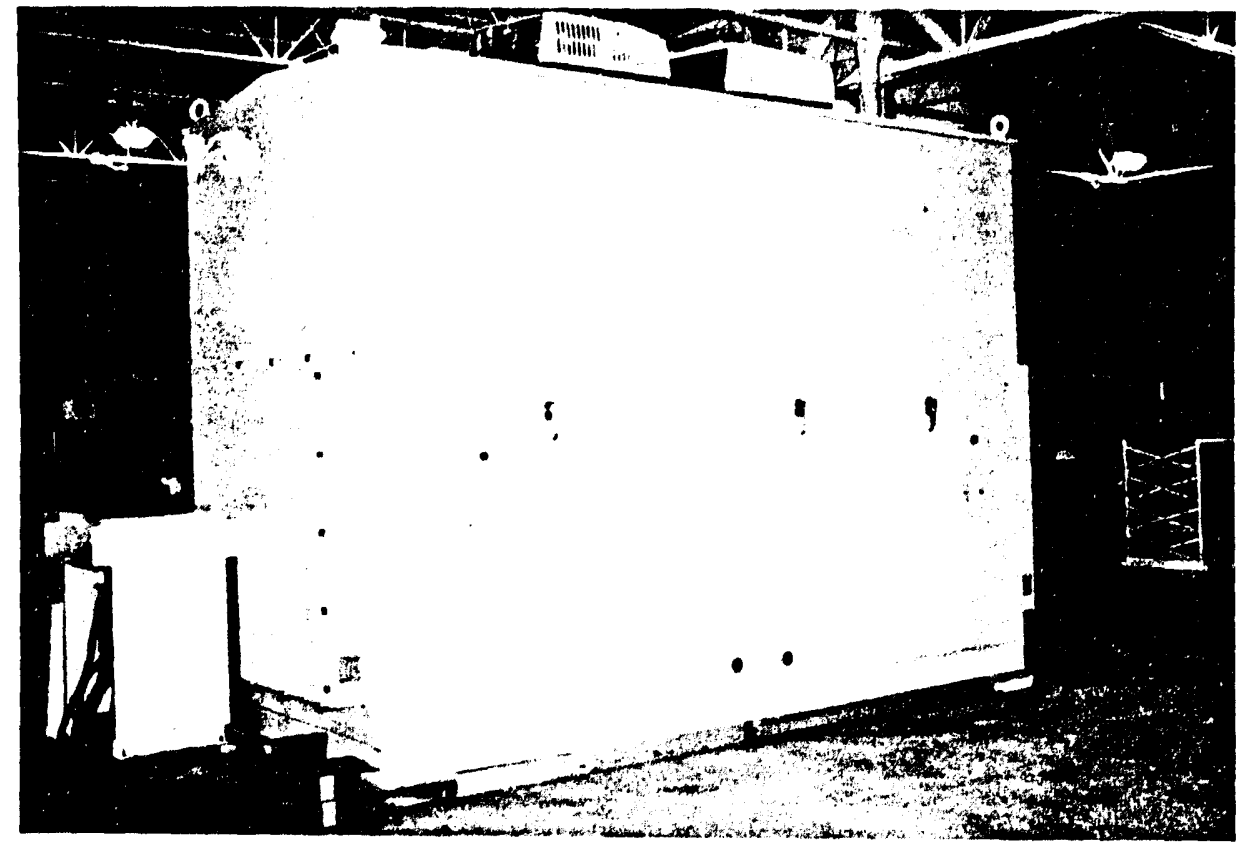

Figure 6-1. AC Battery Container when Closed 


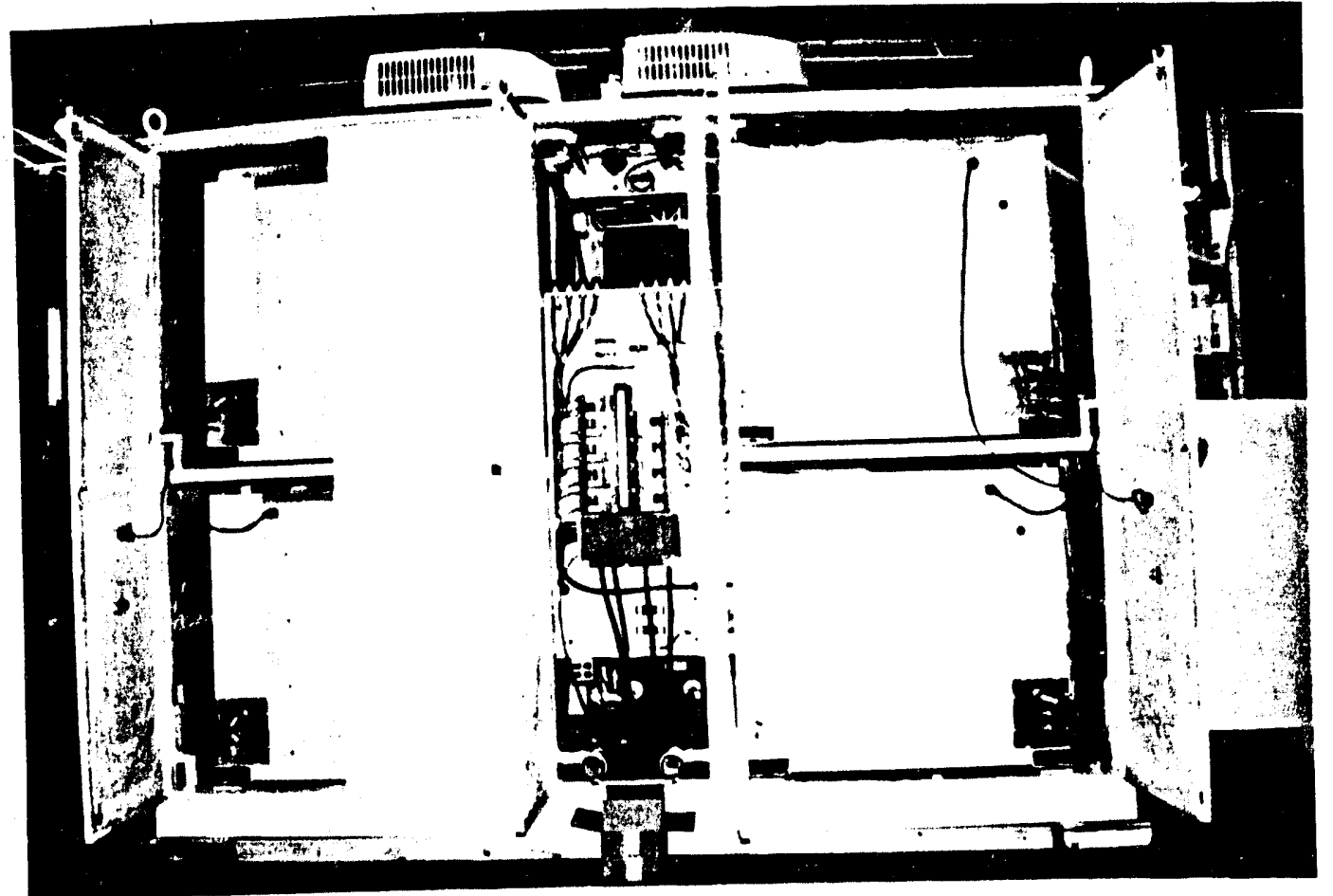

Figure 6-2. Opened AC Battery Container Showing Orientation of Modules

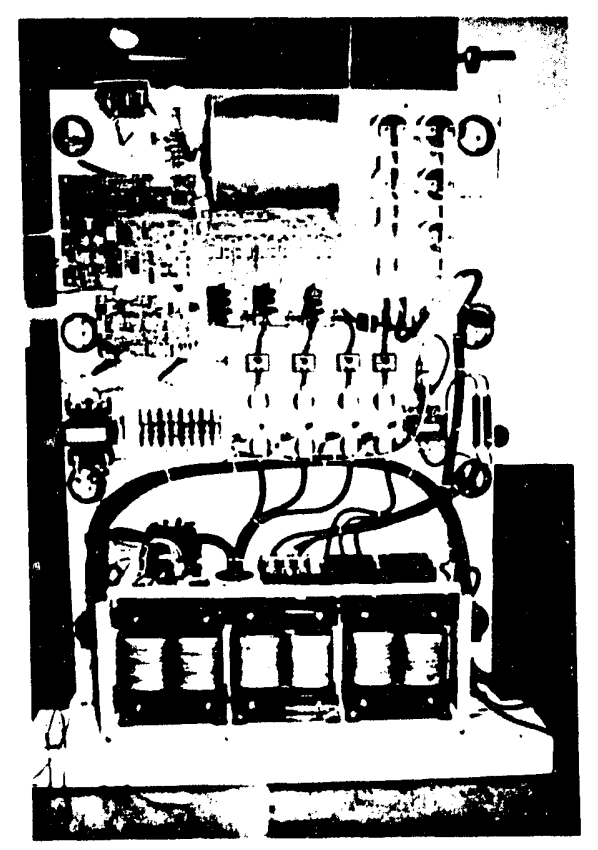

Figure 6-3. PCS for One Module of the AC Battery System 


\section{EPRI Intensive Monitoring Instrumentation System}

Early in the development of the AC Battery design, EPRI became involved with the program by funding an extensive data acquisition system that would provide detailed operational data for two of the AC Battery modules. The system, known as the EPRI Intensive Monitoring Instrumentation System (IMIS), was designed and fabricated during the third quarter FY93. In late July, design work was completed on the EPRI IMIS and assembly was begun. This system will provide detailed performance data on two intensively monitored modules of the AC Battery. Data on each battery in these two modules as well as other information will be collected during all operations. This information will prove to be invaluable in evaluating individual battery performance in long series strings. Information on temperature effects during various operational scenarios is also expected in the evaluation effort.

Figure 6-4 is a photograph of the boxes that contain the EPRI IMIS. There are two boxes on one end of the container and one on the opposite end.

\section{Factory Acceptance and Characterization Testing}

In early August, the container wiring installation was completed, and the unit was turned over to engi- neering for factory testing. System (container) testing was initiated including point-to-point wiring check-out, installation, and interconnection of the modules, parallel operation of the modules, and debugging of the system control software. While numerous minor problems were encountered and corrected as is typical of this kind of prototype testing, overall, the system check-out went well with the exception of the debugging of the system software.

During the week of August 23, representatives from the PG\&E field test team and SNL visited Omnion to participate in the factory testing of the AC Battery system. Demonstration of hardware operation and interface with the local utility system concluded successfully. However, system software exhibited serious problems during the demonstration.

After spending considerable time trying to fully debug the system software, SNL made a decision to delay scheduled system delivery and revise the functions of the system software to take advantage of the SCADA software developed by PG\&E. This decision was precipitated in part by the problems being encountered in debugging Omnion's PC-based software and in part by the advantages of simplifying and streamlining the system software to fully utilize the control functionality of the PG\&E SCADA software. Had the use of SCADA software been anticipated and fully understood at the
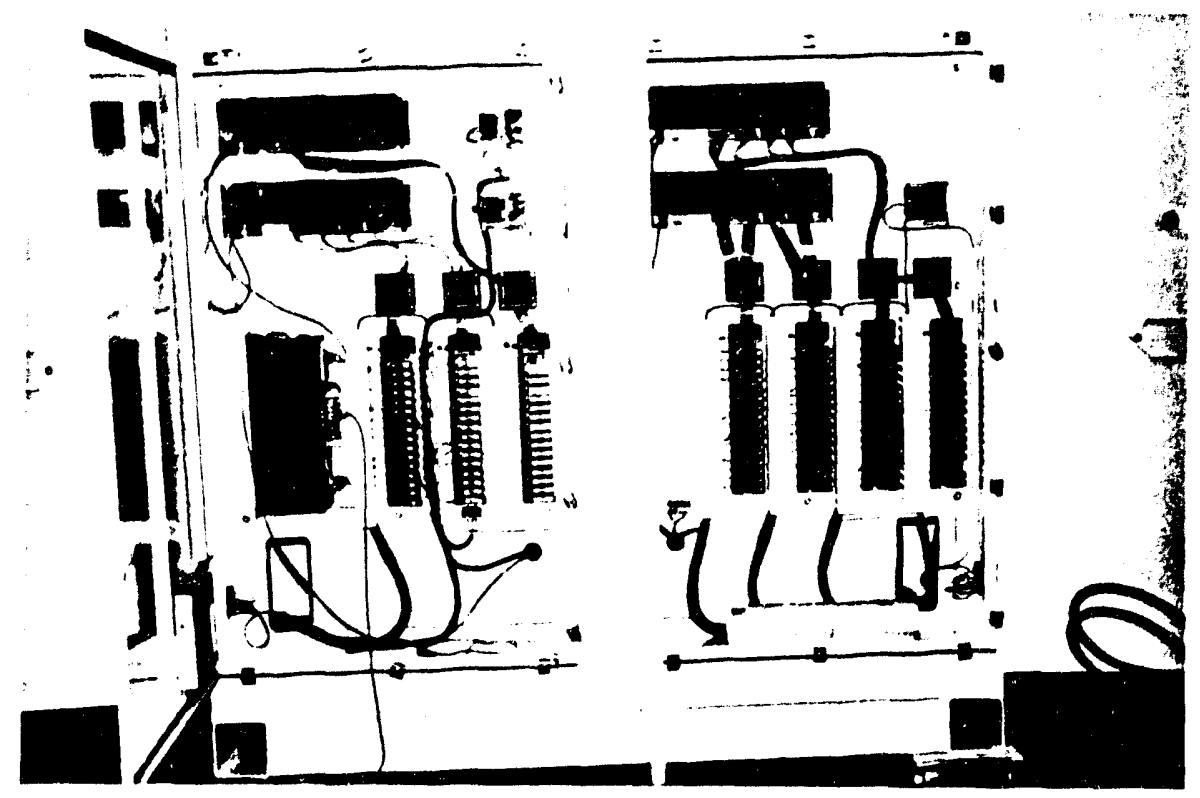

Figure 6-4. EPRI IMIS Boxes 
beginning of the project, this approach would have been incorporated from the very beginning of the development. As a result of the decision to rewrite the system software, new system software was specified in conjunction with PG\&E personnel to fully utilize the features inherent in PG\&E's SCADA software. The decision to rewrite the system software resulted in schedule delays and inherent additional costs. However, a substantially higher quality product has been developed that can readily be incorporated into other utility system operations. SCADA systems are increasingly being employed by utilities to control and monitor both generation and T\&D operations. This approach puts the system exactly in-step with progressive utility practices.

To gain a more comprehensive understanding of the performance of the AC Battery from its assembly at the factory through end-of-life, a baseline benchmark test was defined with mutual agreement among DelcoRemy, Omnion, PG\&E, and SNL. This test consists of a $100 \%$ discharge (to minimum string voltage of 506 VDC) at the 1 -hr rate of $167 \mathrm{~kW}$ (specified 1-hr capacity for system) to determine the actual time required to deplete the entire system (each module). At various points of special interest during initial and life testing, the baseline test will be conducted to generate a life history database that will ultimately define the capacity and life expectancy of the AC Battery system. The first test will be conducted at Omnion just prior to shipping; the second will be conducted at PG\&E as soon as the initial installation and safety checks have been completed. At other points during field testing, identical baseline tests will be performed to generate the life history database for the AC Battery.

\section{Miscellaneous Items}

Several power milestones were noted during the final quarter of FY93. During acceptance testing on August 25, 1993, the AC Battery system was operated with all eight modules in parallel at $100 \mathrm{~kW}$ of power. On September 13,1993, the AC Battery system was operated at its rated capacity of $250 \mathrm{~kW}$ of power. No system anomalies were noted during these tests.

Because of the delays during final check-out of the system, several changes were made to the delivery schedule. Initially, the AC Battery was scheduled for shipping in late August immediately following acceptance testing. This date was slipped to mid-October to allow for complete checkout of the system after the system software rewrite completion. The system is scheduled to be in place and fully functional at PG\&E on November 8, 1993. 


\section{System Field Evaluation}

In the System Field Evaluation element, the qualification of hardware incorporating the prototype design and associated manufacturing methods represents the final step of engineering developmant. The process involves the characterization of performance, maintenance requirements, and reliability of integrated systems at relevant utility sites. Two key activities have been initiated in this program element, and their progress is reported here.

\section{Pacific Gas \& Electric}

\section{Background}

In August 1990, PG\&E met with Omnion Power Engineering Corporation to discuss a new battery storage system for grid-connected applications. The AC Battery System promised a number of attractive features, including a high degree of modularity, mass produced components, factory assembly, safe and efficient maintenance, and high power quality. PG\&E followed closely the development of the system, provided ongoing design support, and later entered into a contractual agreement with SNL in November 1992 to host a utility demonstration of the proposed system. PG\&E will test the AC Battery prototype under simulated utility operating conditions at the Modular Generation Test Facility (MGTF). The MGTF is a unique test facility, owned and operated by PG\&E, where precommercial prototypes of various utility-generation sources can be tested in a controlled environment.

Under the scope of the SNL contract, PG\&E will develop a test plan for the AC Battery prototype in various operating modes. In addition to purely operational tests, PG\&E will also evaluate the maintainability of the system under simulated field conditions. PG\&E was charged with the following tasks:

- Design Input

- Review of Preliminary and Final Designs

- Test Site Selection

- Development of Test Plan

- Pre-shipment System Checkout
- Installation and Test in Laboratory

- Field Test

- Final Report

During FY93, significant progress was made toward better understanding the design, application, and operation of the AC Battery system.

\section{Status}

\section{Site Preparation}

During the second and third quarter of 1993, PG\&E successfully prepared the AC Battery test site, located adjacent to the Smart Substation at PG\&E's Technical and Ecological Services Department in San Ramon, CA.

The AC Battery will be electrically connected to the 480-V secondary of a 1-MVA transformer in the Smart Substation yard. A control building, approximately 50 $\mathrm{ft}$ from the AC Battery pad, will house the control computer running the various SCADA applications supporting the testing and operation of the unit. A switchgear building houses protective equipment and current/voltage transformers for output measurements. A schematic of the Smart Substation showing the location of the AC Battery system is shown in Figure 7-1.

Conduit has been installed between these structures and a central pull-box in the Substation yard. Power cables have been pulled through the conduit, ready for connection to the AC Battery. A circuit breaker, current transducers (CTs), and power transducers (PTs) have been installed. Power transducers have been calibrated by the TES Standards Laboratory and await shipment of the container for installation.

A $17 \times 8 \mathrm{ft}$ concrete foundation with steel reinforcing bar has been poured onto which the AC Battery container will be lowered. A second foundation for the $277 /$ 480-V autotransformer has been poured. The entire test site has been enclosed with cyclone fencing, including a walk-through gate and large swing gate for fork-lift access.

Safety equipment has been installed including three $\mathrm{CO}_{2}$ fire extinguishers, a box to hold safety goggles, a shower/eyewash station with associated plumbing, and warning signs. Landscaping has been installed includ- 


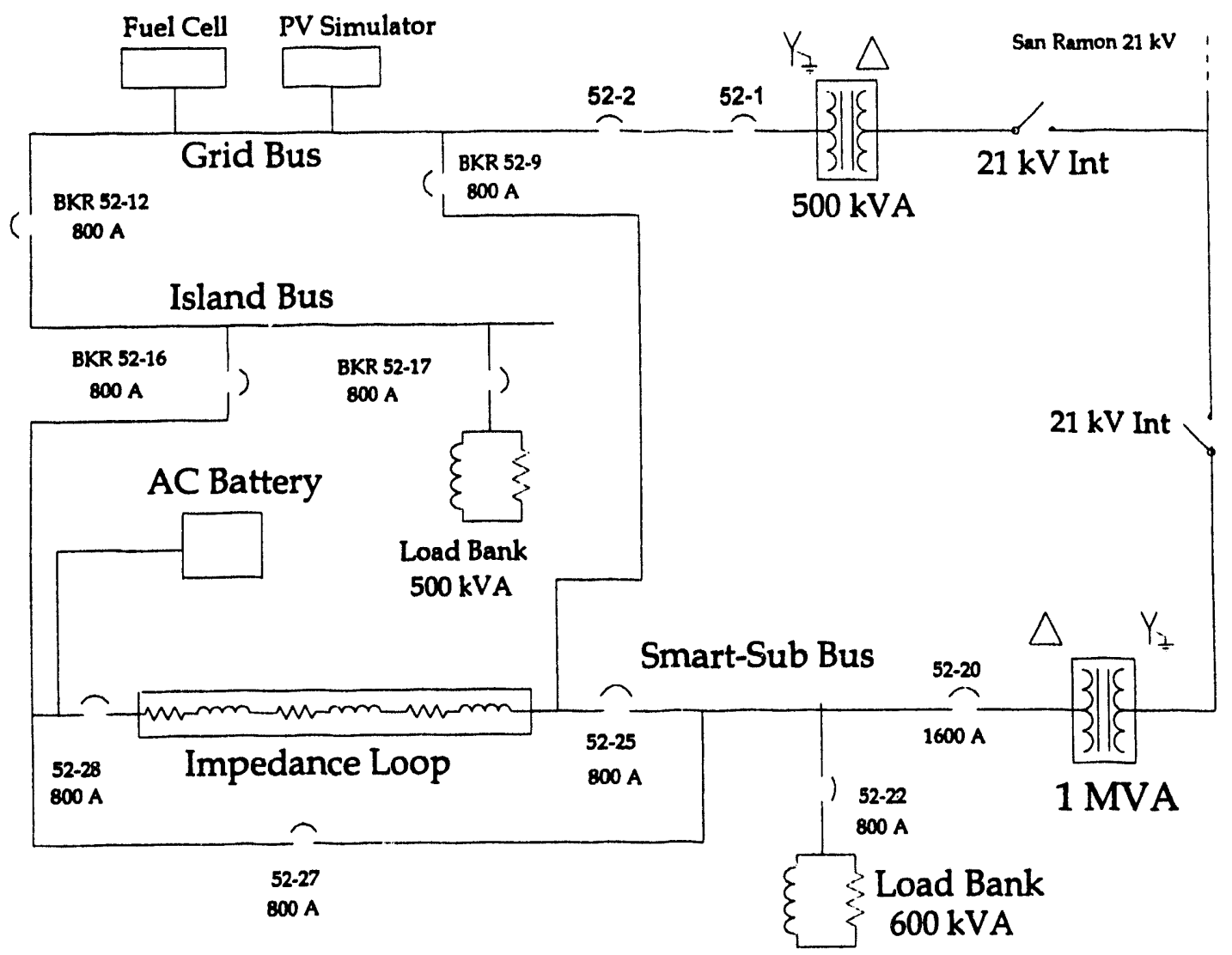

Figure 7-1. Schematic of PG\&E's Smart Substation with AC Battery Installed

ing potted trees and plants, underground drip irrigation, and an electrical timer.

The physical site preparation is therefore complete and ready for off-loading the AC Battery container. For the actual installation, a crane will be contracted to lift the container over the fence and set it onto the concrete pad.

\section{Test Plan}

A comprehensive test plan has been prepared and reviewed by SNL, Omnion, and EPRI. The document is currently in publication through the PG\&E R\&D Reports Group. The report, which includes detailed objectives and procedures, includes the following tests:

- Protection and Pre-Parallel Inspection. Electrical protection and paralleling requirements for utility interconnection are addressed in these tests. The system will be approved for operation by PG\&E protection personnel.

- Start-Up and Internal Protection. Start-up refers to a procedure initiated by Omnion to methodically step through field start-up. The internal protection tests address container control functions that ensure safety to the system, the utility, and personnel, given system problems or abnormal operating conditions.

- Start-up

- Internal Protection

- Steady-State Performance Tests. The steadystate performance tests cover all aspects of the system's normal operating modes. Specificaliy evaluated here are the initial benchmark characterization, constant power discharge capacities, recharge characteristics, converter and system round-trip efficiencies, power factor control and static VAR compensation, load following capacities, dual-peak (opportunity charging) capacities, harmonics, noise, radio frequency interference (RFI), thermal regulation, and system auxiliary losses.

- Nominal Benchmark Discharge

- Power Factor Control and Power Quality

- Block Load Characterizations

- Load Follow Characterizations

- Auxiliary Load Characterization

- Thermal Regulation 
- Dynamic Response Tests. The dynamic response tests cover two main areas: first, the system's speed of response and stability following abrupt changes in the commanded mode of operation and, second, the ability to respond to dynamic (abnormal) conditions originating from the utility. This second area includes scenarios such as utility voltage swings or the threat of islanding, which follows from a loss-of-utility condition.

- Speed and Stability

- Interconnection Tolerance Protection

- Islanding

- Long-Term Behavior Tests. The long-term behavior tests will ascertain the system's lifecycle performance characteristics. The duration of the long-term tests will likely be between 6 mo and a year, assuming that there are not significant periods of down-time.

\section{SCADA Interface}

PG\&E desired to control the AC Battery through a standard SCADA communications protocol in use throughout the company. Several SCADA "platforms" exist that implement this protocol. Among these, a software package developed in-house, PC-SCADA was used since it provided the necessary flexibility required for the project. The existing version of PC-SCADA was DOS-based, but during the first and second quarter of 1993, PC-SCADA was converted (outside the project) to run under the Windows operating environment. PG\&E selected the Windows product, since its multitasking capabilities were required to perform certain functions of battery system control. The AC Battery project therefore served as a beta-test for the new SCADA software.

PG\&E hosted a course on the DOS-based version for the internal project team and a representative of Omnion on February 22-24 in San Ramon. This course served as an introduction to the capabilities of the SCADA software in order to facilitate the development of communication software between the PG\&E Master Controller and the AC Battery Container.

PG\&E successfully implemented data acquisition and a set of battery control modes using the Windowsbased PC-SCADA. Furthermore, a "demand generator" application was developed to simulate real-time substation loads. Another application that averages and stores AC Battery data was developed. All of these programs were demonstrated at Omnion during the week of September 20. A schematic of the SCADA design and interface with the AC Battery system is shown in Figure 7-2.

Since that time, PG\&E has agreed to take responsibility for developing additional code related to the scheduling of the various modes, such as charge, discharge, and load following, originally to be implemented by the manufacturer in the container computer. Specifications for the additional software are complete, and the product should be ready at the time of factory testing.

\section{Design Input}

A number of activities related to the design of the AC Battery system were performed. On February 3, PG\&E met with SNL and Omnion at the manufacturer's headquarters to review design details and to define the respective responsibilities of the software developers in ensuring communications between the Master Station and the container. PG\&E husted a safety review meeting on March 25, attended by Division planners, protection engineers, operators, and researchers. A design requirements document was submitted to SNL in May. Four PG\&E representatives witnessed factory testing during the week of September 20.

\section{Safety Manual}

An "Operational Safety Procedure" manual was written during September and approved on September 21 by the AC Battery Operations Manager and the Technical and Ecological Services Health and Safety Coordinator. This document discusses the potential hazards of operation, hazardous materials, safety equipment and procedures, maintenance related to safety, operator training requirements, and emergency procedures. A copy of the manual will be located at the AC Battery test site and will be read and signed by all operators.

\section{Special Evaluation at SNL - PREPAC\&D Lead-Acid Battery}

Testing of the 12 C\&D Charter Power Systems, Inc., (C\&D) flooded lead-acid cells that PREPA is installing in their 20-MW BES system has continued. This PREPA facility will contain 6000 of these cells configured in five parallel strings. Each cell has a nominal 2000-Ah capacity. The BES system will be used to provide frequency regulation and spinning reserve for the PREPA system. The main objective of the tests at SNL is to assess the thermal load that will be imposed on the battery facility during normal operation of the 


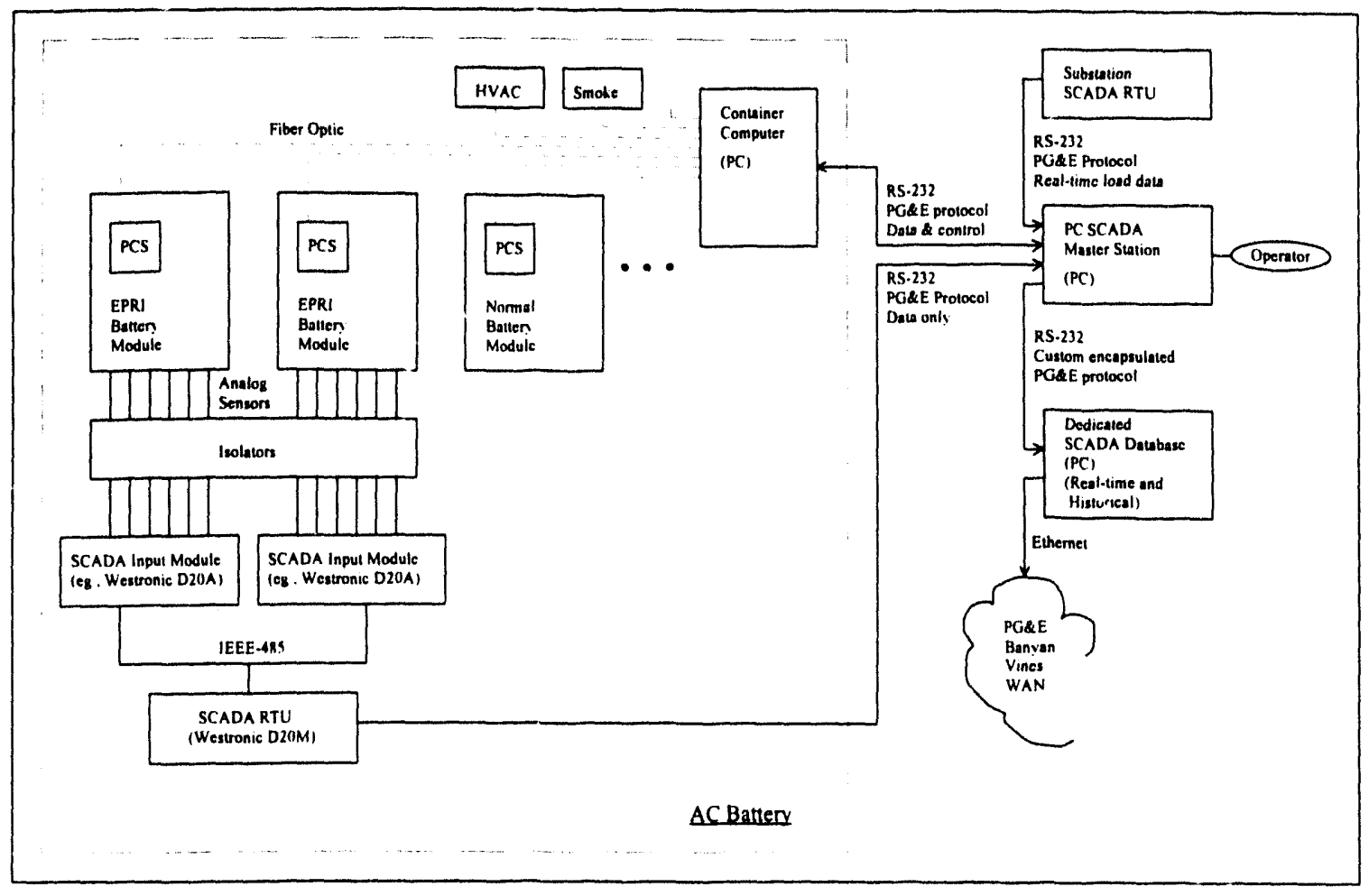

Figure 7-2. Schematic of SCADA System and AC Battery Container

BES system. If the results indicate that the cooling system has been undersized, then adjustments can be made before operation of the facility begins.

\section{Set-Up of Test Parameters}

The test at SNL is using 12 cells identical to those that were shipped to Puerto Rico. These have been configured as a single series string operating at a nominal $24 \mathrm{~V}$. To create an environment for the battery that is similar to what it will experience in the Puerto Rico BESS, the cells have been arranged back-to-back on two levels with the same rack system that is being used in Puerto Rico as shown in Figure 7-3. This duplicates the arrangement and separation of the cells in the BES system. Ambient temperatures in Puerto Rico are expected to be relatively high for much of the year, so a thermal enclosure that was large enough to house the entire battery string was built inside the test laboratory. This 900- $\mathrm{ft}^{3}$ chamber can be heated to temperatures in excess of $100^{\circ} \mathrm{F}$ by means of internal heater panels. Tests were run under various temperature conditions to determine whether the operation of the battery or the heat rejected were significantly affected by the ambient temperature.

A test cycle that simulates the actual use situation for the BES system has also been devised. The first part of the cycle is composed of several sessions of frequency regulation separated by intermediate charges. These are followed by a spinning reserve discharge, and then a final refreshing charge that brings the battery back to $100 \%$ SOC. As diagrammed in Figure 7-4, one of these UES cycles typically contains three frequency regulation sessions and requires approximately one week to complete. Although the battery starts out at $100 \%$ SOC, it operates between 92 and $72 \%$ SOC during most of the frequency regulation part of the cycle. One spinning reserve cycle per week corresponds fairly well to the $\mathbf{5 5}$ times per year estimated for that mode of use at PREPA. The first half of the spinning reserve profile is spent at constant power, and then the power ramps down to zero for the second half.

Power levels for the various portions of the UES cycle were scaled to the 12-cell string values from estimates of the PREPA BES system operating parameters made by United Engineers and Constructors (now Raytheon Engineers and Constructors). They found that frequency regulation at PREPA could be represented by three power levels with operating times in the ratio of $1: 2: 13$. These were used to set up a basic $160-\mathrm{min}$ building block for frequency regulation that is composed of 32 asymmetrically arranged 5 -min segments as shown in Figure 7-5. Table 7-1 lists the power levels 


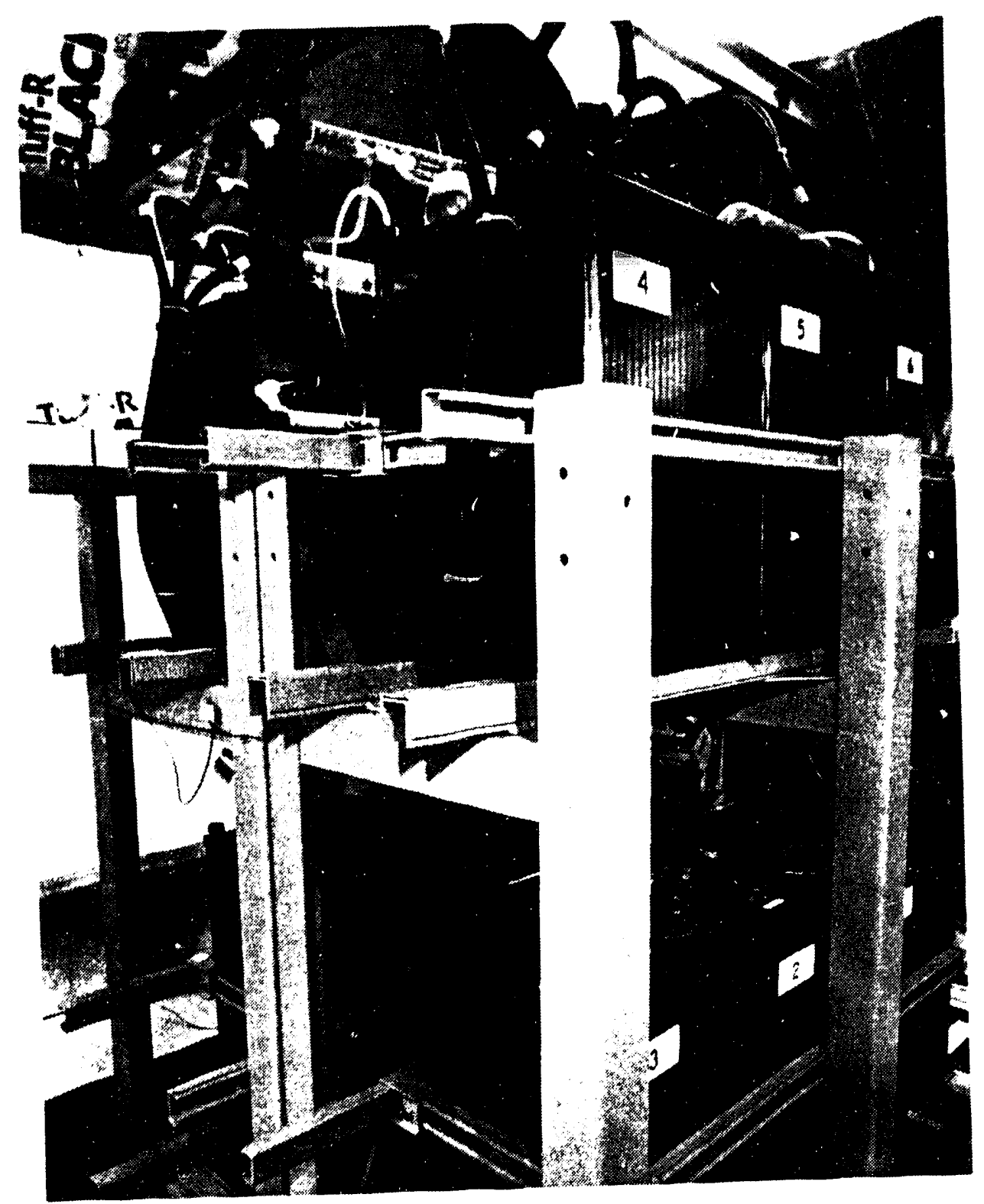

Figure 7-3. Twelve-Cell Series String of Lead-Acid Batteries Mounted for Testing

estimated for PREPA and the corresponding scaled values for the 12 -cell string. One area in which the actual test parameters deviated from these scaled values was the high level recharge power during frequency regulation where the power was reduced to $18.2 \mathrm{~kW}$ so that the battery could be operated at up $1095 \%$ SOC. With these parameters, th: first frequency regulation session usually ran for $4(0.50 \mathrm{hr}$ before the battery had to be recharged and the second and third sessions each ran for approximately $30 \mathrm{hr}$. This operating mode produced a capacity turnover rate (battery capacity discharged in 24 hr divided by rated battery capacity of 2.55. A second exception to the scaled parameters was the discharge power level during the spinning reserve part of the test. The number of load modules needed to handle $42 \mathrm{~kW}$ was not initially available, so the power was reduced to $31.5 \mathrm{~kW}$. In order to partly compensate for the reduced power, the length of time was increased from $30 \mathrm{~min}$. total, to $40 \mathrm{~min}$. This kept the battery capacity discharged during the test approximately the same as for the actual scaled power level

Calculation of the battery SOC during the tests was originally based on a $95 \%$ coulombic efficiency. With this efficiency factor, the battery was being recharged to a higher SOC level than desired during the intermediate 


\section{Weekly Pattern}

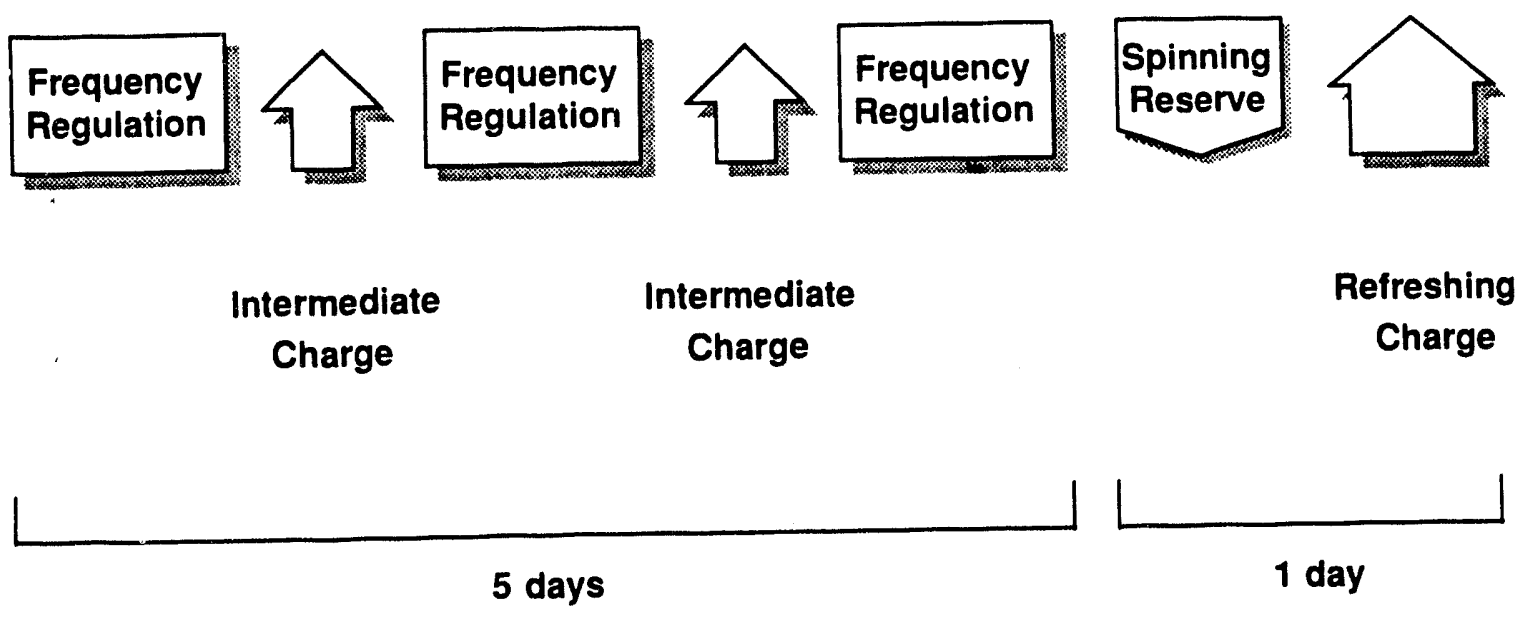

Figure 7-4. Diagram of the UES Cycle

Table 7-1. Estimated and Scaled Power Levels for the UES Cycle

\begin{tabular}{lcc} 
Application & $\begin{array}{c}\text { Est. BES System } \\
\text { Power (MW) }\end{array}$ & $\begin{array}{c}\text { Scaled Power Level } \\
\text { (kW) }\end{array}$ \\
\hline Frequency Regulation & 2.0 & 4.00 \\
Frequency Regulation & 6.0 & 12.0 \\
Frequency Regulation & 10.0 & 20.0 \\
Spinning Reserve, constant & $21,15 \mathrm{~min}$ & $42,15 \mathrm{~min}$ \\
Spinning Reserve, ramp & $21-0,15 \mathrm{~min}$ & $42-0,15 \mathrm{~min}$
\end{tabular}

charge periods. This caused voltage levels to hit their limit during the first part of the following frequency regulation session. A change to assume a $100 \%$ coulombic efficiency corrected this problem, although it was apparent that with this factor a slight undercharge was occurring. The battery voltage at the start of the third frequency regulation session typically declined compared to the same point in the second session. This drop was small, about $0.1 \mathrm{~V}$ at ambient, and decreased to approximately $0.025 \mathrm{~V}$ during the elevated temperature UES cycles, indicating the battery was operating more efficiently at those conditions. No difficulty was encountered in chaining together three frequency regulation sessions using this SOC calculation method.

\section{Collection of Thermal Data}

During the past quarter, tests have concentrated on completing collection of the thermal data and analyzing 


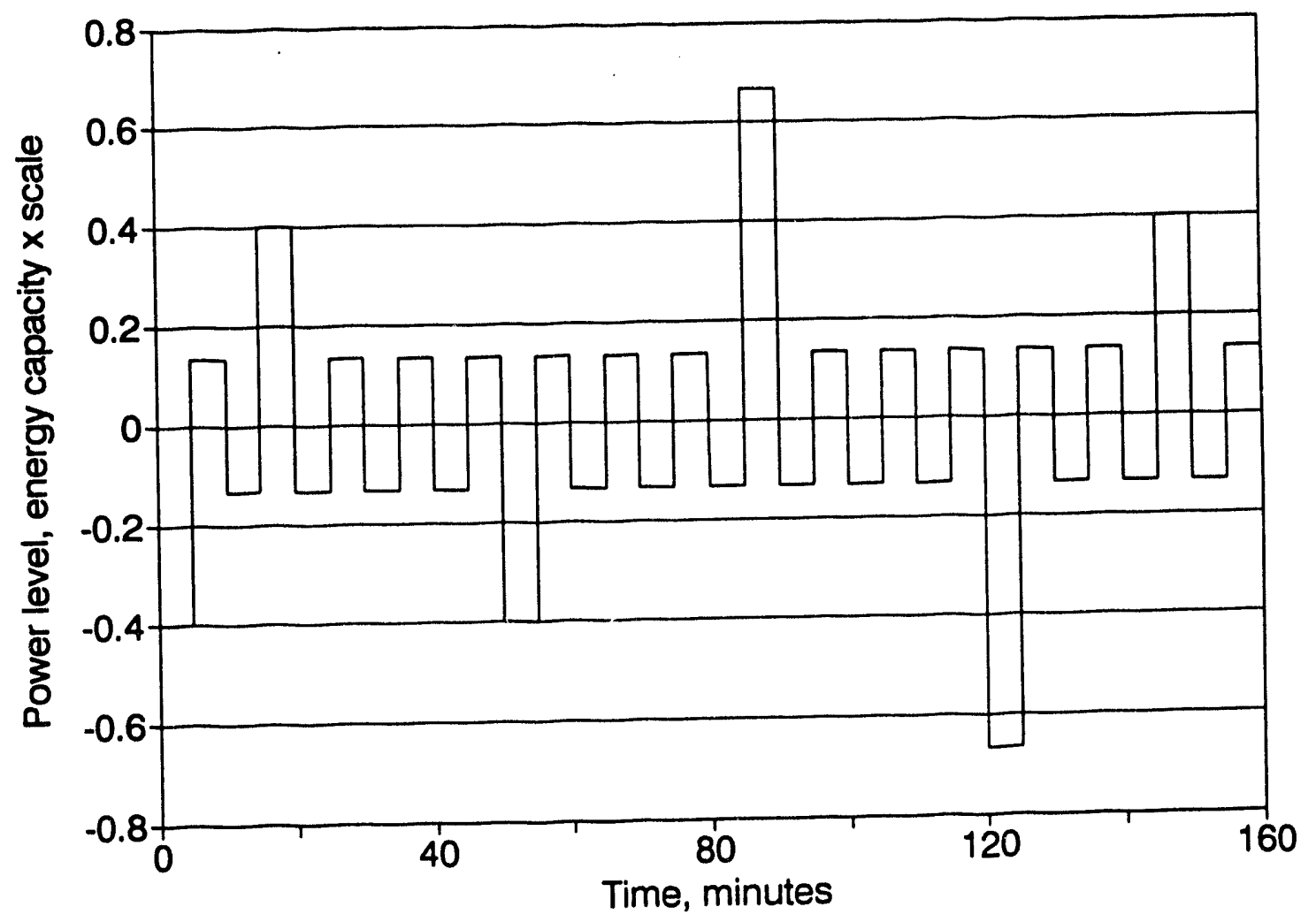

Figure 7-5. Basic 160-min Subcycle That Serves as a Building Block for Frequency Regulation Testing. Between 10 and 20 subrycles run consecutively form a frequency regulation session.

the results. Earlier results were measured with a starting temperature in the chamber either at ambient or at $100^{\circ} \mathrm{F}$. At the beginning of this quarter, the chamber temperature was lowered to a nominal $90^{\circ} \mathrm{F}$ in order to acquire data at an intermediate temperature. In the first UES cycle under this condition, the average electrolyte temperature increased from $87.6^{\circ} \mathrm{F}$ at the beginning of the test to a maximum of $102.5^{\circ} \mathrm{F}$ during frequency regulation. The peak temperature during the spinning reserve part of the test was about $107^{\circ} \mathrm{F}$. During a second UES cycle, the average temperature began at $87.5^{\circ} \mathrm{F}$ and the maximum during frequency regulation was $102.9^{\circ} \mathrm{F}$. In this case, the spinning reserve peak temperature was $108.3^{\circ} \mathrm{F}$. A third UES cycle at $90^{\circ} \mathrm{F}$ in which operation in frequency regulation mode was resumed immediately after completion of the final refreshing charge was run to see if a different equilibrium temperature would be reached starting with a warm battery. This test started from a slightly higher initial temperature of $93.2^{\circ} \mathrm{F}$, but the peak temperatures during the UES cycle were comparable to the first two cycles at $90^{\circ} \mathrm{F}$. Cell temperatures returned to their previous frequency regulation levels in the first session after the refreshing charge.
Data collection at the $90^{\circ} \mathrm{F}$ starting temperature went smoothly except for the fact that the power at the end of the constant part of the spinning reserve test dropped down to about $22 \mathrm{~kW}$ for 9-10 min in all cases. This was because of a thermal cutoff of one or more of the load modules on the cycler that overheated because of a high ambient temperature in the test laboratory. Inadequate air conditioning in the building caused this to be a recurring difficulty during the hot summer months. It is expected that the spinning reserve test will run to completion at full power again once outdoor temperatures have cooled in the fall.

Figure 7-6 shows how representative temperature data from one of the $90^{\circ} \mathrm{F}$ tests compare to that obtained starting from ambient and $100^{\circ} \mathrm{F}$. In general, the most recent results were consistent with the earlier experiments. During frequency regulation, a thermal equilibrium was reached within roughly the first $10 \mathrm{hr}$. Temperature data were stored twice per 160-min frequency regulation subcycle, once immediately after the second intermediate power level discharge and once after the high power level discharge, so the effects on temperature of power changes between the individual 5-min 
Starting Chamber Temperature: Ambient

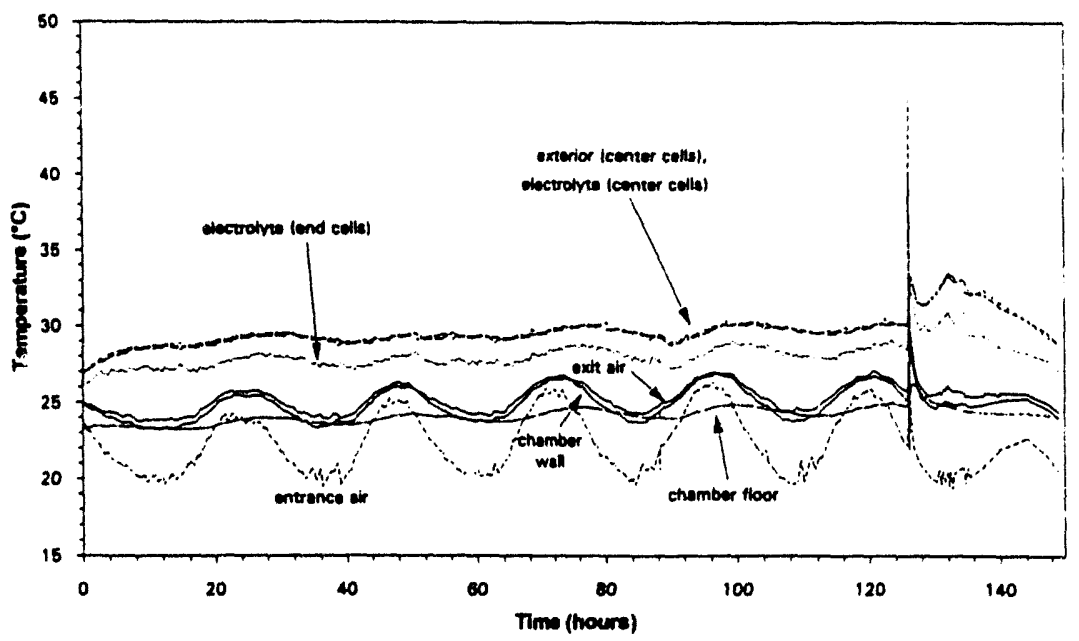

Starting Chamber Temperature: $32.20 \mathrm{C}(800 \mathrm{~F}$

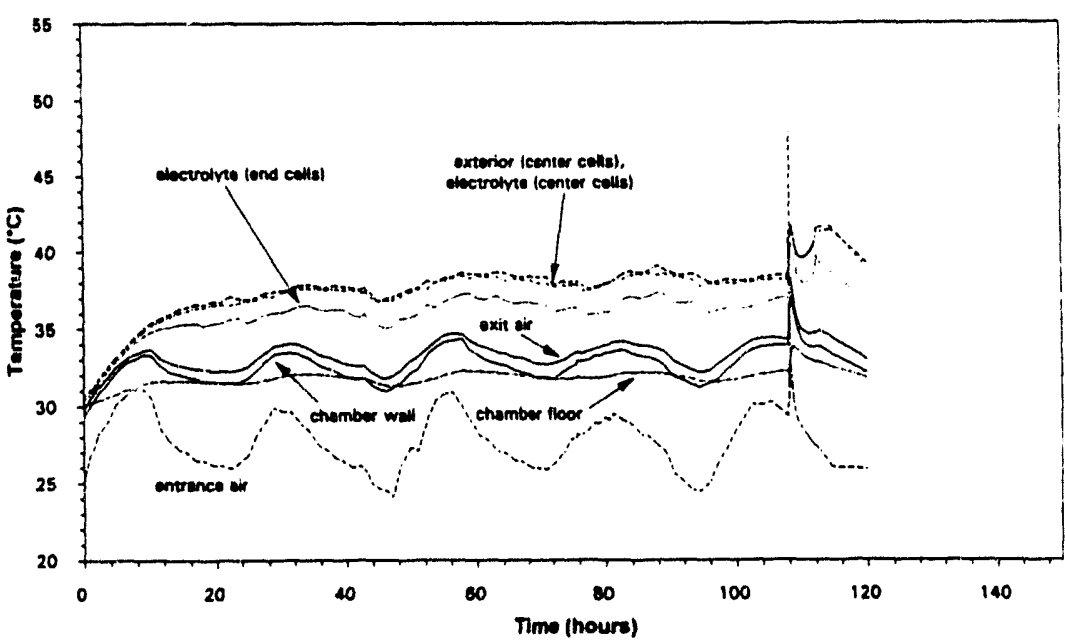

Sterting Chamber Tempsrature: $37.80 \mathrm{C}$ (1000F)

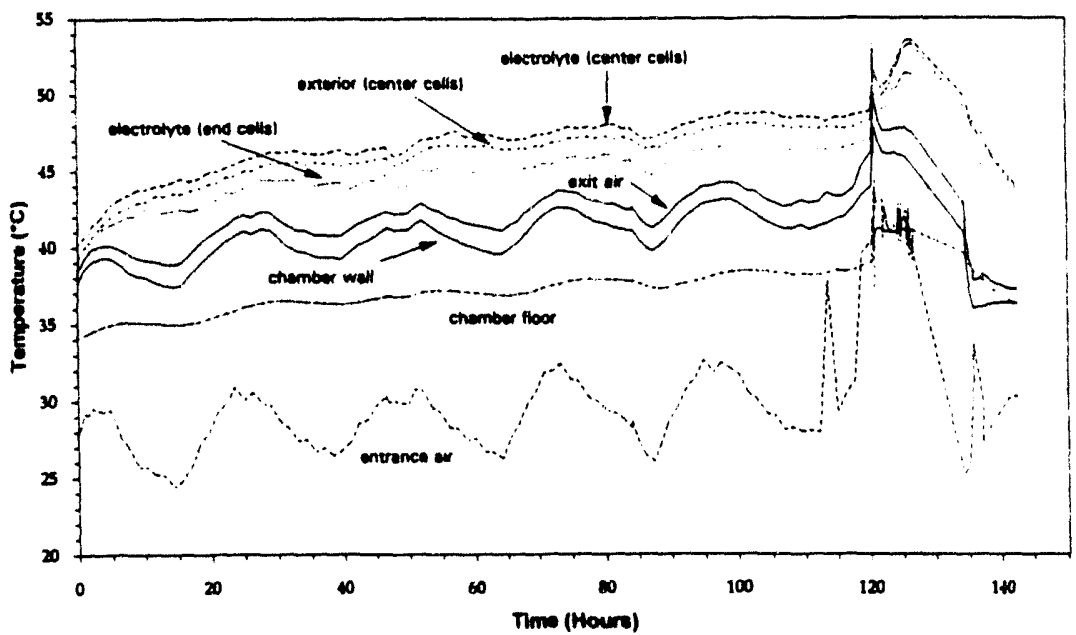

Figure 7-6. Representative Cell and Chamber Temperatures for UES Cycles Starting from Different Conditions 
segments were not resolved. However, the large thermal mass of the battery would likely prevent these shifts from being detected in such a short time anyway. Even the 3-1/3-hr intermediate charge did not show up clearly during review of the temperature data from a single experiment. As before, the end cells in the battery stack were significantly cooler than the cells in the center of the rows and the difference appeared to be nearly the same regardless of the starting temperature for the test. Since the end cells have more exposed surfaces, radiation to the cooler chamber walls should be more effective for them, and convective cooling may also be more efficient. Exterior temperatures of the center cells tracked closely with their electrolyte temperatures. This was also true for experiments starting at ambient temperature, but at $100^{\circ} \mathrm{F}$ the cell exterior was slightly cooler than the electrolyte. The temperature of the entrance air to the chamber has continued to cycle over a $5^{\circ} \mathrm{C}\left(9^{\circ} \mathrm{F}\right)$ range, depending on the time of day. This diurnal cycle was also reflected in the exit air and chamber wall temperatures, and to a lesser extent in the cell temperatures. It does appear that the separation between the exit air and chamber wall temperature is increasing as the starting temperature for the UES cycle increases.

A replicate UES cycle at $100^{\circ} \mathrm{F}$ was carried out, since all of the power supplies were not operating at the beginning of one of the two earlier cycles at this temperature. The results were similar to the earlier ones, and the spinning reserve part of the test did run all the way through at programmed power levels in contrast to the previous UES cycles at $100^{\circ} \mathrm{F}$.

The step change nature of the current profile during the frequency regulation part of the UES cycle afforded an opportunity to calculate a battery resistance from the operating data. Changes in voltage and current between the three different discharge power levels were employed to calculate the resistance by a method originally obtained from Powerplex Technologies, Inc. This type of analysis had previously been used to calculate open-circuit voltages for termination of modulated discharge experiments during sodium/sulfur cell testing at SNL. Since the voltage shifts were small, several trials were necessary to choose the best data point within each segment before the analysis results were self-consistent. Representative data are shown in Figure 7-7. In general, the calculated resistances ranged from 110-175 $\mu \mathrm{ohms} /$ cell, which was slightly higher than the $65 \mu \mathrm{ohms}$ at full charge quoted by C\&D for this type of cell. As will be explained later, the resistances proved to be useful for confirming battery resistance values needed for the analysis of thermal data collected during the spinning reserve part of the UES cycles.

\section{Evaluation of Battery Operating Characteristics}

The battery had been operated for $\sim 3$ mo by the end of the fiscal year. One-third of this time was spent setting up and testing the operating cycle and two-thirds collecting thermal data. Data had been logged for a total of 39 sessions of frequency regulation and 14 spinning reserve discharges (each UES cycle contains three frequency regulation sessions and one spinning reserve discharge).

Electrolyte levels had dropped to the low mark after $2-1 / 2$ mo of operation, so the cells were watered. A total volume of $9.5 \mathrm{~L}$ was required to bring the electrolyte back up to the full level. Electrolyte densities were measured several times following watering and, after an initial drop, approached values indicating thorough mixing by the time the battery had gone through several deep cycles. Table 7-2 shows a summary of the temperature corrected density values.

Capacity tests were also repeated after watering for comparison to results recorded before the thermal testing began. Several discharges were run with results that improved somewhat, but never reached the maximum values that were measured in the initial capacity tests (see Table 7-3). The battery has not been equalized since the testing began, and this may be responsible for the slightly lower capacity measured recently, although the cell voltage spread at the tail of the refreshing charge is still within $\pm 50 \mathrm{mV}$ of the string average as specified by the manufacturer.

\section{Analysis of Thermal Data}

An improved thermal model has been used to analyze the experimental results and to predict the expected thermal behavior of the PREPA BES system. To briefly recap, the functional form of the model is as shown below:

$$
\begin{aligned}
& \mathrm{MC}_{\mathrm{p}} \frac{\mathrm{dT}}{\mathrm{dt}}+\mathrm{h} \Lambda\left(\mathrm{T}-\mathrm{T}_{\mathrm{s}}(\mathrm{t})\right)=\dot{\mathrm{Q}} \text { or } \\
& \mathrm{A} \frac{\mathrm{dT}}{\mathrm{dt}}+\mathrm{B}\left(\mathrm{T}-\mathrm{T}_{\mathrm{s}}(\mathrm{t})\right)=\dot{\mathrm{Q}}
\end{aligned}
$$

where:

$M$ is the mass of a cell $(204 \mathrm{~kg})$

$\mathrm{C}_{\mathrm{p}}$ is the effective heat capacity of a cell $\left(669 \mathrm{~J} / \mathrm{kg}-{ }^{\circ} \mathrm{C}\right)$

$\mathrm{T}$ is the cell temperature $\left({ }^{\circ} \mathrm{C}\right)$

$T_{s}(t)$ is the time-dependent heat sink temperature $\left({ }^{\circ} \mathrm{C}\right)$

$t$ is time (s) 


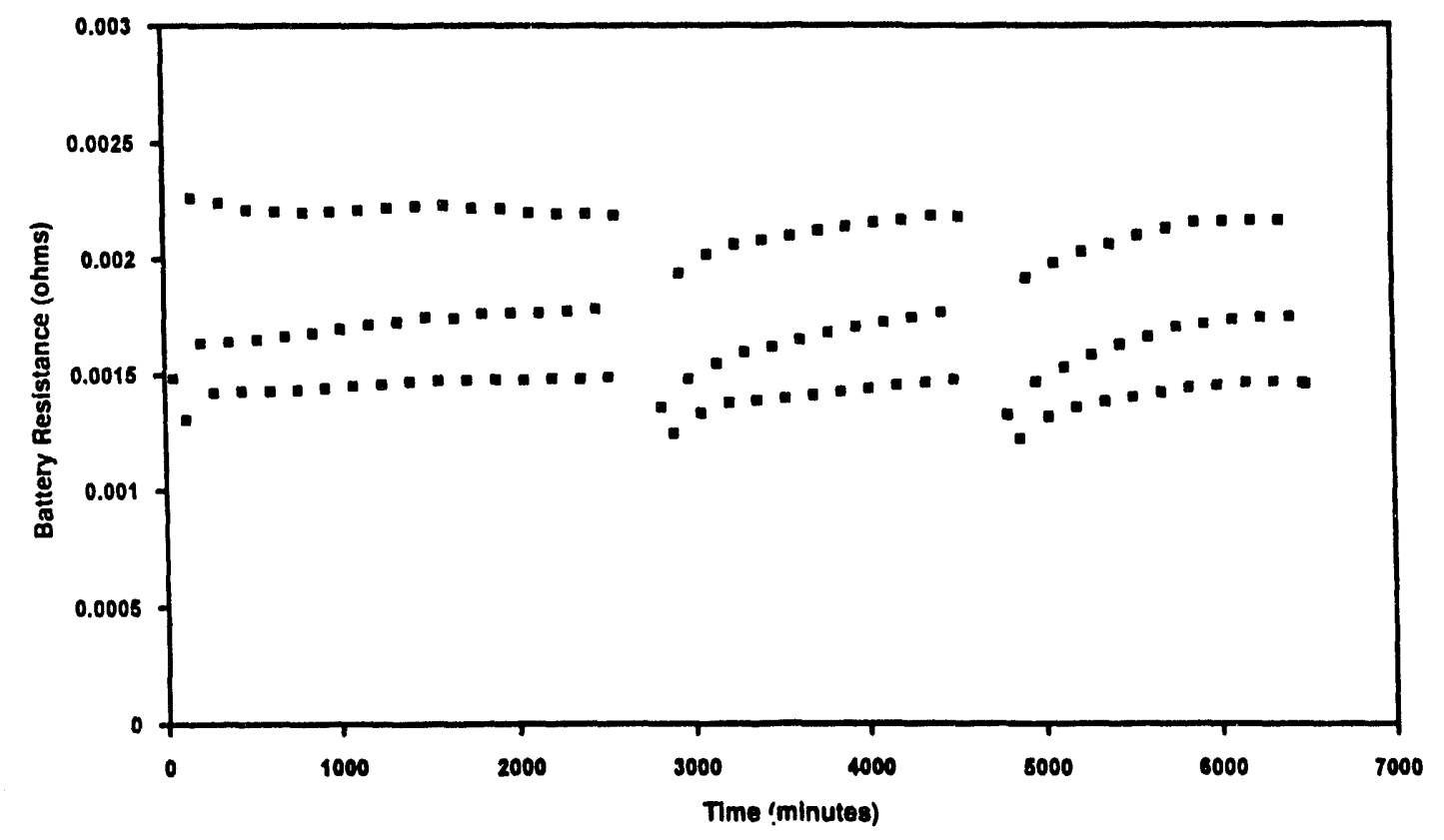

Figure 7-7. Battery Resistances Calculated from Voltage and Current Data Measured During Frequency Regulation Starting at $90^{\circ} \mathrm{F}$. Three resistance values were derived for each subcycle from one shift between the low and high discharge power levels and from two shifts between the low and intermediate discharge power levels.

$Q$ is the heat generation rate of a cell (W)

$\mathrm{h}$ is the cell to air heat transfer coefficient $\left(\mathrm{W} / \mathrm{m}^{2}-^{\circ} \mathrm{C}\right)$

$\Lambda$ is the surface area of a cell $\left(0.93 \mathrm{~m}^{2}\right)$

$A$ is a parameter $\left(1.37 \times 10^{5} \mathrm{~J} /{ }^{\circ} \mathrm{C}\right)$

$\mathrm{B}$ is a parameter to be determined $\left(\mathrm{W} /{ }^{\circ} \mathrm{C}\right)$

The model incorporates a time-dependent heat sink temperature to account for the variation caused by the diurnal air temperature swings in the test facility. The exit air temperature is used as the heat sink temperature. In this approach, the heat transfer coefficient represents the effective convective and radiative heat transfer from the battery.

Numerical solution of the model yields two parameters for the frequency regulation portion of each data set: $A / B$, the thermal time constant of the cells, and $Q / B$, the thermal power of the cells. $\mathrm{Q} / \mathrm{B}$ is also a measure of the difference between the equilibrium cell temperature and the heat sink temperature. Table 7-4 lists these best fit parameters for the UES cycles conducted and analyzed thus far. Temperature measurements were fit separately for each cell and then averaged between different cycles except for the data starting at $100^{\circ} \mathrm{F}$ where only one cycle was used. Since the results were consistently different for end and center cells, the parameters were averaged a second time according to the two types of cell locations. The standard deviation in the table reflects the spread between the three different cells that were monitored for each type of location. In general, the center cells were seen to be somewhat warmer at equilibrium, which probably also accounts for their slightly longer time constant.

The parameters in Table 7-4 were reduced using known physical properties of the cells to produce the final parameters in Table 7-5. These derived heat transfer coefficients and thermal powers are fairly consistent given the simplicity of the model. The values in the table have been averaged as was done in Table 7-4. In addition, the results for the UES cycle starting at $37.8^{\circ} \mathrm{C}$ $\left(100^{\circ} \mathrm{F}\right)$ were corrected for the radiative heat received from the heating panels in the chamber at that temperature. No correction was made to the $32.2^{\circ} \mathrm{C}\left(90^{\circ} \mathrm{F}\right)$ data, but the adjustment is expected to be negligible at the lower temperature. Center cells have lower heat transfer coefficients because they are shielded by the adjacent cells in the array and are therefore less able to reject heat by convection or radiation. The thermal power of the six cells monitored would be expected to be the same during each test and should also be fairly constant under the various nominal test temperatures employed, once a correction for the effect of the heaters has been applied. 
Table 7-2. Sulfuric Acid Density in PREPA Battery Cells at Full Charge

\begin{tabular}{lcccc} 
Date & $\begin{array}{c}\text { Avg. Density } \\
\left(\mathbf{g} / \mathrm{cm}^{3}\right)\end{array}$ & $\begin{array}{c}\text { Standard Deviation of } \\
\text { Density }\left(\mathbf{g} / \mathrm{cm}^{3}\right)\end{array}$ & $\begin{array}{c}\text { Temperature } \\
\left({ }^{\circ} \mathrm{C}\right)\end{array}$ & $\begin{array}{c}\text { Density Corrected to } \\
25^{\circ} \mathbf{C}\left(\mathbf{g} / \mathrm{cm}^{3}\right)\end{array}$ \\
\hline $3 / 25 / 93$ & 1.246 & 0.003 & 25.8 & 1.246 \\
$5 / 3 / 93$ & 1.246 & 0.003 & 24.2 & 1.246 \\
$5 / 14 / 93$ & 1.245 & 0.003 & 25.9 & 1.246 \\
$5 / 24 / 93$ & 1.248 & 0.003 & 23.4 & 1.247 \\
$7 / 19 / 93$ & 1.232 & 0.003 & 35.5 & 1.238 \\
$8 / 24 / 93$ & 1.216 & 0.004 & 31.2 & 1.220 \\
$9 / 2 / 93$ & 1.224 & 0.027 & 25.0 & 1.224 \\
& $1.232^{*}$ & 0.003 & & 1.232 \\
$9 / 7 / 93$ & 1.234 & 0.009 & 26.1 & 1.235 \\
& $1.237^{*}$ & 0.003 & & 1.238
\end{tabular}

* Average density recalculated excluding a value from one of the 12 cells. The density measurement from this cell was enough lower than the rest to shift the average significantly.

This seems to be true of the results in Table 7-5, taking the experimental scatter of the data into account.

An examination of the gross thermal energy balance for this system was performed to see whether the sources of thermal power (battery and heaters) and loss factors (cooling air and conduction through the chamber walls) had been properly accounted for. While the net power was not zero, the differences were small compared to the larger values that were subtracted to obtain the net power result. It was concluded that the results were sufficiently consistent to be useful for predicting the behavior of the PREPA BES system.

A final modification of the model used to represent the experimental data was necessary to handle the spinning reserve part of the test. This was because the battery heat generation rate could not be assumed to be constant with time during this mode of operation as it was during frequency regulation. Battery current is nearly constant during the first half of the spinning reserve test, but then ramps linearly to zero during the second half of the test. The heat generation rate was taken as proportional to the square of the current times the battery resistance for this calculation. Since the currents were available from the test data, a least squares fit of the model to the experimental data could be done as before to determine two parameters. In this case, the two parameters were $A / B$, which is a time constant as it was earlier, and $\mathrm{R} / \mathrm{B}$, which is a parameter containing the battery resistance.

Initial attempts to fit both of these parameters to the data led to physically unreasonable results. This was because of the short duration of the spinning reserve tests themselves, which did not allow thermal equilibrium to be established, and the fact that the temperature data tended to be rather noisy during this particular time interval. Fixing the time constant at $7 \mathrm{hr}$, which is consistent with the frequency regulation results, enabled reasonable values to be found for the one remaining free parameter. Figure 7-8 shows a typical fit to the spinning reserve data.

Table 7-6 lists values for $\mathrm{R} / \mathrm{B}$ and the resulting cell electrical resistance. These resistances were somewhat larger than those quoted for the cell by the manufacturer $\left(65 \times 10^{-6} \mathrm{ohm}\right.$ at top of charge) or those found from the experimental voltage and current data $\left(110-175 \times 10^{-6}\right.$ $\mathrm{ohm}$ ). An average value of approximately $250 \times 10^{-6}$ ohms per cell was obtained from fits of all of the spinning reserve test data. The trend in resistance vs the test temperature was also opposite that expected. Although the actual cell resistance should fall as the test tempera- 


\section{Table 7-3. Capacity Test Data on the PREPA Battery}

\begin{tabular}{cccc} 
Date & $\begin{array}{c}\text { Measured } \\
\text { Capacity (Ah) }\end{array}$ & $\begin{array}{c}\text { Temperature at } \\
\text { Start }\left({ }^{\circ} \mathrm{C}\right)\end{array}$ & $\begin{array}{c}\text { Capacity } \\
\text { Corrected } \\
\text { to } 25^{\circ} \mathrm{C} \text { (Ah) }\end{array}$ \\
\hline $12 / 18 / 92$ & 2318 & $21.4^{*}$ & 2393 \\
$12 / 21 / 92$ & 2290 & 21.4 & 2364 \\
$3 / 10 / 93$ & 2413 & 28.5 & 2339 \\
$3 / 11 / 93$ & 2450 & 29.5 & 2355 \\
$8 / 26 / 93$ & 2152 & 28.9 & 2079 \\
$8 / 26 / 93$ & 2266 & 35.7 & 2067 \\
$9 / 8 / 93$ & 2129 & 24.4 & 2140 \\
$9 / 8 / 93$ & 2380 & 33.6 & 2209 \\
$9 / 10 / 93$ & 2243 & 28.1 & 2182 \\
$9 / 10 / 93$ & 2337 & 32.5 & 2189
\end{tabular}

- Cell temperatures not available, battery temperafure estimated to be similar to the $12 / 21$ test because of an equivalent chamber temperature

Table 7-4. Average Parameters Obtained from Fits of the Model to Experimental Data

\begin{tabular}{ccccc} 
& \multicolumn{2}{c}{ End Cells } & \multicolumn{2}{c}{ Center Cells } \\
\cline { 2 - 5 } $\begin{array}{c}\text { Nominal Test } \\
\text { Temperature } \\
\left({ }^{\circ} \mathrm{C}\right)\end{array}$ & $\begin{array}{c}\text { AV }(\text { Std. Dev. }) \\
(\mathrm{hr})\end{array}$ & $\begin{array}{c}\text { Q/B (Std. Dev. }) \\
\left({ }^{\circ} \mathrm{C}\right)\end{array}$ & $\begin{array}{c}\text { AB (Std. Dev.) } \\
(\mathrm{hr})\end{array}$ & $\begin{array}{c}\text { O/B (Std. Dev.) } \\
\left({ }^{\circ} \mathrm{C}\right)\end{array}$ \\
\hline Ambient & $6.4(0.2)$ & $2.8(0.2)$ & $7.8(0.3)$ & $4.3(0.4)$ \\
32.2 & $6.0(1.1)$ & $3.1(0.4)$ & $8.8(0.3)$ & $4.8(0.1)$ \\
37.8 & $5.1(0.3)$ & $3.1(0.7)$ & $6.9(0.6)$ & $5.2(0.6)$
\end{tabular}


Table 7-5. Reduced Data for the PREPA Battery Cells

End Cells

Center Cells

\begin{tabular}{|c|c|c|c|c|}
\hline \multirow[b]{2}{*}{$\begin{array}{c}\text { Nominal Test } \\
\text { Temperature } \\
\left({ }^{\circ} \mathrm{C}\right)\end{array}$} & \multicolumn{2}{|c|}{ End Cells } & \multicolumn{2}{|c|}{ Center Cells } \\
\hline & $\begin{array}{c}h \text { (Std. Dov.) } \\
\left(W / m^{2}-^{\circ} \mathrm{C}\right)\end{array}$ & $\begin{array}{l}\text { Q (std. Dev.) } \\
\text { (W) }\end{array}$ & $\begin{array}{c}h(\text { Std. Dov.) } \\
\left(W / \mathrm{m}^{2}-^{\circ} \mathrm{C}\right)\end{array}$ & $\begin{array}{c}Q \text { (Sid. Dov.) } \\
\text { (W) }\end{array}$ \\
\hline Ambient & $6.4(0.2)$ & $16.5(1.3)$ & $5.3(0.2)$ & $21.0(1.3)$ \\
\hline 32.2 & $6.7(0.8)$ & $19.2(2.0)$ & $4.6(0.2)$ & $20.5(0.9)$ \\
\hline 37.8 & $8.1(0.6)$ & $19.3(3.8)$ & $5.9(0.4)$ & $25.7(3.1)$ \\
\hline
\end{tabular}

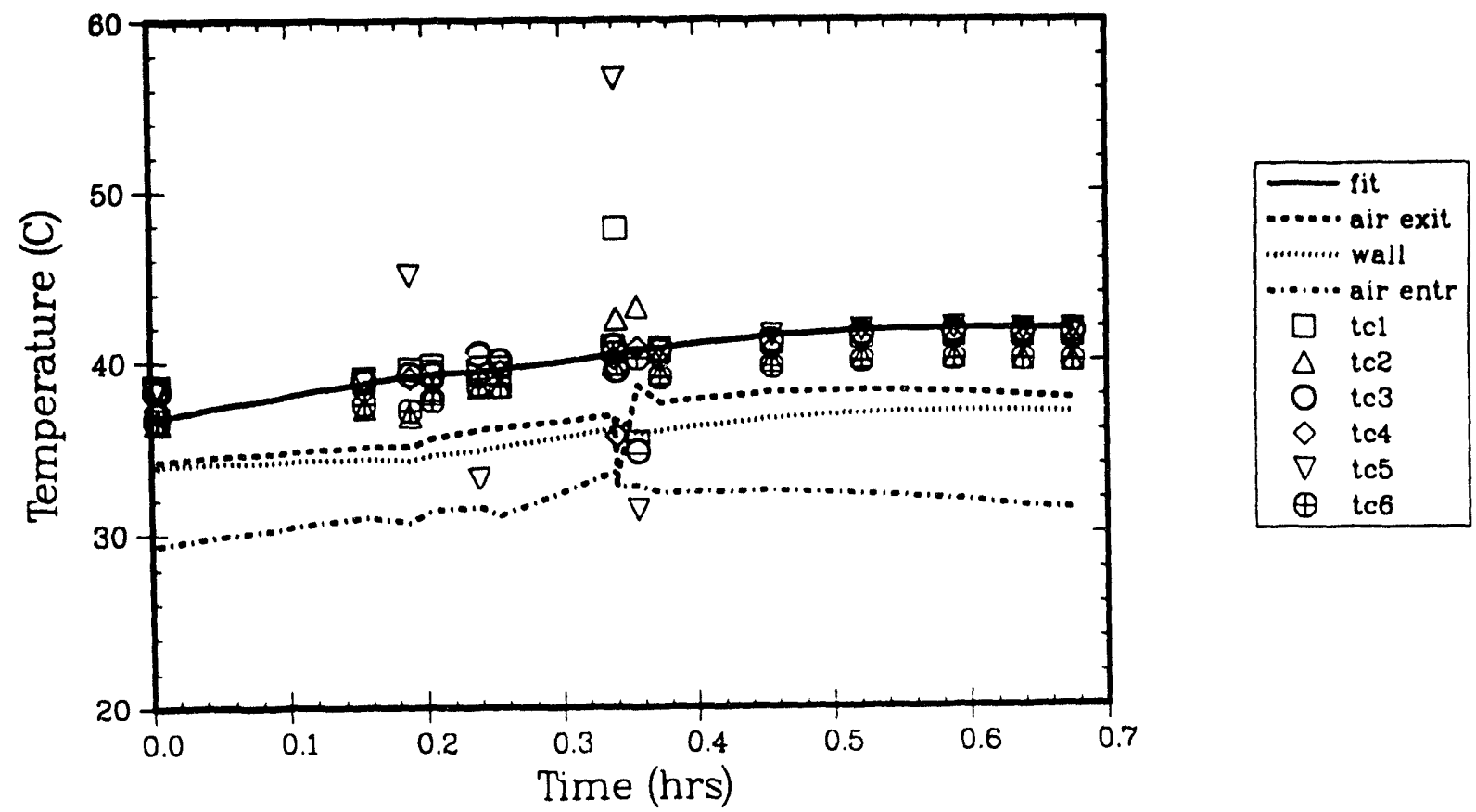

Figure 7-8. Typical Fit of Model to Spinning Reserve Test Data Using Only One Degree of Freedom (90 ${ }^{\circ} \mathrm{F}$ UES Cycle, 7/14/93)

ture increases, the cell resistance derived from the spinning reserve tests will also be influenced by other factors inherent in the thermal model. In this case, the battery is receiving more radiated heat from the heater panels at higher chamber temperatures and will therefore be warmer than the environment. Since the model does not explicitly include this effert, the only way it can be accounted for is by increasing the apparent bat- tery resistance, which increases the thermal power generated by the cells. It was believed that this trend would dominate; but instead, the calculated battery resistance is lower at the higher temperatures. Another possible explanation is that the noise in the measurements could be obscuring the real trend, but this cannot be determined until more low noise data are collected and analyzed. 


\section{Table 7-6. Cell Electrical Resistance Parameters from Fits of Spinning Reserve Test Data}

\begin{tabular}{ccc}
$\begin{array}{c}\text { Test Temperature } \\
\text { ('F) and Date }\end{array}$ & $\begin{array}{c}\mathrm{R} / \mathrm{B} \\
\left({ }^{\circ} \mathrm{C} / \mathrm{A}^{2}\right) \times 10^{4}\end{array}$ & $\begin{array}{c}\text { R } \\
\text { ohms } \times 10^{6}\end{array}$ \\
\hline Ambient $-5 / 28 / 93$ & 0.70 & 380 \\
$90 \cdot 7 / 14 / 93$ & 0.52 & 280 \\
$90 \cdot 7 / 21 / 93$ & 0.43 & 230 \\
$100 \cdot 6 / 15 / 93$ & 0.43 & 230 \\
$100 \cdot 6 / 25 / 93$ & 0.30 & 160
\end{tabular}

The final task in the analysis of the thermal data is to use the results obtained from the test facility to predict the thermal behavior in the Puerto Rico BES system. There are two major differences between the facilities to be considered when doing this. First, radiative heat losses from the battery will be lower in Puerto Rico because the field of view of most of the cells will include less of the external walls. Second, air flow per cell is much higher in Puerto Rico than in the SNL test chamber. For simulating the BES system, the heat sink temperature was calculated from the air flow rate and the thermal power removed by the air. It was assumed that all of the heat would be removed by air flow. Substituting the expression below into the model allows calculation of the exit air temperature, $T_{s}(t)$ :

$$
h \Lambda\left(T-T_{s}(t)\right)=\rho \dot{V} C_{a}\left(T_{s}(t)-T_{i n}\right)
$$

where:

$\rho$ is the ambient air density $\left(1.14 \mathrm{~kg} / \mathrm{m}^{3}\right)$

$V$ is the volumetric air flow rate per cell $\left(0.019 \mathrm{~m}^{3} / \mathrm{s}\right.$ at PREPA)

$\mathrm{C}_{\mathrm{a}}$ is the heat capacity of the air $\left(1000 \mathrm{~J} / \mathrm{kg}-{ }^{\circ} \mathrm{C}\right)$

$\mathrm{T}_{\text {in }}$ is the cooling air inlet temperature $\left({ }^{\circ} \mathrm{C}\right)$

In order to account for the field of view, which only affects radiative heat transfer, the heat transfer coefficient was separated into a radiative and a convective component. In the SNL facility, the view factor is approximately 0.25 , which leads to a calculated radiative heat transfer coefficient of $1.5 \mathrm{~W} / \mathrm{m}^{2}-{ }^{\circ} \mathrm{C}$. This coefficient is reduced to $0.75 \mathrm{~W} / \mathrm{m}^{2}-{ }^{\circ} \mathrm{C}$ at the PREPA BES facility to account for the parallel rows of cells that are not present at SNL. The total heat transfer coefficient for the PREPA facility is estimated to be $4.5 \mathrm{~W} / \mathrm{m}^{2}-{ }^{\circ} \mathrm{C}$.
These parameters were used in the model to calculate the temperature rise in the battery at the BES system for a 110-hr period of frequency regulation followed immediately by a $40-\mathrm{min}$ spinning reserve discharge. The battery was assumed to generate $20 \mathrm{~W}$ of thermal power during frequency regulation, as determined from fits to the SNL facility data, and the thermal power during the spinning reserve part of the cycle was calculated from the current assuming a cell resistance of $250 \times 10^{-6}$ ohms. Figure 7-9 shows the calculated temperature rise at e ambient during frequency regulation. The steady state temperature rise was just under $6^{\circ} \mathrm{C}$ and should be independent of the initial condition. The thermal response during the spinning reserve discharge is shown in Figure 7-10. Initially, the temperature begins at the steady-state temperature reached during frequency regulation and then increases by approximately $4^{\circ} \mathrm{C}$. No cooling ramp at the end of the spinning reserve test has been included.

Although the development of the analytical model and the bulk of the experimental testing have now been finished, there are still a few pieces of data and some additional calculations that remain to be completed for this program during the next quarter. These include collecting thermal data while the frequency regulation test is operating at a capacity turnover rate of 3 vs the 2.55 that was employed for the rest of the UES cycles, and obtaining additional spinning reserve test data when outdoor temperatures are cool enough to run at full power all the way through without overheating the test equipment. The calculation of the battery temperatures at the Puerto Rico facility will also be improved based on refined input parameters from the additional test data and better alignment with the expected BES system operating characteristics. 


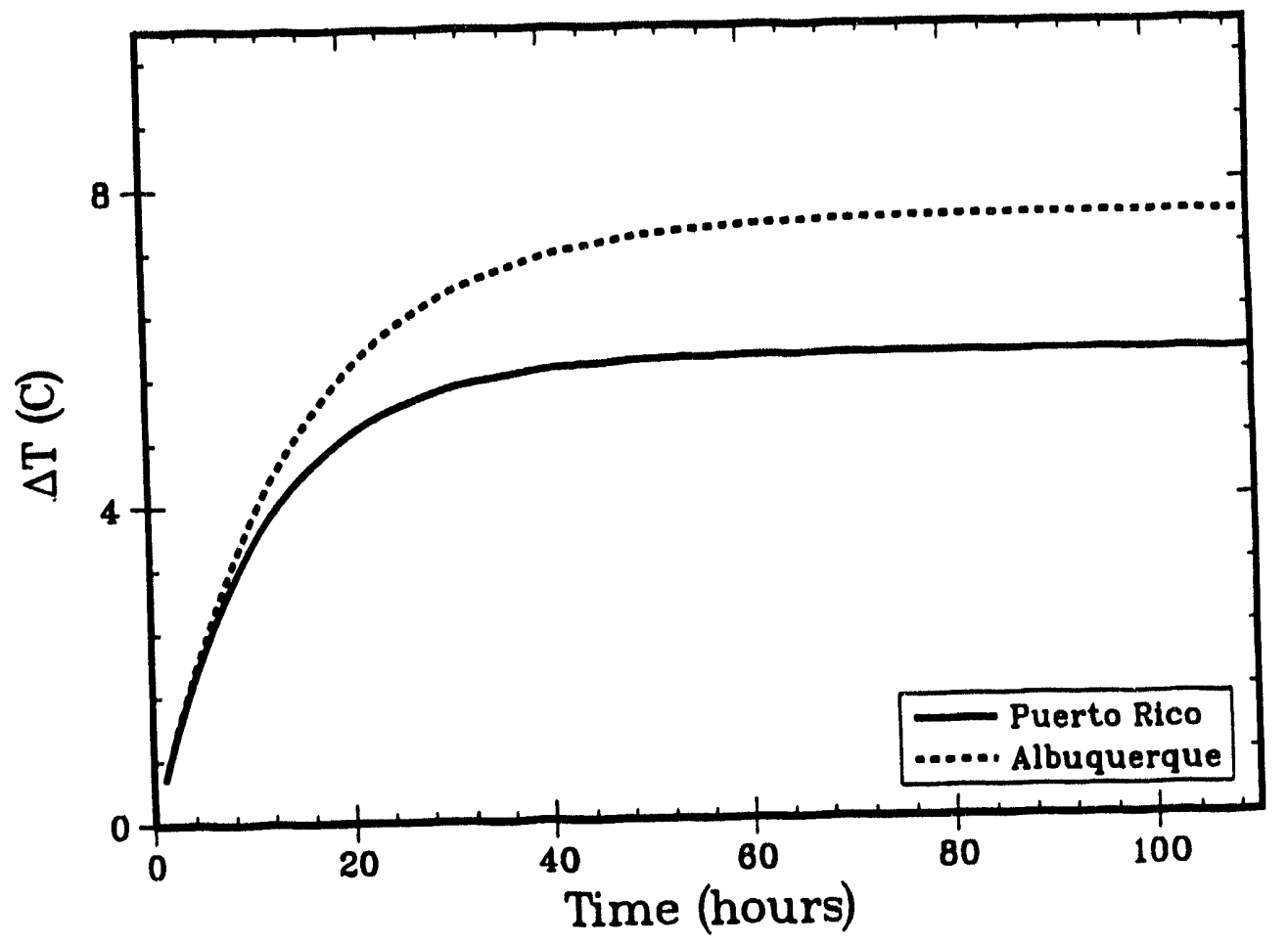

Figure 7.9. Calculated Temperature Rise During $110 \mathrm{hr}$ of Frequency Regulation

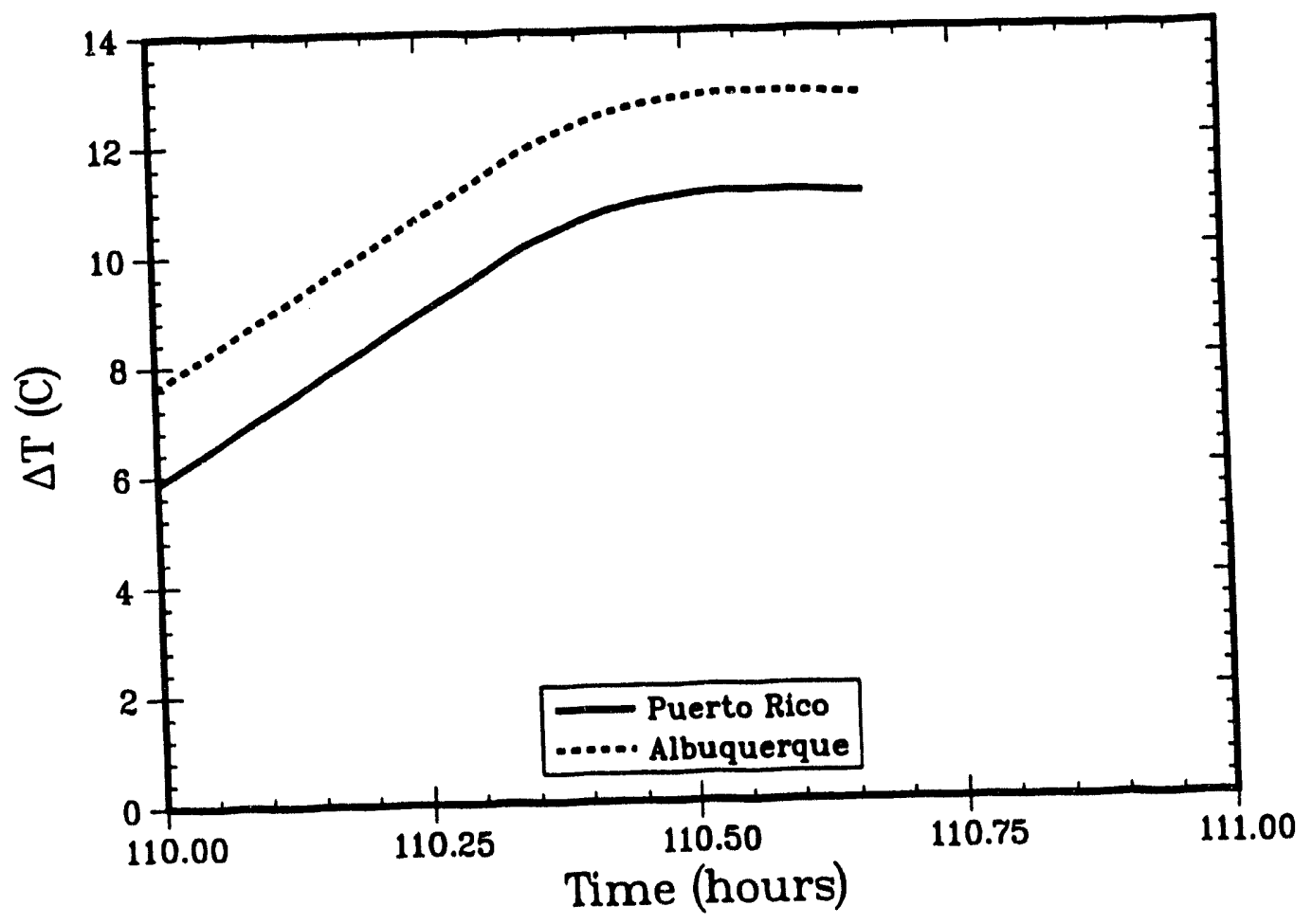

Figure 7-10. Calculated Temperature Rise During a Spinning Reserve Discharge That Follows a Long Period of Frequency Regulation 


\section{Appendix: Presentations and Publications}

\section{Presentations}

Anderson, M., and S. Eckroad, "Design Concepts for VRLA Battery Systems," Utility Battery Storage Systems Program Review, Valley Forge, Pennsylvania, November 1992.

Braithwaite, J. W., and A. A. Koenig, "Development of the Sodium/Sulfur Battery Technology for Utility Applications," Fourth International Conference, Batteries for Energy Storage, Berlin, Germany, September 1993.

Butler, P. C., "Utility Battery Storage Systems Program Overview," Utility Battery Storage Systems Program Review, Valley Forge, Pennsylvania, November 1992.

Eaton, R., P. C. Butler, A. Akhil, and J. Hurwitch, "Overview of the U.S. Department of Energy Utility Battery Storage Systems Program," Fourth International Conference, Batteries for Energy Storage, Berlin, Germany, September 1993.

Eidler, P., “Zinc/Bromine Battery Development," Utility Battery Storage Systems Program Review, Valley Forge, Pennsylvania, November 1992.

Eidler, P., P. Lex, J. Bolstad, and R. Miles, "The Zinc/ Bromine Battery for Utility Storage Applications," Fourth International Conference, Batteries for Energy Storage, Berlin, Germany, September 1993.

Flemming, R., “AC Battery Development," Fifth Utility Battery Group Meeting, Indianapolis, Indiana, May 1993.

Freese, J. M., "Testing of Advanced Batteries at Sandia," Utility Battery Storage Systems Program Review, Valley Forge, Pennsylvania, November 1992.

Freese, J. M., "Thermal Testing of the PREPA Battery," Fourth Utility Battery Group Meeting, Valley Forge, Pennsylvania, November 1992.
Jabbour, S., "Battery Benefits at Chugach Electric Association," Utility Battery Storage Systems Program Review, Valley Forge, Pennsylvania, November 1992.

Jabbour, S., "Battery Benefits at San Diego Gas and Electric," Utility Battery Storage Systems Program Review, Valley Forge, Pennsylvania, November 1992.

Jungst, R. G., J. M. Freese, and G. P. Rodriguez, "Implementation of a Frequency Regulation/Spinning Reserve Test Cycle for PREPA Battery Cells," Fifth Utility Battery Group Meeting, Indianapolis, Indiana, May 1993.

Jungst, R. G., J. M. Freese, G. P. Rodriguez, R. C. Dykhuizen, J. W. Braithwaite, and C. Woods, "Dynamic Thermal Testing of Lead-Acid Batteries for the PREPA Battery Energy Storage System," Fourth International Conference, Batteries for Energy Storage, Berlin, Germany, September 1993.

Klassen, S. E., "Advanced Battery R\&D at Sandia," Utility Battery Storage Systems Program Review, Valley Forge, Pennsylvania, November 1992.

Koenig, A. A., "NAS-P ${ }_{a c}$ : A Modular Battery Energy Storage Unit for Utility Power Applications," IECEC, Atlanta, August 1993.

Koenig, A. A., "Progress in Development of a Sodium Sulfur BES for Utility Applications," Utility Battery Group (UBG) Meeting, Albuquerque, May 1993.

Koenig, A. A., "Sodium/Sulfur Battery Development," Utility Battery Storage Systems Program Review, Valley Forge, Pennsylvania, November 1992.

Meyer, H. "AC Battery Development," Utility Battery Storage Systerns Program Review, Valley Forge, Pennsylvania, November 1992.

Norris, B., and R. Winter, "PG\&E Battery Application Developments," Utility Battery Storage Systems Program Review, Valley Forge, Pennsylvania, November 1992. 
Norris, B. L., "Transportable Battery System Economics," Fourth International Conference, Batteries for Energy Storage, Berlin, Germany, September 1993.

Prabhakhara, P., "Battery Benefits at Oglethorge Power Corporation," Utility Battery Storage Systems Program Review, Valley Forge, Pennsylvania, November 1992.

Szymborski, J., "The Maturing of a Valve-Regulated (VRLA) Battery Technology: Ten Years of Experience," Fifteenth International Telecommunications Energy Conference (INTELEC), Paris, France, September 1993.

Szymborski, J., "Advanced VRLA Batteries for Utility Applications," Utility Battery Storage Systems Program Review, Valley Forge, Pennsylvania, November 1992.

Szymborski, J., and R. G. Jungst, "The Development of Advanced Lead-Acid Batteries for Utility Applications," Fourth International Conference, Batteries for Energy Storage, Berlin, Germany, September 1993.
Winter, R. O., "PG\&E Utility-Scale Battery Demonstration," Fifth Utility Battery Group Meeting, Indianapolis, Indiana, May 1993.

Winter, R. O., "Utility-Scale Battery Deployment," Fourth International Conference, Batteries for Energy Storage, Berlin, Germany, September 1993.

\section{Publications}

Akhil, A. A., L. Lachenmeyer, S. J. Jabbour, and H. K. Clark, Specific Systems Studies of Battery Energy Storage for Electric Utilities. Sandia National Laboratories, SAND93-1754, August 1993.

Butler, P. C., Utility Battery Storage Systems Program Report for FY92. Sandia National Laboratories, SAND92-2272, January 1993. 


\section{Distribution}

ABB Power T\&D Co., Inc. (2)

Attn: P. Danfors

H. Weinrich

630 Sentry Parkway

Blue Bell, PA 19422

AC Battery Corporation

Attn: R. Flemming

P.O. Box 325

East Troy, WI 53120

Alaska Energy Authority

Attn: D. Denig-Chakroff

P.O. Box 190869

Anchorage, AK 99519-0869

American Electric Power Service Corp.

Attn: C. Shih

1 Riverside Plaza

Columbus, $\mathrm{OH} 43215$

Argonne National Laboratories (3)

Attn: C. Christianson

W. DeLuca

K. Myles

CTD, Building 205

9700 South Cass Avenue

Argonne, IL 60439

Arizona Public Service

Attn: R. Hobbs

P.O. Box 5399

Phoenix, AZ 85072

AT\&T Energy Systems

Attn: M. Bize

3000 Skyline Drive

Mesquite, TX 75149

Bechtel

Attn: W. Stolte

P.O. Box 193965

San Francisco, CA 94119-3965

Bonnevilie Power Administration

Attn: J. Ray

Routing EO

P.O. Box 3621

Portland, OR 97208
C\&D Charter Power Systems, Inc.

Attn: S. Misra

3043 Walton Road

P.O. Box 239

Plymouth Meeting, PA 19462-0239

California State Air Resources Board

Attn: J. Holmes

Research Division

P.O. Box 2815

Sacramento, CA 95812

Chugach Electric Association, Inc.

Attn: T. Lovas

P.O. Box 196300

Anchorage, AK 99519-6300

Consolidated Edison (2)

Attn: M. Lebow

N. Tai

4 Irving Place

New York, NY 10003

Corn Belt Electric Cooperative

Attn: R. Stack

P.O. Box 816

Bloomington, IL 61702

Decision Focus, Inc.

Attn: S. Jabbour

650 Castro Street, Suite 300

Mountain View, CA 94041

Delco-Remy

Attn: R. Rider

7601 East 88th Place

Indianapolis, IN 46256

Doug Danley

18131 Metz Dr.

Germantown, MD 20874

Eagle-Picher Industries

Attn: J. DeGruson

C \& Porter Street

Joplin, MO 64802 
East Penn Manufacturing Co., Inc.

Attn: M. Stanton

Deka Road

Lyon Station, PA 19536

Electric Power Research Institute (6)

Attn: J. Birk

S. Chapel

S. Eckroad

R. Schainker

P. Symons

R. Weaver

3412 Hillview Avenue

P. O. Box 10412

Palo Alto, CA 94303

Electrotek Concepts, Inc.

Attn: H. Barnett

P.O. Box 16548

Chattanooga, TN 37416

Eltech Research Corporation

Attn: E. Rudd

625 East Street

Fairport Harbor, OH 44077

Energetics, Inc. (5)

Attn: J. Badin

D. Baker

J. Hurwitch

C. Matzdorf

P. Taylor

7164 Columbia Gateway Drive

Columbia, MD 21046

Energy Systems Consulting

Attn: A. Pivec

41 Springbrook Road

Livingston, NJ 07039

Exxon Research Company (2)

Attn: P. Grimes

R. Bearden

P.O. Box 536

1900 East Linden Avenue

Linden, NJ 07036

Firing Circuits, Inc.

Attn: J. Mills

P.O. Box 2007

Norwalk, CT 06852-2007
General Electric Company (2)

Attn: E. Larson

D. Swann

Building 2, Room 605

1 River Road

Schenectady, NY 12345

General Electric Drive Systems

Attn: C. Romeo

1501 Roanoke Blvd.

Salem, VA 24153

Giner, Inc.

Attn: A. LaConti

14 Spring Street

Waltham, MA 02254-9147

GNB Industrial Battery Company (3)

Attn: S. Deshpande'

G. Hunt

J. Szymborski

Woodlake Corporate Park

829 Parkview Blvd.

Lombard, IL 60148-3249

Hawaii Electric Light Co.

Attn: C. Nagata

P.O. Box 1027

Hilo, HI 96720

Hughes Aircraft Company

Attn: R. Taenaka

P.O. Box 2999

Torrance, CA 90509-2999

Integrated Power Corp.

Attn: J. Adelman

7524 Standish Place

Rockville, MD 20855

ILZRO

Attn: R. Nelson

P.O. Box 12036

Research Triangle Park, NC 27709

Johnson Controls Battery Group, Inc. (4)

Attn: P. Eidler

R. Miles

T. Ruhlmann

W. Tiedeman

5757 N. Green Bay Avenue

P. O. Box 591

Milwaukee. WI 53201 
Johnson Controls Battery Group, Inc.

Attn: J. Zagrodnik

12500 W. Silver Spring Drive

P. O. Box 591

Milwaukee, WI 53201-0591

Lawrence Berkeley Laboratory (3)

Attn: E. Cairns

K. Kinoshita

F. McLarnon

University of California

One Cyclotron Road

Berkeley, CA 94720

Jo Meglen

P.O. Box 3232

Oakton, VA 22124

N.E.T.S.

Attn: T. Neubauer

P.O. Box 32584

Juneau, AK 99803

National Renewable Energy Laboratory (3)

Attn: R. McConnell

J. Ohi

N. Rau

1617 Cole Blvd.

Golden, CO 80401-3393

New York Power Authority

Attn: B. Chezar

1633 Broadway

New York, NY 10019

Northern States Power

Attn: M. Rogers

414 Nicollet Mall

Minneapolis, MN 55401

Oak Ridge National Laboratory (3)

Attn: B. Hawsey, Bldg. 3025, MS-6040

J. Stoval, Bldg. 3147, MS-6070

J. VanCoevering, Bldg. 3147, MS-6070

P.O. Box 2008

Oak Ridge, TN 37831

Oglethorpe Power Company (2)

Attn: K. Scruggs

C. Ward

2100 E. Exchange Place

P.O. Box 1349

Tucker, GA 30085-1349
Omnion Power Corporation (2)

Attn: H. Meyer

$$
\text { F. Ruf }
$$

P.O. Box 879

East Troy, WI 53120

Pacific Gas \& Electric (3)

Attn: G. Ball

B. Norris

R. Winter

3400 Crow Canyon Road

San Ramon, CA 94583

Pacific Northwest Laboratory (2)

Attn: J. DeSteese, K5-02

K. Drost

Battelle Blvd.

Richland, WA 99352

Power Technologies, Inc.

Attn: P. Prabhakara

1482 Erie Blvd.

P.O. Box 1058

Schenectady, NY 12301

Power Technologies, Inc.

Attn: H. Clark

775 Sunrise Ave.

Suite 210

Roseville, CA 95661

Puerto Rico Power Authority

Attn: W. Torres

G.P.O. Box 4267

San Juan, Puerto Rico 00936-426

R\&D Associates

Attn: J. Thompson

2100 Washington Blvd.

Arlington, VA 22204-5706

RMS Company

Attn: K. Ferris

87 Martling Ave.

Pleasantville, NY 10570

Robicon Corporation

Attn: A. Maruschak

100 Sagomore Hill Road

Pittsburgh, PA 15239 
Sacramento Municipal Utility District

Attn: L. Wittrup

6201 S. Street

Sacramento, CA 95817

Salt River Project

Attn: H. Lundstrom

MS PAB 357, Box 52025

Phoerix, AZ 85072-2025

San Diego Gas \& Electric Company (2)

Attn: T. Nelson

J. Wight

P.O. Box 1831

San Diego, CA 92112

W. J. Schafer Associates

Attn: S. Schoenung

303 Lindbergh Avenue

Livermore, CA 94550-9551

R. K. Sen \& Associates

Attn: R. Sen

3808 Veazey Street NW

Washington, DC 20016

Silent Power, Inc.

Attn: J. Rassmussen

163 West 1700 South

Salt Lake City, UT 84115

Silent Power, Inc. (2)

Attn: W. Auxer

A. Koenig

489 Devon Park Drive

Suite 315

Wayne, PA 19087

Silent Power, Ltd.

Attn: M. McNamee

Davy Road, Astmoor

Rurcorn, Cheshire

UNITED KINGDOM WA7 1PZ

Southern California Edison (2)

Atrn: A. Rodriguez

R. Scheffler

2244 Walnut Grove Avenue

P.O. Box 800

Rosemeade, CA 91770

SRI International

Attn: C. Seitz

333 Ravenswood Ave.

Menlo Park, CA 94025
Stuart Kuritzky

347 Madison Avenue

New York, NY 10017

Superconductivity, Inc.

Attn: J. Emerick

2114 Eagle Drive

Middleton, WI 53562

United Engineers and Contractōrs

Attn: A. Randall

700 South Ash St.

P.O. Box 5888

Denver, CO 80217

University of Missouri - Rolla

Attn: M. Anderson

112 Electrical Engineering Building

Rolla, MO 65401-0249

University of Wisconsin - Madison

Attn: D. Divan

Dept. of Electrical \& Computer Eng.

1415 Johnson Drive

Madison, WI 53706

U.S. Department of Energy

Attn: T. Petersik

Energy Information Administration

EI-531 FORSTL

Washington, DC 20585

U.S. Department of Energy

Attn: M. Gunn

Office of Energy Management

EE-14 FORSTL

Washington, DC 20585

U.S. Department of Energy (21)

Attn: R. Eaton (20)

N. Rossmeiss!

Office of Energy Management

EE-142 FORSTL

Washington, DC 20585

U.S. Department of Energy

Attn: A. Landgrebe

Office of Propulsion Systems

EE-321 FORSTL

Washington, DC 20585 
U.S. Department of Energy

Attn: G. Buckingham

Albuquerque Operations Office

Energy Technologies Division

Albuquerque, NM 87115

U.S. Windpower, Inc.

Attn: B. Erdman

6952 Preston Avenue

Livermore, CA 94550

Westinghouse STC

Attn: H. Saunders

1310 Beulah Road

Pittsburgh, PA 15235

W. R. Grace \& Company

Attn: S. Strzempko

62 Whittemore Avenue

Cambridge, MA 02140

Yuasa-Exide

Attn: F. Tarantino

P.O. Box 14205

Reading, PA 19612-4205

Zaininger Engineering Co., Inc.

Attn: H. Zaininger

1590 Oakland Road, Suite B211

San Jose, CA 95131
MS 0513 H. Schmitt (Org. 2000)

MS 1070 R. Bair (Org. 2200)

MS 0613 R. Clark (Org. 2206)

MS 0613 L. Lachenmeyer (Org. 2206)

MS 0613 K. Grothaus (Org. 2222)

MS 0613 D. Doughty (Org. 2223)

MS 0613 P. Butler (Org. 2225) (10)

MS 0613 A. Akhil (Org. 2225)

MS 0613 J. Braithwaite (Org. 2225)

MS 0613 N. Clark (Org. 2225)

MS 0613 J. Freese (Org. 2225)

MS 0613 R. Jungst (Org. 2225)

MS 0613 S. Klassen (Org. 2225)

MS 0214 J. Kerr, Attn: D. Wilt (Org. 10214)

MS 0735 D. Arvizu (Org. 6200)

MS 0752 T. Bickel (Org. 6213)

MS 0753 W. Bower (Org. 6218)

MS 0753 R. Bonn (Org. 6218)

MS 9103 P. Falcone (Org. 8111)

MS 9054 W. McLean (Org. 8300)

MS 9018 Central Technical Files (Org. 8523-2)

MS 0899 Technical Library (Org. 7141) (5)

MS 0619 Technical Publications (Org. 7151)

MS 0100 Document Processing for DOE/OSTI (Org. 7613-2) (10) 

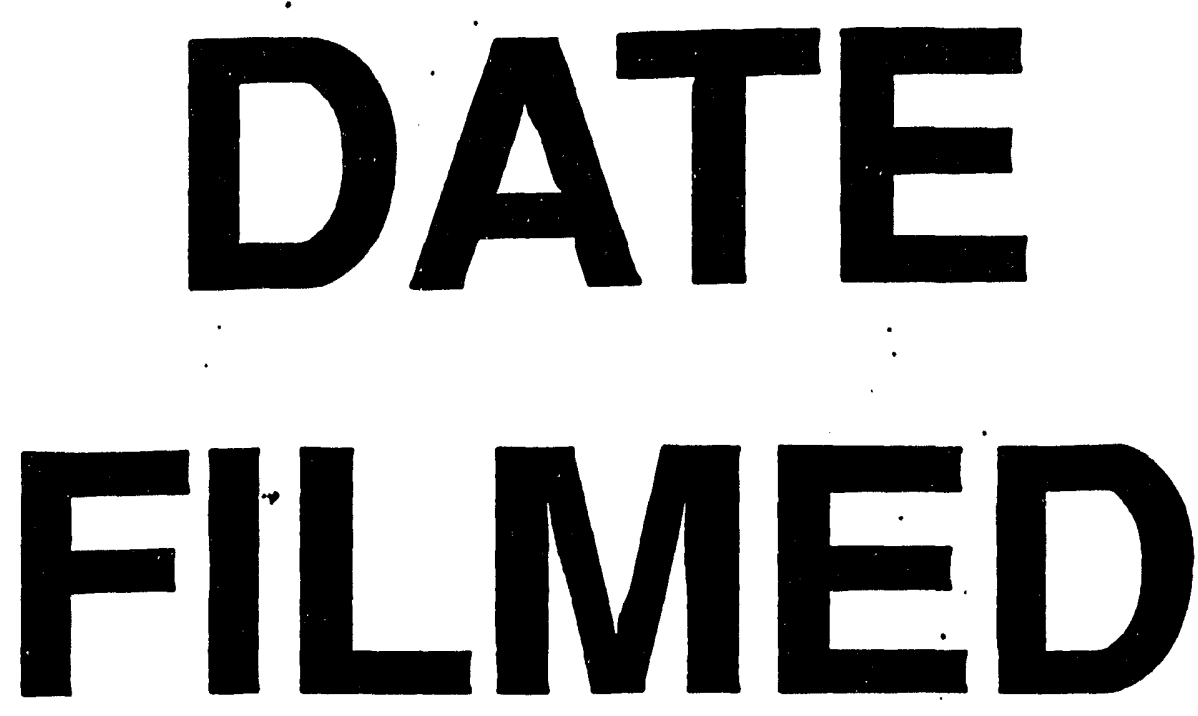

$3 / 22 / 94$
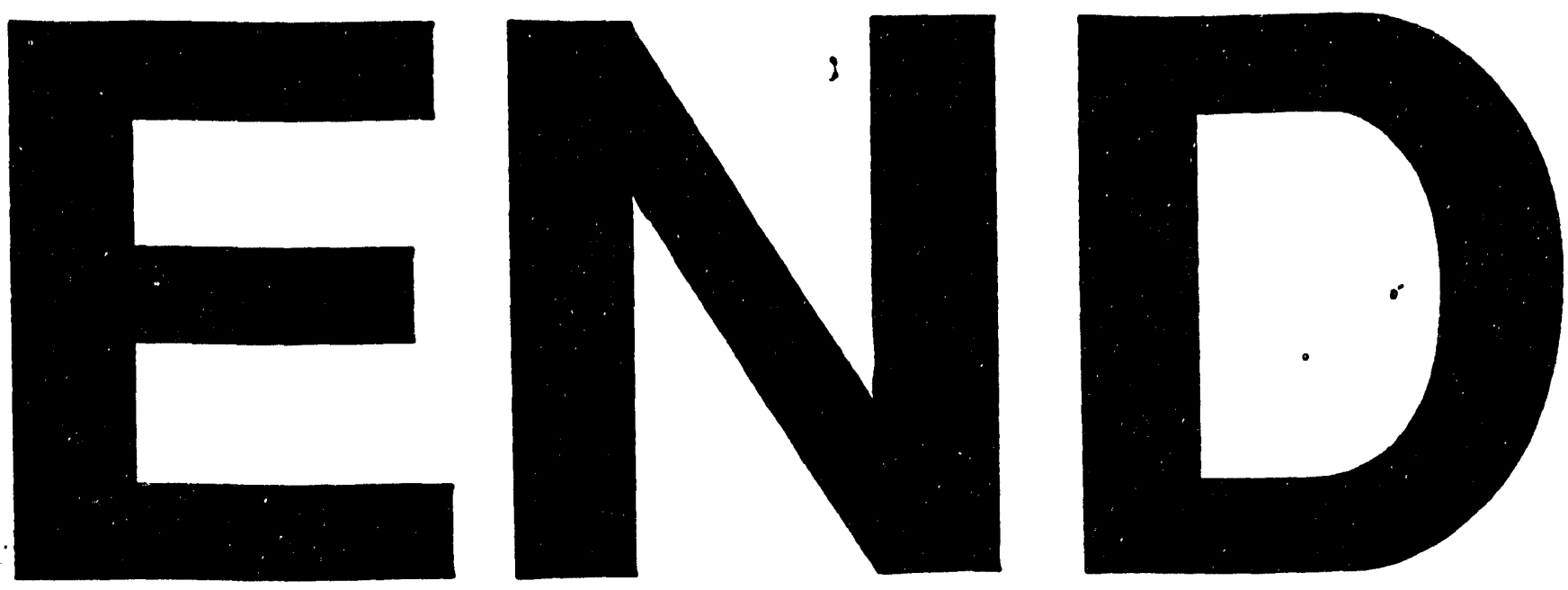
